U.S. Department of Energy

Vehicle Technologies, EE-2G

1000 Independence Avenue, S.W.

Washington, D.C. 20585-0121

FY2011

\title{
EVALUATION OF THE 2010 TOYOTA PRIUS HYBRID SYNERGY DRIVE SYSTEM
}

Prepared by:

Oak Ridge National Laboratory

Mitch Olszewski, Program Manager

\section{Submitted to:}

Energy Efficiency and Renewable Energy

FreedomCAR and Vehicle Technologies

Vehicle Systems Team

Susan A. Rogers, Technology Development Manager

March 2011 
NATIONAL LABORATORY

MANAGED BY UT-BATTELLE

FOR THE DEPARTMENT OF ENERGY

\section{Energy and Transportation Science Division}

\section{EVALUATION OF THE 2010 TOYOTA PRIUS HYBRID SYNERGY DRIVE SYSTEM}

T. A. Burress

S. L. Campbell

C. L. Coomer

C. W. Ayers

A. A. Wereszczak

J. P. Cunningham

L. D. Marlino

L. E. Seiber

H. T. Lin

Publication Date: March 2011

Prepared by the

OAK RIDGE NATIONAL LABORATORY

Oak Ridge, Tennessee 37831

managed by

UT-BATTELLE, LLC

for the

UT-BATTELLE

ORNL-27 (4-00)

U.S. DEPARTMENT OF ENERGY

Under contract DE-AC05-00OR22725 


\title{
DOCUMENT AVAILABILITY
}

Reports produced after January 1, 1996, are generally available free via the U.S. Department of Energy (DOE) Information Bridge:

Web site: http://www.osti.gov/bridge

Reports produced before January 1, 1996, may be purchased by members of the public from the following source:

\author{
National Technical Information Service \\ 5285 Port Royal Road \\ Springfield, VA 22161 \\ Telephone: 703-605-6000 (1-800-553-6847) \\ TDD: $703-487-4639$ \\ Fax: 703-605-6900 \\ E-mail: info@ntis.fedworld.gov \\ Web site: http://www.ntis.gov/support/ordernowabout.htm
}

Reports are available to DOE employees, DOE contractors, Energy Technology Data Exchange (ETDE) representatives, and International Nuclear Information System (INIS) representatives from the following source:

Office of Scientific and Technical Information

P.O. Box 62

Oak Ridge, TN 37831

Telephone: 865-576-8401

Fax: 865-576-5728

E-mail: reports@osti.gov

Web site: http://www.osti.gov/contact.html

This report was prepared as an account of work sponsored by an agency of the United States Government. Neither the United States government nor any agency thereof, nor any of their employees, makes any warranty, express or implied, or assumes any legal liability or responsibility for the accuracy, completeness, or usefulness of any information, apparatus, product, or process disclosed, or represents that its use would not infringe privately owned rights. Reference herein to any specific commercial product, process, or service by trade name, trademark, manufacturer, or otherwise, does not necessarily constitute or imply its endorsement, recommendation, or favoring by the United States Government or any agency thereof. The views and opinions of authors expressed herein do not necessarily state or reflect those of the United States Government or any agency thereof. 


\section{TABLE OF CONTENTS}

LIST OF FIGURES . Page

2. HYBRID ELECTRIC DRIVE SYSTEM DESIGN AND PACKAGING .......................................... 3

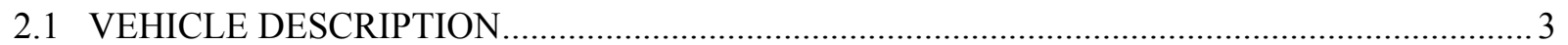

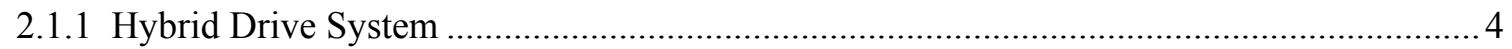

2.2 PCU

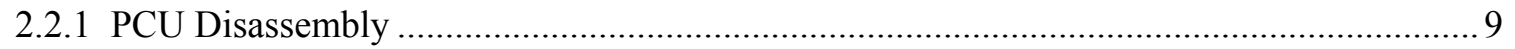

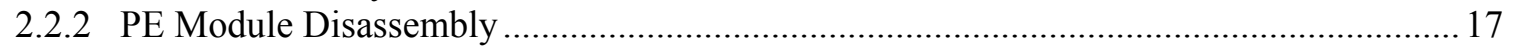

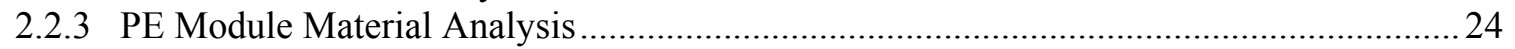

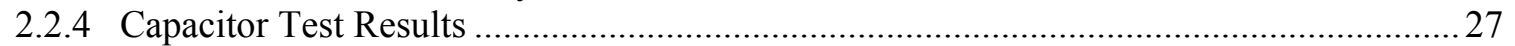

2.2.4.1 Parameter assessments of the $888 \mu \mathrm{F}$ dc-link smoothing capacitor

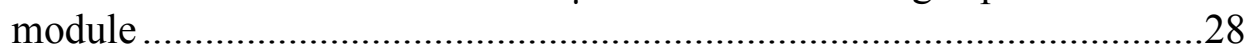

2.2.4.2 Continuous ripple current tests with large dc-link capacitor module.......33

2.2.4.3 Parameter assessments of battery level filter capacitor............................35

2.2.4.4 Parameter assessments of the small dc-link capacitor.............................36

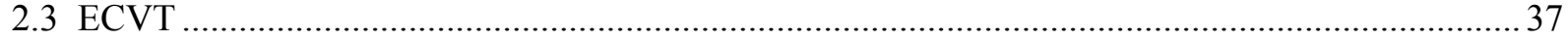

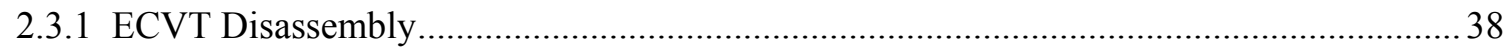

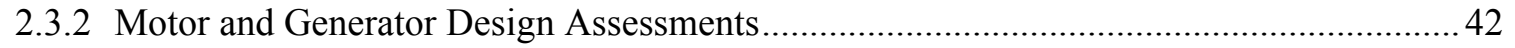

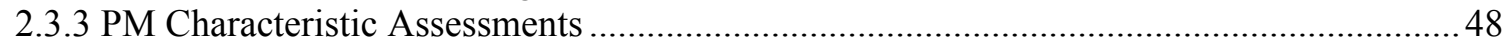

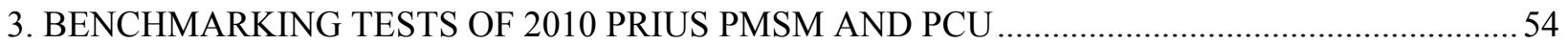

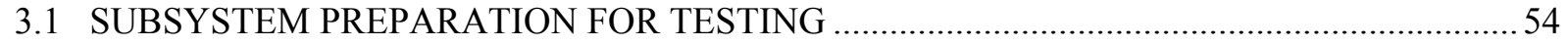

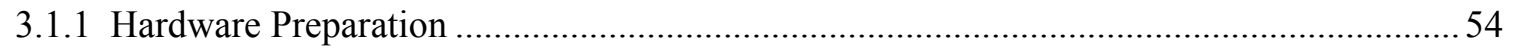

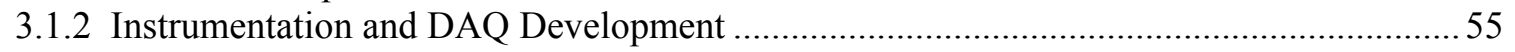

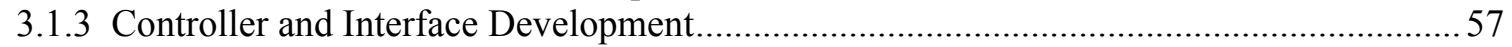

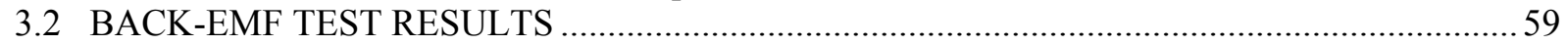

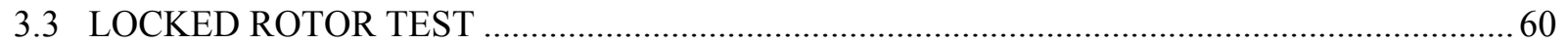

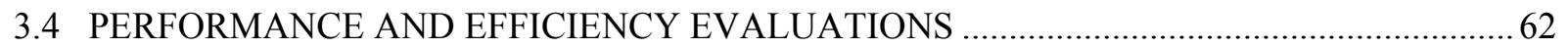

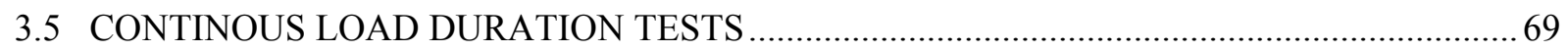

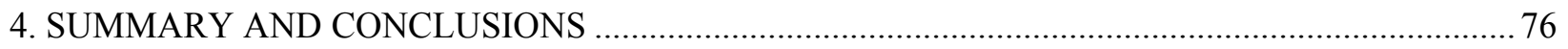

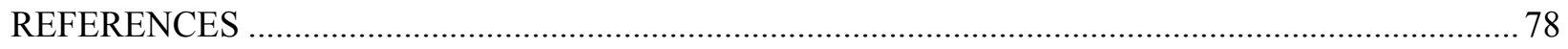

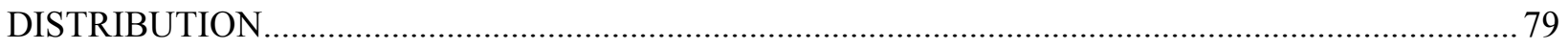




\section{LIST OF FIGURES}

Figure

Page

1.1. Flow diagram of baseline benchmarking approach. .................................................................. 3

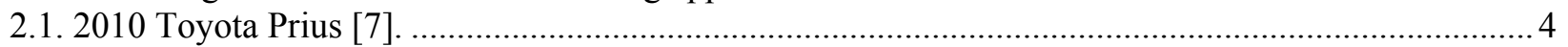

2.2. Comparison of PCUs (which include motor and generator inverters). ............................................. 6

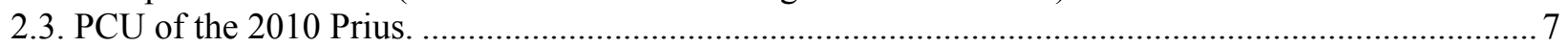

2.4. Compartments of the 2010 Prius inverter and converter assembly............................................... 8

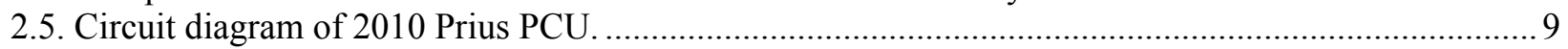

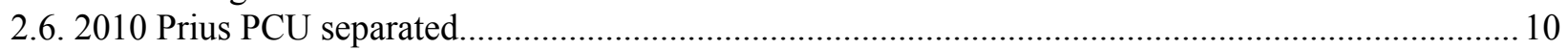

2.7. Controller and driver circuitry for dc-dc convert and inverters. .................................................... 11

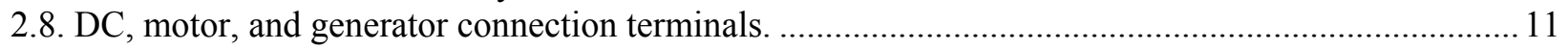

2.9. Underside of power module/cooling structure (top) and bottom compartment (bottom) ................... 12

2.10. Bottom compartment containing inductor, capacitors, and dc-dc converter................................... 12

2.11. 2004 Prius bottom compartment containing compressor inverter and $12 \mathrm{~V} \mathrm{dc}-\mathrm{dc}$ converter............ 13

2.12. 2010 Prius main capacitor module removed from housing. ........................................................... 15

2.13. X-ray of 2010 Prius main capacitor top view (left) and side view (right). .................................... 16

2.14. X-ray of 2010 Prius $0.562 \mu \mathrm{F}$ (left) and $0.8 \mu \mathrm{F}$ (right) filter capacitors........................................ 16

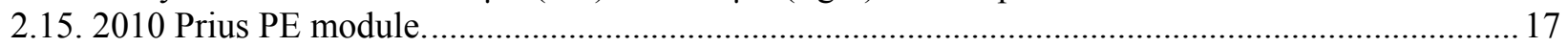

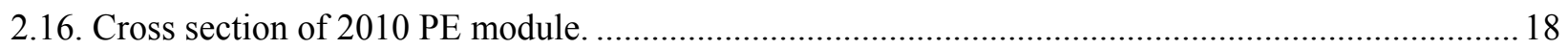

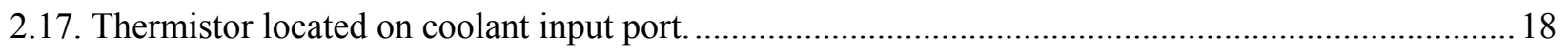

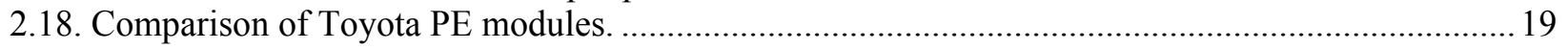

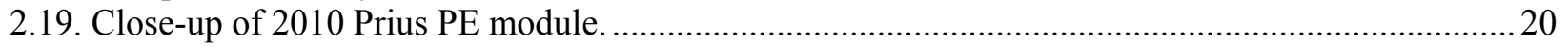

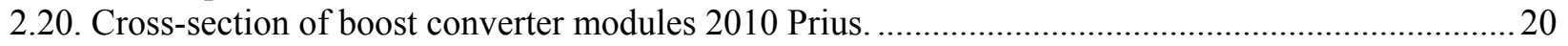

2.21. Boost converter modules from Camry (left) and 2004 Prius (right) ............................................2 21

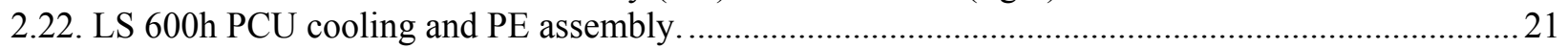

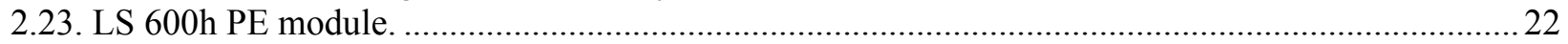

2.24. Dimensions (mm) of inverter PE devices from Camry (left), 2004 Prius (middle), and 2010 Prius

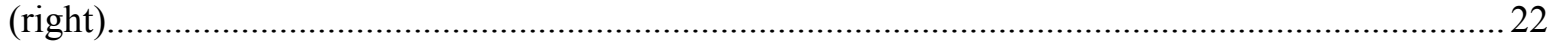

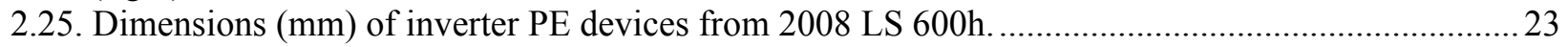

2.26. Dimensions (mm) of bi-directional boost converter PE devices of 2010 Prius...............................23

2.27. Side (left) and top (right) cross-sectional views of extracted 2010 Prius PE module.......................24

2.28. Comparison of thermal conduction path in 2004 Prius (left) and 2010 Prius (right).......................25

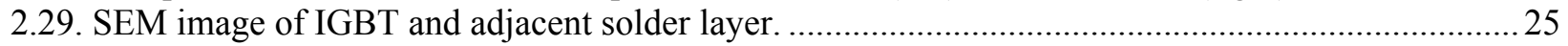

2.30. SEM image of reaction layer and nickel plating on solder layer. .............................................26

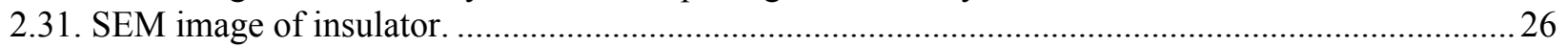

2.32. SEM image of aluminum layers between insulator and cooling channels.......................................2 27

2.33. 2010 Prius $888 \mu \mathrm{F}$ capacitor module equivalent capacitance vs. frequency....................................22

2.34. 2004 Prius $1,130 \mu \mathrm{F}$ capacitor module equivalent capacitance vs. frequency................................. 29

2.35. 2010 Prius $888 \mu \mathrm{F}$ capacitor module equivalent capacitance variation with ambient temperature. .. 29

2.36. 2010 Prius $888 \mu \mathrm{F}$ capacitor module ESR vs. frequency............................................................ 30

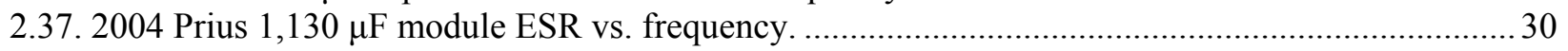

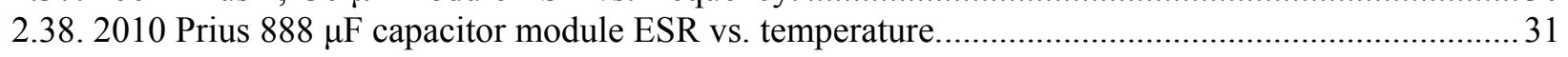

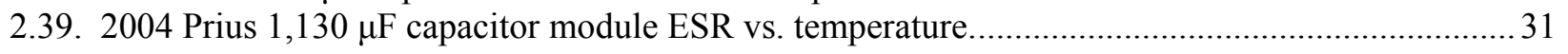

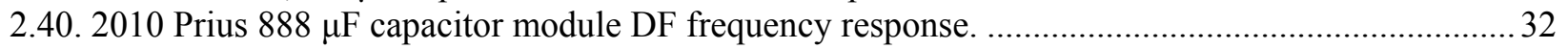

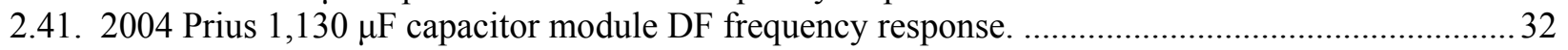

2.42. 2010 Prius $888 \mu \mathrm{F}$ capacitor module DF temperature response. .................................................... 33

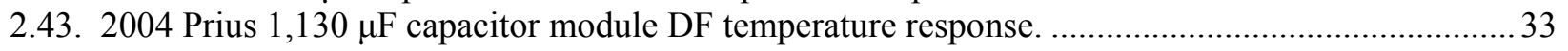

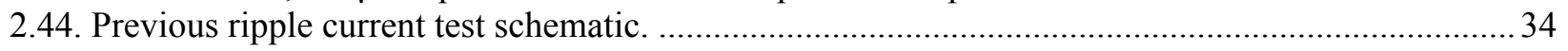




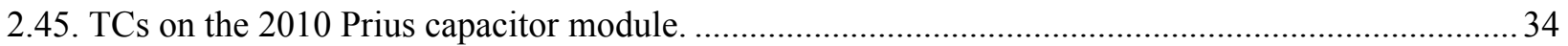

2.46. 2010 Prius capacitor module steady state temperature response vs. ripple current. ......................... 35

2.47. 2004 Prius capacitor module steady state temperature response vs. ripple current at $4 \mathrm{kHz} \ldots \ldots \ldots \ldots . . . .35$

2.48. Capacitance, ESR, and DF vs. frequency for 2010 Prius battery level $315 \mu \mathrm{F}$ capacitor.................. 36

2.49. Capacitance, ESR, and DF vs. frequency for 2004 Prius battery level $282 \mu \mathrm{F}$ capacitor................. 36

2.50. Capacitance, ESR, and DF vs. frequency for 2010 Prius dc-link $0.562 \mu \mathrm{F}$ capacitor. ..................... 37

2.51. Capacitance, ESR, and DF vs. frequency for 2010 Prius dc-link $0.8 \mu F$ capacitor. ......................... 37

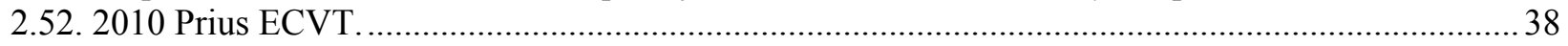

2.53. Mechanical diagram of 2010 Prius, 2004 Prius, Camry, and LS 600h gear systems........................ 38

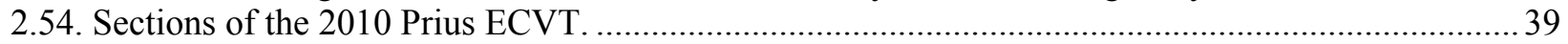

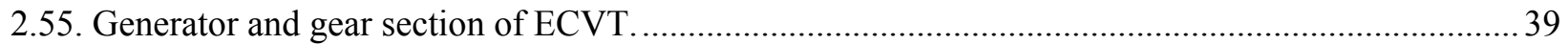

2.56. Generator and gear section of ECVT with ring gear and speed reduction planetary shown. ............40

2.57. Motor and gear section with speed reduction planetary sun and carrier shown...............................40

2.58. 2010 Prius, 2004 Prius, and 2007 Camry gear teeth.................................................................... 41

2.59. 2007 Camry and 2010 Prius power-split planetary and speed reduction planetary........................ 42

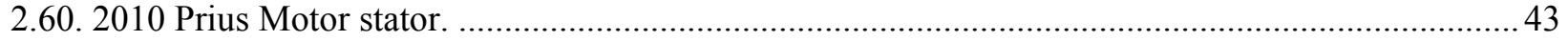

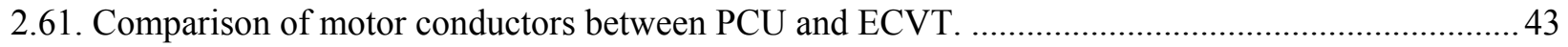

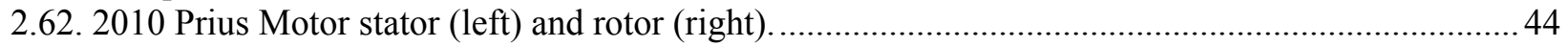

2.63. Comparison of motor rotor laminations, Camry (left), LS 600h (middle), and 2010 Prius (right).... 44

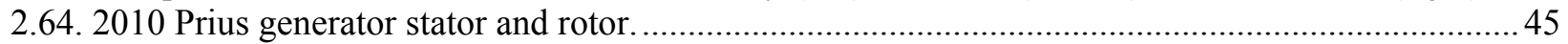

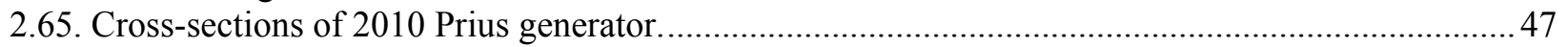

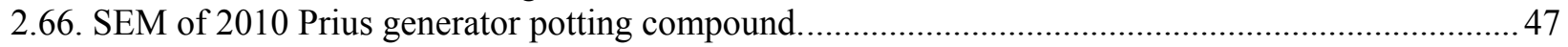

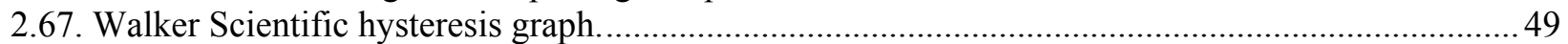

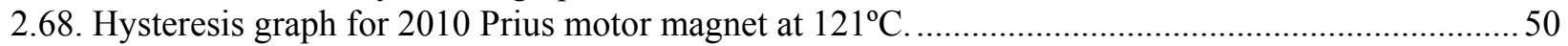

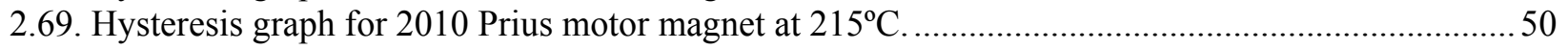

2.70. Intrinsic hysteresis graphs for 2010 Prius motor magnet at various temperatures...........................51

2.71. Intrinsic hysteresis graphs for 2004 Prius motor magnet at various temperatures............................52

2.72. Remanent flux density for LS 600h, Camry, 2004 Prius, and 2010 Prius motor magnet.................53

2.73. Coercivity of LS 600h, Camry, 2004 Prius, and 2010 Prius motor magnet.....................................53

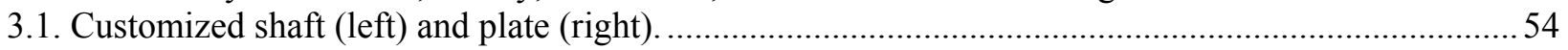

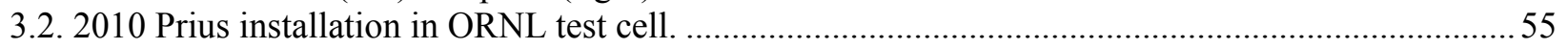

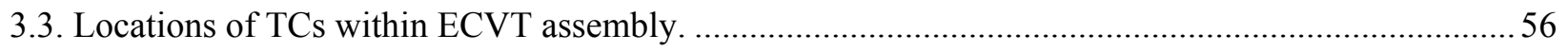

3.4. Device temperature monitoring locations within 2010 Prius PCU..................................................5 57

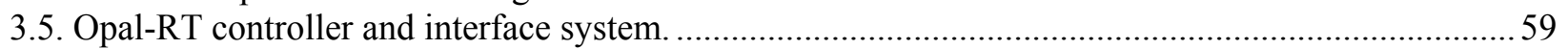

3.6. 2010 Prius, LS 600h, and Camry motor back-emf test results........................................................5

3.7. 2010 Prius locked rotor torque vs. position for various current levels. ........................................... 60

3.8. 2007 Camry locked rotor torque vs. position for various de currents............................................. 61

3.9. 2010 Prius, 2008 LS 600h, and 2007 Camry peak locked rotor torque vs. dc current.......................61

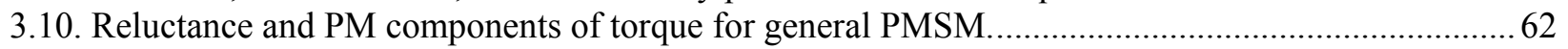

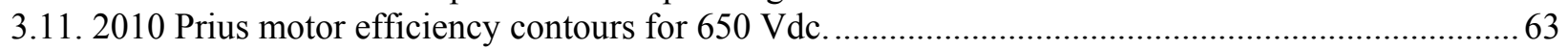

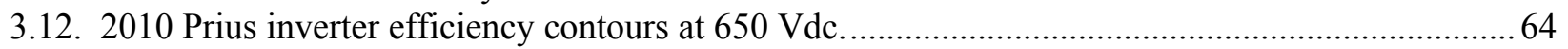

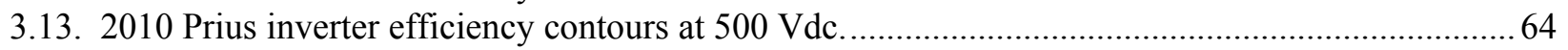

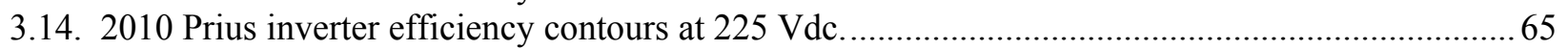

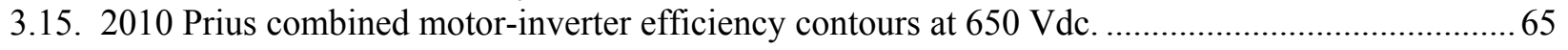

3.16. 2010 Prius combined motor-inverter efficiency contours at $500 \mathrm{Vdc}$..........................................66

3.172010 Prius combined motor-inverter efficiency contours at $225 \mathrm{Vdc}$..........................................66

3.18. 2010 Prius motor-inverter combined efficiency contours at $650 \mathrm{~V}$ for $77 \%$ and above.................... 67

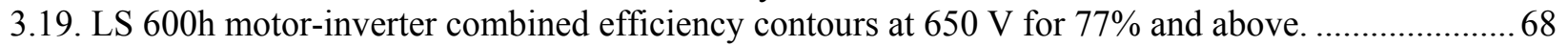

3.20. 2007 Camry motor/inverter efficiency contours at $650 \mathrm{~V}$ for $77 \%$ and above................................6 68

3.21. 2004 Prius motor/inverter efficiency contours for $77 \%$ and above. ............................................. 69

3.22. 2010 Prius temperatures during $25 \mathrm{~kW}$ continuous test at $3,000 \mathrm{rpm}$ with $25^{\circ} \mathrm{C}$ coolant................ 70 
3.23. 2010 Prius temperatures during $50 \mathrm{~kW}$ continuous test at $5,000 \mathrm{rpm}$ with $50^{\circ} \mathrm{C}$ coolant.

3.24. 2010 Prius temperatures during $50 \mathrm{~kW}$ continuous test at $7,000 \mathrm{rpm}$ with $25^{\circ} \mathrm{C}$ coolant................ 71

3.25. 2010 Prius $25 \mathrm{~kW}$ continuous duration vs. speed with $50^{\circ} \mathrm{C}$ coolant.......................................... 72

3.26. 2010 Prius $50 \mathrm{~kW}$ continuous duration vs. speed with $50^{\circ} \mathrm{C}$ coolant....................................... 72

3.27. 2010 Prius continuous duration at $3,000 \mathrm{rpm}$ with various power levels and coolant temperatures. 73

3.28. 2010 Prius continuous duration at 5,000 rpm with various power levels and coolant temperatures. 73

3.29. LS $600 \mathrm{~h}$ and Camry continuous duration at 5,000 rpm with various power levels and coolant

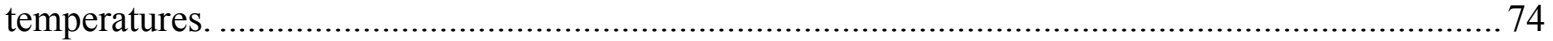

3.30. 2010 Prius continuous duration at 7,000 rpm with various power levels and coolant temperatures. 74 


\section{LIST OF TABLES}

Table

Page

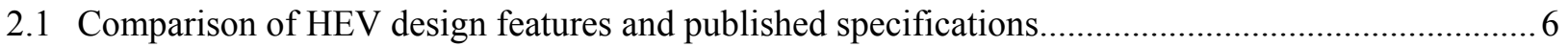

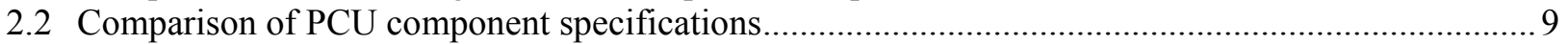

2.3 Mass and volume measurements for the 2010 Prius inverter and converter ................................. 14

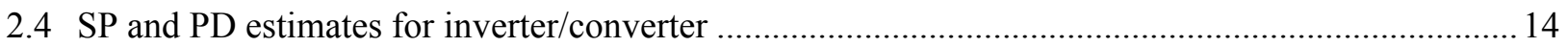

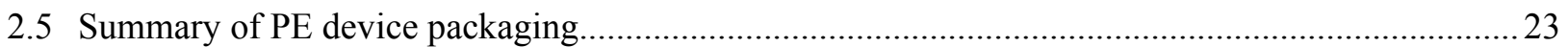

2.6 Comparison of gear teeth on 2007 Camry vs. 2010 Prius gears. ................................................. 42

2.72010 Prius, LS600h, Camry, and 2004 Prius motor design characteristics ................................. 456

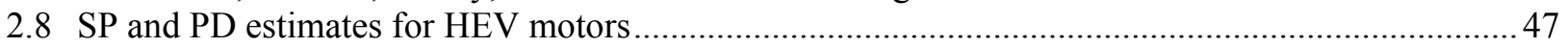

2.92010 Prius, LS600h, Camry, and 2004 Prius generator design characteristics .............................. 48

3.1 Conditions monitored during 2010 Prius evaluations ............................................................ 56

4.1 2010 Prius, 2008 LS 600h, 2007 Camry, and 2004 Prius design comparison highlights ................. 77 


\section{ACRONYMS AND ABBREVIATIONS}

\begin{tabular}{|c|c|c|c|}
\hline AlN & aluminum nitride & MPG & miles per gallon \\
\hline $\mathrm{A} / \mathrm{C}$ & air conditioning & $\mathrm{NdFeB}$ & neodymium iron boron \\
\hline ac & alternating current & Ni-MH & nickel metal hydride \\
\hline APEEM & $\begin{array}{r}\text { Advanced Power Electronics and } \\
\text { Electric Machines }\end{array}$ & $\begin{array}{l}\text { NTRC N } \\
\text { OD }\end{array}$ & $\begin{array}{r}\text { ational Transportation Research Center } \\
\text { outer diameter }\end{array}$ \\
\hline AWG & American wire gauge & OEM & original equipment manufacturers \\
\hline $\mathrm{CT}$ & current transducer & ORNL & Oak Ridge National Laboratory \\
\hline DAQ & data acquisition system & $\mathrm{PC}$ & personal computer \\
\hline DBA & direct bond aluminum & PCB & printed circuit board \\
\hline $\mathrm{dc}$ & direct current & PCU & power control unit \\
\hline DF & dissipation factor & PD & power density \\
\hline DOE & U.S. Department of Energy & $\mathrm{PE}$ & power electronic \\
\hline ECU & electronic control unit & PEEMRC & Power Electronics and Electric \\
\hline \multirow[t]{2}{*}{ ECVT } & electronically-controlled continuously & & Machinery Research Center \\
\hline & variable transmission & PEM & power electronics module \\
\hline EDS & energy-dispersive spectroscopy & PI & proportional-integral \\
\hline \multirow[t]{2}{*}{ EETT } & Electrical and Electronics & $\mathrm{PM}$ & permanent magnet \\
\hline & Technical Team & PMSM & permanent magnet synchronous motor \\
\hline $\mathrm{emf}$ & electromotive force (measured in volts) & $\mathrm{R} \& \mathrm{D}$ & research and development \\
\hline EMI & electromagnetic interference (EMI) & rms & root mean square \\
\hline ESR & equivalent series resistance & rpm & revolutions per minute \\
\hline EV & electric vehicle & RTV & room temperature vulcanizing \\
\hline FCVT & FreedomCAR and Vehicle Technologies & SEM & scanning electron microscopy \\
\hline $\mathrm{HEV}$ & hybrid electric vehicle & $\mathrm{Si}$ & silicon \\
\hline $\mathrm{HV}$ & high voltage & $\mathrm{SP}$ & specific power \\
\hline IC & integrated circuit & SVPWM & space vector pulse width modulation \\
\hline ICE & internal combustion engine & $\mathrm{TC}$ & thermocouple \\
\hline ID & inner diameter & USCAR & United States Council for \\
\hline IGBT & insulated-gate bipolar transistor & & Automotive Research \\
\hline LV & low voltage & VSATT & Vehicle Systems Analysis \\
\hline MG & motor-generator & & Technical Team \\
\hline MG1 & secondary electric motor & VTP & Vehicle Technologies Program \\
\hline MG2 & primary electric motor & yttria & yttrium oxide \\
\hline
\end{tabular}




\section{INTRODUCTION}

Subsystems of the 2010 Toyota Prius hybrid electric vehicle (HEV) were studied and tested as part of an intensive benchmarking effort carried out to produce detailed information concerning the current state of nondomestic alternative vehicle technologies. Feedback provided by benchmarking efforts is particularly useful to partners of the Vehicle Technologies collaborative research program as it is essential in establishing reasonable yet challenging programmatic goals which facilitate development of competitive technologies. The competitive nature set forth by the Vehicle Technologies Program (VTP) not only promotes energy independence and economic stability, it also advocates the advancement of alternative vehicle technologies in an overall global perspective. These technologies greatly facilitate the potential to reduce dependency on depleting natural resources and mitigate harmful impacts of transportation upon the environment.

\subsection{PROGRAM OVERVIEW}

The U.S. Department of Energy (DOE) and United States Council for Automotive Research (USCAR) (composed of automotive manufacturers General Motors, Ford, and Chrysler) are currently part of a cooperative research effort known as the FreedomCAR Partnership. The cooperative effort represents DOE's commitment to developing public/private partnerships to fund high-risk, high-payoff research into advanced automotive technologies. The long-term focus of DOE's VTP is to develop "leap frog" technologies that will provide Americans with greater freedom of mobility and energy security, while lowering costs and reducing impacts on the environment [1]. Program activities include research, development, demonstration, testing, technology validation, and technology transfer.

As a part of the VTP, the Advanced Power Electronics and Electric Machines (APEEM) subprogram provides support through a three-phase approach which is intended to:

- Identify overall propulsion and vehicle-related needs by analyzing programmatic goals and reviewing industry's recommendations and requirements, then develop the appropriate technical targets for systems, subsystems, and component research and development (R\&D) activities;

- Develop and validate individual subsystems and components, including electric motors and power electronics (PEs), accessories, and devices to reduce parasitic losses; and

- Determine how well the components and subassemblies work together in a vehicle environment or as a complete propulsion system and whether the efficiency and performance targets at the vehicle level have been achieved.

The research performed in this area will help remove technical and cost barriers to enable the development of technology for use in such advanced vehicles as hybrid electric, plug-in hybrid electric, electric, and fuel-cell-powered vehicles.

\subsection{RESEARCH FACILITIES}

Subsystem-level evaluations are conducted by Oak Ridge National Laboratory's (ORNL) Power Electronics and Electric Machinery Research Center (PEEMRC), which is a broad-based research center for PEs and electric machinery (motor) development. Located in the national user facility known as the National Transportation Research Center (NTRC), the PEEMRC has more than 9,000 square feet of space for developing and building the next generation prototypes of PEs and electric machine technologies. 


\subsection{SCOPE AND OBJECTIVE}

Benchmarking efforts at the PEEMRC support the VTP by providing the current status and capabilities of nondomestic technologies found in alternative vehicles such as HEVs. This information is crucial in determining and verifying targets for various initiatives within the VTP. For example, feedback from an intensive electric motor evaluation aids program direction such that electric motor design projects have overall targets which are highly competitive with nondomestic technologies. The overall agenda of the benchmarking project is described by the following objectives:

- Provide status of non-domestic alternative vehicle technologies through assessment of design, packaging, fabrication, operation, and performance during comprehensive evaluations:

o Compare results with other alternative vehicle technologies; and

o Distribute findings in open literature.

- Support VTP planning and assist in guiding research efforts:

o Confirm validity of the program technology targets; and

o Provide insight for program direction.

- Produce a technical basis that aids in modeling/designing :

o Supply data and other information necessary to develop and/or verify subsystem models.

- Foster collaborations with the Electrical and Electronics Technical Team (EETT) and the Vehicle Systems Analysis Technical Team (VSATT):

o Identify unique permanent magnet synchronous motor (PMSM), inverter, converter, drivetrain, and thermal management technologies; and

o Ascertain what additional testing is needed to support R\&D.

The PEEMRC performed subsystem benchmarking assessments of the 2004 Toyota Prius HEV in 20042005. This work has been fully reported in two reports [2,3]. Similar research and testing efforts were conducted with the hybrid subsystems of the 2005 Honda Accord [4], 2007 Toyota Camry [5], and 2008 Lexus LS600h [6] in 2006, 2007, and 2008, respectively. This report presents the results from benchmarking evaluations of the 2010 Toyota Prius electric drive subsystems.

\subsection{APPROACH}

Benchmarking evaluations are separated into two primary categories: (1) design and packaging assessments, and (2) subsystem and component testing. Design and packaging assessments include intensive studies of components and subsystems which yield benefits of lower cost, increased power density (PD), increased specific power (SP), enhanced operation, or improved durability in alternative vehicles. Component testing procedures entail comprehensive examinations of peak performance, continuous capabilities, and general operation characteristics. These studies typically focus on PEs, electric machines, and components integrated or associated with PEs and electric machines.

In order to ensure 2010 Toyota Prius HEV technologies were fully benchmarked in tandem with the needs of the VTP partners, an ORNL benchmarking evaluation plan was developed. After the plan was subjected to an internal review it was dispersed to the automotive manufacturer partners of USCAR within the EETT and various DOE national laboratories. A flow diagram which portrays the baseline benchmarking approach is shown in Fig. 1.1. Conclusions from the 2010 Prius design and packaging assessments are presented in Section 2 and empirical results from PMSM and power control unit (PCU) tests are provided in Section 3. 


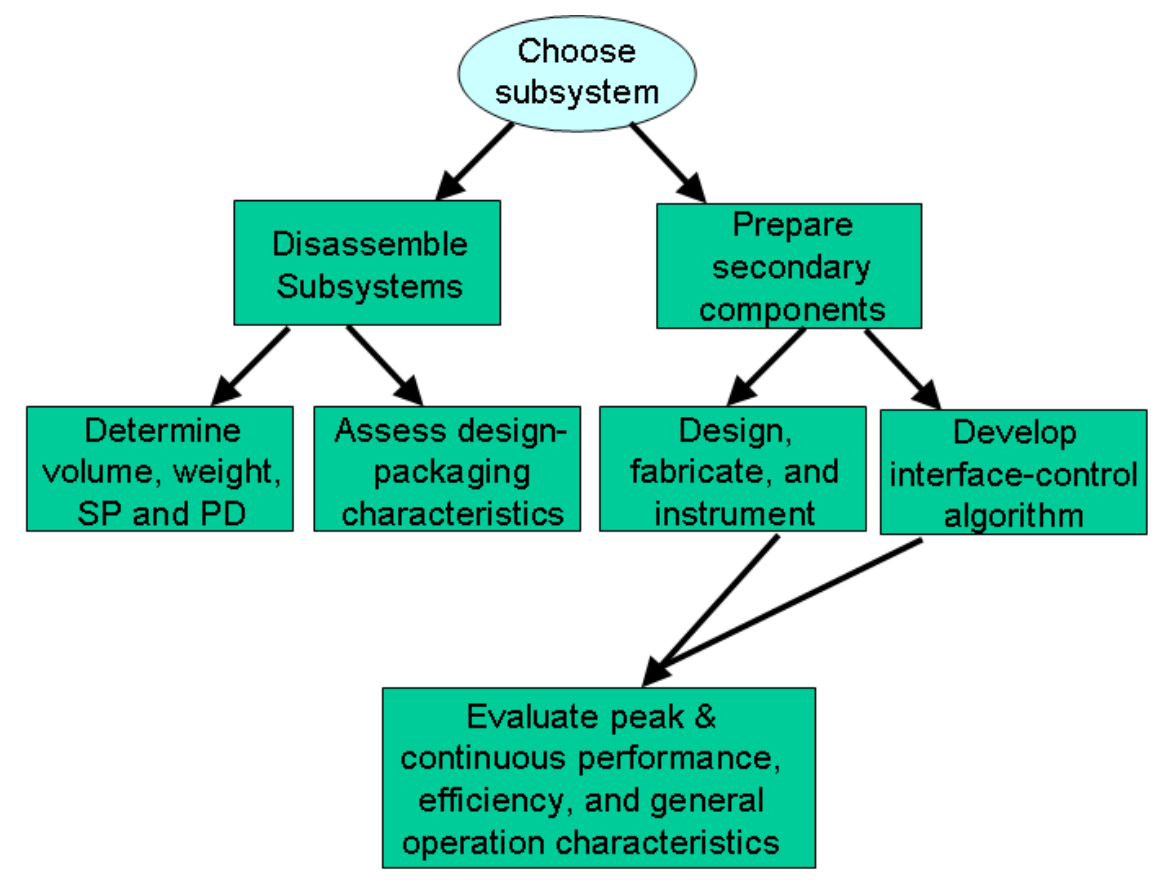

Fig. 1.1. Flow diagram of baseline benchmarking approach.

\section{HYBRID ELECTRIC DRIVE SYSTEM DESIGN AND PACKAGING}

This section presents a comprehensive report of the design and packaging characteristic assessments of the 2010 Toyota Prius HEV subsystems. After a general description of the vehicle design is provided, explanations of the hybrid system functionalities are presented with accompanying illustrations and photographs. Then in depth exposition begins with the PCU, wherein converter and inverter components such as PEs devices and capacitors are fully examined. Finally, the electronically-controlled continuously variable transmission (ECVT) is thoroughly reviewed and focus is placed on the thermal management system, gear train, PMSM design, and PM characteristics. Detailed comparisons between the 2010 Toyota Prius, 2008 Lexus LS 600h, 2007 Toyota Camry, and 2004 Toyota Prius design and packaging characteristics are provided in each subsection.

\subsection{VEHICLE DESCRIPTION}

The 2010 Toyota Prius, shown in Fig. 2.1 [7], is from the first production year of what is referred to as the third generation Prius, with the second generation production years ranging from 2004-2009, and the first generation production years ranging from 1997-2003. In terms of fuel economy, the 2010 Prius is reported to have improved fuel economy over the second generation Prius, with an estimated 51 miles per gallon (MPG) for city driving conditions and $48 \mathrm{MPG}$ for highway driving conditions. According to published specifications [8], the front wheel drive is powered by a $98 \mathrm{hp}(73 \mathrm{~kW}) 1.8$ Liter 4-cylinder Atkinson cycle internal combustion engine (ICE) and with the help of a $36 \mathrm{hp}(27 \mathrm{~kW})$ nickel-metal hydride battery pack, the system has a net power rating of $134 \mathrm{hp}(100 \mathrm{~kW})$. 


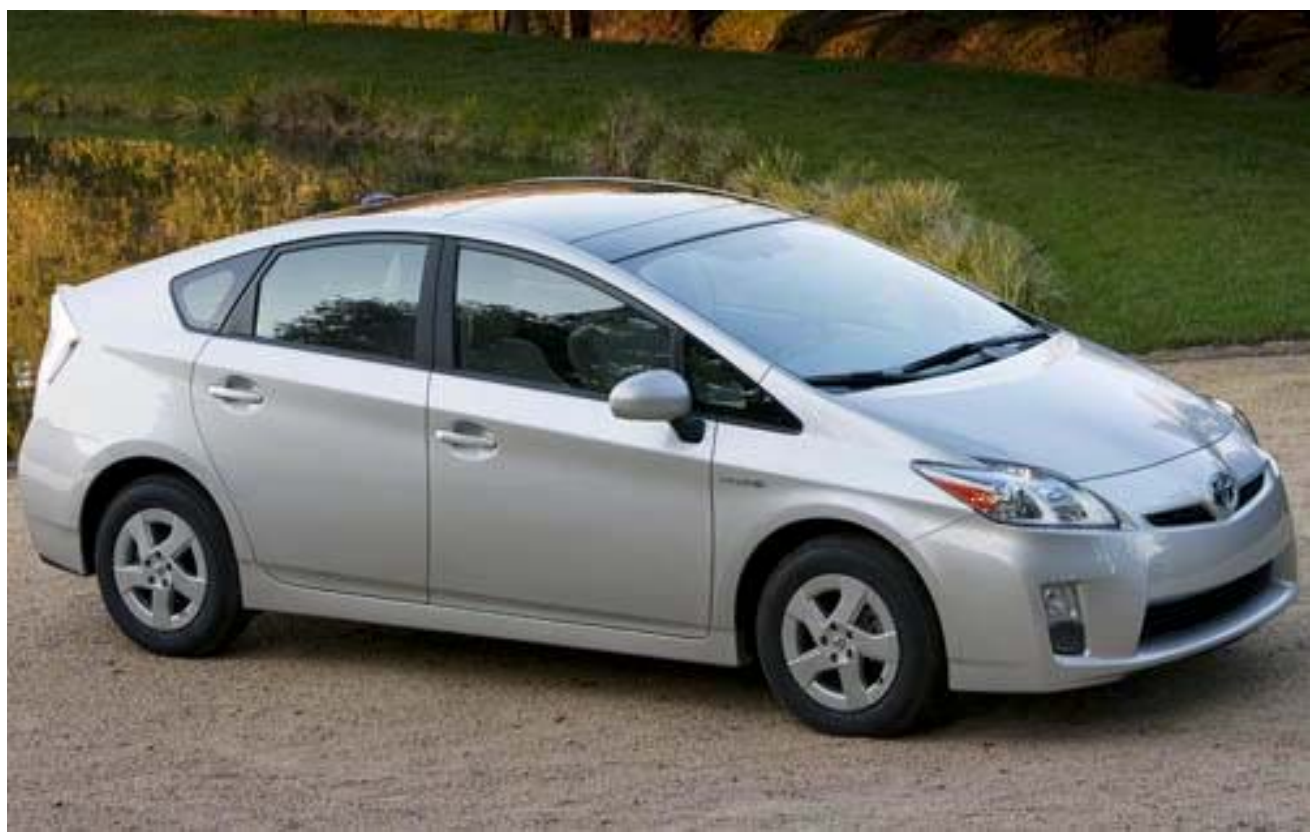

Fig. 2.1. 2010 Toyota Prius [7].

\subsubsection{Hybrid Drive System}

The 2010 Toyota Prius is equipped with the Hybrid Synergy Drive system which includes an ICE, an electric motor, and a generator. These systems are integrated with a power splitting planetary gear which provides various power flow configurations for different modes of operation. The primary electric motor (MG2) assists the ICE in providing mechanical drive power for the vehicle and also acts as a generator to recharge the battery during regenerative braking. A secondary electric motor (MG1) functions as a generator to transfer power from the ICE to recharge the battery and also to utilize the ICE as a power source to supply MG2, which ultimately assists in the propulsion of the vehicle. This is often referred to as an ECVT, as the power-split planetary and electric motors are utilized to vary the gear ratio between the ICE and the drive wheels without the use of clutches or hydraulic apparatuses. While the basic functionality of the 2010 Prius hybrid system is similar to its predecessors, it is most similar to the 2007 Camry hybrid in terms of the specific design.

These vehicles can utilize the electric motor to provide all of the traction power during acceleration from a stop. This operation mode is valid unless the engine is needed for any of several reasons (more torque, low battery state of charge, high battery temperature, proper engine temperature, etc.). The clutch-less, ECVT contains a planetary gear which allows various schemes of power flow from the battery, ICE, and motor to the output shaft. The planetary gear configuration of the ECVT provides the opportunity to operate the ICE throughout a more efficient torque-speed range by appropriately controlling the torques and speeds of MG1 and MG2. Contained within the PCU are electronics devices which manage power flow to and from the battery, generator, and motor. The 2010 Prius, Lexus, and Camry electric-machines and inverter drives are rated at $650 \mathrm{Vdc}$ (versus $500 \mathrm{Vdc}$ for the 2004 Prius) and are liquid-cooled by means of a typical ethylene glycol mixture. The systems use sealed nickel metal hydride (Ni-MH) batteries with $1.2 \mathrm{~V}$ cells in series to produce voltages of $201.6 \mathrm{~V}, 288 \mathrm{~V}$, and $245 \mathrm{~V}$, respectively. Although the voltage and battery capacity of 6.5 ampere-hours matches the 2004 Prius, the published rated power of the battery pack has increase from $28 \mathrm{hp}(20.9 \mathrm{~kW})$ to $36 \mathrm{hp}(26.8 \mathrm{~kW})$. This is perhaps an indication of an improved battery cooling system. 
Although the basic functionality of the ECVT and PCU are similar to the Hybrid Synergy Drive components of the other Toyota HEVs, there are considerable differences in the design and packaging characteristics of the systems. Table 2.1 presents an overview of several general HEV design features and published specifications and indicates similarities and differences between the 2010 Prius, Lexus, Camry, and Prius vehicles. The primary drive PMSM is referred to as MG2 and the generator is referred to as MG1. Although both PMSMs can function as a motor or a generator, MG2 is commonly referred to as "motor" and MG1 is commonly referred to as "generator." Both MG1 and MG2 are powered by separate three-phase inverters which share the same direct current (dc)-link. The battery voltage is boosted by a bidirectional dc-dc converter which feeds the dc-link. This configuration facilitates the use of multiple power flow modes wherein the ICE, MG1, and/or MG2 may supply energy to the battery pack, the battery pack may supply MG1/MG2 alone, or the ICE and battery pack can simultaneously power the vehicle.

Design and packaging assessments are presented in Subsections 2.2 and 2.3 beginning with the PCU and concluding with the ECVT, respectively. Studies on the PCU include subjects such as general design and packaging, double-sided cooling infrastructure, PE devices, and multifaceted capacitor assessments. Assessment topics associated with the ECVT are general design and packaging, PMSM design, and magnet hysteresis measurements. These assessments provide useful feedback regarding technological developments and other characteristics needed to determine packaging complexity and fabrication costs.

\subsection{PCU}

The primary discrepancy between the 2010 Prius PCU and previous PCU designs is the introduction of an integrated cooling technique with the PEs module. In previous Toyota designs, the PEs module is a stand-alone unit that is mounted to a cast aluminum heat exchanger, whereas the 2010 Prius PEs module is brazed directly to a cooling infrastructure. This significantly improves the capability of the cooling system to remove heat from the PEs devices. While this is not as effective as the double-sided cooling technique used in the LS 600h PCU, it is simpler and more cost effective.

Much like the 2007 Camry and 2008 LS600h PCU designs, the size and proportions of the 2010 Prius PCU, shown in Fig. 2.2, are similar to that of a conventional $12 \mathrm{Vdc}$ car battery. The 2010 Prius PCU weighs $13.0 \mathrm{~kg}$ versus about $17.4 \mathrm{~kg}$ and $17.9 \mathrm{~kg}$ for the Camry and LS 600h PCUs, respectively. A reduction of mass is expected when considering the lower power rating of the 2010 Prius. Another explanation for the reduction in mass is that the 2010 Prius utilizes a light weight aluminum cooling infrastructure, where as the 2004 Prius and 2007 Camry designs use a cast aluminum heat exchanger. Interestingly, the 2010 Prius PCU volume of $16.2 \mathrm{~L}$ is significantly greater than that of the $11.7 \mathrm{~L}$ and 13.7 L volumes of the Camry and LS 600h PCUs, respectively. It should be noted that both second and third generation Prius PCUs include a $202 \mathrm{~V}$ to $12 \mathrm{~V} \mathrm{dc}$-dc converter for the accessory voltage supply, replacing the alternator. As indicated in Fig. 2.3, connector terminals are connected to the $202 \mathrm{~V}$ battery supply, and additional connector terminals provide a fused link from the $202 \mathrm{~V}$ battery supply for the external inverter which drives the air conditioning $(\mathrm{A} / \mathrm{C})$ compressor. This small, three-phase inverter for the compressor is located within the 2004 Prius PCU. One coolant port, seen in Fig. 2.3, is located below

the interface to the vehicle ECU and the other coolant port is located on the opposite end of the PCU. The ethylene-glycol and water mixture flows from the PCU output port through a heat exchanger on the ECVT and subsequently to a radiator which is separate from the high-temperature ICE coolant radiator. Motor and generator interconnections differ significantly from the Camry design in which only three bolts secure the cable harness to the PCU, where as the 2010 Prius and LS 600h designs include bolts which secure the cables directly to terminals in addition to the mechanical support from cable harness bolts. 
Table 2.1. Comparison of HEV design features and published specifications

\begin{tabular}{|c|c|c|c|c|}
\hline Design Feature & 2008 LS 600h & Hybrid Camry & 2004 Prius & 2010 Prius \\
\hline Motor peak power rating & $\begin{array}{c}165 \mathrm{~kW} @ 5250 \\
\text { revolutions per } \\
\text { minute (rpm) } \\
\text { (disputed) }\end{array}$ & $\begin{array}{l}105 \text { kW@ } 9500 \\
\text { rpm (disputed) }\end{array}$ & $\begin{array}{l}50 \mathrm{~kW} @ 1200- \\
1540 \mathrm{rpm}\end{array}$ & $60 \mathrm{~kW}$ \\
\hline Motor peak torque rating & $300 \mathrm{Nm}$ & $270 \mathrm{Nm}$ & $400 \mathrm{Nm}$ & $207 \mathrm{Nm}$ \\
\hline Rotational speed rating & $10,230 \mathrm{rpm}$ & $14,000 \mathrm{rpm}$ & $6,000 \mathrm{rpm}$ & $13,500 \mathrm{rpm}$ \\
\hline Separate generator used? & Yes & Yes & Yes & Yes \\
\hline Generator specifications & Not published & Not published & $33 \mathrm{~kW}$ & $42 \mathrm{~kW}$ \\
\hline Source of power to MG2 & $\begin{array}{l}\text { Battery and/or } \\
\text { ICE via } \\
\text { generator }\end{array}$ & $\begin{array}{l}\text { Battery and/or } \\
\text { ICE via generator }\end{array}$ & $\begin{array}{l}\text { Battery and/or } \\
\text { ICE via generator }\end{array}$ & $\begin{array}{l}\text { Battery and/or } \\
\text { ICE via generator }\end{array}$ \\
\hline PMSM rotor design & $\begin{array}{l}\text { Interior PMs } \\
\text { with triangular } \\
\text { configuration }\end{array}$ & $\begin{array}{c}\text { Interior PMs with } \\
\text { "V" } \\
\text { configuration }\end{array}$ & Similar to Camry & Similar to Camry \\
\hline $\begin{array}{l}\text { Motor winding } \\
\text { configuration }\end{array}$ & Parallel & Parallel & Series & Series \\
\hline Number of rotor poles & 8 & 8 & 8 & 8 \\
\hline $\begin{array}{l}\text { Bi-directional dc-dc } \\
\text { converter output voltage }\end{array}$ & $\sim 288-650 \mathrm{Vdc}$ & $250-650 \mathrm{Vdc}$ & $200-500 \mathrm{Vdc}$ & $200-650 \mathrm{Vdc}$ \\
\hline $\begin{array}{l}\text { Bi-directional dc-dc } \\
\text { converter power rating }\end{array}$ & $36.5 \mathrm{~kW}$ & $30 \mathrm{~kW}$ & $20 \mathrm{~kW}$ & $27 \mathrm{~kW}$ \\
\hline PMSM cooling & $\begin{array}{c}\text { Same as Camry, } \\
\text { yet with oil } \\
\text { squirters for } \\
\text { stator } \\
\end{array}$ & $\begin{array}{l}\text { Oil circulation } \\
\text { and water/glycol } \\
\text { heat exchanger }\end{array}$ & Same as Camry & $\begin{array}{l}\text { Same as Camry, } \\
\text { yet no direct heat } \\
\text { exchanger }\end{array}$ \\
\hline $\begin{array}{l}\text { Inverter/converter } \\
\text { cooling }\end{array}$ & $\begin{array}{c}\text { Water/glycol } \\
\text { loop }\end{array}$ & $\begin{array}{c}\text { Water/glycol } \\
\text { loop }\end{array}$ & $\begin{array}{c}\text { Water/glycol } \\
\text { loop }\end{array}$ & $\begin{array}{c}\text { Water/glycol } \\
\text { loop }\end{array}$ \\
\hline Hybrid transmission & $\begin{array}{l}\text { Same as Camry, } \\
\text { yet Ravigneaux } \\
\text { high and low } \\
\text { gear used for } \\
\text { speed reduction }\end{array}$ & $\begin{array}{l}\text { Planetary gears } \\
\text { used for speed } \\
\text { reduction and } \\
\text { power split }\end{array}$ & $\begin{array}{c}\text { A single } \\
\text { planetary gear } \\
\text { used for power } \\
\text { split }\end{array}$ & Same as Camry \\
\hline $\begin{array}{l}\text { Fan-cooled high-voltage } \\
\text { (HV) Ni-MH battery }\end{array}$ & $\begin{array}{c}288 \mathrm{~V}, 6.5 \mathrm{Ah}, \\
36.5 \mathrm{~kW}\end{array}$ & $\begin{array}{c}244.8 \mathrm{~V}, 6.5 \mathrm{Ah}, \\
30 \mathrm{~kW}\end{array}$ & $\begin{array}{c}201.6 \mathrm{~V}, 6.5 \mathrm{Ah}, \\
20 \mathrm{~kW}\end{array}$ & $\begin{array}{c}201.6 \mathrm{~V}, 6.5 \mathrm{Ah}, \\
27 \mathrm{~kW}\end{array}$ \\
\hline
\end{tabular}
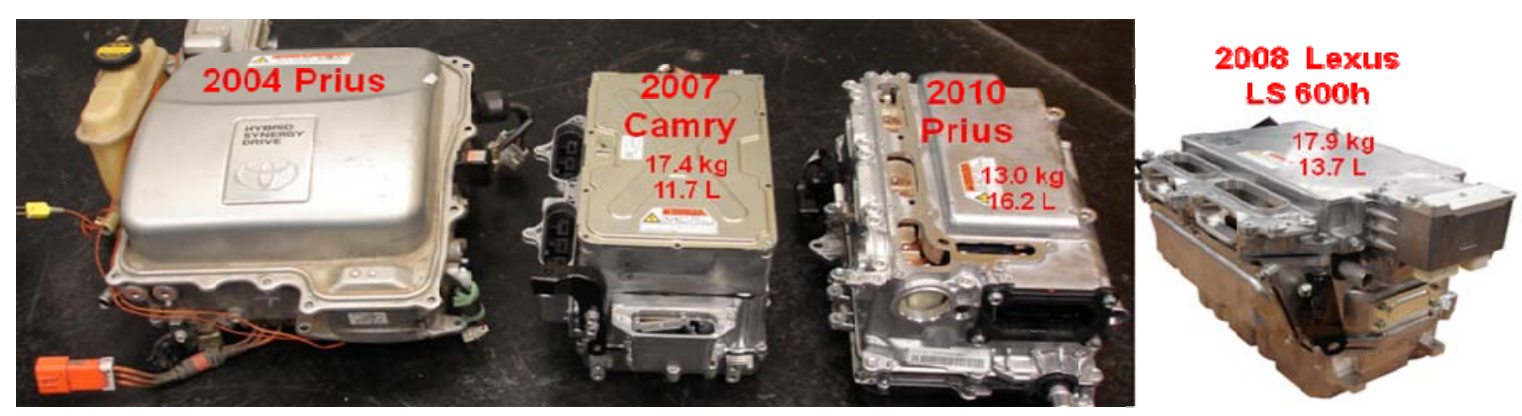

Fig. 2.2. Comparison of PCUs (which include motor and generator inverters). 

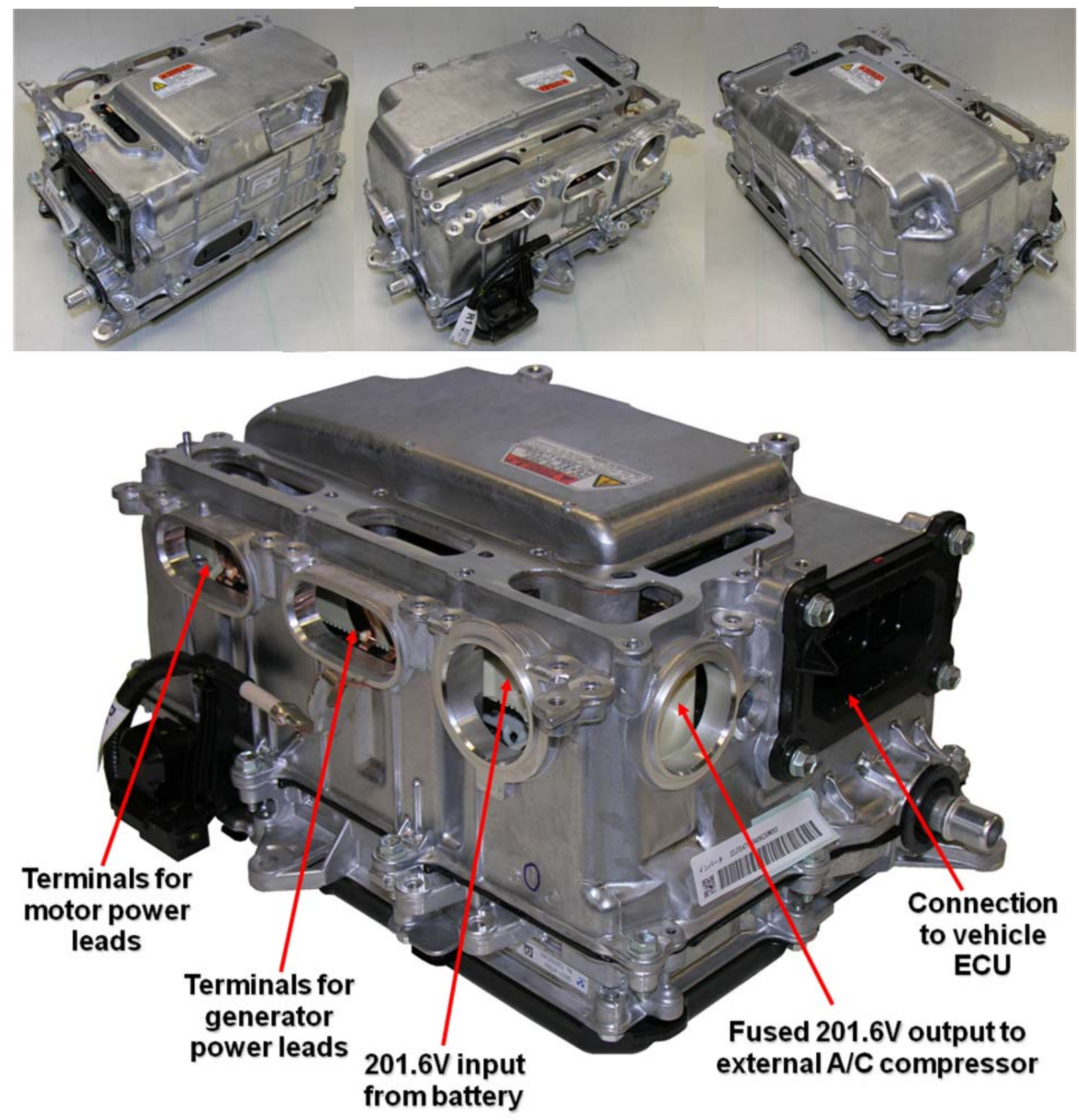

Fig. 2.3. PCU of the 2010 Prius.

Within the 2010 Prius PCU are components associated with a bi-directional dc-dc converter, motor inverter, and generator inverter and their general locations are shown in Fig. 2.4. Contrary to the Camry PCU design described in [5], but similar to the LS 600h [6], the 2010 Prius controller, power supply, and driver electronics for the bi-directional dc-dc converter and inverters are grouped together onto two printed circuit boards (PCBs) located in the uppermost compartment indicated in Fig. 2.4. The Camry PCU design includes four separate PCBs dedicated to these functions and the bi-directional dc-dc converter PCBs and PEs are located in a separate compartment. The main capacitor module shares the uppermost compartment, and includes many small capacitors which are combined to serve as two large capacitors; one at battery level and one on the output of the boost converter. Similar to the 2004 Prius, the main capacitor module is a separate unit, and is not molded with the housing of the PCU, as are the 
Camry and LS $600 \mathrm{~h}$ capacitor modules. Attached to the side of the main capacitor module is a small $54 \mathrm{k} \Omega$ ceramic resistor that is connected the across the HV dc-link capacitor terminals and is located on the side of the PCU. The resistor, sized the same as the Camry and LS 600h, functions as a voltage bleedoff for the capacitor and may contribute some filtering effects.

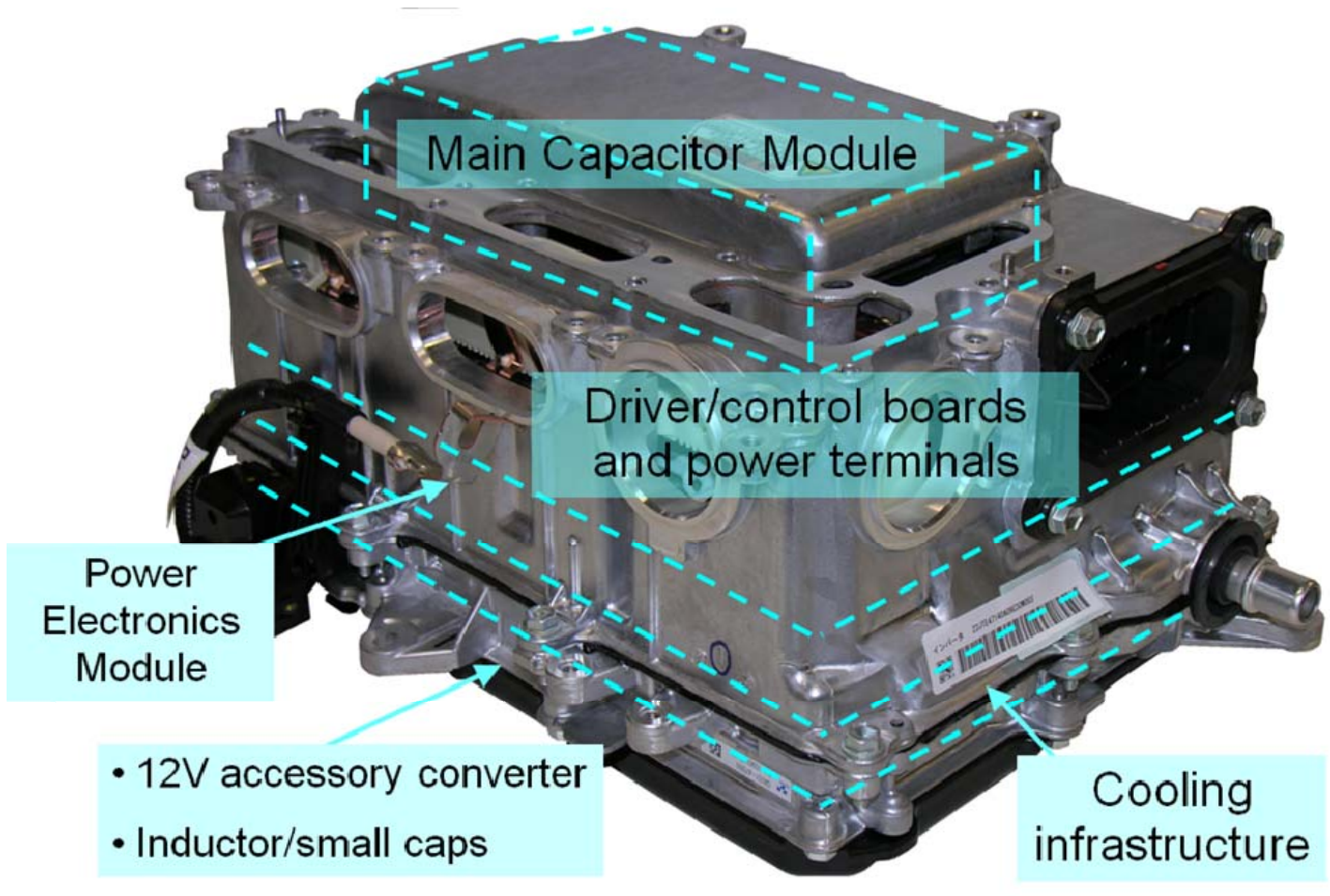

Fig. 2.4. Compartments of the 2010 Prius inverter and converter assembly.

The 2010 Prius and LS 600h PEs devices are located in the compartment below the controller and driver electronics and the bi-directional dc-dc converter PEs are grouped together with the inverter PEs, as further explained in Section 2.2.1. While the PEs module and cooling infrastructure is one unit, separate sections are shown in Fig. 2.4 since the lower-most compartment also utilizes the heat exchanger. The lower-most compartment houses the $200 \mathrm{~V}$ to $12 \mathrm{~V} \mathrm{dc}$-dc converter as well as the large inductor and small capacitors associated with the bi-directional dc-dc boost converter which supplies the motor and generator inverters.

Because the Ni-MH battery is rated at $27 \mathrm{~kW}$, it is assumed that the bi-directional dc-dc converter will not operate at power levels exceeding $27 \mathrm{~kW}$. Similarly, it is assumed that the motor inverter has a peak power rating that matches the measured power rating of the motor. The overall circuit diagram of the PCU is shown in Fig. 2.5. A 201.6 Vdc battery supplies power to the PCU, which is connected to the low voltage (LV) side of the boost converter. A $470 \mathrm{~V}, 315 \mu \mathrm{F}$ capacitor is connected across the input with a $225.6 \mu \mathrm{H}$ inductor between the battery and the boost converter PEs module. A small $53.8 \mathrm{k} \Omega$ resistor is in parallel with a $860 \mathrm{~V}, 0.562 \mu \mathrm{F}$ capacitor, which is integrated into the main capacitor module.

Additionally, separate $900 \mathrm{~V}, 0.8 \mu \mathrm{F}$, and $950 \mathrm{~V}, 0.562 \mu \mathrm{F}$ filter capacitor modules (located in the bottom portion of the $\mathrm{PCU}$ ) and a $750 \mathrm{~V}, 888 \mu \mathrm{F}$ smoothing capacitor is a part of this parallel configuration which is connected to the HV side of the boost converter. This HV bus serves as the dc link for both the motor and generator inverter. Table 2.2 provides specification comparisons between the components found in the 2004 Prius, Camry, LS 600h, and 2010 Prius PCU. The boosted voltage ranges from 202$650 \mathrm{Vdc}$ depending on driving conditions such as desired acceleration and required regenerative braking 
and is controlled accordingly by commands from the motor-generator (MG) electronic control unit (ECU) and the vehicle ECU. Detailed capacitor test results are provided in Section 2.2.4.

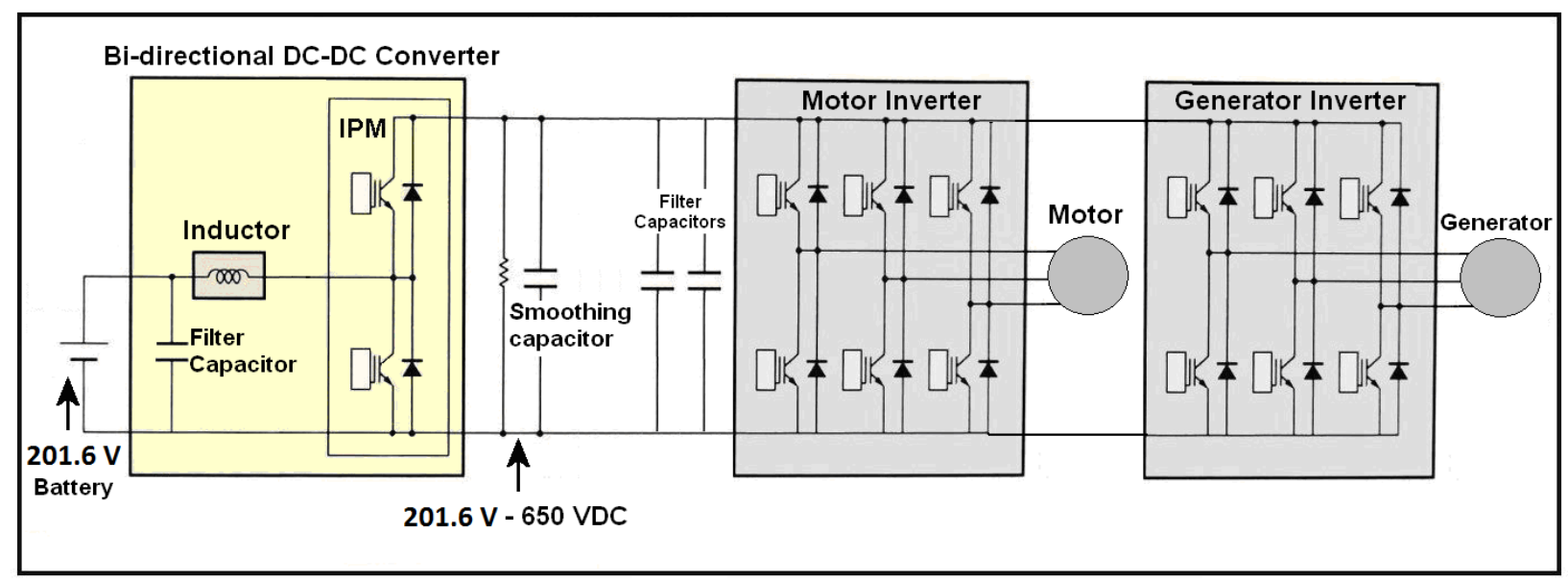

Fig. 2.5. Circuit diagram of 2010 Prius PCU.

Table 2.2. Comparison of PCU component specifications

\begin{tabular}{|c|c|c|c|c|}
\hline Design Feature & LS 600h & Hybrid Camry & 2004 Prius & 2010 Prius \\
\hline $\begin{array}{l}\text { DC-dc converter power } \\
\text { rating }\end{array}$ & $36.5 \mathrm{~kW}$ & $30 \mathrm{~kW}$ & $20 \mathrm{~kW}$ & $27 \mathrm{~kW}$ \\
\hline Battery voltage & $288 \mathrm{~V}$ & $244.8 \mathrm{~V}$ & $201.6 \mathrm{~V}$ & $201.6 \mathrm{~V}$ \\
\hline Filter capacitor (LV side) & $500 \mathrm{Vdc}, 378 \mu \mathrm{F}$ & $500 \mathrm{Vdc}, 378 \mu \mathrm{F}$ & $600 \mathrm{Vdc}, 282 \mu \mathrm{F}$ & $470 \mathrm{Vdc}, 315 \mu \mathrm{F}$ \\
\hline Inductor & $329 \mu \mathrm{H}$ at $1 \mathrm{kHz}$ & $212 \mu \mathrm{H}$ at $1 \mathrm{kHz}$ & $373 \mu \mathrm{H}$ at $1 \mathrm{kHz}$ & $225.6 \mu \mathrm{H}$ at $1 \mathrm{kHz}$ \\
\hline Small resistor (HV side) & $53.8 \mathrm{k} \Omega$ & $53.8 \mathrm{k} \Omega$ & $64.3 \mathrm{k} \Omega$ & $53.8 \mathrm{k} \Omega$ \\
\hline $\begin{array}{l}\text { Small filter capacitor (HV } \\
\text { side) }\end{array}$ & $\begin{array}{l}750 \mathrm{Vdc}, 0.6 \mu \mathrm{F} \\
750 \mathrm{Vdc}, 1.2 \mu \mathrm{F}\end{array}$ & $750 \mathrm{Vdc}, 0.9 \mu \mathrm{F}$ & $750 \mathrm{Vdc}, 0.1 \mu \mathrm{F}$ & $\begin{array}{c}860 \mathrm{Vdc}, 0.562 \mu \mathrm{F} \\
900 \mathrm{Vdc}, 0.8 \mu \mathrm{F} \\
950 \mathrm{Vdc}, 0.562 \mu \mathrm{F}\end{array}$ \\
\hline $\begin{array}{l}\text { Smoothing capacitor (HV } \\
\text { side) }\end{array}$ & $750 \mathrm{Vdc}, 2629 \mu \mathrm{F}$ & $750 \mathrm{Vdc}, 2098 \mu \mathrm{F}$ & $600 \mathrm{Vdc}, 1,130 \mu \mathrm{F}$ & $750 \mathrm{Vdc}, 888 \mu \mathrm{F}$ \\
\hline
\end{tabular}

\subsubsection{PCU Disassembly}

Figure 2.6 shows the 2010 Prius PCU with the upper half of the housing removed and placed beside it. Eleven bolts hold the assembly together with a compound similar to a room temperature vulcanizing (RTV) silicone applied to the mating surfaces in order to seal the unit. The main capacitor module is secured in the housing with four bolts and the small, white ceramic resistor is fastened to the side of the module. The copper bus bars near the bottom-right side of the image connect directly to hybrid battery supply. The common bus bar immediately enters the capacitor module, while the positive input traverses the width of the PCU and then enters the capacitor module and is also connected to the inductor in the bottom compartment by means of long vertical bus bars.

Next, the control/interface circuit board as well as the dc input, dc output, motor, and generator connection terminals were removed, as shown in Fig. 2.7. This circuit board, shown on the right, is multilayered and includes power regulation electronics, two identical MG microprocessors, a boostconverter microprocessor, two Tamagawa AU2802 integrated circuits (ICs) for MG speed/position detection, hardware for vehicle communication, MG current measurement, safety interlock devices, and temperature feedback. The design of this circuit board is very similar to that of the 2007 Camry. The circuit board seen in the middle portion of Fig. 2.7 is the driver/power supply board, and it is also similar 
to that of the Camry. The driver board includes regulated isolation power supplies, isolated driver electronics, and hardware to prevent faults and overlapping as well as voltage, current, and temperature sensing circuitry for each insulated-gate bipolar transistor (IGBT). There are 22 groups of 5 pins for driving and sensing purposes for each IGBT. More information regarding the PEs modules for the inverters and converter is provided in Sections 2.2.2 and 2.2.3.

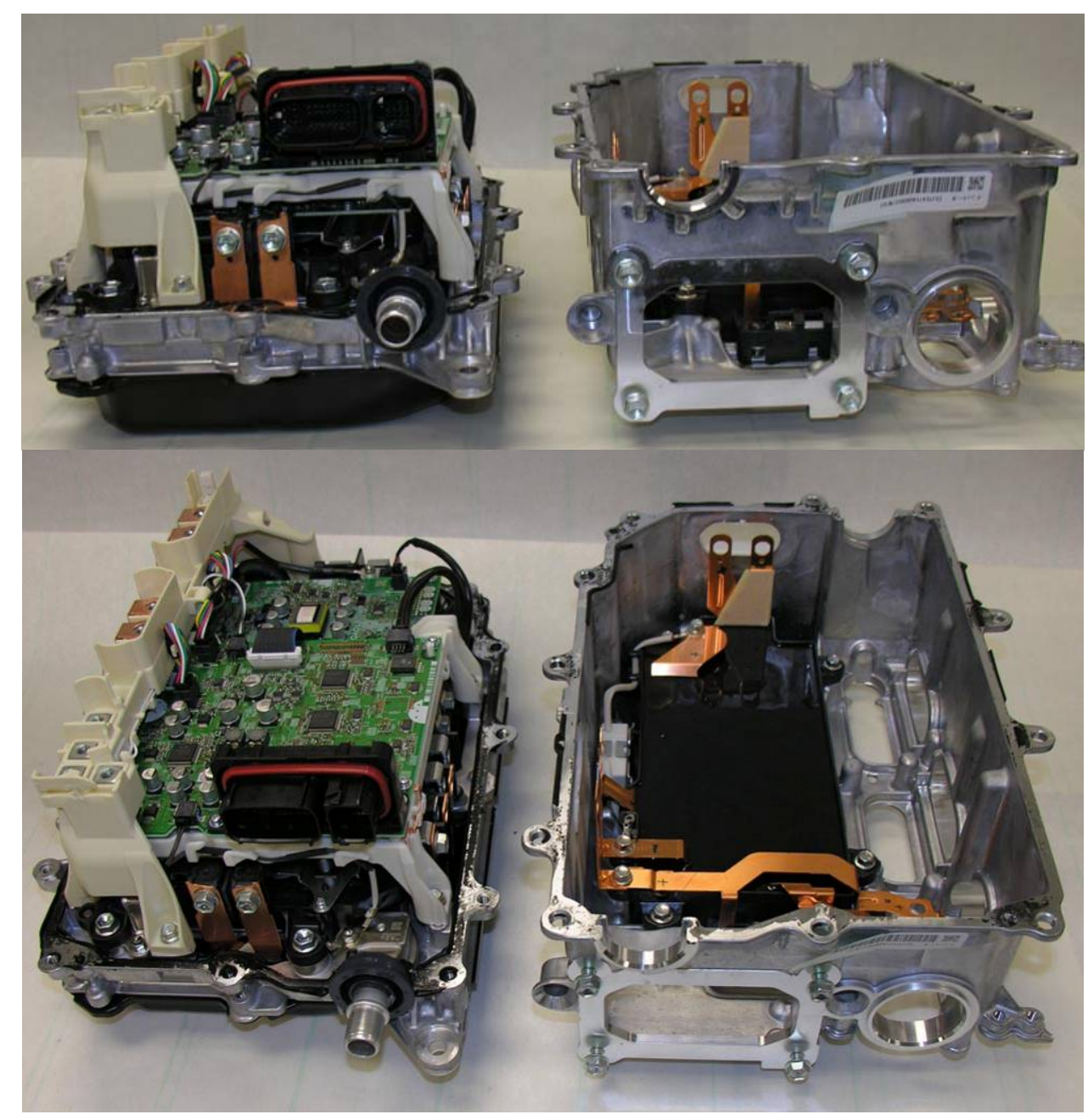

Fig. 2.6. 2010 Prius PCU separated.

A side view of the connection terminals is provided in Fig. 2.8. As the copper bus bars extend from the motor and generator inverter outputs, two of the three phases pass through black current transducers (CTs) before reaching the connection terminals at the top of the assembly. Two interlock devices are located on the connection terminal assembly in order to disable the system if the terminal cover or battery connector is removed. In Fig. 2.9, the PEs module with integrated cooling has been removed and placed beside the bottom compartment. Input and output ports for the cooling system have rubber seals to prevent moisture from entering into the interior of the PCU assembly. A significant amount of gray thermal grease is used between the bottom side of the cooling structure and the bottom compartment. Four small, cylindrically shaped pieces are associated with the four bolts that are used to mount the large inductor in the bottom compartment. The footprint of the $200 \mathrm{~V}$ to $12 \mathrm{~V} \mathrm{dc}$-dc converter is larger than the inductor footprint, and more thermal grease is used in this area of the mating surface. Two separate capacitor modules $(900 \mathrm{~V}, 0.8 \mu \mathrm{F}$ and $950 \mathrm{~V}, 0.562 \mu \mathrm{F})$ have two copper bus bars which extend vertically 
from the bottom compartment. The bus bars are substantially thick (probably to reduce inductance and resistance) and bolt directly to the PEs module. Three copper bus bars are grouped together, two of which are for each terminal of the inductor. The other bus bar provides a common for the $200 \mathrm{~V}$ to $12 \mathrm{~V} \mathrm{dc}-\mathrm{dc}$ converter, and the positive supply for this converter is connected to the input terminal of the inductor, which is visible in Fig. 2.10. The location of the two capacitors is indicated and the top of the inductor is also visible in this image. In all of the previous PCU designs, the inductor is completely enclosed with potting compound, with no copper visible. The output of the inductor is connected to the middle point of the dc-dc converter leg and the leg is in parallel with the motor and generator inverter legs, thereby connecting directly to the dc-link. This architecture is further described in Section 2.2.2. Circuitry for the $12 \mathrm{~V}$ converter is shown and can be compared with that of the 2004 Prius, which is shown in Fig. 2.11. It is noticeable that more emphasis was placed on packaging of the 2010 Prius design than that of the 2004 Prius.

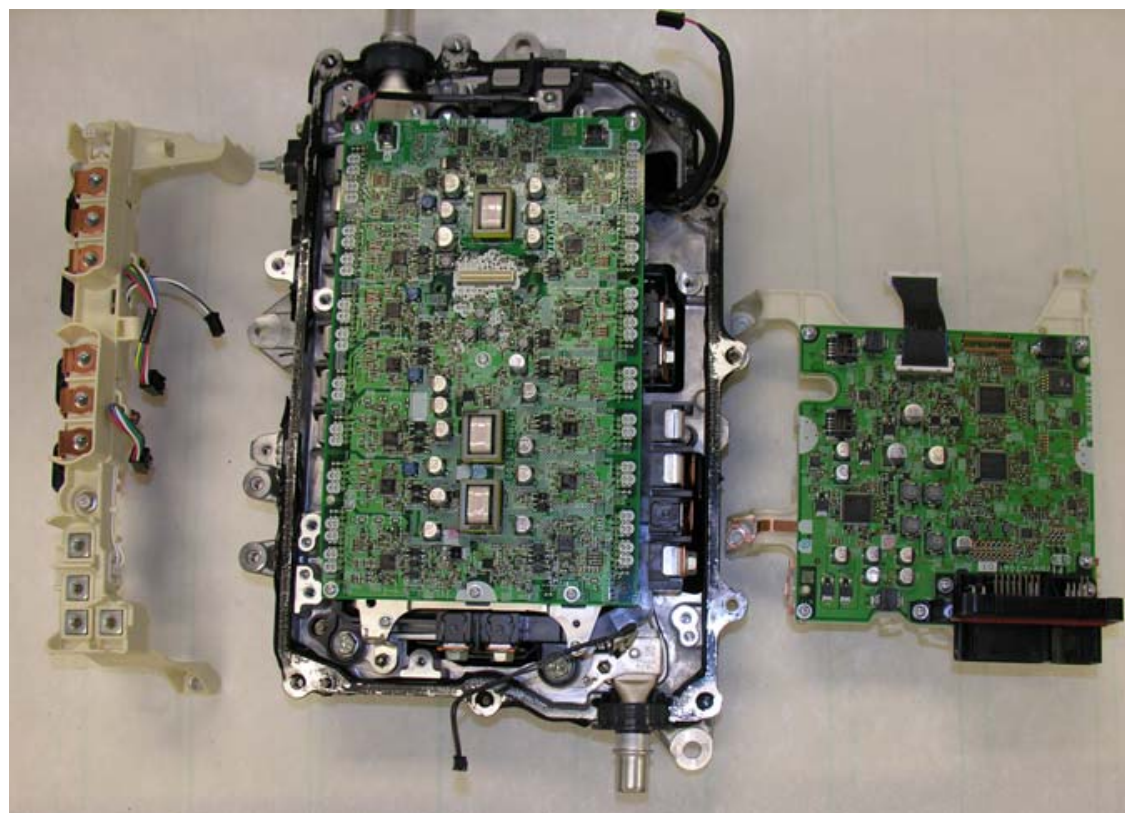

Fig. 2.7. Controller and driver circuitry for dc-de convert and inverters.

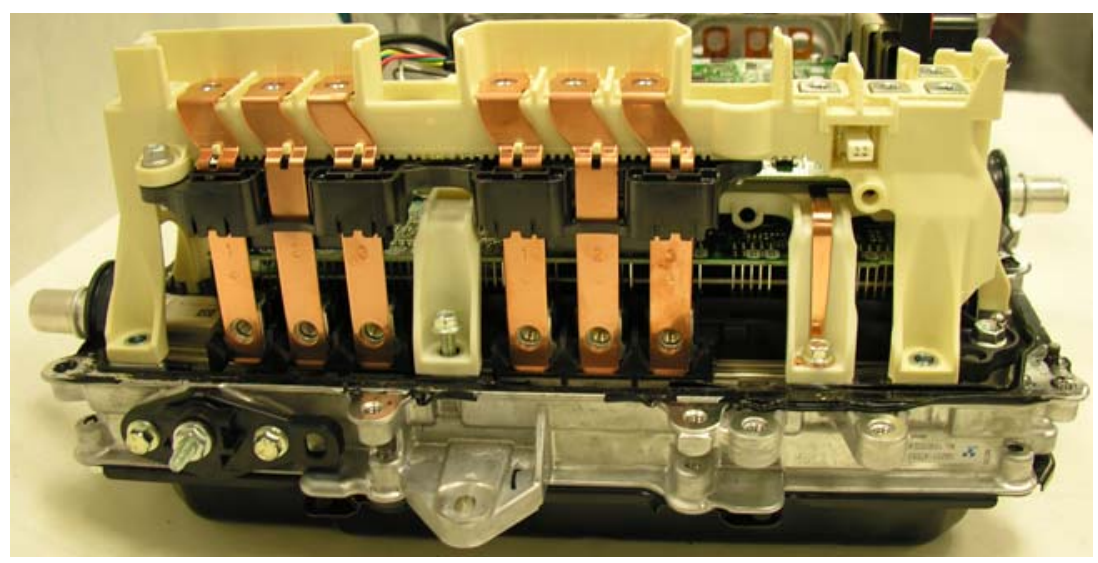

Fig. 2.8. DC, motor, and generator connection terminals. 


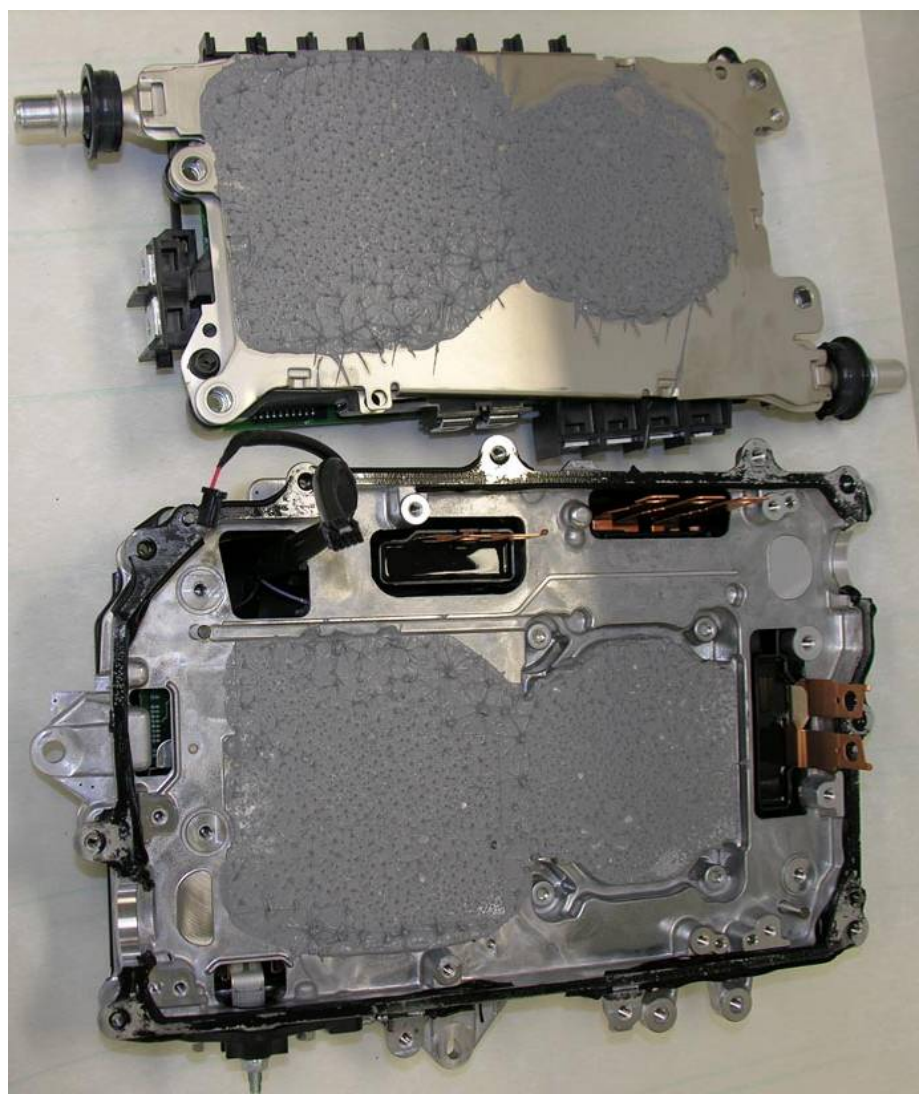

Fig. 2.9. Underside of power module/cooling structure (top) and bottom compartment (bottom).

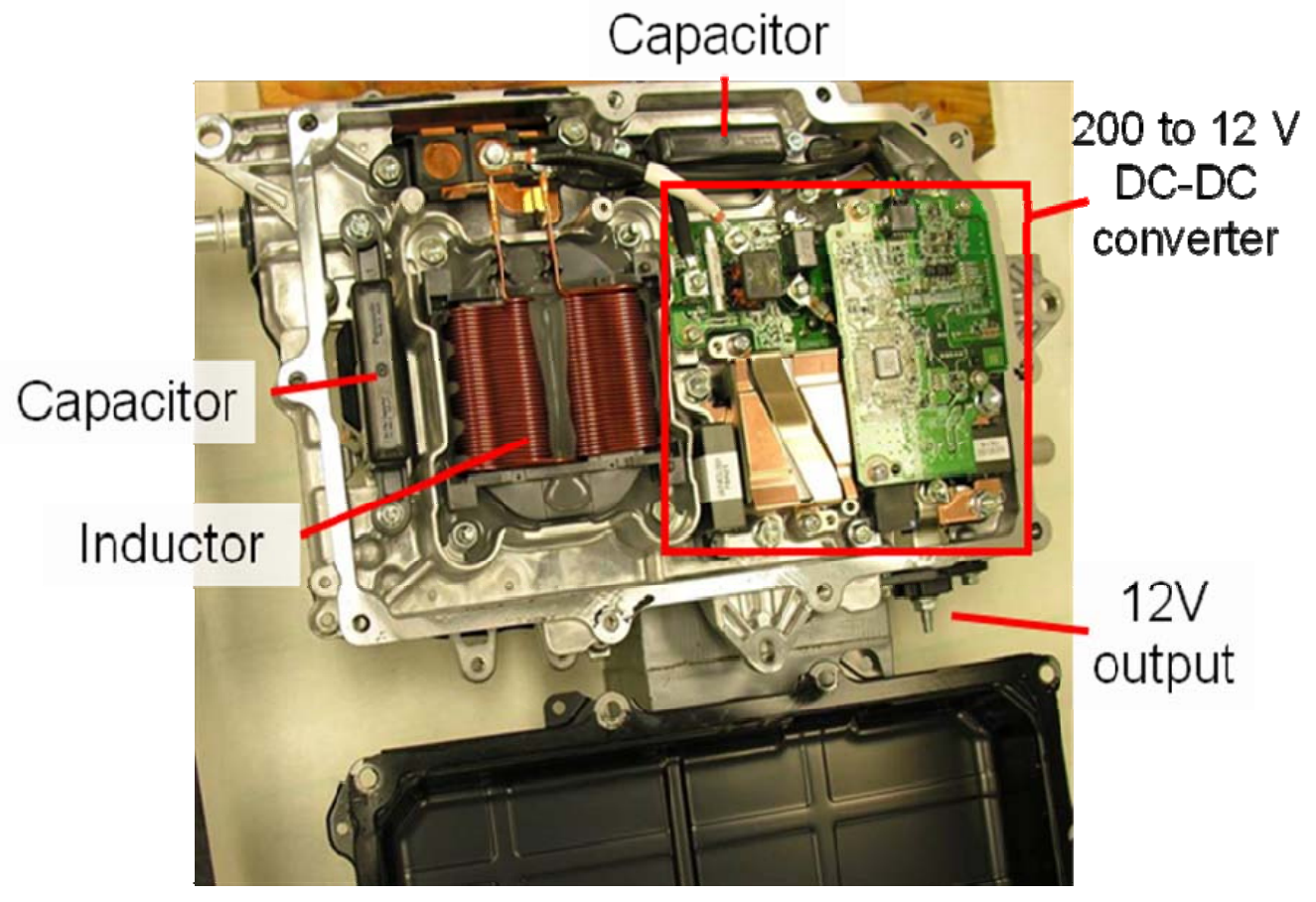

Fig. 2.10. Bottom compartment containing inductor, capacitors, and dc-dc converter. 


\section{Converter and Three phase inverter for air conditioning compressor motor}

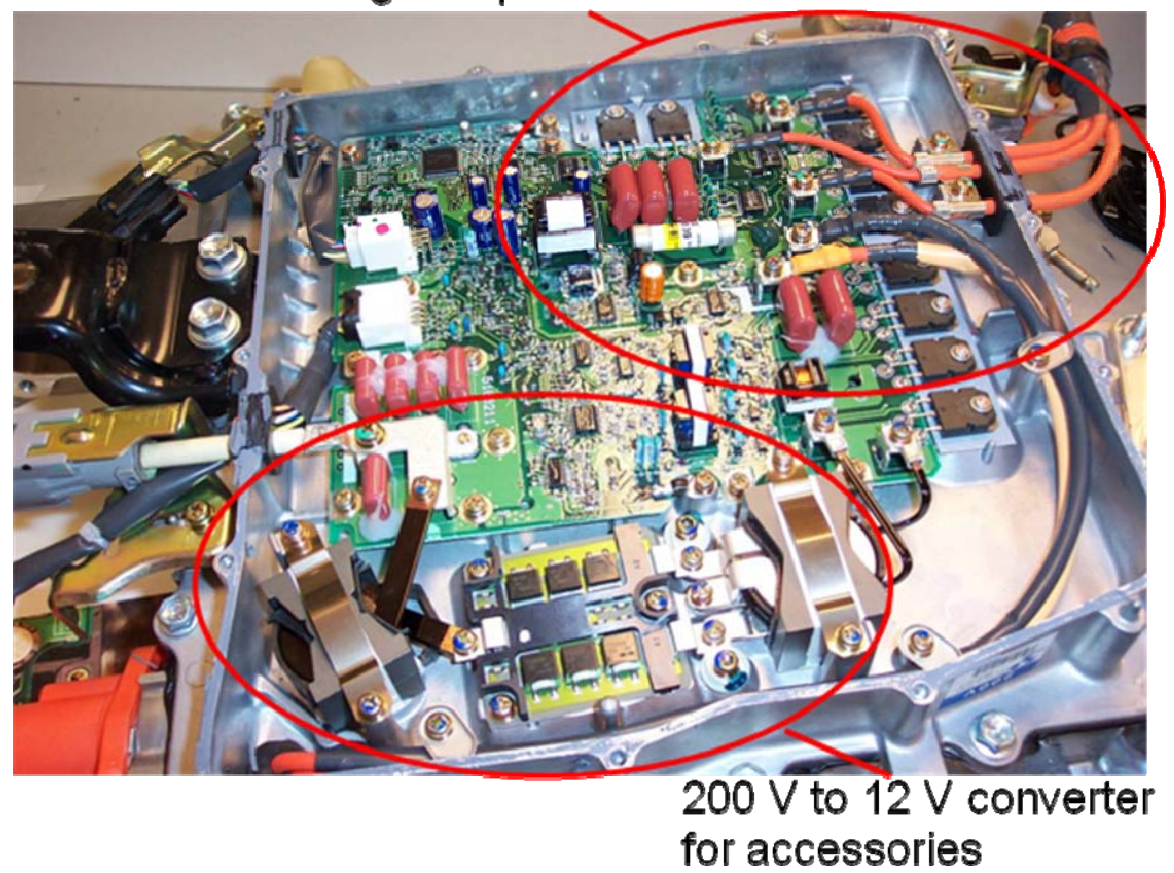

Fig. 2.11. 2004 Prius bottom compartment containing compressor inverter and 12V dc-dc converter.

Table 2.3 provides mass and volume measurements of the 2010 Prius motor inverter, dc-dc converter, and their sub-components. For certain components, the dimensions and volumes are approximate since the geometries are sometimes irregular. Much of the items of the PCU are shared between the inverters and dc-dc converter. Thus, the mass and volume of these items were tallied separately and then divided accordingly. As explained further in Section 2.2.2, based on device count about 55\% of the PEs are dedicated to motor inverter, $27 \%$ to the generator inverter, and $18 \%$ to the dc-dc converter. Since the devices in the bi-directional dc-dc (boost) converter are larger, the percentage of power electronics module (PEM) area devoted to each component is about $49 \%, 29 \%$, and $22 \%$ for the motor inverter, generator inverter, and the dc-dc converter, respectively. It is therefore reasonable to distribute the mass and volumes of the shared items across the motor inverter, generator inverter, and dc-dc converter according to the percentages $50 \%, 30 \%$, and $20 \%$, respectively. For example, about $50 \%$ of the driver board is dedicated to the motor inverter since about $50 \%$ of the IGBTs are included in the motor inverter. Likewise, $20 \%$ of the mass and volume of the shared items is attributed to the dc-dc converter. The large capacitor module is the largest and heaviest item of the PCU. 
Table 2.3. Mass and volume measurements for the 2010 Prius inverter and converter

\begin{tabular}{|l|c|c|}
\hline \multicolumn{1}{|c|}{ Item } & Mass (kg) & Volume (L) \\
\hline $\begin{array}{l}\text { Inverter/converter as received from original equipment } \\
\text { manufacturers (OEM ) }\end{array}$ & 13.0 & 16.2 \\
\hline Items shared by inverters and converter & 7.23 & 10.83 \\
\hline PEM, driver boards, cooling infrastructure & 2.3 & X \\
\hline Housing for PEM, driver boards, cooling infrastructure & 0.89 & 5.48 \\
\hline Control board and associated components & 0.33 & 0.64 \\
\hline Main capacitor module and housing & 2.22 & 2.65 \\
\hline Connector terminals and CTs Complete motor inverter & 0.82 & 2.06 \\
\hline 2 small capacitors, resistor, remaining bus bars & 0.68 & $\mathrm{X}$ \\
\hline Motor inverter & 3.62 & 5.42 \\
\hline Ratio from shared tally & $\mathbf{3 . 6}$ & $\mathbf{5 . 4}$ \\
\hline \multicolumn{1}{|c|}{ Complete converter } & $\mathbf{5 . 1}$ & \\
\hline Bi-directional dc-dc converter & & 2.17 \\
\hline Ratio from shared tally & 1.11 & 2.59 \\
\hline Inductor (without housing) & 0.795 & $\mathbf{4 . 8}$ \\
\hline & $\mathbf{1 . 9}$ & $\mathbf{2 . 8}$ \\
\hline 202V to 12 V dc-dc converter & & \\
\hline Components (circuit boards, passive components, etc) & 3.67 & \\
\hline Housing & & \\
\hline & & \\
\hline
\end{tabular}

Based on the results shown in Table 2.3, Table 2.4 provides the peak PD and peak SP of both the motor inverter and the bi-directional dc-dc converter. Comparisons to corresponding estimates for the 2010 Prius, LS 600h, Camry, and 2004 Prius are also shown. Since the mass of the 2010 Prius PCU is much lower than that of the other systems, the inverter SP is significantly higher than that of the Camry, and especially the 2004 Prius. Even so, the SP calculation seemed quite large upon initial inspection. However, considering that about $2 \mathrm{~kg}$ is devoted to the accessory converter, the mass of the inverters and boost converter sum up to only $11 \mathrm{~kg}$. The LS 600h has the highest PD since the power capability of the LS $600 \mathrm{~h}$ motor inverter is much higher than that of the other systems, while their sizes are relatively similar. Since the 2010 Prius PCU volume is reasonably high, the inverter PD is lower than that of the LS $600 \mathrm{~h}$ and Camry. Although the power capability of the 2010 Prius bi-directional dc-dc converter increased by about $35 \%$ in comparison with the 2004 Prius, the mass only increased by about $6 \%$ and the volume decreased by about $6 \%$. Thus, there was an improvement of the SP and PD of the boost converter, but not as significant as that of the motor inverter.

Table 2.4. SP and PD estimates for inverter/converter

\begin{tabular}{|l|c|c|c|c|}
\hline \multicolumn{1}{|c|}{ Parameter } & LS 600h & Camry & 2004 Prius & 2010 Prius \\
\hline $\begin{array}{l}\text { Motor inverter peak SP } \\
\text { (without converter), kW/kg. }\end{array}$ & $110 / 7.4=\mathbf{1 4 . 9}$ & $70 / \sim 7.5=\sim \mathbf{9 . 3}$ & $50 / 8.8=\mathbf{5 . 7}$ & $60 / 3.6=\mathbf{1 6 . 6}$ \\
\hline $\begin{array}{l}\text { Motor inverter peak PD } \\
\text { (without converter), kW/L. }\end{array}$ & $110 / 6.4=\mathbf{1 7 . 2}$ & $70 / \sim 6=\sim \mathbf{1 1 . 7}$ & $50 / 8.7=\mathbf{5 . 7}$ & $60 / 5.4=\mathbf{1 1 . 1}$ \\
\hline $\begin{array}{l}\text { Bi-directional dc-dc } \\
\text { converter SP, } \mathrm{kW} / \mathrm{kg} .\end{array}$ & $36.5 / 6.9=\mathbf{5 . 3}$ & $30 / \sim 6.6=\sim \mathbf{4 . 5}$ & $20 / 4.8=\mathbf{4 . 2}$ & $27 / 5.1=\mathbf{5 . 3}$ \\
\hline $\begin{array}{l}\text { Bi-directional dc-dc } \\
\text { converter PD, } \mathrm{kW} / \mathrm{L} .\end{array}$ & $36.5 / 4=\mathbf{9 . 1}$ & $30 / 3.5=\mathbf{8 . 6}$ & $20 / 5.1=\mathbf{3 . 9}$ & $27 / 4.8=\mathbf{5 . 7}$ \\
\hline
\end{tabular}

This low converter PD is largely the result of the non-optimal packaging of the converter filter capacitor in the Prius inverter/converter housing. 
The main capacitor of the 2010 Prius PCU is shown in Fig. 2.12. It is important to note that that the 2010 Prius and LS 600h capacitor modules contain both capacitors which are connected to the HV and LV side of the bi-directional boost converter, whereas the corresponding Camry capacitors are housed in separate modules. Figure 2.13 shows the negative image of an x-ray of the capacitor module. The x-ray shows that there are 3 discrete sub-modules in parallel that form the $888 \mu \mathrm{F}$ capacitor, with each sub-module having a capacitance of $296 \mu \mathrm{F}$. The equivalent Camry and 2004 Prius capacitor has $12-87 \mu \mathrm{F}$ and 8-142 $\mu \mathrm{F}$ sub-modules in parallel to provide a total capacitance of $2,098 \mu \mathrm{F}$ and $1,130 \mu \mathrm{F}$, respectively. Also visible are two $157.5 \mu \mathrm{F}$ sub-modules which are in parallel and form the $315 \mu \mathrm{F}$ battery level filter capacitor. The cells which form these capacitors span the entire width of the module, whereas the Camry and 2004 Prius capacitors are much smaller and only span half of the module's width. The LS 600h cells are also small, yet they are vertically oriented. The fuse for the $202 \mathrm{~V}$ supply to the $\mathrm{A} / \mathrm{C}$ compressor is visible in the bottom portion of the $\mathrm{x}$-rays. On the opposite end of the module is the small $0.562 \mu \mathrm{F}$ capacitor. Figure 2.14 shows $\mathrm{x}$-ray images of the $0.8 \mu \mathrm{F}$ and $0.562 \mu \mathrm{F}$ filter capacitors, which appear to be single capacitor cells.

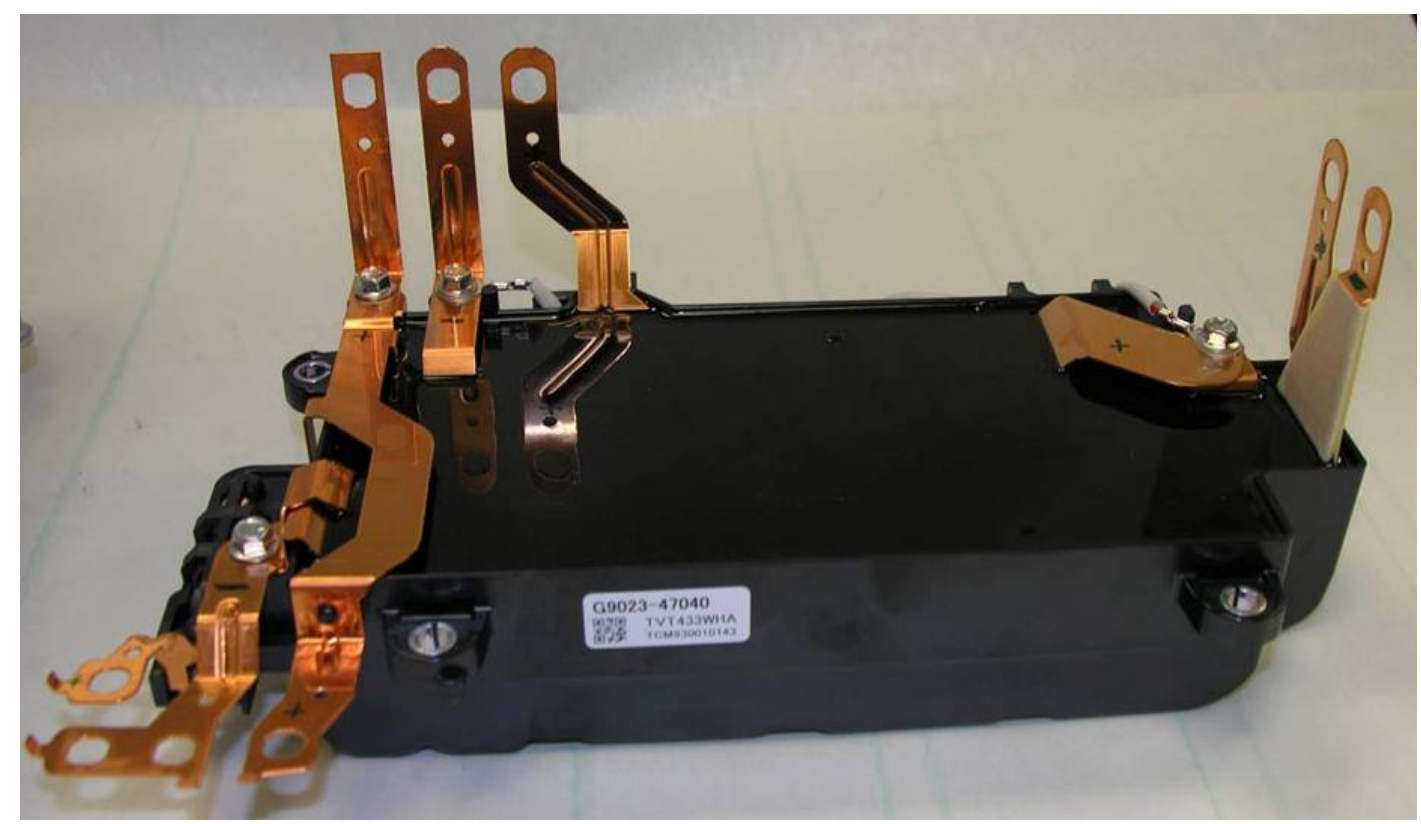

Fig. 2.12. 2010 Prius main capacitor module removed from housing. 


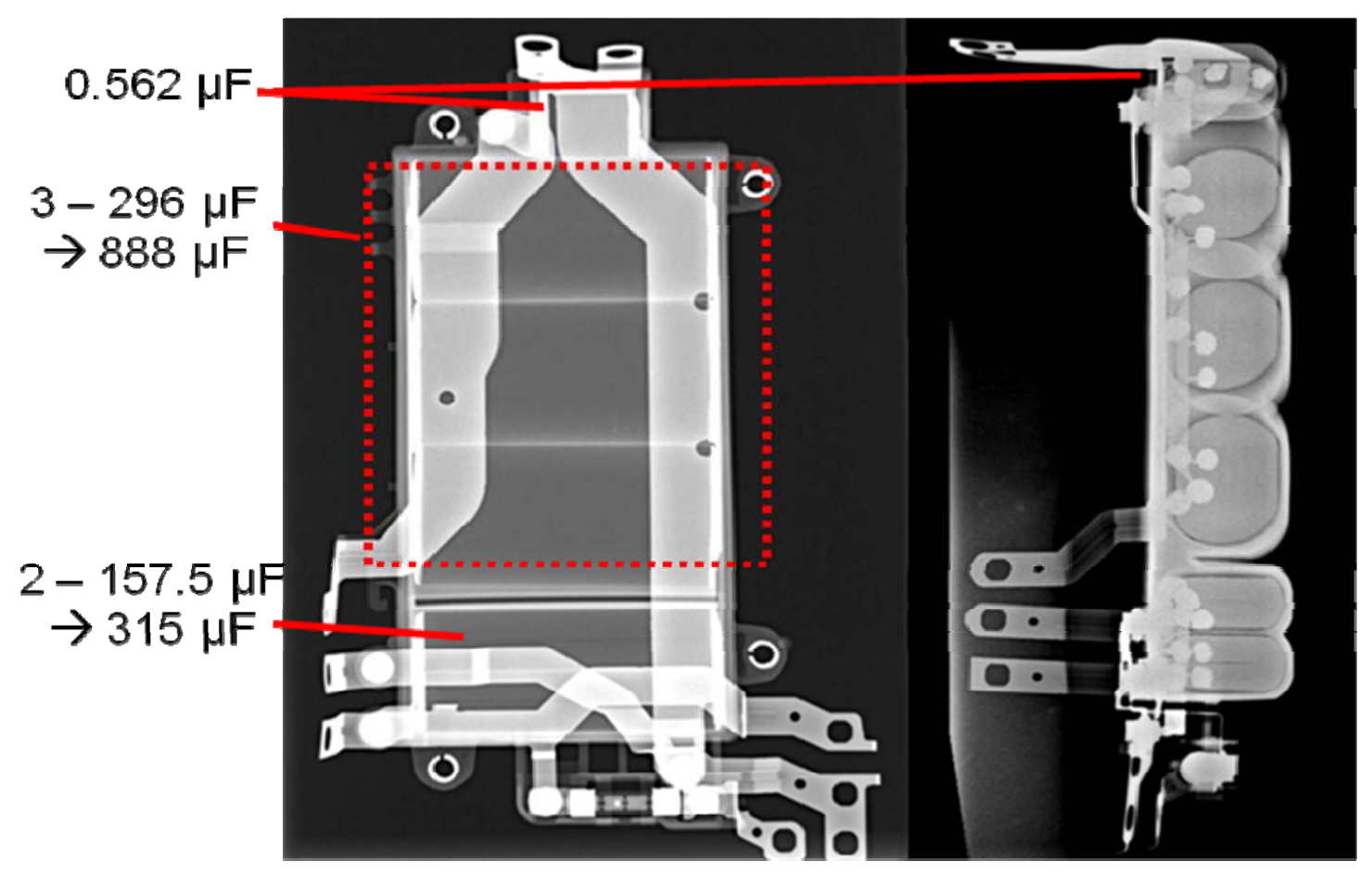

Fig. 2.13. X-ray of 2010 Prius main capacitor top view (left) and side view (right).
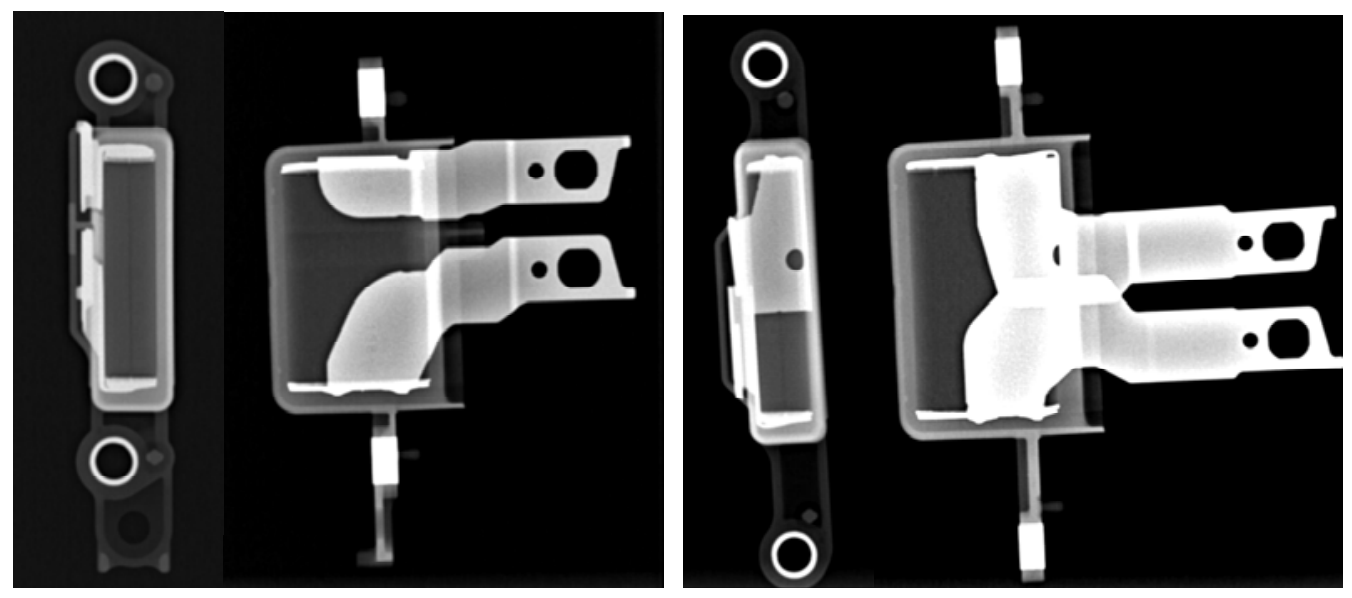

Fig. 2.14. X-ray of 2010 Prius $0.562 \mu F$ (left) and $0.8 \mu F$ (right) filter capacitors.

A primary function of these capacitors is to attenuate voltage transients and surges which are associated with the build-up and collapse of the energy stored in the $329 \mu \mathrm{H}$ inductor (shown in Fig. 2.15). The lower switch (3 IGBTs in parallel) of the dc-dc converter cycles at 5 or $10 \mathrm{kHz}$ with a variable duty cycle in order to build-up and store energy in the inductor. As the duty cycle is varied, the output voltage of the inductor also varies accordingly. Due to the inherent voltage ripple and potentially HV produced by the collapsing inductor field, these capacitors serve to stabilize the battery voltage and dc-link voltage as well as protect the PEs devices from potential over-voltage conditions. The inductor has two coils in series and the core was secured with bolts and immersed in a potting compound. 


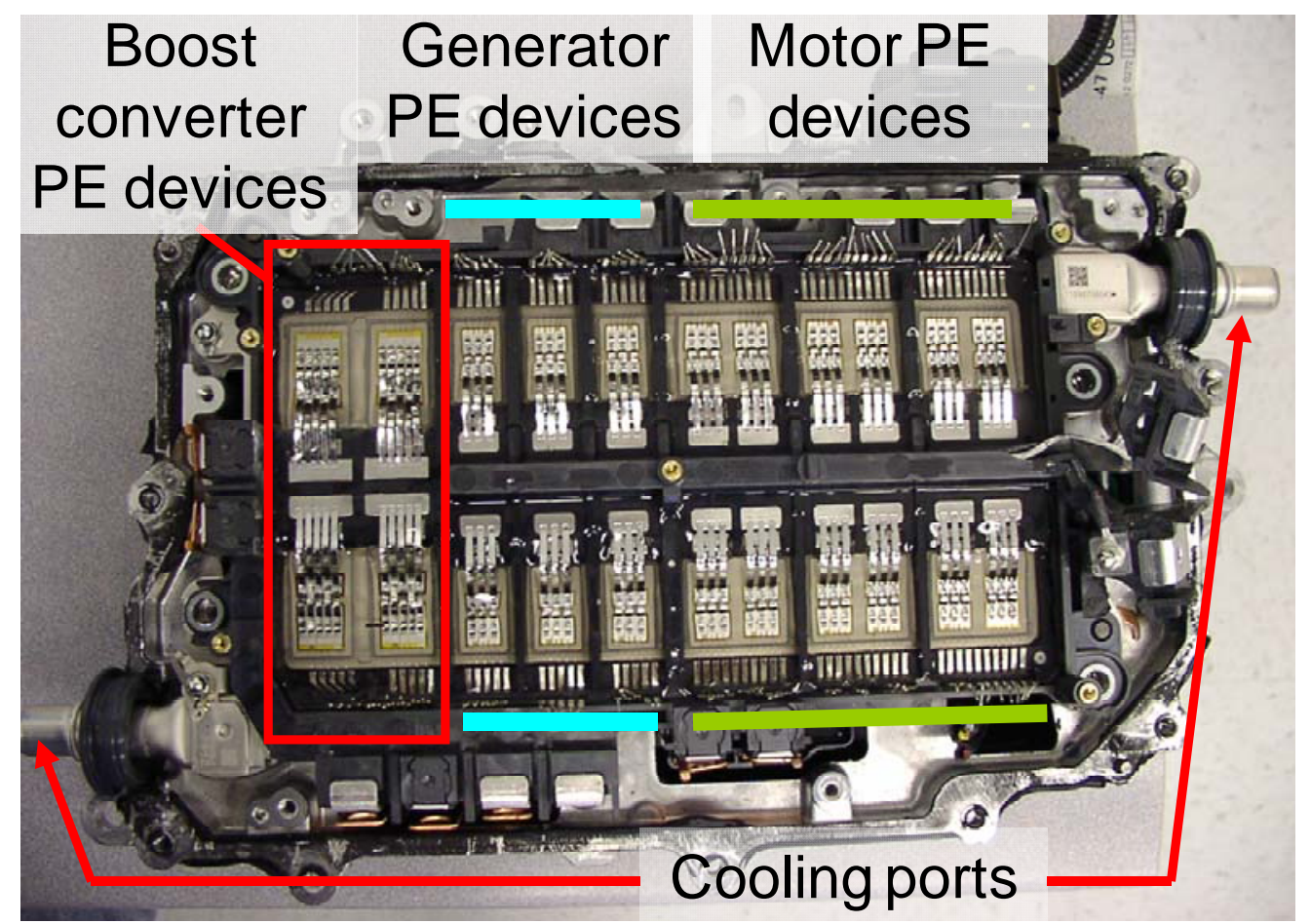

Fig. 2.15. 2010 Prius PE module.

\subsubsection{PE Module Disassembly}

A total of 22 IGBTs and anti-parallel diodes are located on heat exchanger infrastructure a within the PCU housing. Seven phase legs form the converter and inverters shown in Fig. 2.5, all sharing the same dc-link. As indicated in Fig. 2.15, the motor, generator, and bi-directional boost converter PEs are combined into one package. All the upper devices (IGBTs and diodes) are displayed in the lower half of the image, and likewise, all of the lower devices are seen in the upper half of Fig. 2.15. Each phase leg in the three-phase motor inverter is comprised of four IGBT dies and diode dies, with 12 IGBT dies and 12 diode dies in its entirety. The generator has only two IGBT dies and diode dies for each phase, with a total of six IGBT dies and six diode dies. While the boost converter devices only total up to four IGBT dies and four diode dies, they are much larger than that of the motor and generator inverters. Coolant hose connections are located on each end of the heat exchanger allowing coolant to enter one side and absorb heat as it traverses across the width of the PE module and exits the other port. As seen in Fig. 2.16, the cooling infrastructure is broad just beneath the drive and sense pins of the IGBTs, thereby facilitating flow along the length of the PE module before passing through the thin cooling channels. This promotes more uniform heat transfer amongst all of the PE devices. Just inside the PCU, a thermistor is located on the coolant inlet. As seen in Fig. 2.17, although the thermistor is secured to the coolant inlet, the actual sensing device is not flush with the aluminum surface of the inlet. 


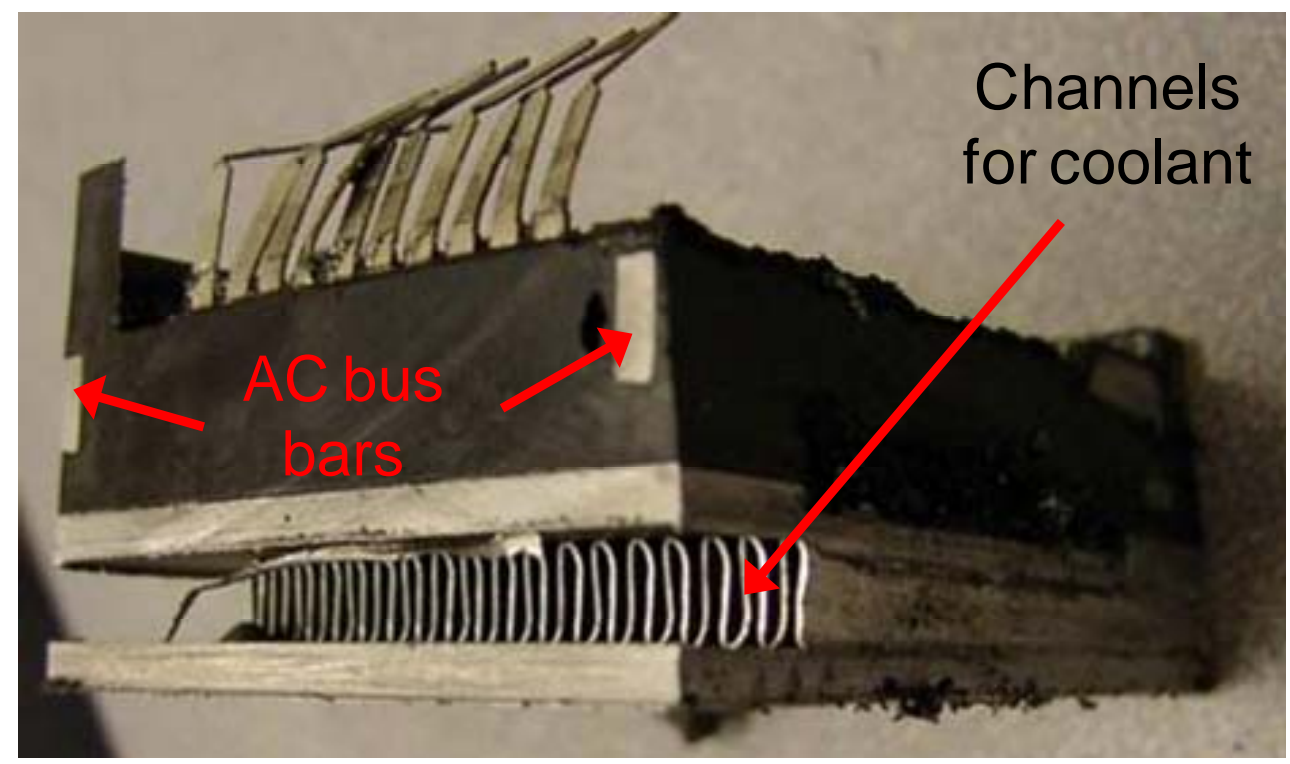

Fig. 2.16. Cross section of 2010 PE module.

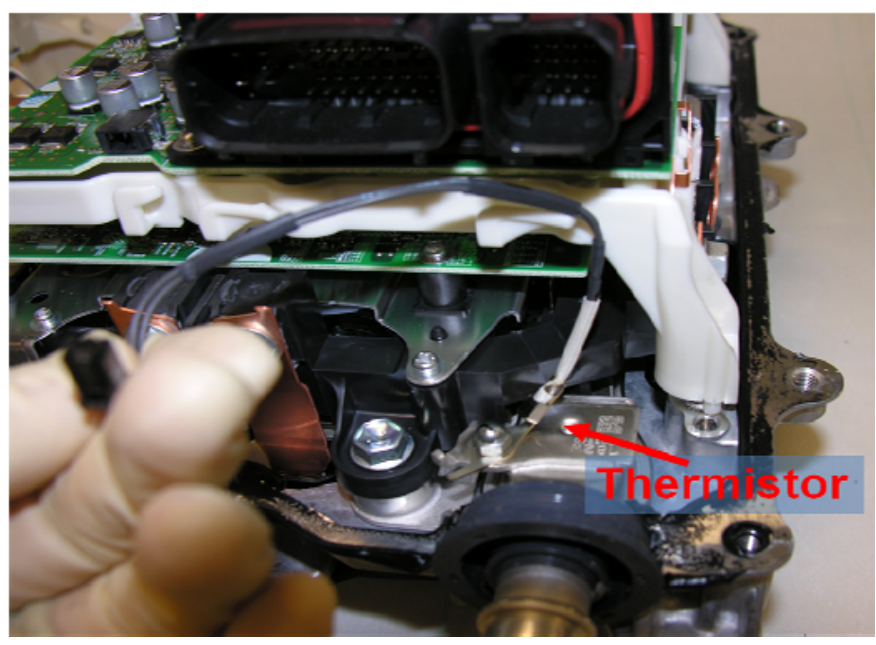

Fig. 2.17. Thermistor located on coolant input port.

One of the most noticeable discrepancies between the 2010 Prius PE module and previous PE module designs in Fig. 2.18 is the orientation of the PE devices. In the 2010 Prius, the PE devices oriented in a manner such that the drive and sense pins are on the outer perimeter of the module. While this likely presents opportunities to improve the layout of the driver circuitry, it more importantly allows more phase legs to be placed along the length of dc bus bar. The Camry and 2004 Prius designs have the motor and generator inverters on opposite sides of the dc bus, with the three-phase outputs also on opposite sides and on outer periphery of the PEs module. Contrarily, the 2010 Prius upper and lower IGBTs of each inverter are on opposite sides of the dc bus. Notice in the 2010 Prius PE module (Fig. 2.18) that the black dividers between each phase are thicker on the left than on the right. This is because the motor and generator alternating current (ac) bus bars are molded in this black material (indicated in Fig. 2.16), and are fed to the two three-phase terminal outputs on the side of the PE module. 

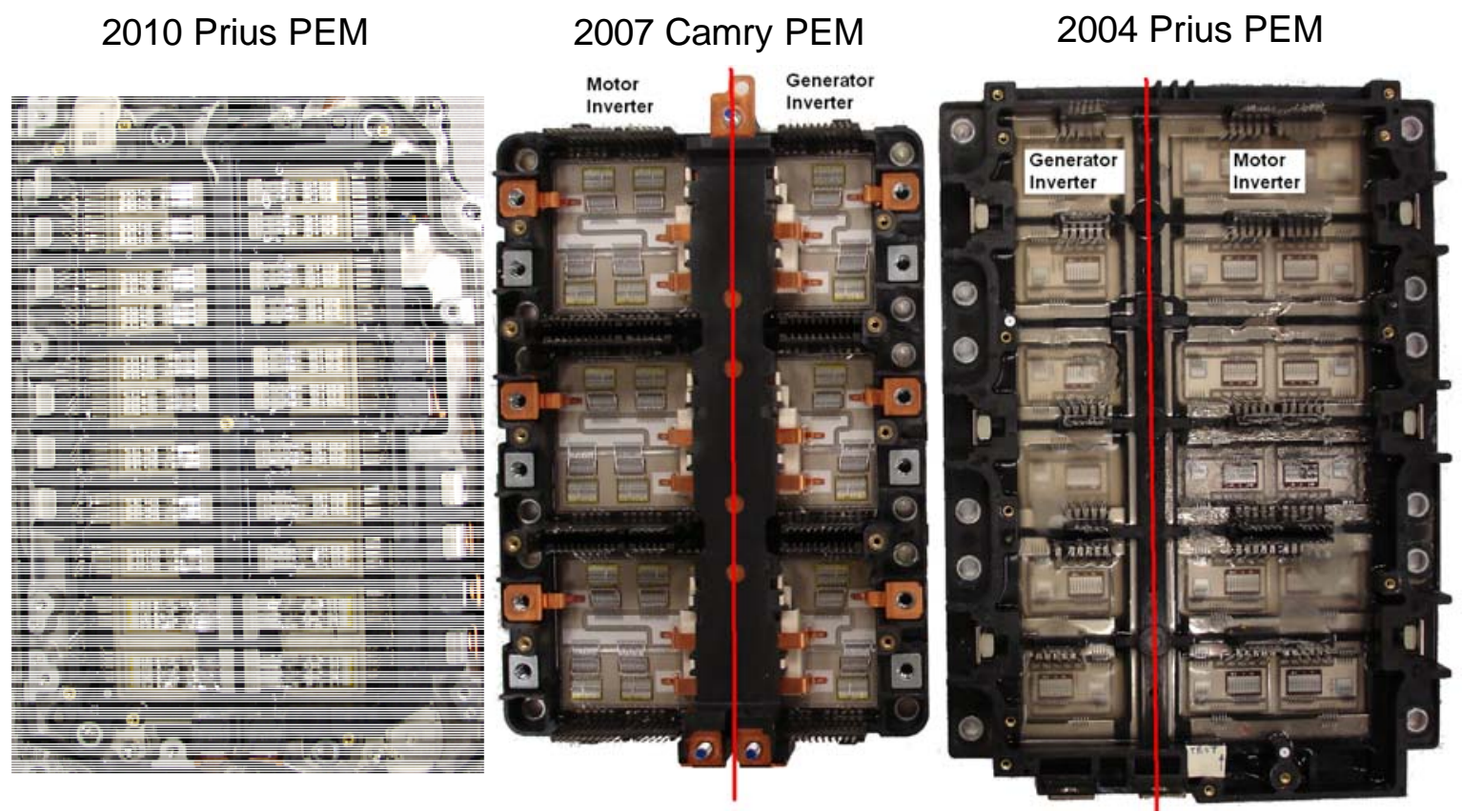

Fig. 2.18. Comparison of Toyota PE modules.

To help portray the layout, it would be advantageous to trace the path from the positive dc-link through one phase leg to the negative dc-link. First, it should be noted that there are two layers of ribbon bonds on each side of the dc-link; three on the top layer and three on the bottom layer which is slightly visible in Figs. 2.19 and 2.20. The bi-directional boost converter uses five ribbon bonds per device. There are also several layers of bus bars for the dc-link and ac outputs extending completely through the middle of the PE module, a few of which are visible in the left side of cross-section in Fig. 2.20. In Fig. 2.18, the bottom bus bar on the right side of this group of bus bars in the middle is the positive dc-link, which is connected with the three lower ribbon bonds to the collectors of the upper phase-legs (all on the right). If the IGBT is activated, current flows out the emitter through the three upper ribbon bonds to the upper bus bar. The collector of the lower IGBT (on the left) is connected by three lower ribbon bonds to this horizontally oriented bus bar, as is the ac output bus bar, which is vertically oriented and placed between each phase. If the lower IGBT is activated, current passes through the IGBT and out the emitter to the three upper layer ribbon bonds which attach to the negative dc-link. 


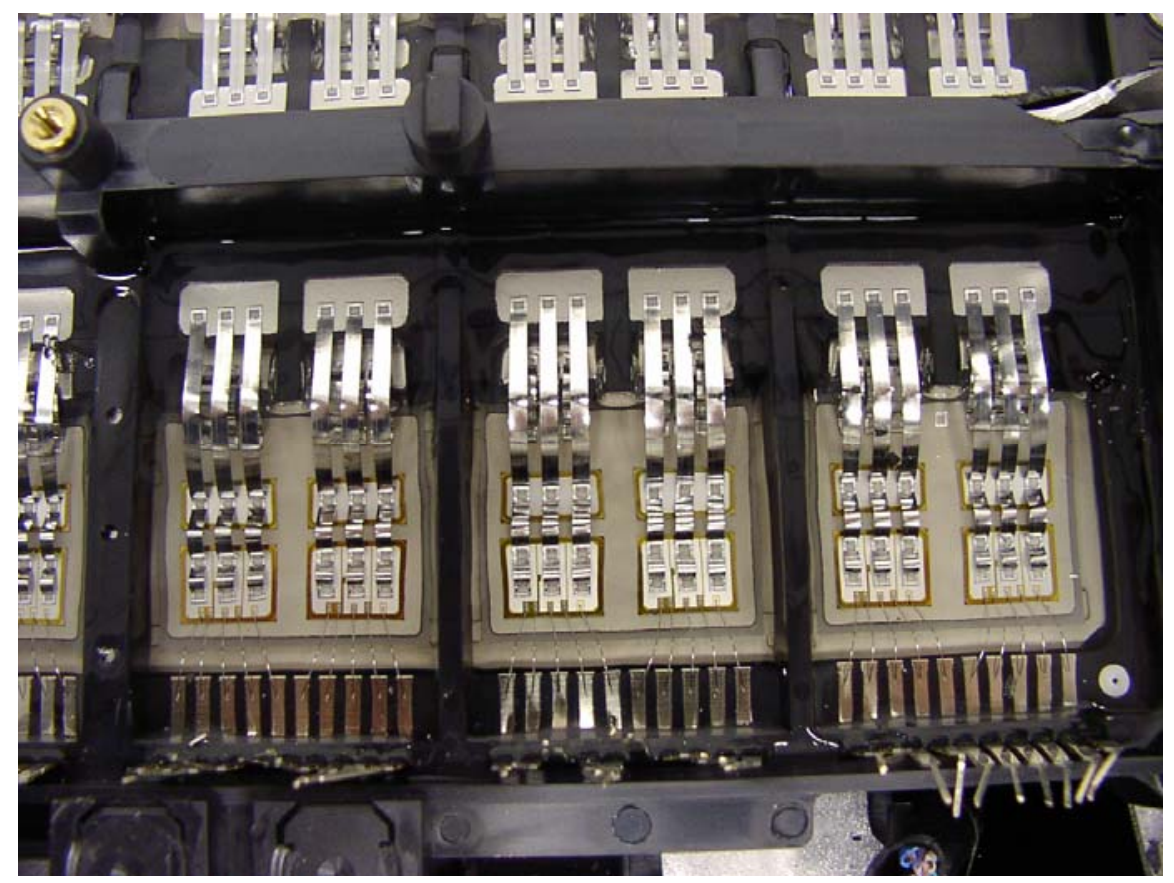

Fig. 2.19. Close-up of 2010 Prius PE module.

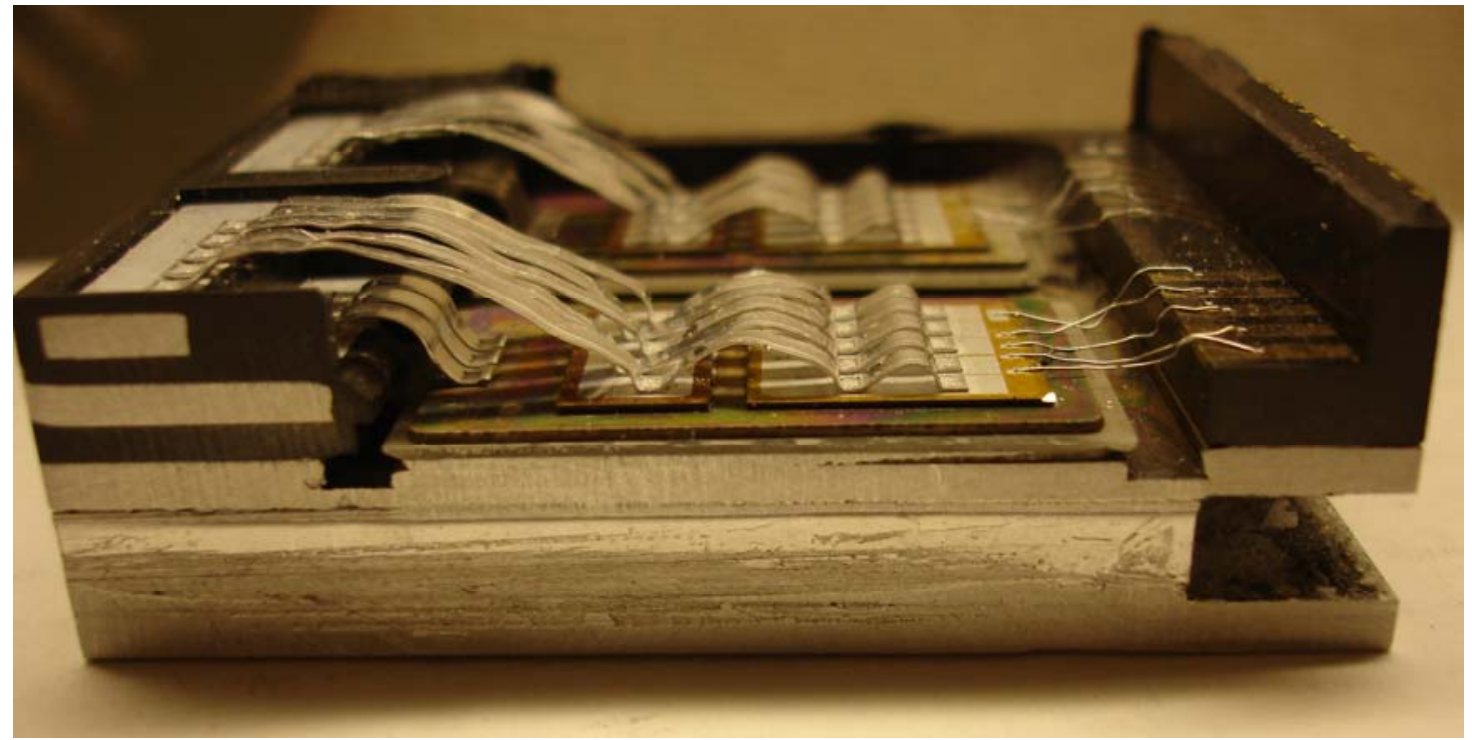

Fig. 2.20. Cross-section of boost converter modules 2010 Prius.

The 2010 Prius layout appears to be more orderly and is advantageous with things such as fewer attachment points and shorter overall conductor length, perhaps improving the parasitic parameters of the devices in addition to the improved parasitic parameters of ribbon bonds versus wire bonds. While there are some inherent benefits of this packaging approach, there are some negative aspects of this design. For example, the 2007 Camry PE module contains six IGBTs and diodes for each phase leg of the motor inverter (versus four for the 2010 Prius). In the Camry PE module shown in Fig. 2.18, a third IGBT is located beneath the dc-link bus bars in the middle. An interesting comparison could be made if three more phase legs were added (one for each phase) to the 2010 Prius motor inverter in order to make an even comparison with the Camry PE module. It seems to be that the 2010 Prius packaging approach 
requires parallel IGBTs to be placed along the length of the dc-link. This is one particularly attractive aspect of the LS 600h design, which is shown in Fig. 2.22 and Fig. 2.23. Nonetheless, the 2010 Prius PE module sufficiently includes the bi-directional boost converter, as opposed to having separate modules such as those of the Camry and 2004 Prius shown in Fig. 2.21.
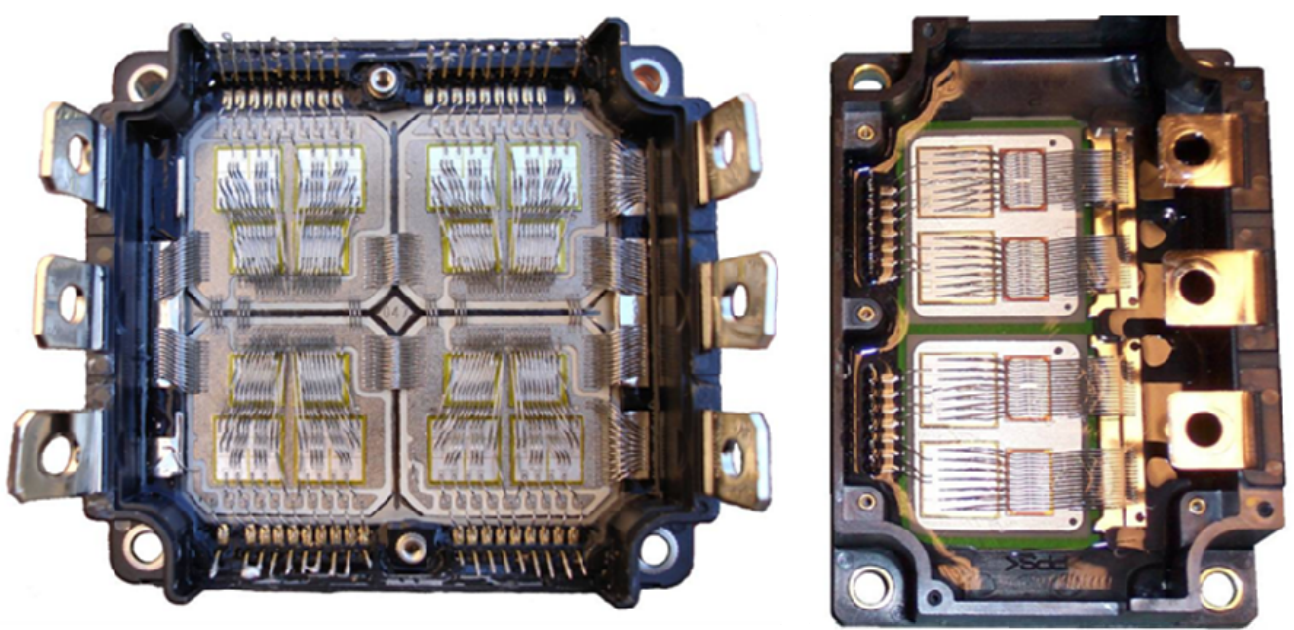

Fig. 2.21. Boost converter modules from Camry (left) and 2004 Prius (right).

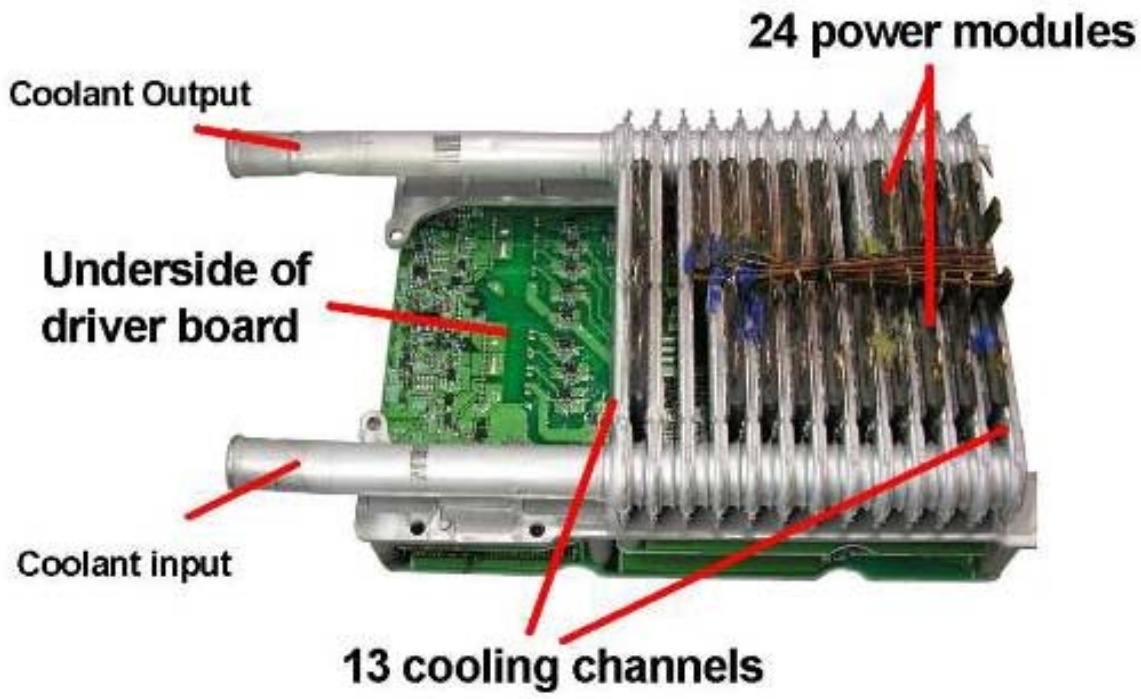

Fig. 2.22. LS 600h PCU cooling and PE assembly. 


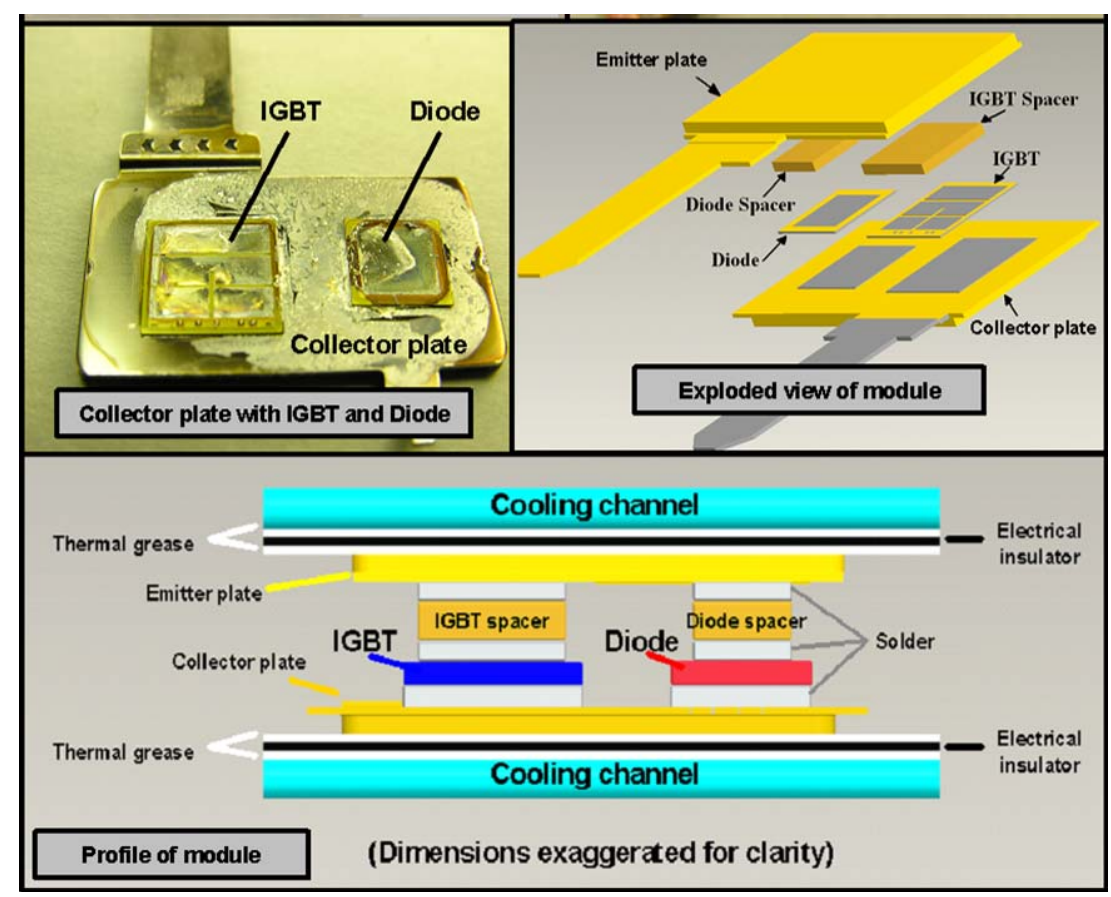

Fig. 2.23. LS 600h PE module.

External dimensions of the 2010 Prius, 2007 Camry, and 2004 Prius IGBT and diode dies are shown in Fig. 2.24. Shown in Fig. 2.25 are the dimensions of the 2008 LS 600h IGBT and diode dies. The size and appearance of the LS 600h IGBT and diode dies are similar to that of the bi-directional dc-dc (boost) converter of the Camry, as shown in Fig. 2.21. The dimensions of the 2010 Prius boost converter are shown in Fig. 2.26. According to the dimensions shown in Fig. 2.24, the square area of silicon (Si) for each IGBT has decreased from $131.9 \mathrm{~mm}^{2}$ to $109.4 \mathrm{~mm}^{2}$, and the total square area of Si used on the motor inverter has decreased from $1583 \mathrm{~mm}^{2}$ to $1313 \mathrm{~mm}^{2}$, a $17 \%$ reduction in moving from the 2004 Prius to the 2010 Prius design. Table 2.5 summarizes the IGBT and diode die count, wire-to-Si bond count on the emitter surface (if any), and amount of Si area used in the LS 600h, Camry, 2004 Prius, and 2010 Prius motor inverters and bi-directional boost converters. The ratios of heat spreader area to total PE device $\mathrm{Si}$ area for the Camry and Prius motor inverter and dc-dc converter are also provided.

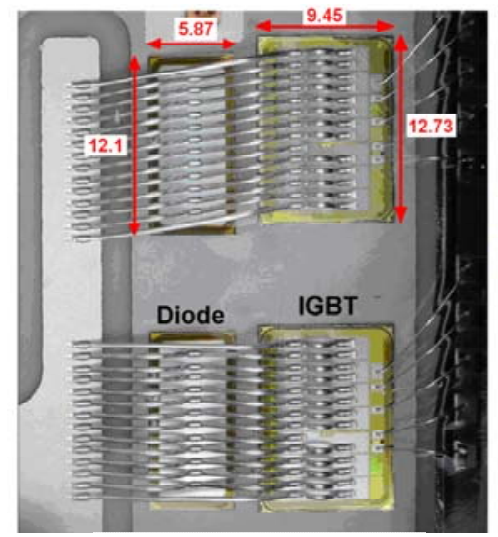

2007 Camry

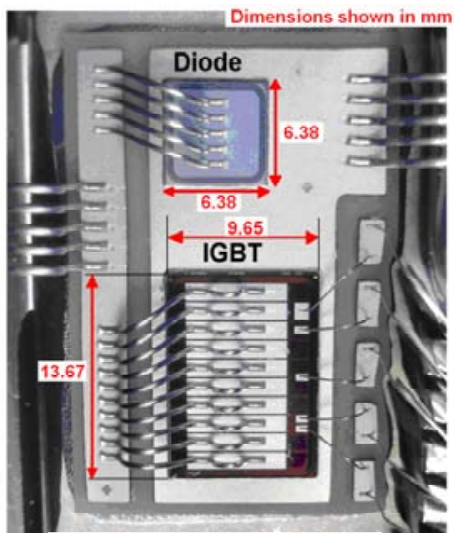

2004 Prius

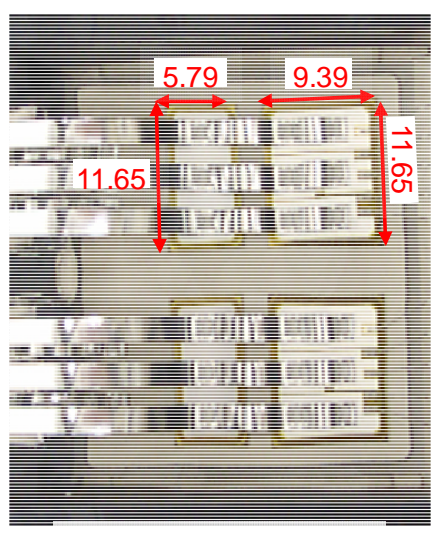

2010 Prius

Fig. 2.24. Dimensions (mm) of inverter PE devices from Camry (left), 2004 Prius (middle), and 2010 Prius (right). 


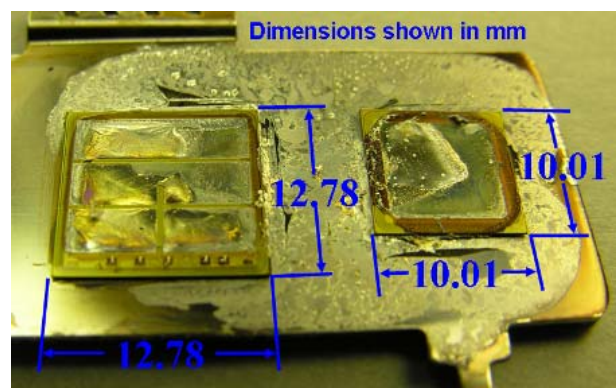

Fig. 2.25. Dimensions (mm) of inverter PE devices from 2008 LS 600h.

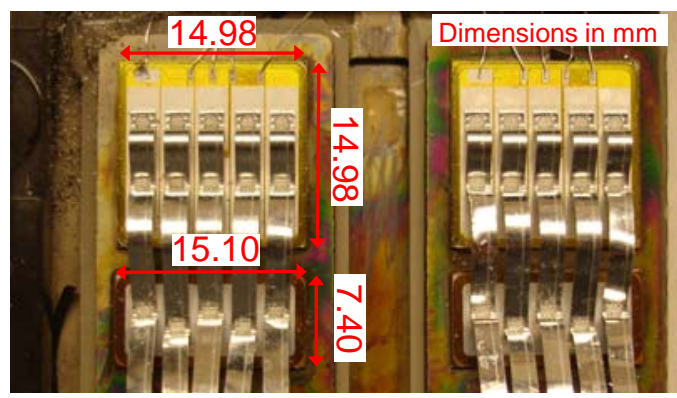

Fig. 2.26. Dimensions (mm) of bi-directional boost converter PE devices of 2010 Prius.

Table 2.5. Summary of PEs device packaging

\begin{tabular}{|c|c|c|c|c|}
\hline \multirow{2}{*}{ Parameter } & \multicolumn{2}{|c|}{ Motor Inverter } & \multicolumn{2}{|c|}{ Boost Converter } \\
\hline & IGBTs & Diodes & IGBTs & Diodes \\
\hline \multicolumn{5}{|l|}{2008 LS 600h } \\
\hline Number of devices & 12 & 12 & 6 & 6 \\
\hline $\begin{array}{l}\text { Area of total Si die per device, } \\
\mathrm{mm}^{2} \text {. }\end{array}$ & 163.3 & 100.2 & 163.3 & 100.2 \\
\hline Summation of $\mathrm{Si}$ area, $\mathrm{mm}^{2}$. & 1960 & 1202 & 980 & 601 \\
\hline \multicolumn{5}{|l|}{2007 Camry } \\
\hline Number of devices & 18 & 18 & 8 & 8 \\
\hline $\begin{array}{l}\text { Emitter wire bond count per } \\
\text { device. }\end{array}$ & 27 & 12 & 18 & 17 \\
\hline $\begin{array}{l}\text { Area of total Si die per device, } \\
\mathrm{mm}^{2} \text {. }\end{array}$ & 120.3 & 71 & 177 & 104 \\
\hline Summation of $\mathrm{Si}$ area, $\mathrm{mm}^{2}$. & 2165 & 1278 & 1400 & 830 \\
\hline \multicolumn{5}{|l|}{2004 Prius } \\
\hline Number of devices. & 12 & 12 & 4 & 4 \\
\hline $\begin{array}{l}\text { Emitter wire bond count per } \\
\text { device. }\end{array}$ & 20 & 5 & 21 & 28 \\
\hline $\begin{array}{l}\text { Area of total Si die per device, } \\
\mathrm{mm}^{2} \text {. }\end{array}$ & 131.9 & 40.7 & 228 & 119 \\
\hline Summation of $\mathrm{Si}$ area, $\mathrm{mm}^{2}$. & 1583 & 488 & 910 & 475 \\
\hline \multicolumn{5}{|l|}{2010 Prius } \\
\hline Number of devices. & 12 & 12 & 4 & 4 \\
\hline $\begin{array}{l}\text { Emitter ribbon bond count per } \\
\text { device. }\end{array}$ & 3 & 3 & 5 & 5 \\
\hline $\begin{array}{l}\text { Area of total Si die per device, } \\
\mathrm{mm}^{2} \text {. }\end{array}$ & 109.4 & 67.5 & 224.4 & 111.7 \\
\hline Summation of Si area, $\mathrm{mm}^{2}$. & 1313 & 809 & 898 & 447 \\
\hline
\end{tabular}


The 2004 Prius IGBT consists of a planar gate structure and includes areas in the drift region below the emitter " $n+$ " and " $p$ " regions which do not pass as much current as the drift region areas below the gate. This inefficiency is due to the shape of the inversion layer which is formed when using a planar gate structure. The Camry, LS 600h, and 2010 Prius IGBTs consist of a trench gate structure which forms a more uniform inversion layer during on-state operation and therefore higher current densities are created in the drift region. All IGBTs include semiconductor junction temperature sensing, gate voltage control, mirror current measurement, and emitter voltage feedback. These signals are used to control the device and prevent fault conditions from occurring. IGBT temperature sensing is carried out in the lower devices of one motor phase, one generator phase, the boost converter, and the upper device of the boost converter.

\subsubsection{PE Module Material Analysis}

Field emission scanning electron microscopy (SEM) was used to image various layers of the 2010 Prius PEs module and quantitative chemical analyses were performed using energy-dispersive spectroscopy (EDS). An overall view of the layers within the PEs module is given in Fig. 2.27. The image on the left shows a vertical cross section of the module, with ribbon bonds visible on the top and the cooling channels on the bottom. Notice the perforations just above the aluminum cooling channels, as pointed out by the red indicator. The image on the right contains a cross section through the horizontal plane where these perforations are located. Despite the sacrifice of thermal conduction characteristics, numerous $3 \mathrm{~mm}$ diameter holes are introduced to alleviate stresses associated with thermal expansion, which are particularly high at the interface of materials with differing coefficients of thermal expansion. Figure 2.28 shows a comparison of the thermal conduction path in the 2004 and 2010 Prius from the PE devices to the ethylene-glycol/water coolant. Both systems have the dies soldered to a Direct Bond Aluminum (DBA) substrate placed on an aluminum nitride (AIN) ceramic insulator for electrical isolation from the cooling infrastructure. Below the AlN insulators, the 2010 Prius has an aluminum layer which has been brazed to the cooling infrastructure. Contrarily, the 2004 Prius PE module has an aluminum layer below the insulator that has been soldered to a thick aluminum base plate, which is bolted to a cast aluminum heat sink with zinc-oxide thermal paste between the base plate and heat sink to fill any voids between the mating surfaces. Ultimately, the length of the conduction path from the bottom of the PE devices is $3.8 \mathrm{~mm}$ for the 2010 Prius versus $9.0 \mathrm{~mm}$ for the 2004 Prius, a $58 \%$ decrease in length. Additionally, a solder layer and thermal paste layer has been eliminated, both of which have relatively low thermal conductivities (compared to aluminum) and therefore the overall thermal conductivity has greatly increased.
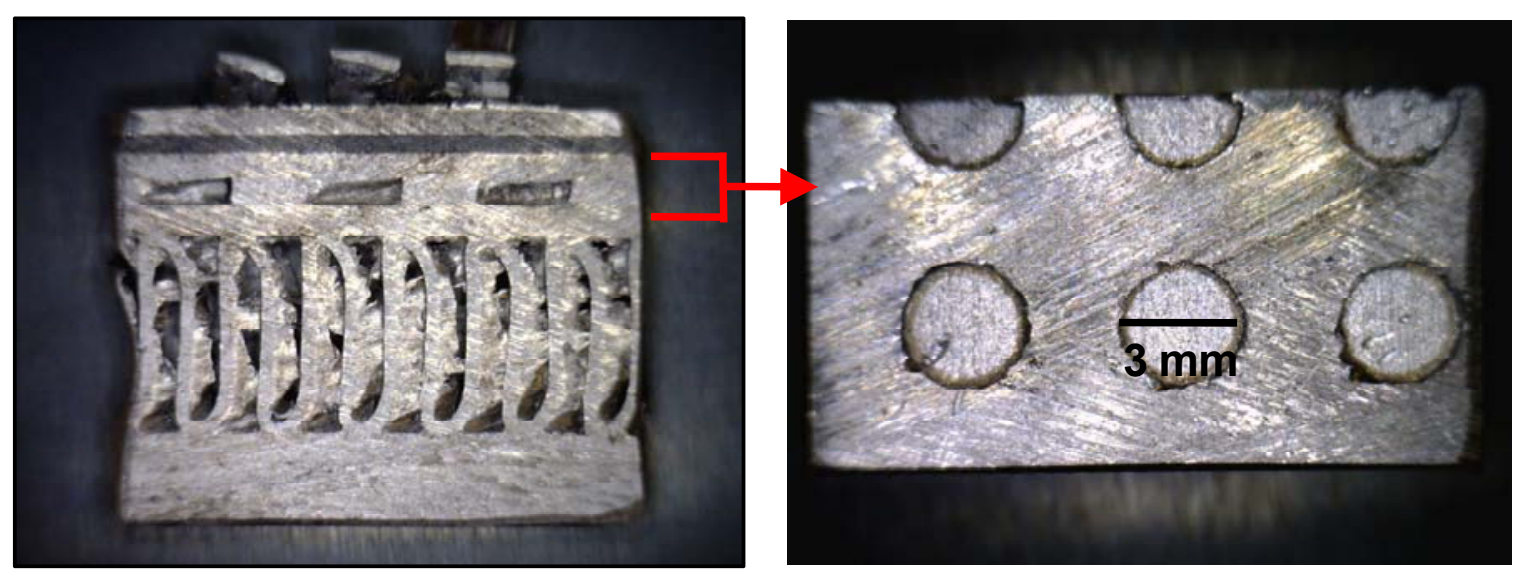

Fig. 2.27. Side (left) and top (right) cross-sectional views of extracted 2010 Prius PE module. 


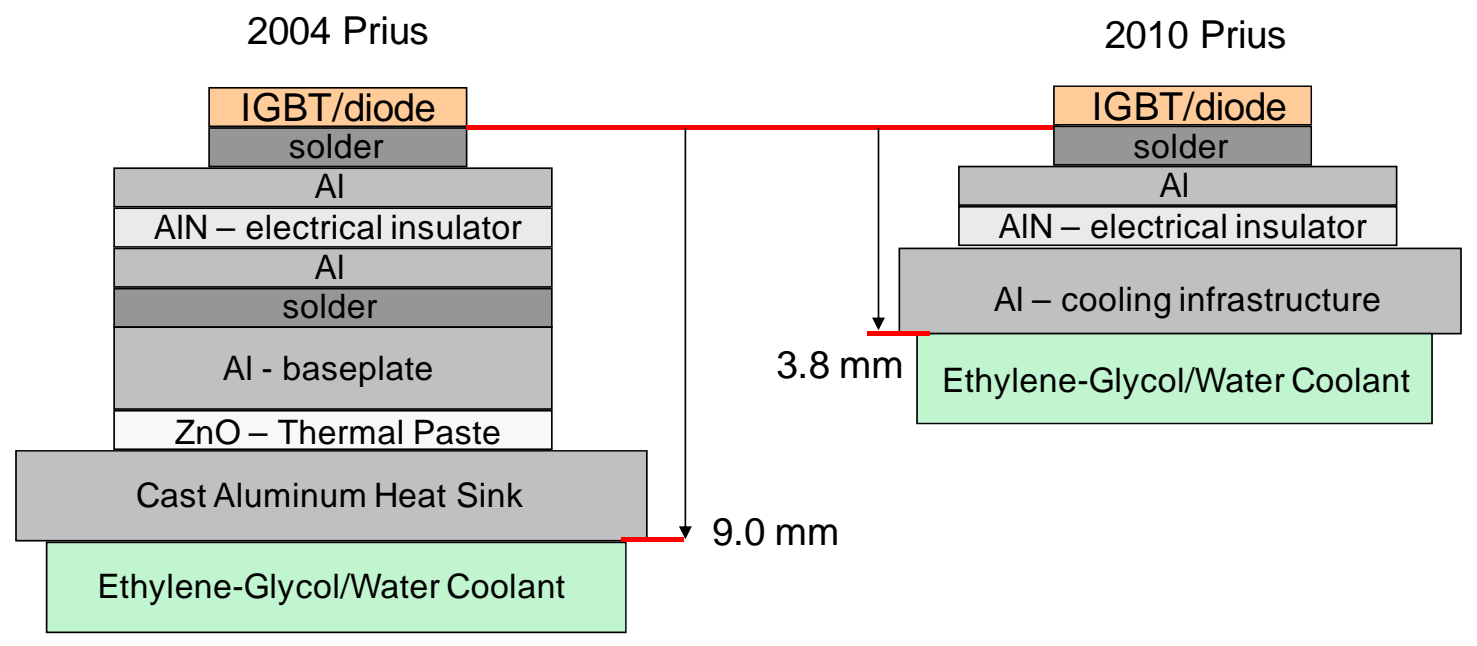

Fig. 2.28. Comparison of thermal conduction path in 2004 Prius (left) and 2010 Prius (right).

Shown in Fig. 2.29 is an SEM image of the region analyzed just below the IGBT. Composition percentages are shown for the lead-free solder layer, which by mass, appears to be about $96.4 \% \mathrm{Sn}$, $1.25 \% \mathrm{Al}, 1.2 \% \mathrm{Ag}$, and $1.14 \% \mathrm{~N}$. In the interface layer between the solder and DBA substrate, a nickel layer is added onto the aluminum trace to improve the mechanical integrity of the interface, as shown in Fig. 2.30. This layer is comprised of $81.8 \% \mathrm{Ni}, 11.6 \% \mathrm{Al}$, and $6.6 \mathrm{P} \%$, by mass. A reaction layer between the solder layer and aluminum layer includes by mass, $77.3 \% \mathrm{Sn}, 11 \% \mathrm{Cu}, 5.5 \% \mathrm{Al}, 3.75 \% \mathrm{Ni}$, $1.19 \% \mathrm{~N}, 0.74 \% \mathrm{Si}$, and $0.57 \% \mathrm{O}$. The incorporation of copper into the solder mixture lowers the melting point, reduces susceptibility to thermal cycle fatigue, and improves wetting properties of molten solder during the assembly process.

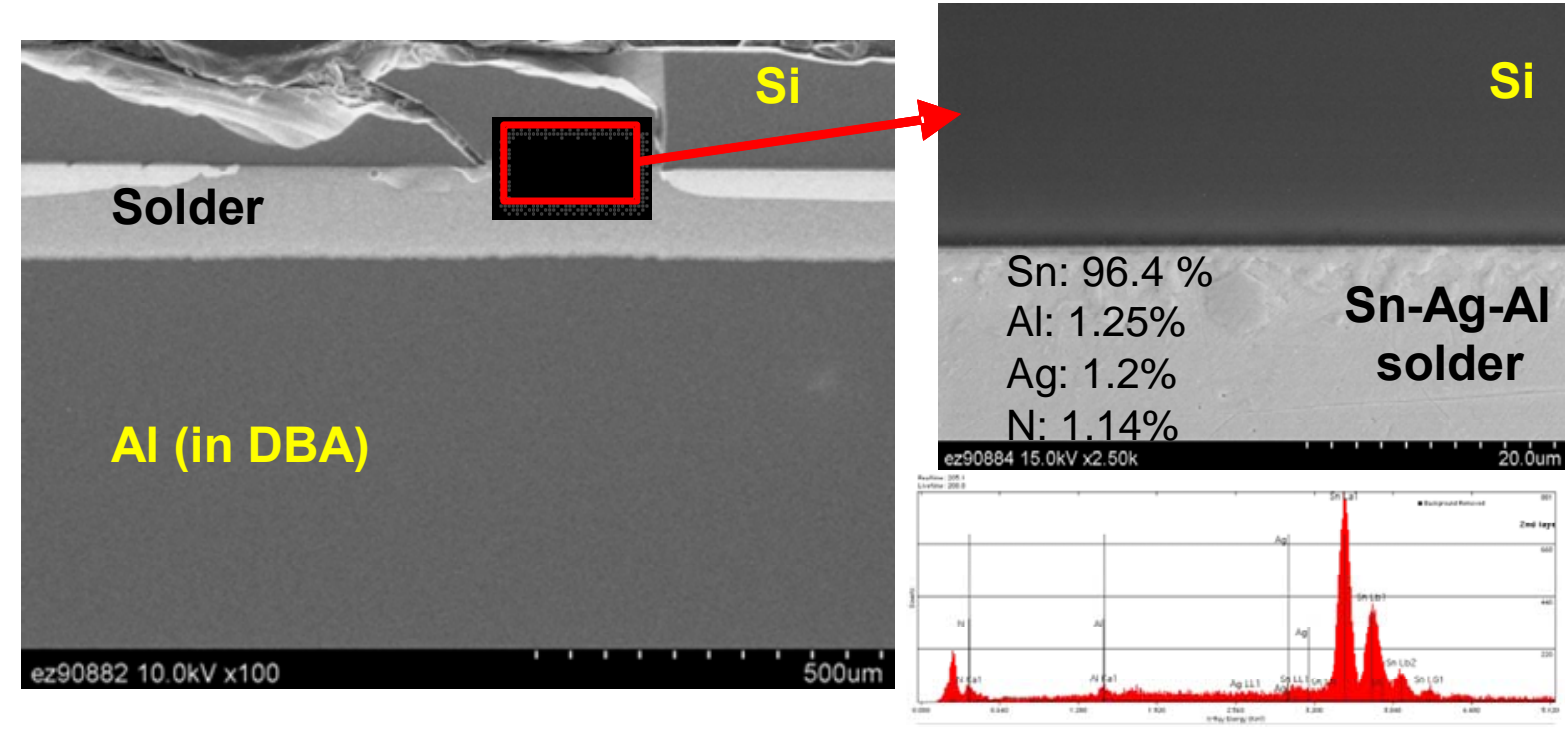

Fig. 2.29. SEM image of IGBT and adjacent solder layer. 

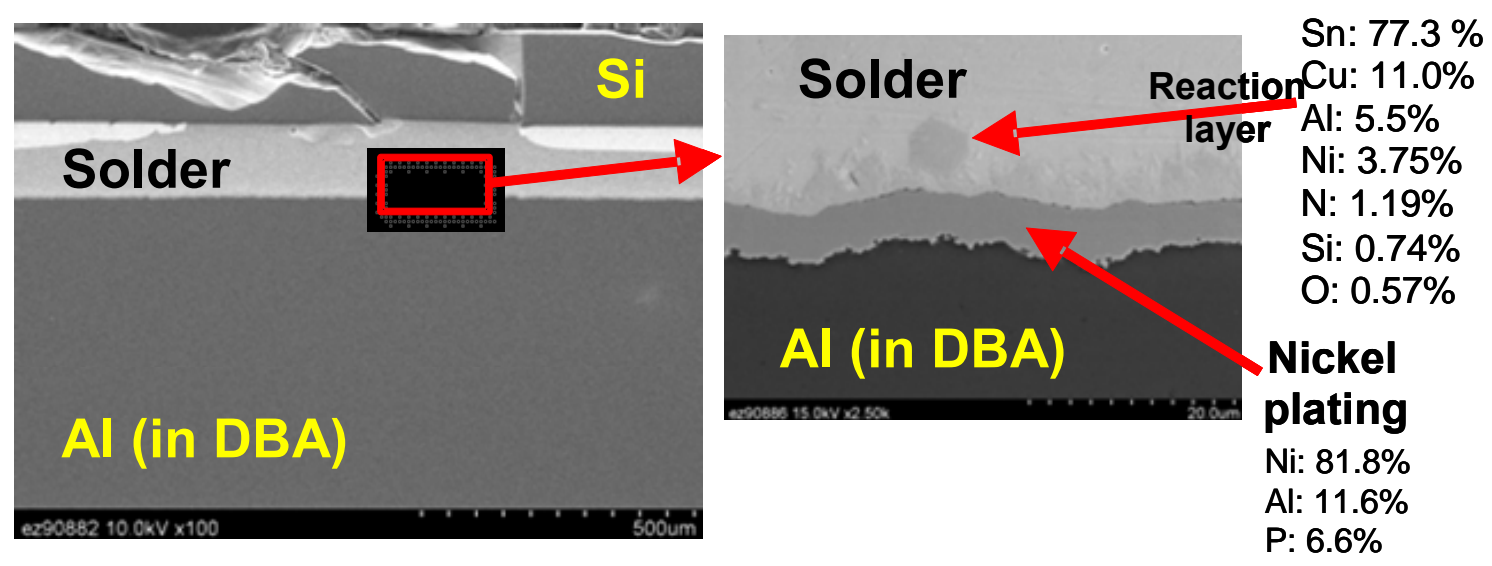

Fig. 2.30. SEM image of reaction layer and nickel plating on solder layer.

An SEM image of the AIN ceramic insulator and results from two quantitative analyses are shown in Fig. 2.31. As indicated, one analysis revealed a mass composition of $94.88 \% \mathrm{Al}$ and $5.12 \% \mathrm{~N}$, while the other analysis shows $55.7 \% \mathrm{Y}, 27.0 \% \mathrm{Al}$, and $17.4 \% \mathrm{O}$. The presence of yttrium oxide (yttria) is assumed to be due to its sintering aiding characteristics. Several sub-layers are present between the AlN insulator and the cooling channels, as shown in Fig. 2.32. Four locations were analyzed, with the uppermost layer, labeled 'Al -1', next to the AlN being nearly pure aluminum. The next layers, labeled 'Al-2' and 'Al-3' are similar aluminum alloys, but with different content of the secondary phase. The composition of the final layer are shown to be $43.4 \% \mathrm{Al}, 31.4 \% \mathrm{Fe}, 20.8 \% \mathrm{Mn}$, and $4.31 \% \mathrm{Si}$. Layers labeled 'Al-3' and 'Al-4' are the same Al-alloy.

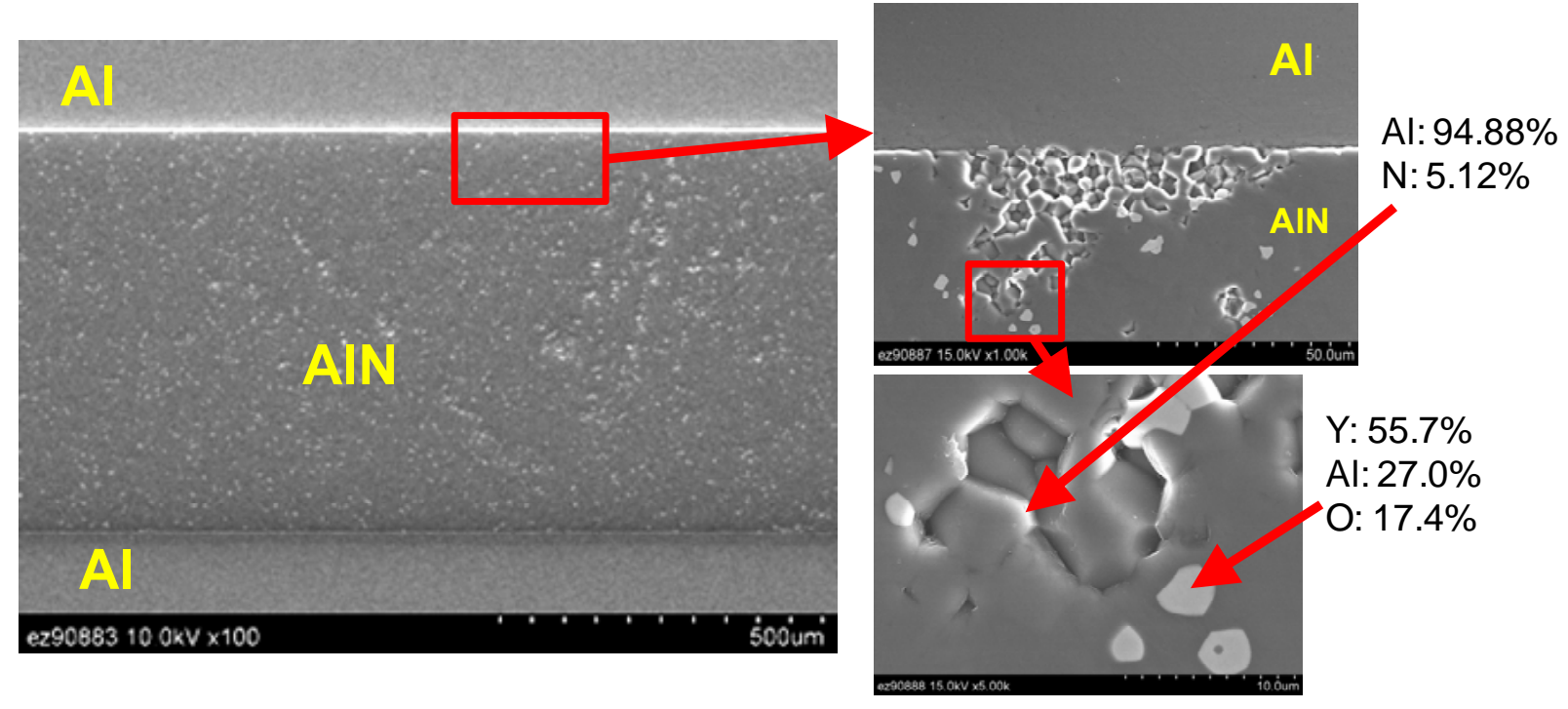

Fig. 2.31. SEM image of insulator. 


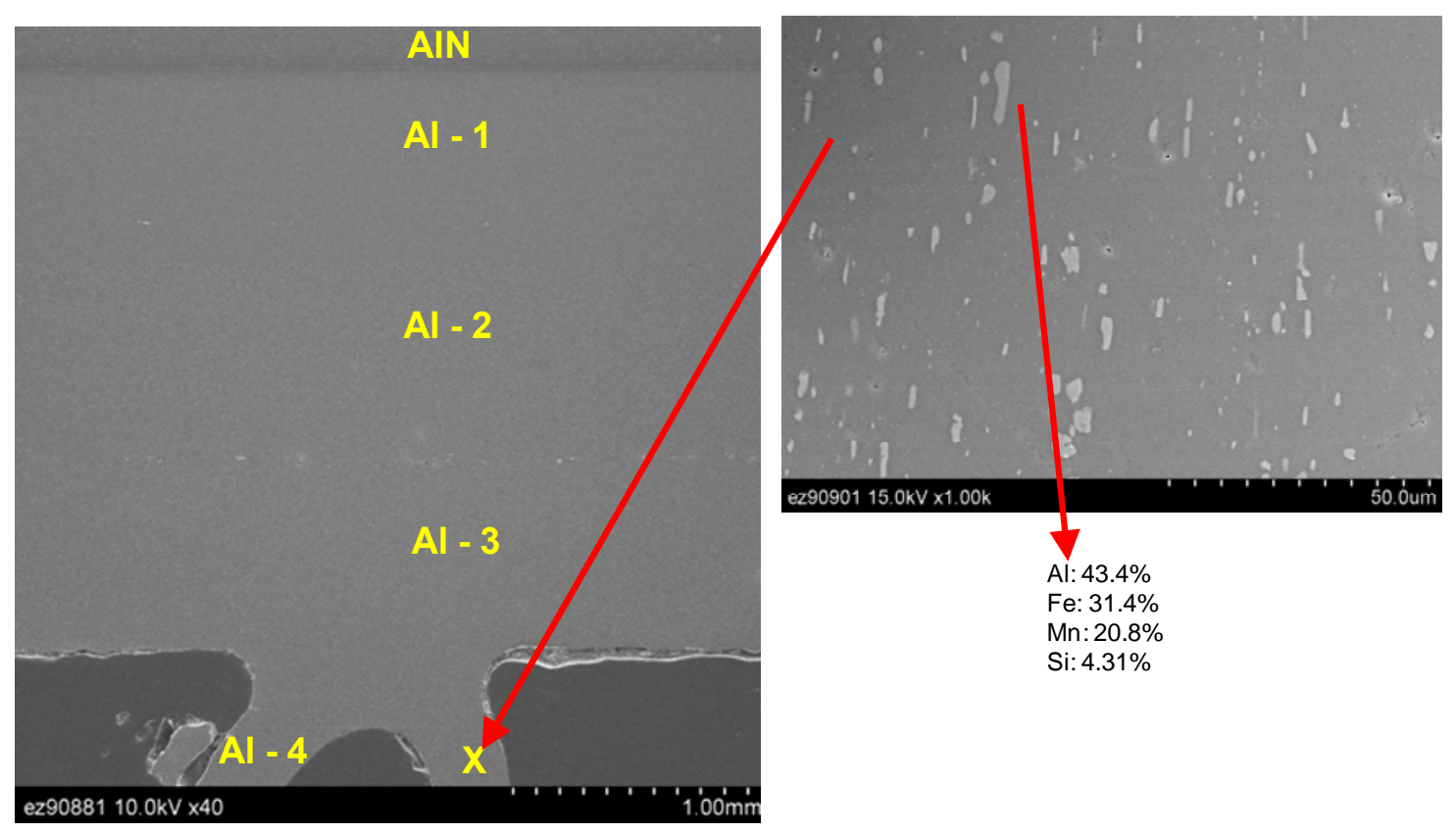

Fig. 2.32. SEM image of aluminum layers between insulator and cooling channels.

\subsubsection{Capacitor Test Results}

As capacitor technologies improve, it is important to ascertain the capabilities and limitations of these new technologies by subjecting them to standardized tests to evaluate their characteristics. Test results will assist in benchmarking not only the capabilities and limitations of these technologies, but also to provide a baseline for comparison. All of the 2010 Prius capacitors are of the metalized plastic film type and were manufactured by Matsushita under the Panasonic brand name. Contrarily, only the small filter capacitors of the Lexus and Camry were manufactured by Panasonic and the large dc-link capacitor modules of the Camry and LS 600h were manufactured by Nichicon. As noted in Section 2.2.1, the capacitor modules are made up of several sub-capacitors.

Two types of capacitor tests were conducted; one without excitation (other than small signals from the LCR meter) and the other with continuous ripple current applied to the capacitor. The former is a capacitor parameter assessment and the latter is a characteristic assessment under continuous ripplecurrent conditions. The parameter assessment does not entail an externally applied dc-bias voltage and ripple current, but uses only signals supplied by an LCR meter. The capacitor parameters that are measured in the assessments are: (1) equivalent series resistance (ESR), (2) dissipation factor (DF), and (3) capacitance. The capacitor is placed in an environmental chamber and the temperature is cycled through temperatures ranging from $-40-140^{\circ} \mathrm{C}$ using steps of $20^{\circ} \mathrm{C}$. These three parameters are measured at each temperature step.

The ESR is the real component of the equivalent impedance of the capacitor and corresponds directly with total energy loss which is dissipated as heat during operation. The DF is the ratio of the ESR over the capacitive reactance, which simplifies to $\omega R C$ and will be represented as the percentage of real power associated with a particular reactive power component. Both of these parameters were measured during assessments and the results were plotted over a wide frequency and temperature range.

In continuous ripple current tests, a dc-bias voltage and ripple current is applied to the capacitor and the temperature of the capacitor is monitored. When a capacitor is used on a dc bus, the maximum ripple 
current capability is an important specification. The ripple-current test determines the amount of heat generated by the capacitor as a function of ripple current at various ambient temperatures.

\subsubsection{Parameter assessments of the $888 \mu \mathrm{F}$ dc-link smoothing capacitor module}

The data acquisition system (DAQ) consists of a Dell Precision 380 Workstation running LABView 8.5. The instruments used to log data are an Espec environmental chamber and an Agilent 4284 LCR meter. At the beginning of the static thermal cycling tests, after all temperature steps and test frequencies have been entered, the program turns on the environmental chamber and commands a target temperature to the chamber. After the target temperature has been reached and a pre-programmed delay time has been met, the program sends a command to the LCR meter to output the first test frequency and then begins to monitor the ESR from the capacitor under test. When that value is stable, the ESR is recorded and the next parameter is measured and recorded. After the values for ESR, DF, and capacitance are recorded at the first test frequency, the command is given to the LCR meter to output the next test frequency and the monitoring and recording process is repeated. After all data are recorded at all test frequencies, the next temperature step is commanded to the environmental chamber and the process is repeated.

Parameter assessments of the $888 \mu \mathrm{F} 2010$ Prius capacitor module was conducted from $-40-140^{\circ} \mathrm{C}$ over a frequency range of 1 to $20 \mathrm{kHz}$. ESR, DF, and capacitance measurements are graphed versus frequency in Fig. 2.33. An interesting fact is observed as the capacitance approaches infinity just beyond $13 \mathrm{kHz}$. The module can be represented as a resistive, inductive, and capacitive circuit with very small resistance and inductance. However, at high frequencies, even a small parasitic inductance component has a significant influence upon the entire equivalent reactance of the module. There is a certain resonant frequency where the capacitive (negative reactance) effect and inductive (positive reactance) effect are equal, and therefore the total reactance is zero and the imaginary admittance or susceptance is infinite. Thus, the equivalent capacitance approaches infinity as the frequency approaches resonant frequency. Just beyond the resonant frequency, the equivalent reactance is inductive and increases from zero as frequency increases.

Figure 2.34 shows that the 2004 Prius capacitor module also has a similar effect near $15 \mathrm{kHz}$.

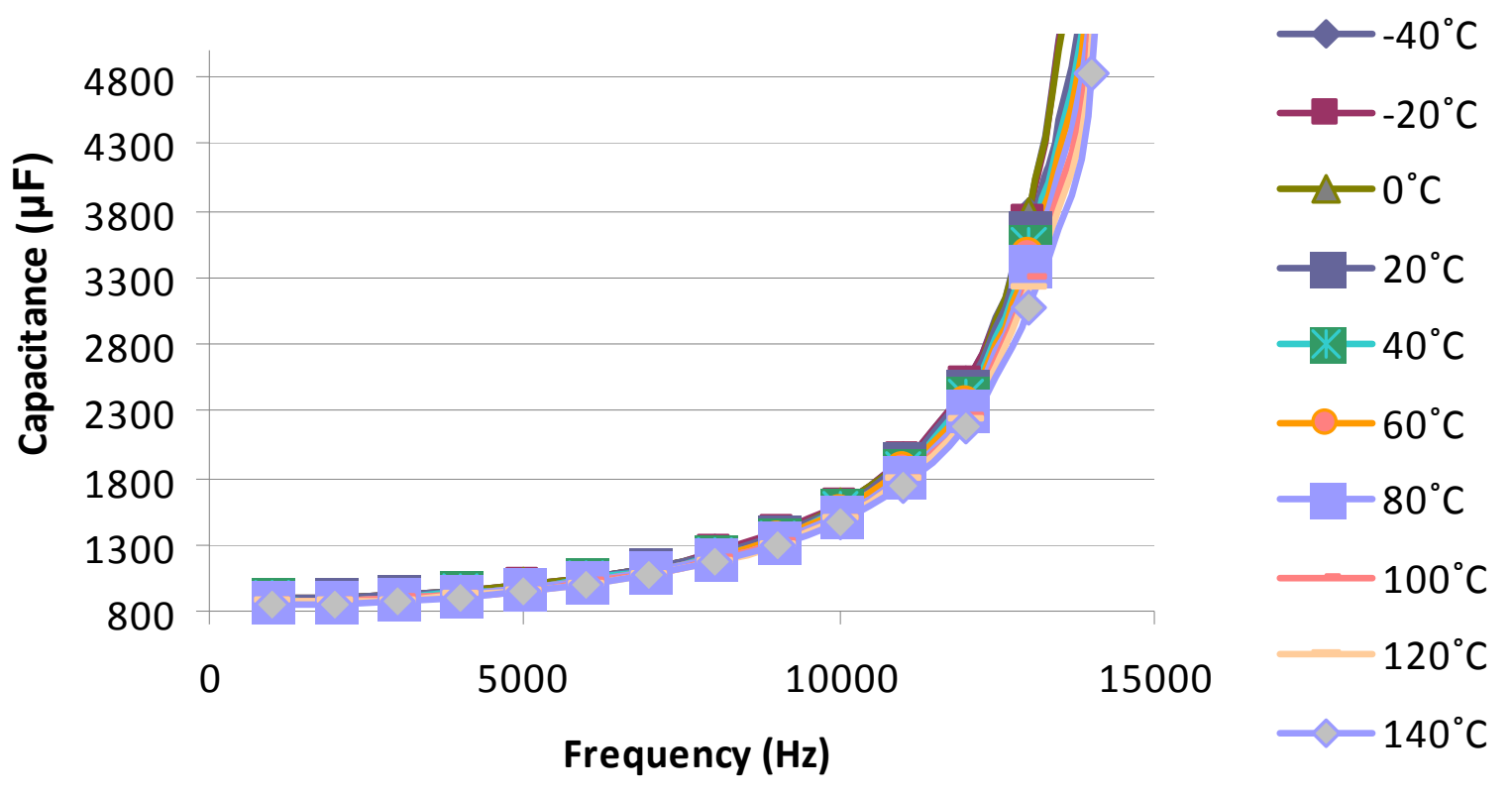

Fig. 2.33. 2010 Prius $888 \mu \mathrm{F}$ capacitor module equivalent capacitance vs. frequency. 


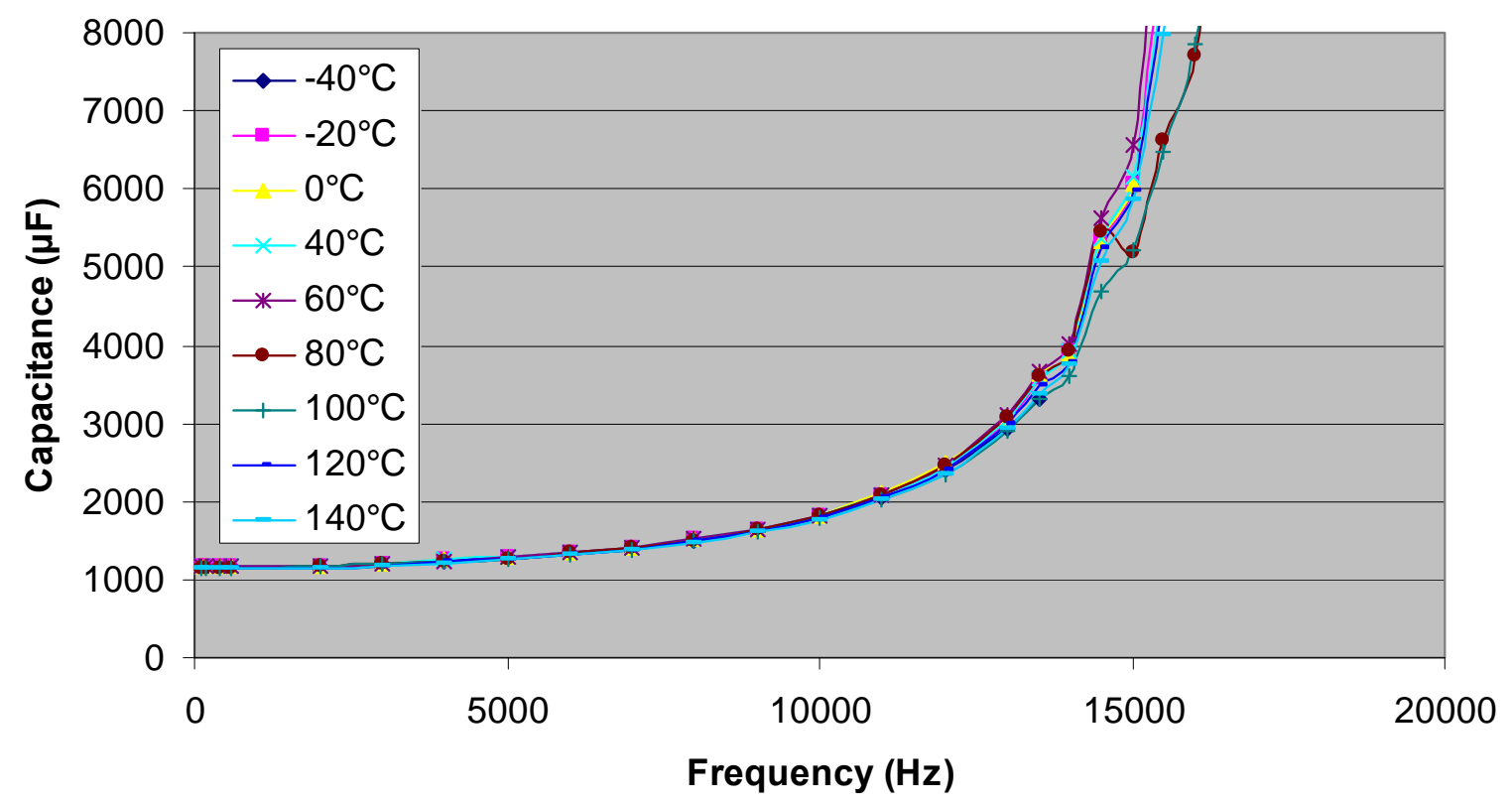

Fig. 2.34 2004 Prius 1,130 $\mu \mathrm{F}$ capacitor module equivalent capacitance vs. frequency.

As shown in Fig. 2.35, the impact of ambient temperature upon the 2010 Prius module capacitance was minimal over the full temperature range, particularly for low frequencies. The largest change in capacitance over the temperature range in this graph is indicated by the $14 \mathrm{kHz}$ trace, which is also the frequency at which the highest capacitance was measured. Overall, the capacitance tends to decrease with increasing temperature. In the Lexus and Camry measurements, capacitance tended to increase with increasing temperature until peaking at a particular temperature (between $-20^{\circ} \mathrm{C}$ and $50^{\circ} \mathrm{C}$ ) and then the capacitance decreased slightly as temperature increased above this temperature. This peak capacitance temperature generally increased with increasing frequency.

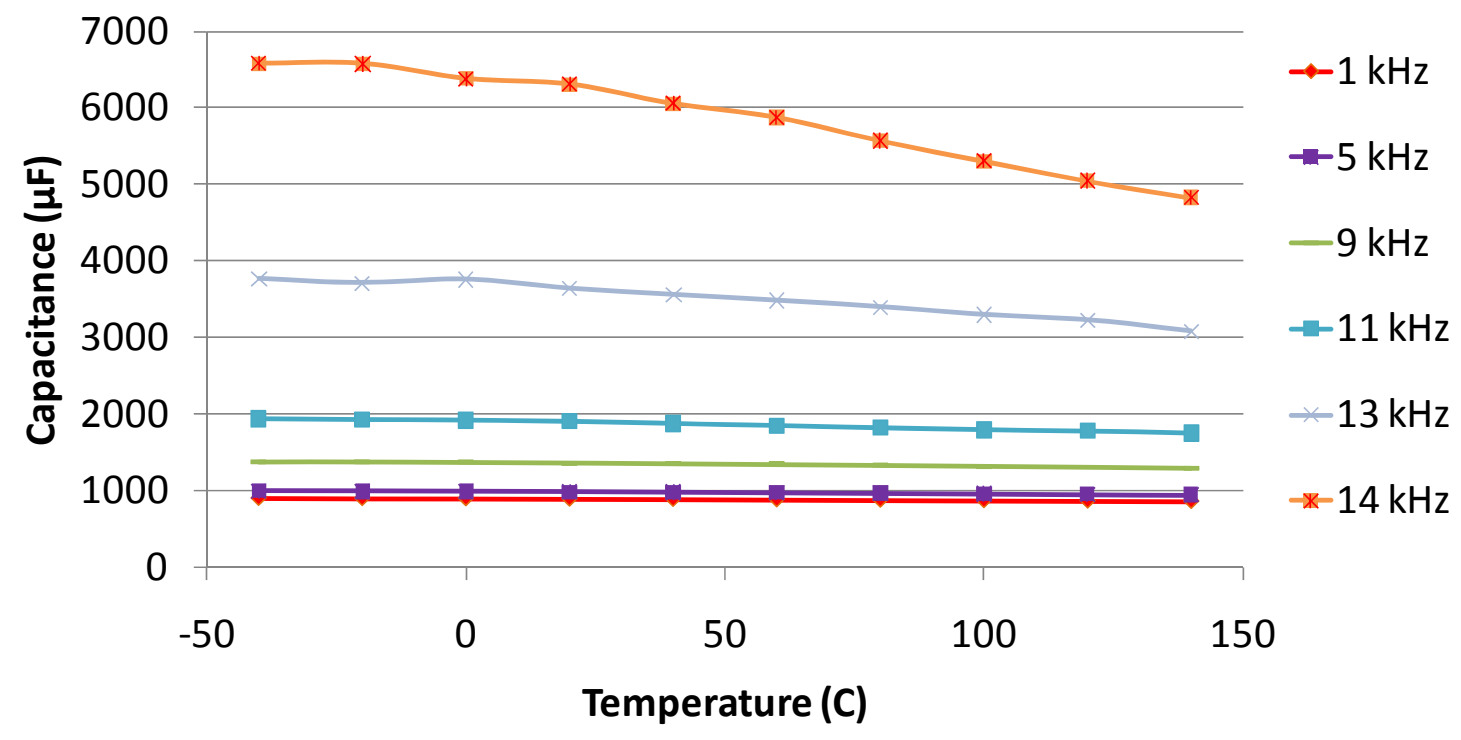

Fig. 2.35. 2010 Prius $888 \mu \mathrm{F}$ capacitor module equivalent capacitance variation with ambient temperature.

Figures 2.36 and 2.37 show the ESR response to frequency for the 2010 Prius and the 2004 Prius modules, respectively. Excluding the lowest data point for the 2010 Prius module, the ESR is generally 
higher than that of the 2004 Prius at low frequencies. However, the ESR of the 2010 Prius module appears to vary less with frequency, with slightly lower ESR values for high frequencies. Measurements indicate that ESR values generally increased with increasing temperature for both modules at all frequencies.
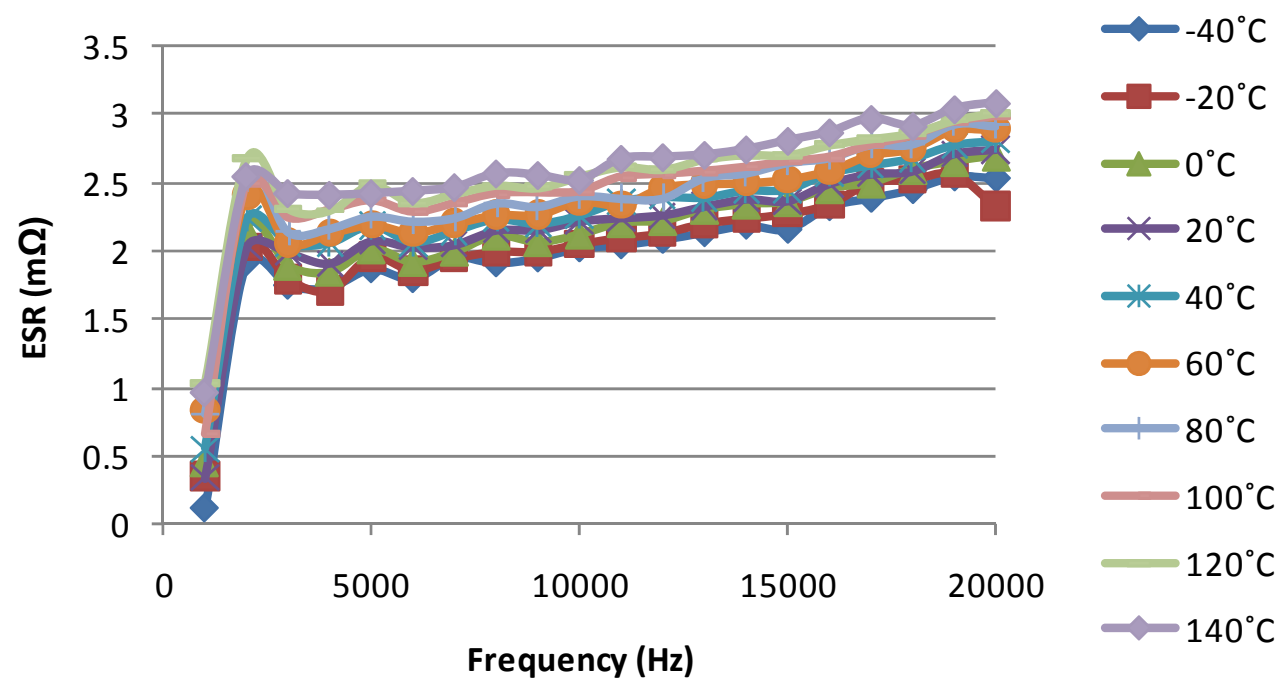

Fig. 2.36. 2010 Prius $888 \mu \mathrm{F}$ capacitor module ESR vs. frequency.

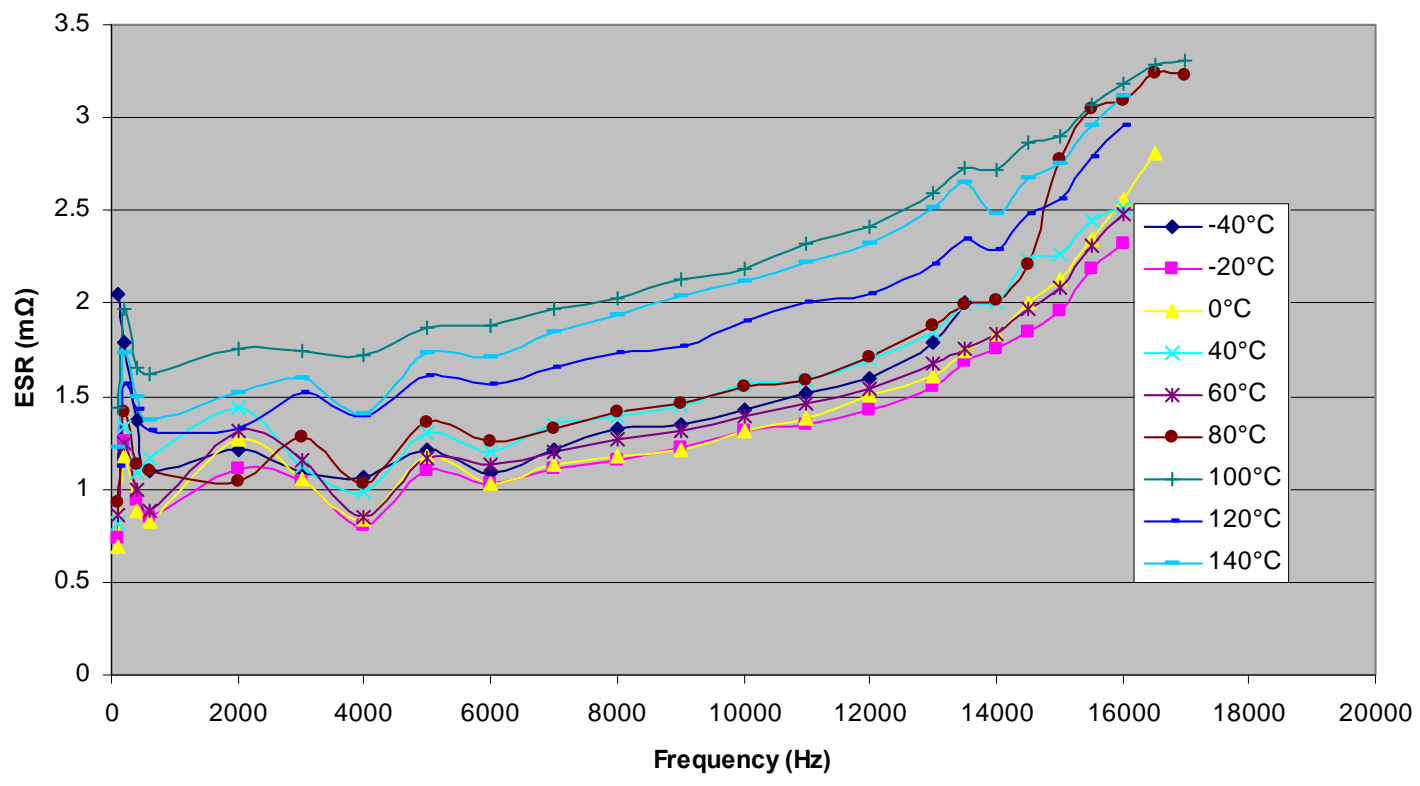

Fig. 2.37. 2004 Prius 1,130 $\mu$ F module ESR vs. frequency.

To obtain a clearer perspective of the impact of temperature upon ESR, Figs. 2.38 and 2.39 shows ESR plotted versus temperature for each frequency for the 2010 Prius and the 2004 Prius capacitor module, respectively. As expected, the ESR generally increases with increasing temperature for both modules. Similar comparisons for the Lexus and Camry can be found in [5] and [6]. 


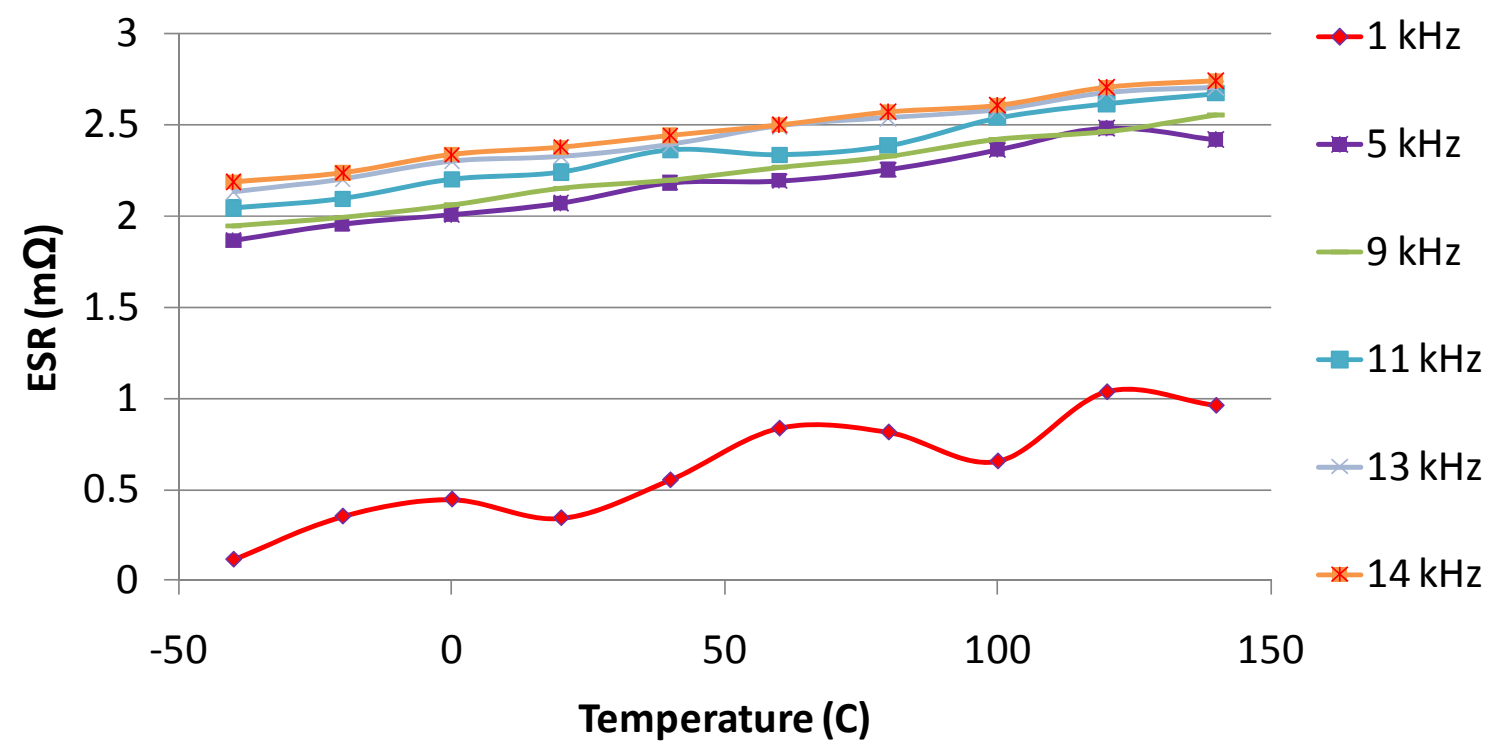

Fig. 2.38. 2010 Prius $888 \mu$ F capacitor module ESR vs. temperature.

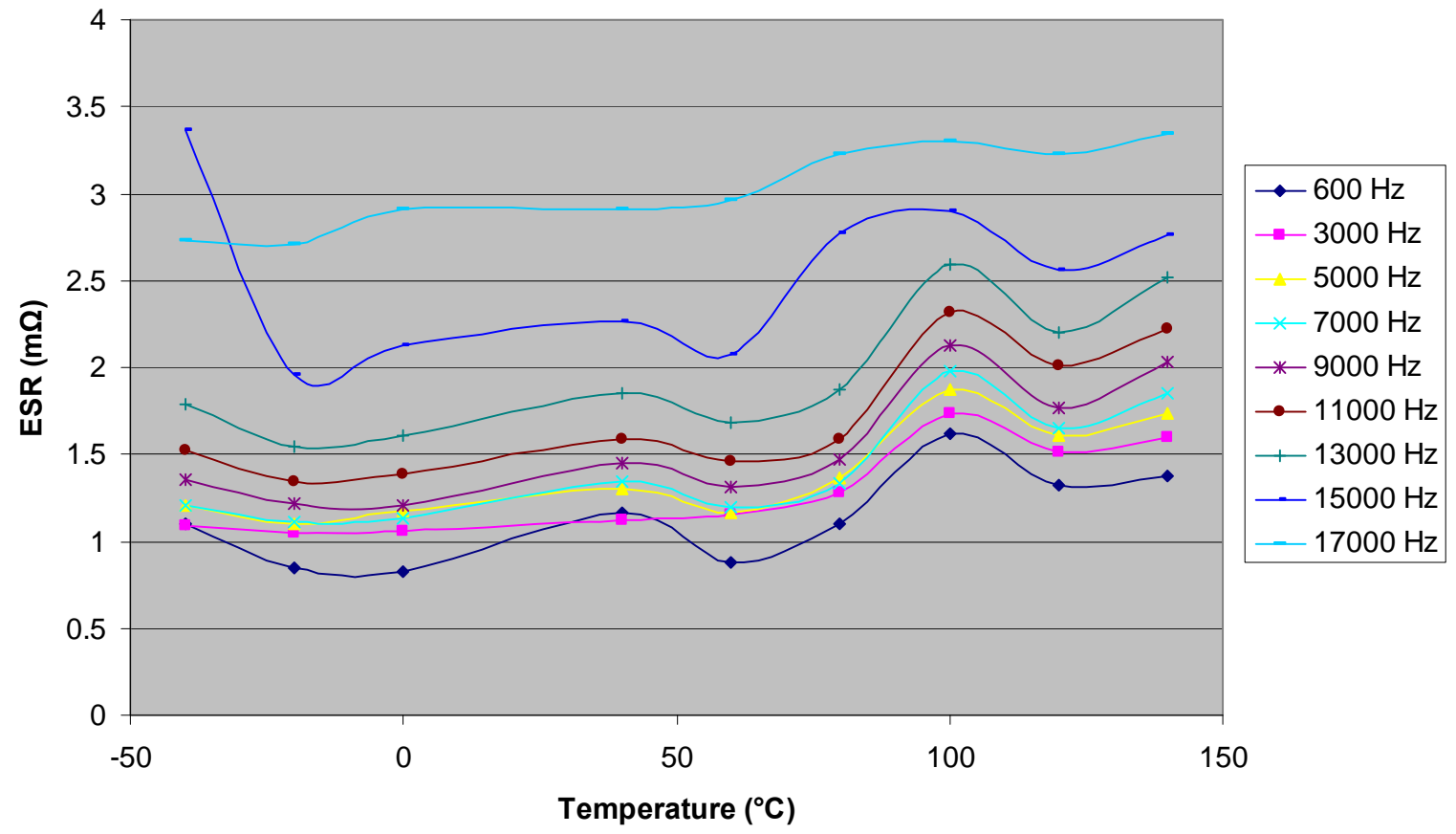

Fig. 2.39. 2004 Prius 1,130 $\mu$ F capacitor module ESR vs. temperature.

The variations of DF with frequency for the 2010 Prius and 2004 Prius capacitor modules are shown in Figs. 2.40 and 2.41, respectively. These graphs are similar to the capacitance versus frequency graphs in Figs. 2.33 and 2.34. Since DF is the product of ESR, capacitance, and frequency, both graphs include curves which approach infinity near the resonant frequency. 

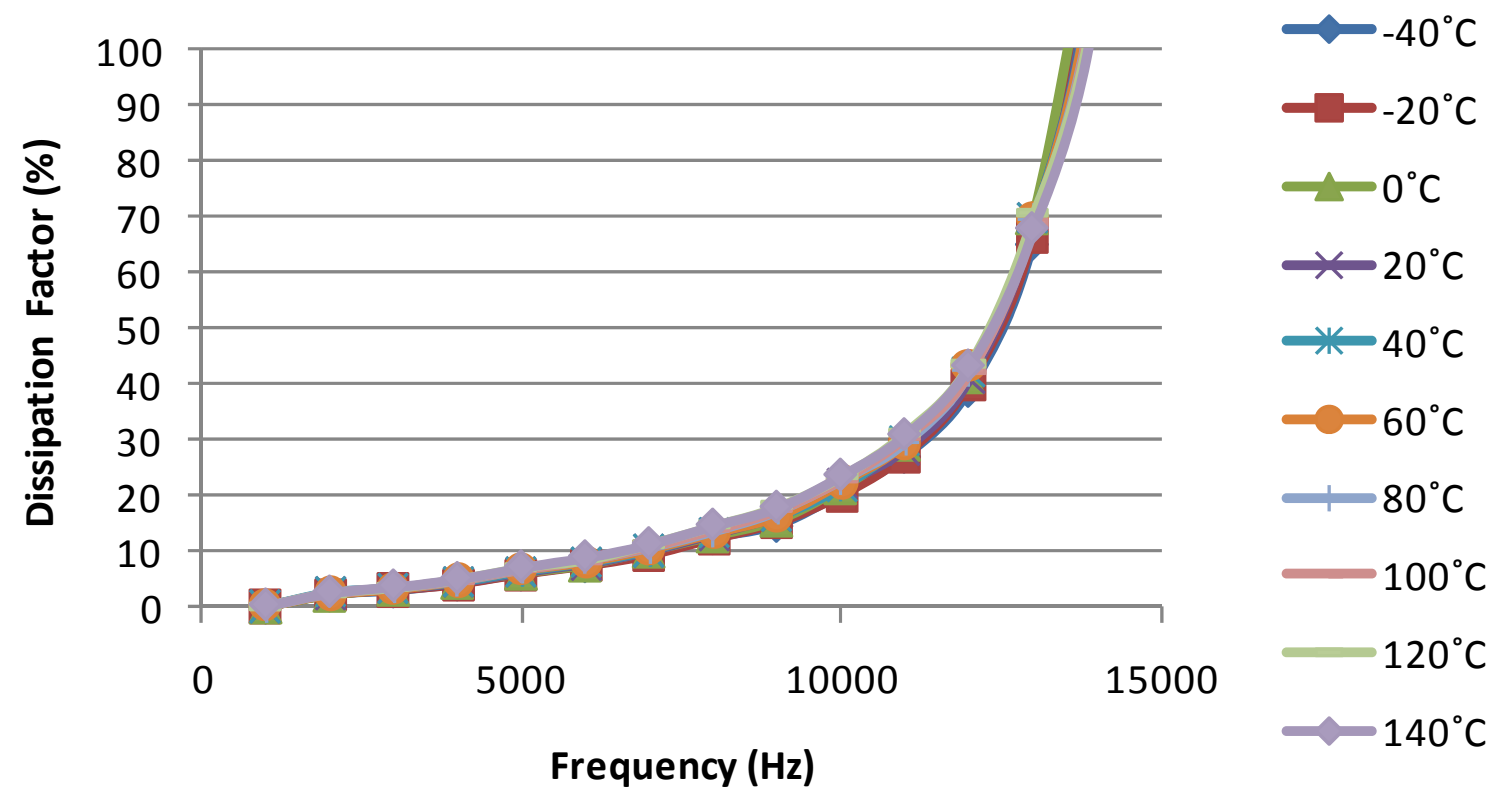

Fig. 2.40. 2010 Prius $888 \mu F$ capacitor module DF frequency response.

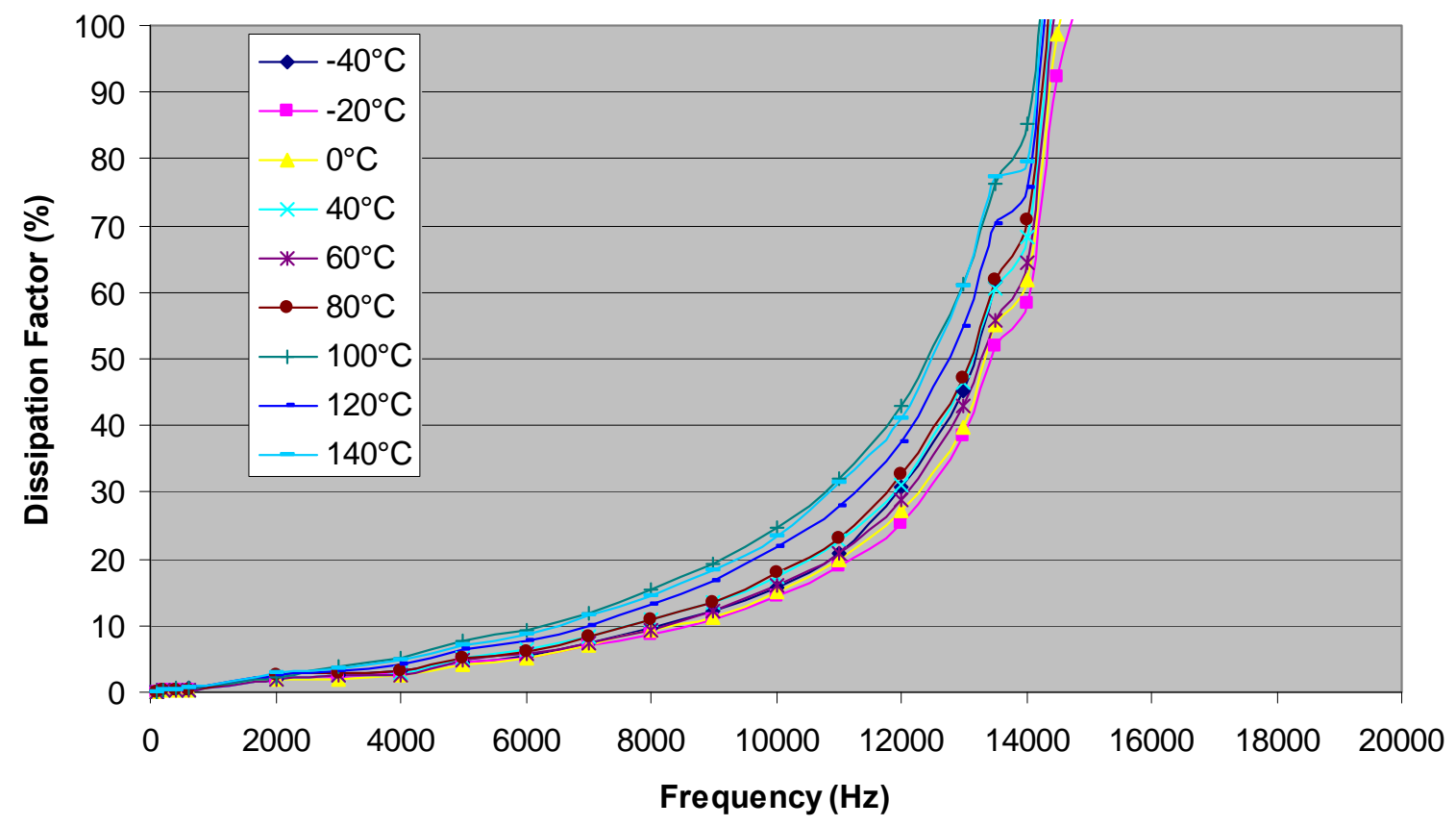

Fig. 2.41. 2004 Prius 1,130 $\mu$ F capacitor module DF frequency response.

The impact of temperature on the DF of the 2010 and 2004 Prius capacitor modules for each test frequency is observed in Figs. 2.42 and 2.43, respectively. Similar to the impact of temperature upon capacitance, the DF generally increases with increasing temperature, except for the $14 \mathrm{kHz}$ trace in Fig. 2.42. Additionally, temperature has a greater impact on DF at higher frequencies for the 2004 Prius module. Since the ESR naturally increases with increasing temperature, the amount of real power dissipated for a particular amount of reactive power increases as temperature increases. 


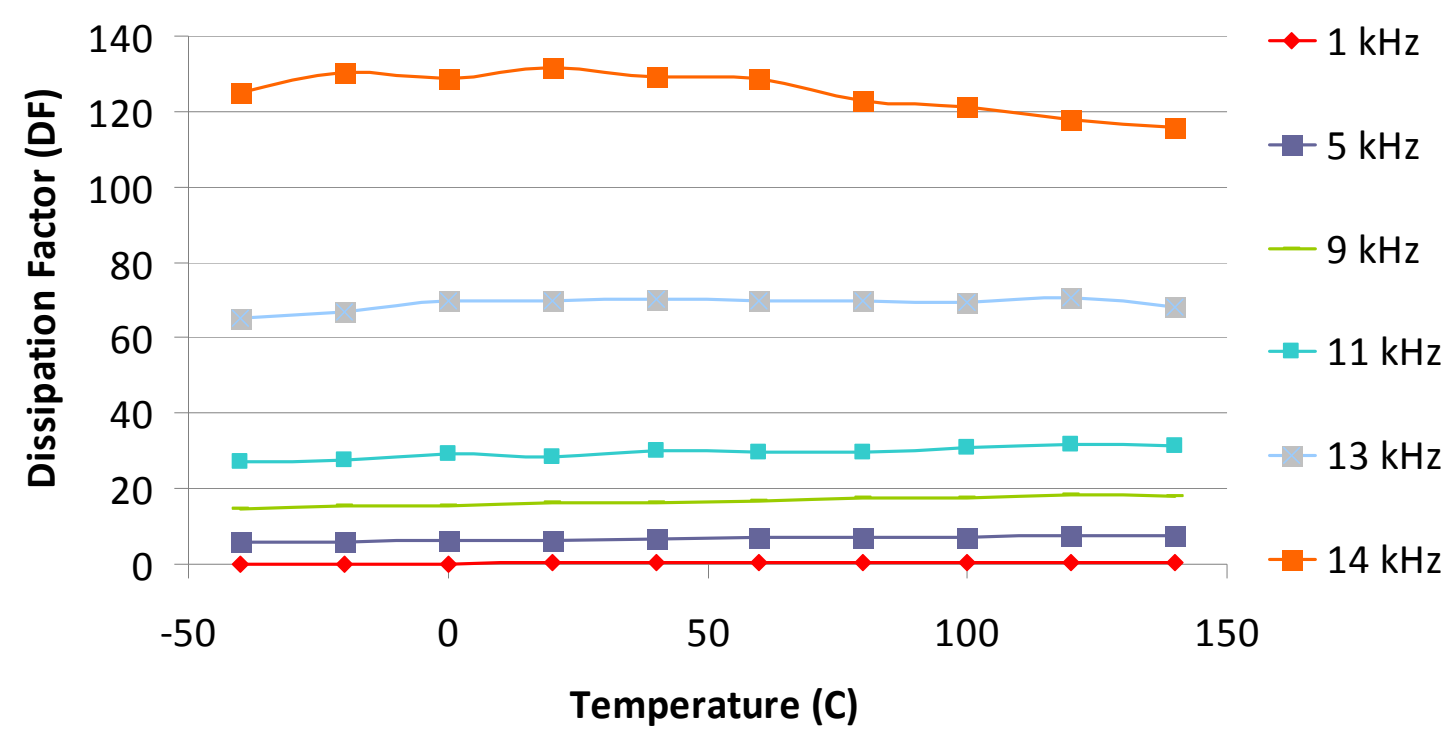

Fig. 2.42. 2010 Prius $888 \mu \mathrm{F}$ capacitor module DF temperature response.

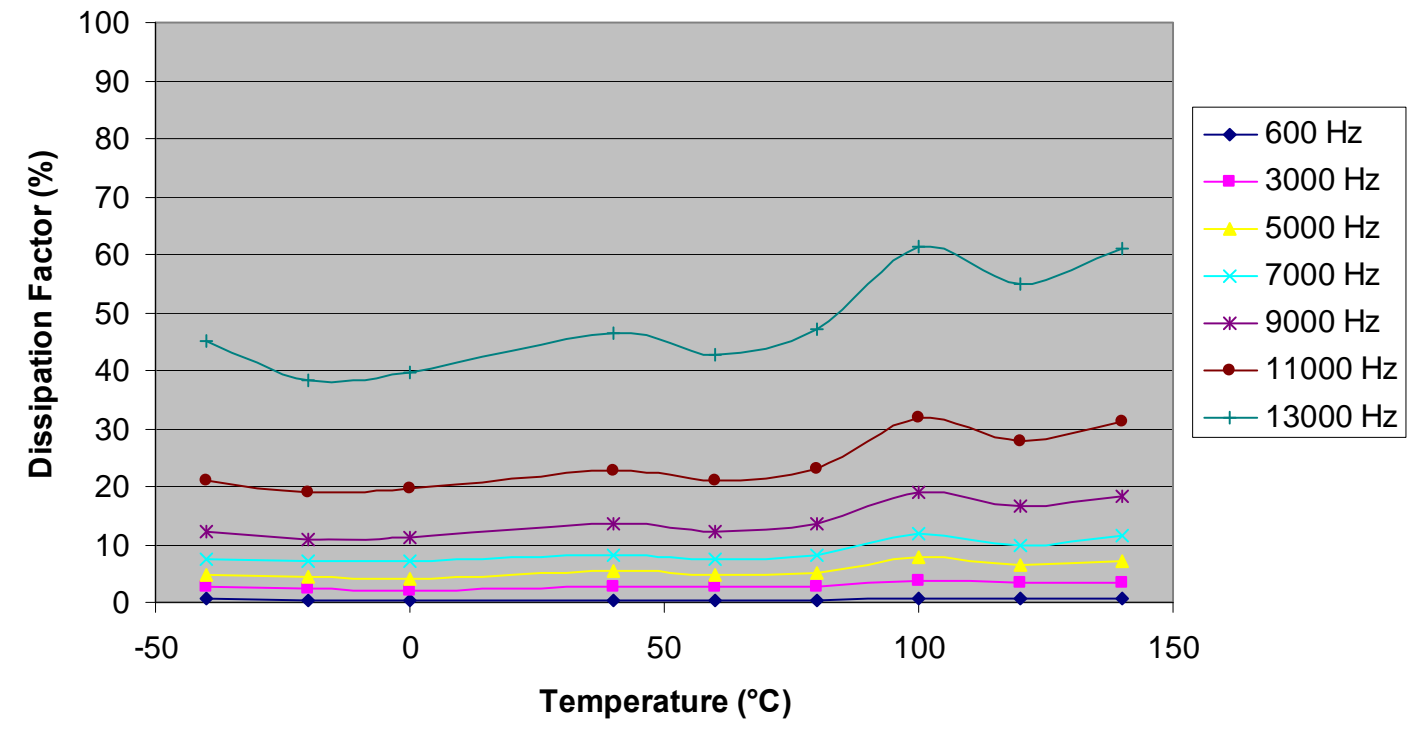

Fig. 2.43. 2004 Prius $1,130 \mu$ F capacitor module DF temperature response.

\subsubsection{Continuous ripple current tests with large dc-link capacitor module}

The 2010 Prius capacitor module was tested with a maximum ripple current of 200 A. Figure 2.44 shows the basic circuit used to apply a ripple current with a dc bias to the capacitor module. However, due to the potentially detrimental impact of this configuration upon the dc supply, the supply and capacitor were excluded during the 2010 Prius tests. Nonetheless, the same fundamental observations can be made without these components. 


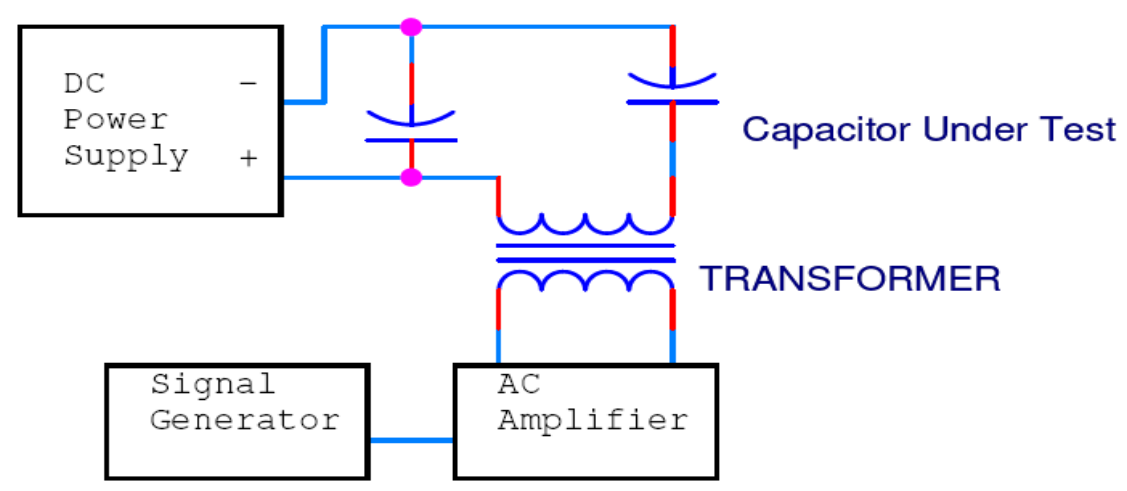

Fig. 2.44. Previous ripple current test schematic.

Thermocouples (TCs) were inserted just below the exterior surface of the 2010 Prius module in the appropriate locations shown in Fig. 2.45. Ripple current, monitored by the root mean square (rms) value, was applied in $50 \mathrm{~A}$ steps from $50 \mathrm{~A}$ up to $200 \mathrm{~A}$. The temperature was allowed to stabilize for 30 minutes before data was recorded. The steady-state TC temperatures were plotted to determine the module's temperature response to ripple current values, as the ambient temperature in the environmental chamber was regulated at 20C. These graphs are shown for the 2010 and 2004 Prius modules in Figs. 2.46 and 2.47, respectively. For the 2010 Prius, the maximum temperature was observed with TC "T2", and the data shown on the graph corresponds with this TC. Both modules performed similarly and sustained operation with high ripple currents without reaching extreme temperatures.

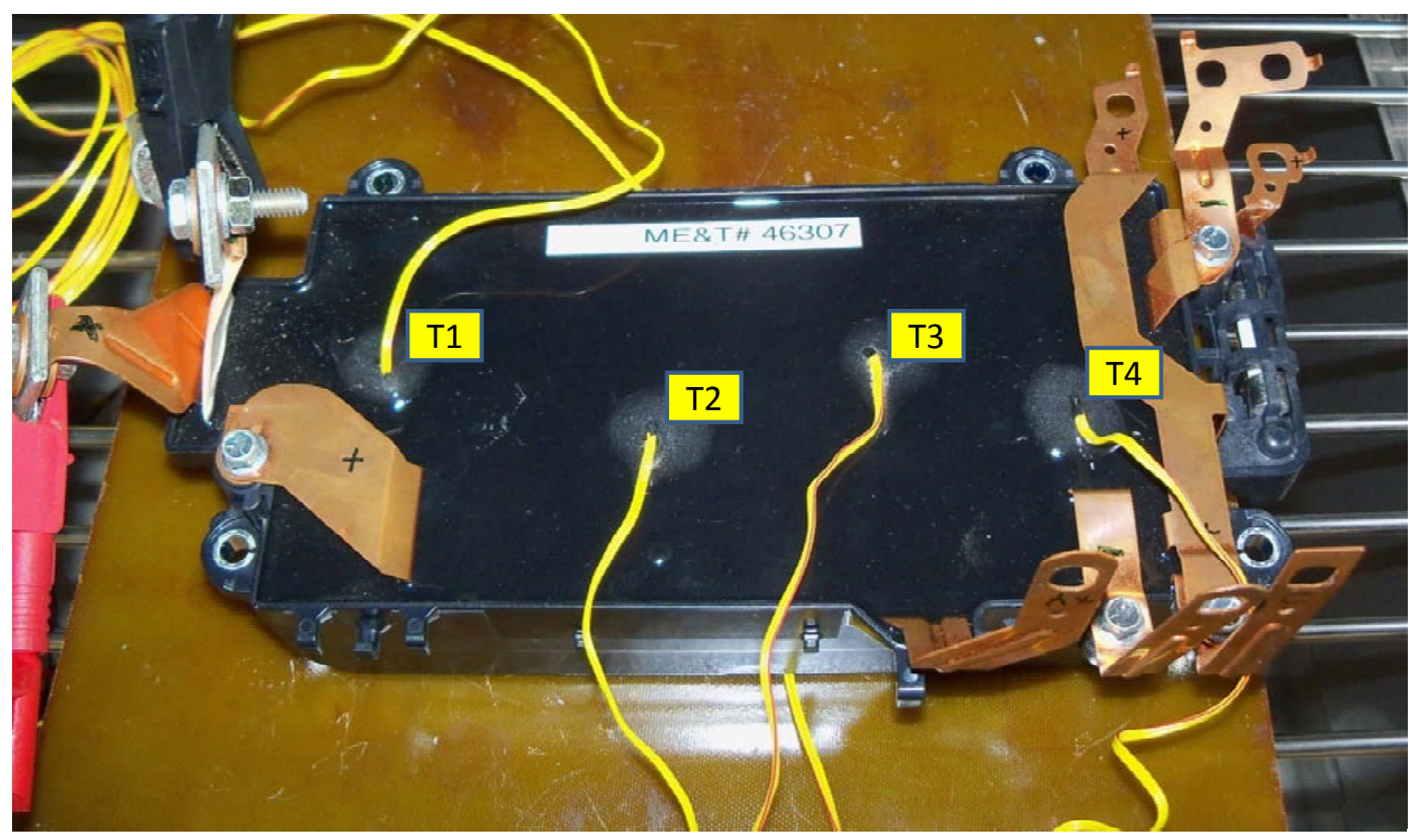

Fig. 2.45. TCs on the 2010 Prius capacitor module. 


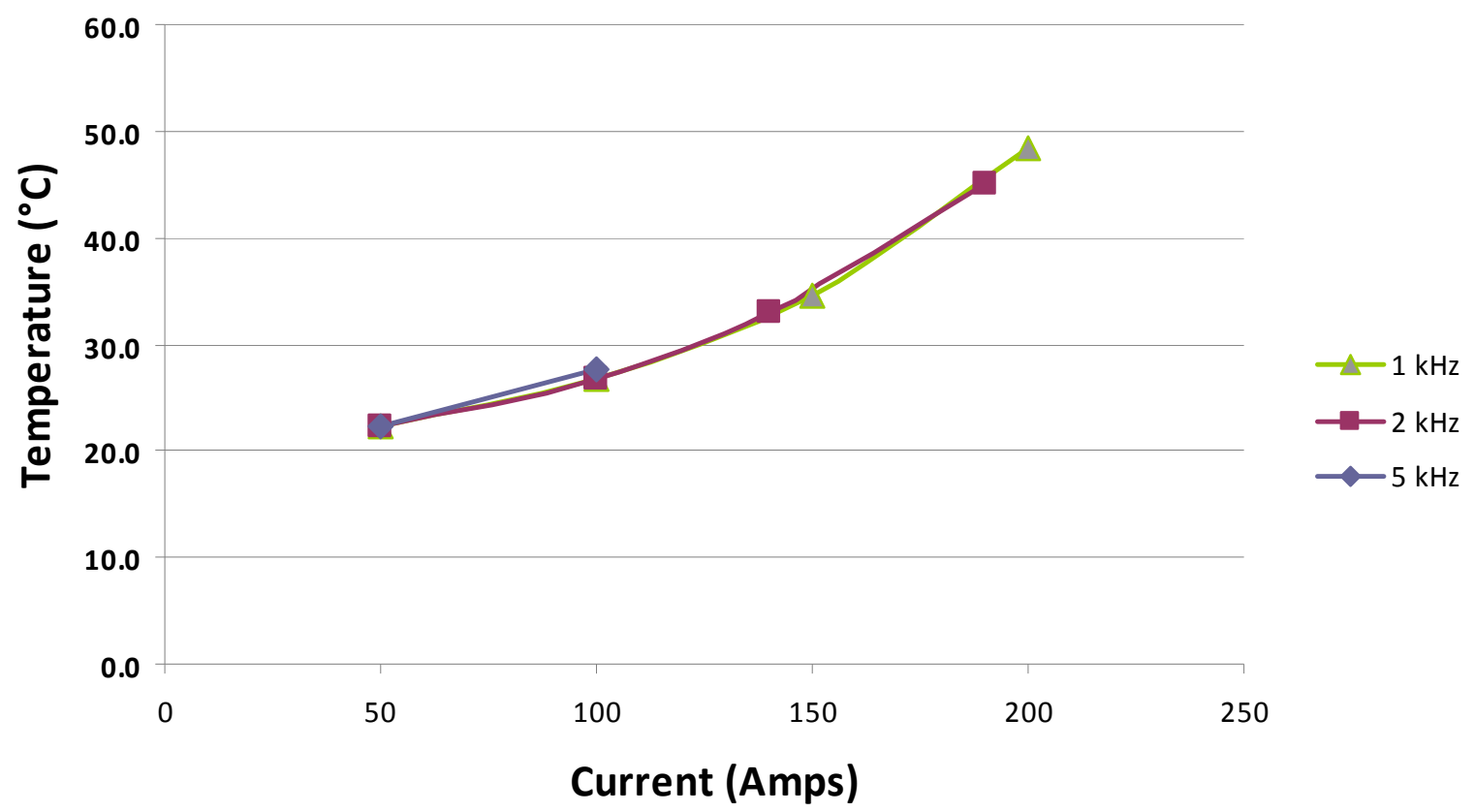

Fig. 2.46. 2010 Prius capacitor module steady state temperature response vs. ripple current.

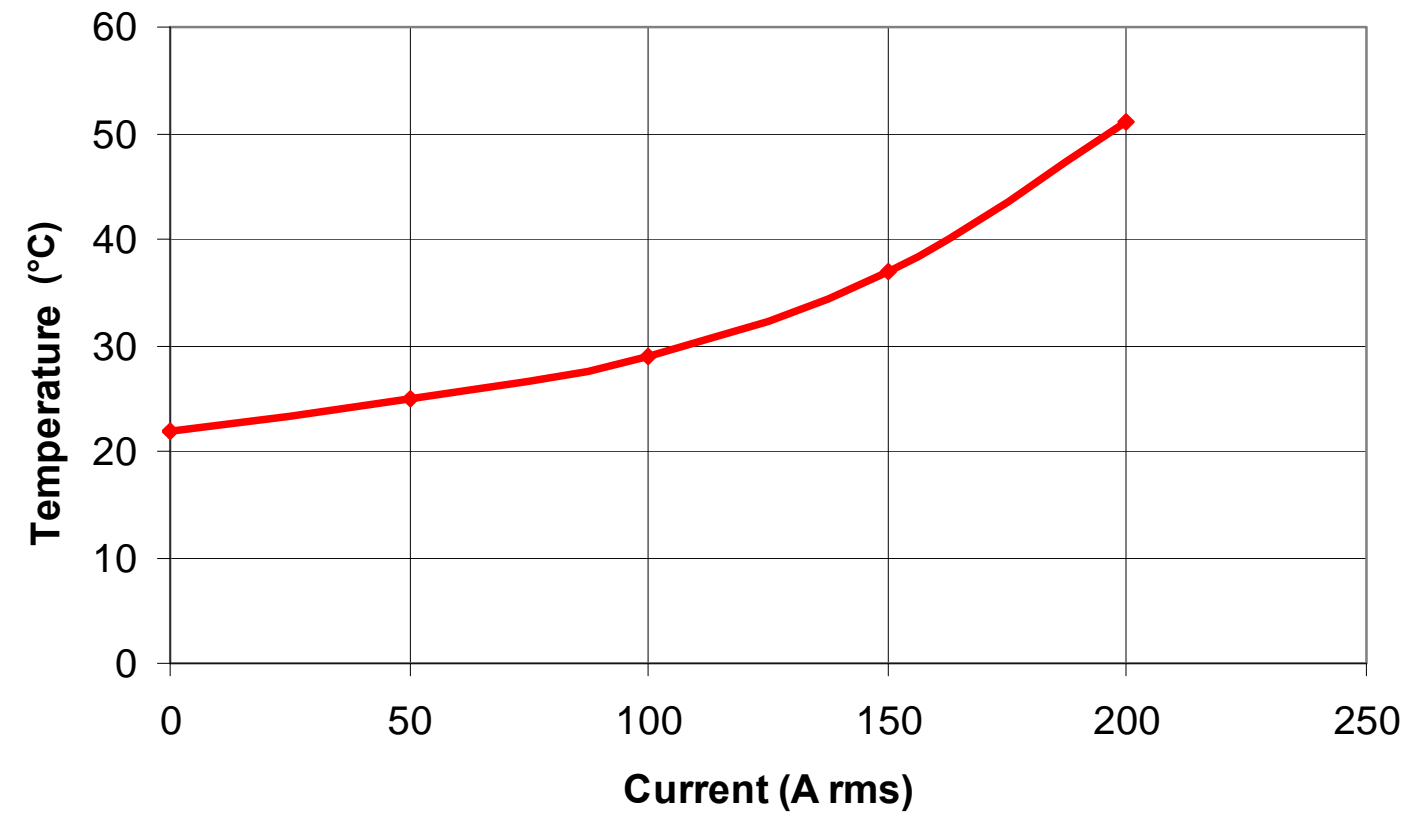

Fig. 2.47. 2004 Prius capacitor module steady state temperature response vs. ripple current at $4 \mathrm{kHz}$.

\subsubsection{Parameter assessments of battery level filter capacitor}

Figures 2.48 and 2.49 compare the capacitor test results of the $470 \mathrm{~V}, 315 \mu \mathrm{F}$ capacitor of the 2010 Prius and the $600 \mathrm{~V}, 282 \mu \mathrm{F}$ capacitor of the 2004 Prius, respectively. Each capacitor resides between the battery and the boost converter and is located within the PCU. Test results from the two modules are quite similar for low frequencies. The capacitance, ESR, and DF of both capacitors increases with 
increasing frequency. The sharp increase of the 2004 Prius capacitance at $20 \mathrm{kHz}$ indicates that the resonance frequency is nearby.

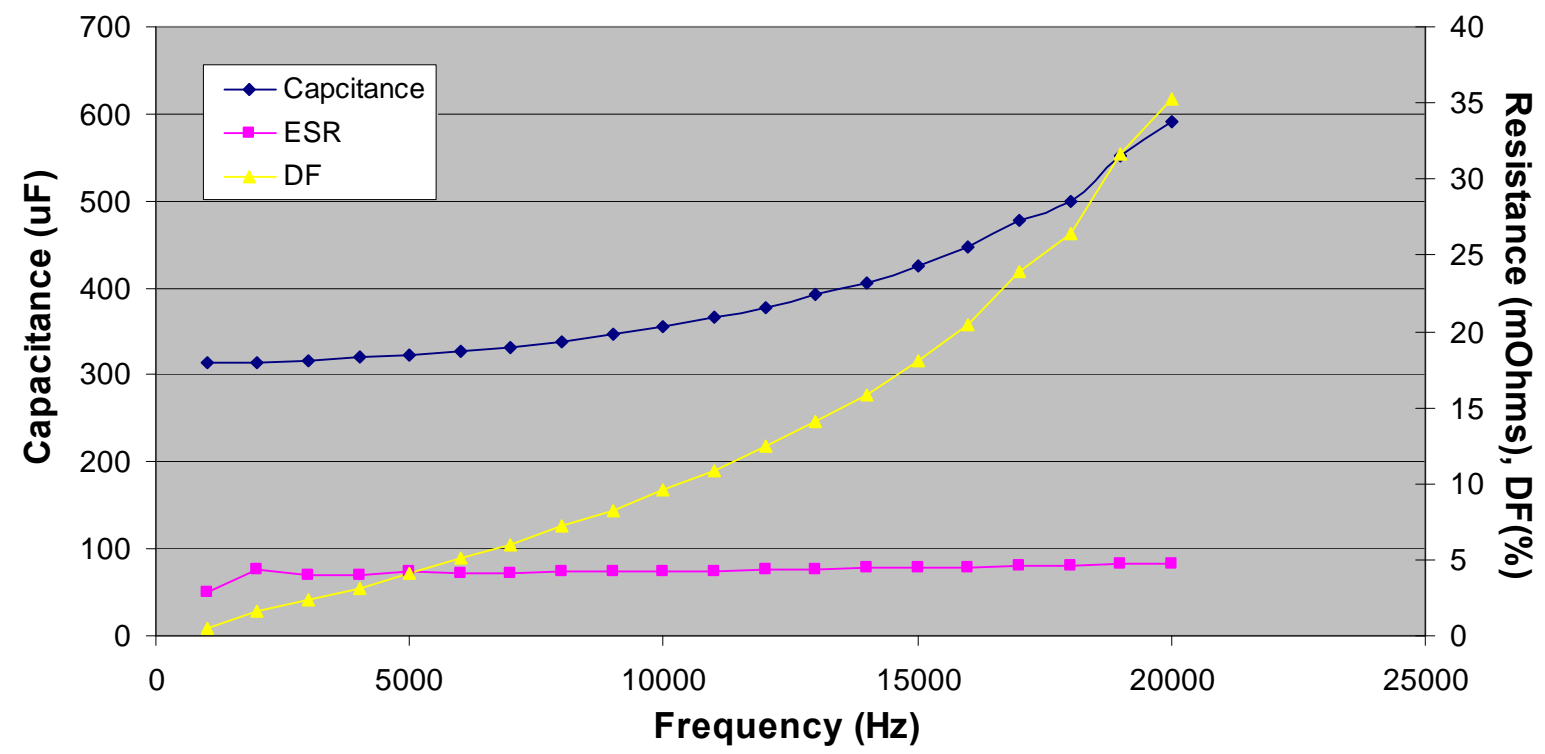

Fig. 2.48. Capacitance, ESR, and DF vs. frequency for 2010 Prius battery level $315 \mu \mathrm{F}$ capacitor.

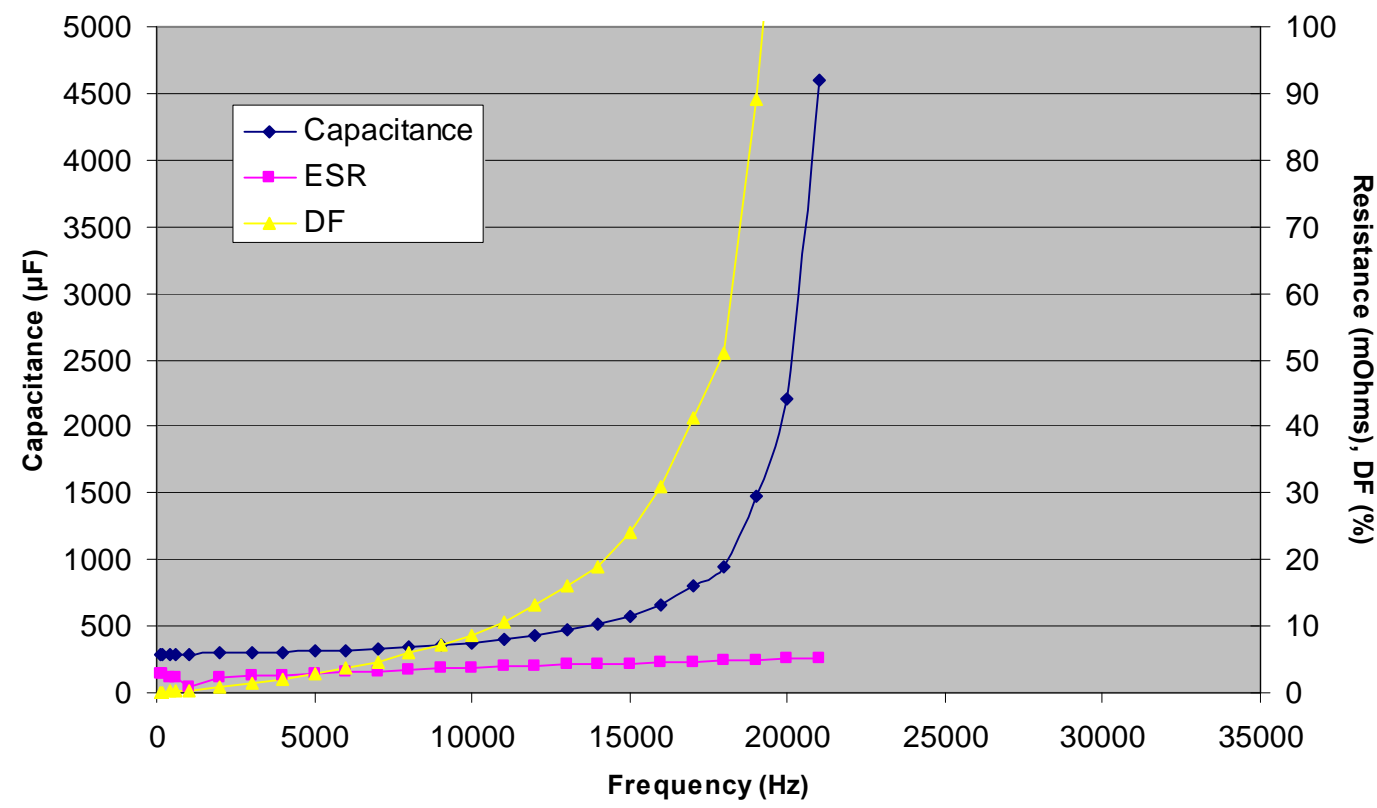

Fig. 2.49. Capacitance, ESR, and DF vs. frequency for 2004 Prius battery level $282 \mu \mathrm{F}$ capacitor.

\subsubsection{Parameter assessments of the small dc-link capacitor}

Figures 2.50 and 2.51 present the capacitor test results of the dc-link $950 \mathrm{~V}, 0.562 \mu \mathrm{F}$ and the $900 \mathrm{~V}$, $0.8 \mu \mathrm{F}$ capacitor of the 2010 Prius, respectively. Both capacitors are of the Panasonic brand and are labeled as "SH film capacitors". Note that the scale for capacitance on the left y-axis has a very small range for both capacitors, and thus their capacitances vary only slightly with frequency. The characteristics of the ESR curves for both capacitors reveal much higher ESR values for low frequencies, 
a common trend among small capacitors. The DF for both capacitors remains relatively low, even at high frequencies.

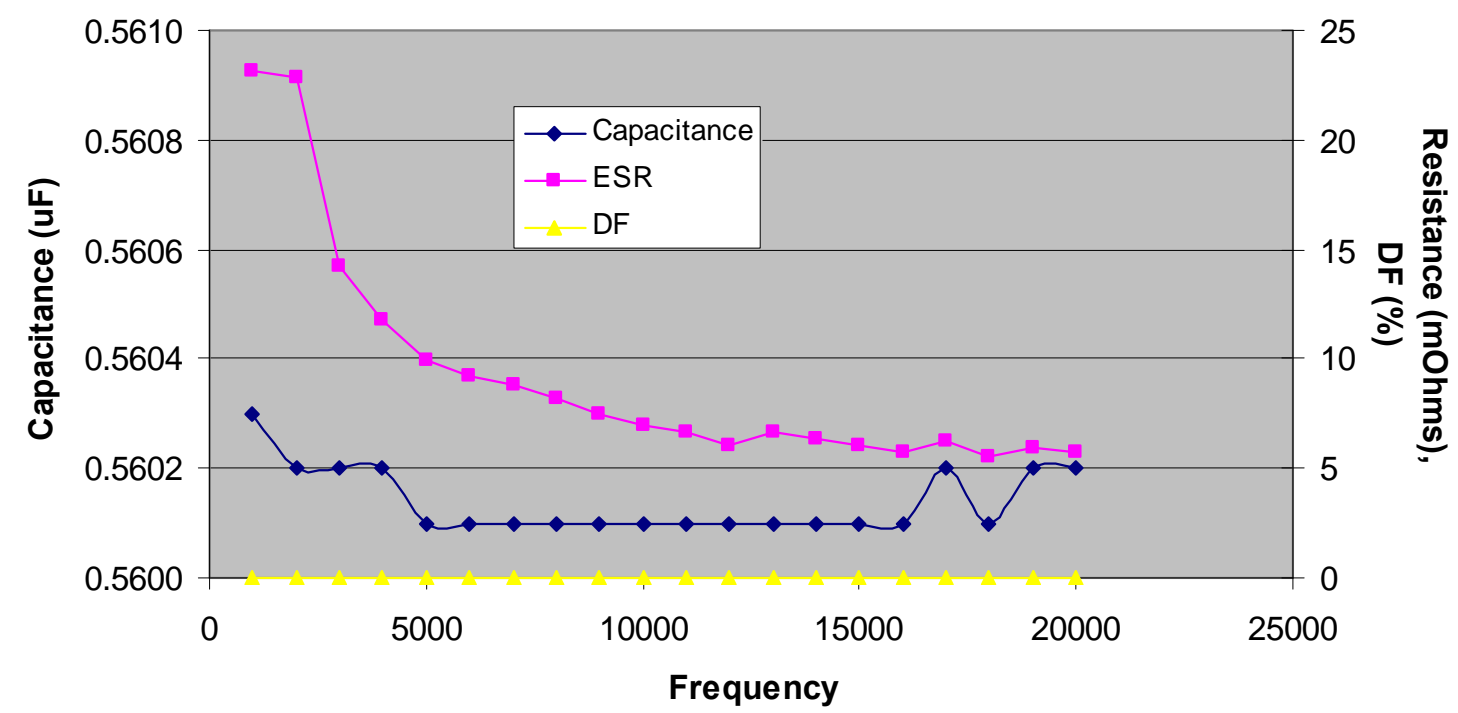

Fig. 2.50. Capacitance, ESR, and DF vs. frequency for 2010 Prius de-link $0.562 \mu$ F capacitor.

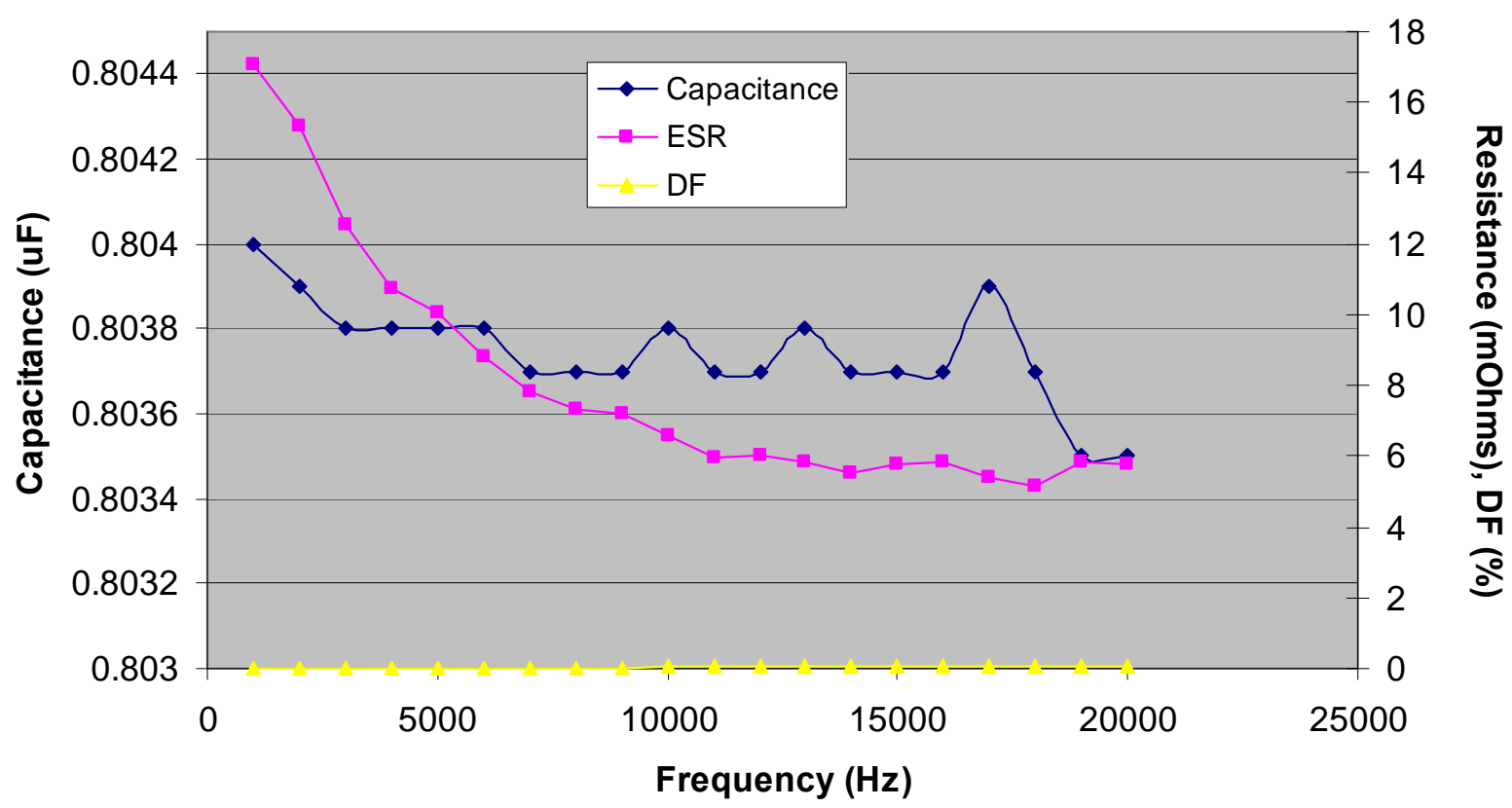

Fig. 2.51. Capacitance, ESR, and DF vs. frequency for 2010 Prius dc-link $0.8 \mu F$ capacitor.

\subsection{ECVT}

The 2010 Toyota Prius ECVT assembly, shown in Fig. 2.52, is comprised of motor, generator, and gear box subassemblies. The overall functionality of the 2010 Prius ECVT, shown in Fig. 2.53, is similar to the Camry and 2004 Prius, yet there are significant differences between the subsystem components. All systems use the sun gear of a planetary gear that is connected to the generator with a hollow rotor shaft, through which a shaft connected to the ICE passes and connects to the planetary carrier. The ring of the 
planetary gear is connected directly to the motor output in the 2004 Prius, and to the motor through a high-speed reduction gear in the 2010 Prius and 2007 Camry. The 2010 Prius, 2004 Prius, and Camry planetary ring gears drive the differential output through a series of drive gears.

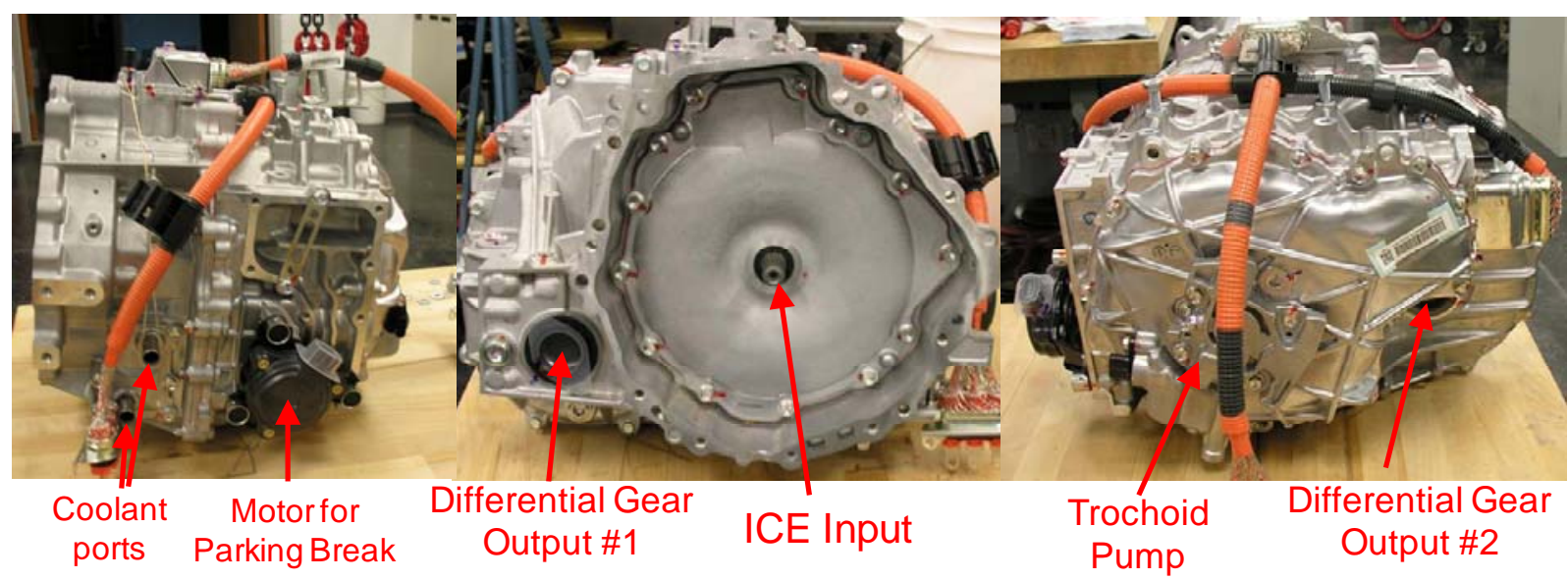

Fig. 2.52. 2010 Prius ECVT.

2004 Prius

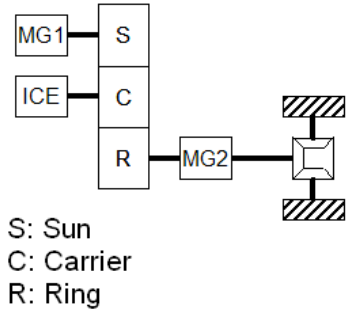

Camry/2010 Prius

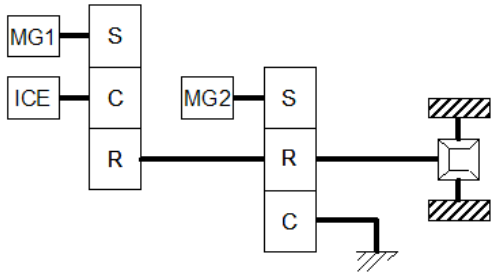

GS450h / LS600h

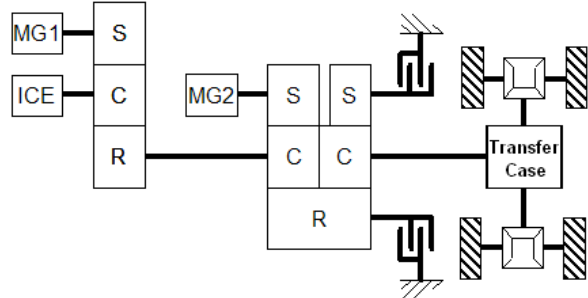

Fig. 2.53. Mechanical diagram of 2010 Prius, 2004 Prius, Camry, and LS 600h gear systems.

\subsubsection{ECVT Disassembly}

An overview of the ECVT sections is shown in Fig. 2.54. Shown in Fig. 2.55 is the section which mounts to the ICE. The generator is located between the bell housing (where the ICE attaches) and the gear section, with the light gray generator stator slightly visible through a small opening in the housing. The power-split planetary carrier with four small gears is visible, as the planetary ring gear has been removed. The differential gear and drive gear is also visible in this figure. The same view of the ECVT is shown in Fig. 2.56, yet with the planetary ring gear installed, as well as the speed reduction planetary carrier and sun gear. The carrier of the speed reduction planetary gear is fixed to the chassis with fingers which fit into groves shown in Fig. 2.57. In this figure, the motor section is shown with the speed-reduction planetary sun gear attached to the motor output shaft. Part of the parking brake mechanism is noticeable in the lower-right portion of this image, and the remainder of the mechanism extends to eventually engage with large notches located on the ring-gear unit. The brake is activated through a cycloidal gear which is driven by a 12-8 switched reluctance motor with a black housing (visible in Fig. 2.54). 


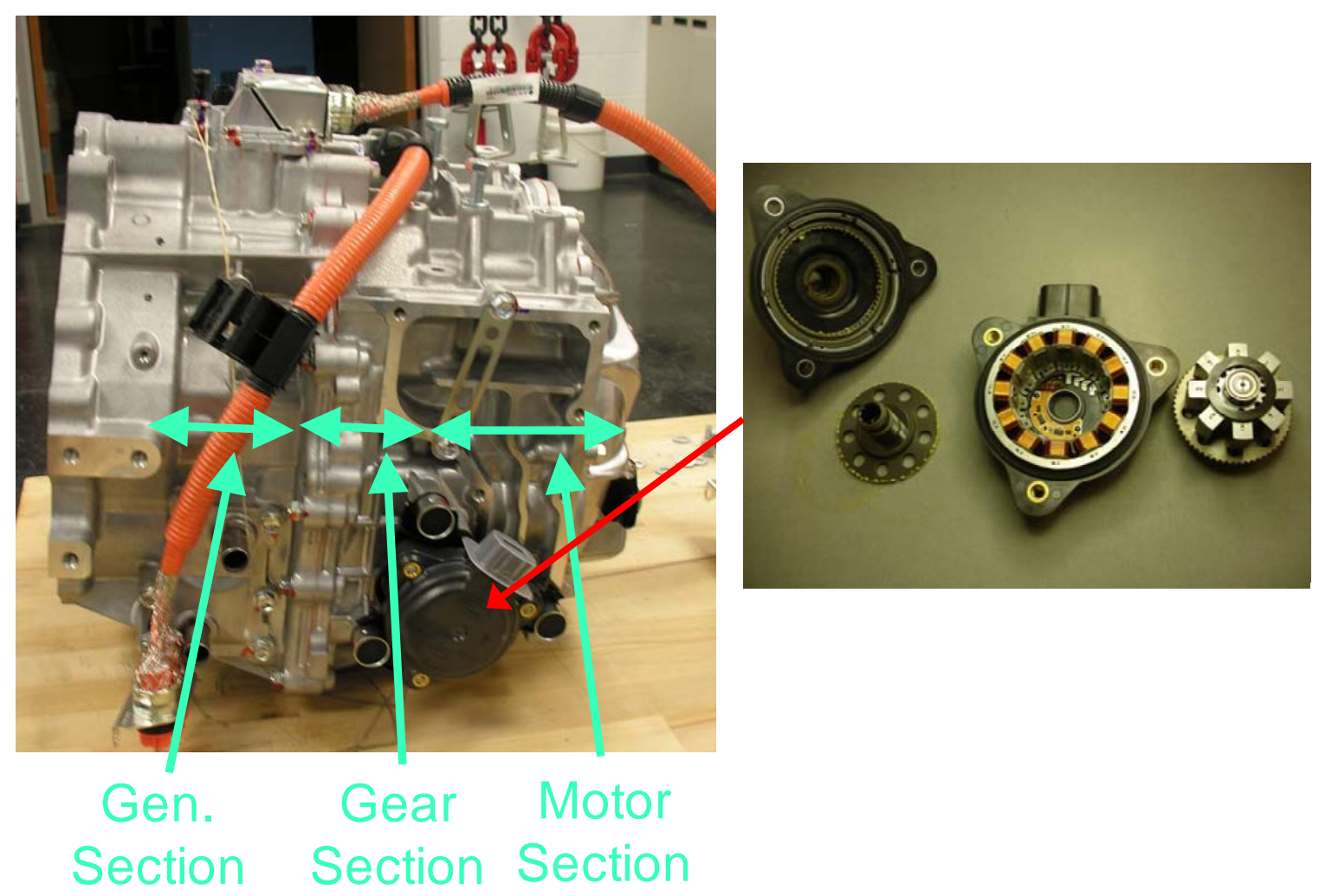

Fig. 2.54. Sections of the 2010 Prius ECVT.

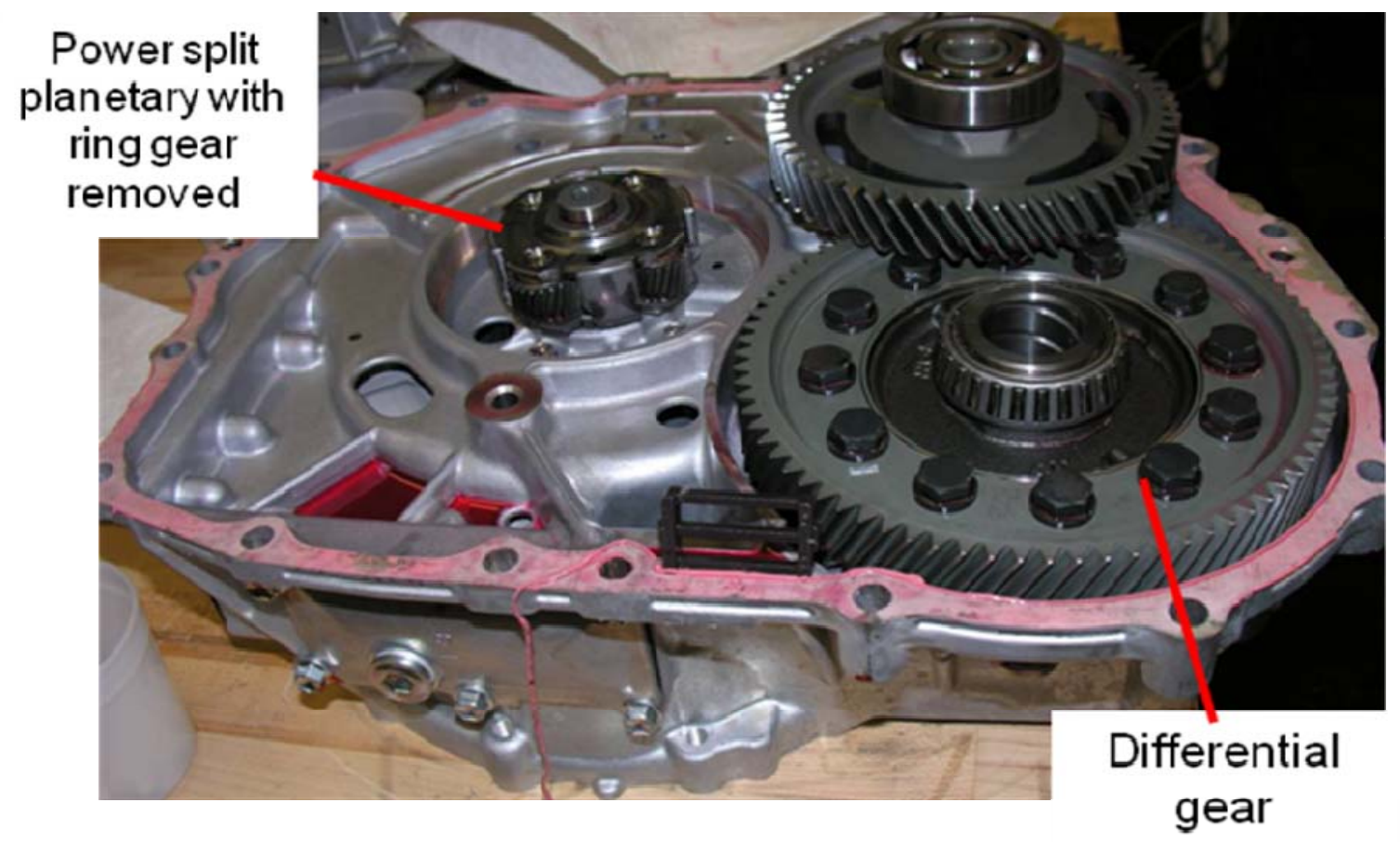

Fig. 2.55. Generator and gear section of ECVT. 


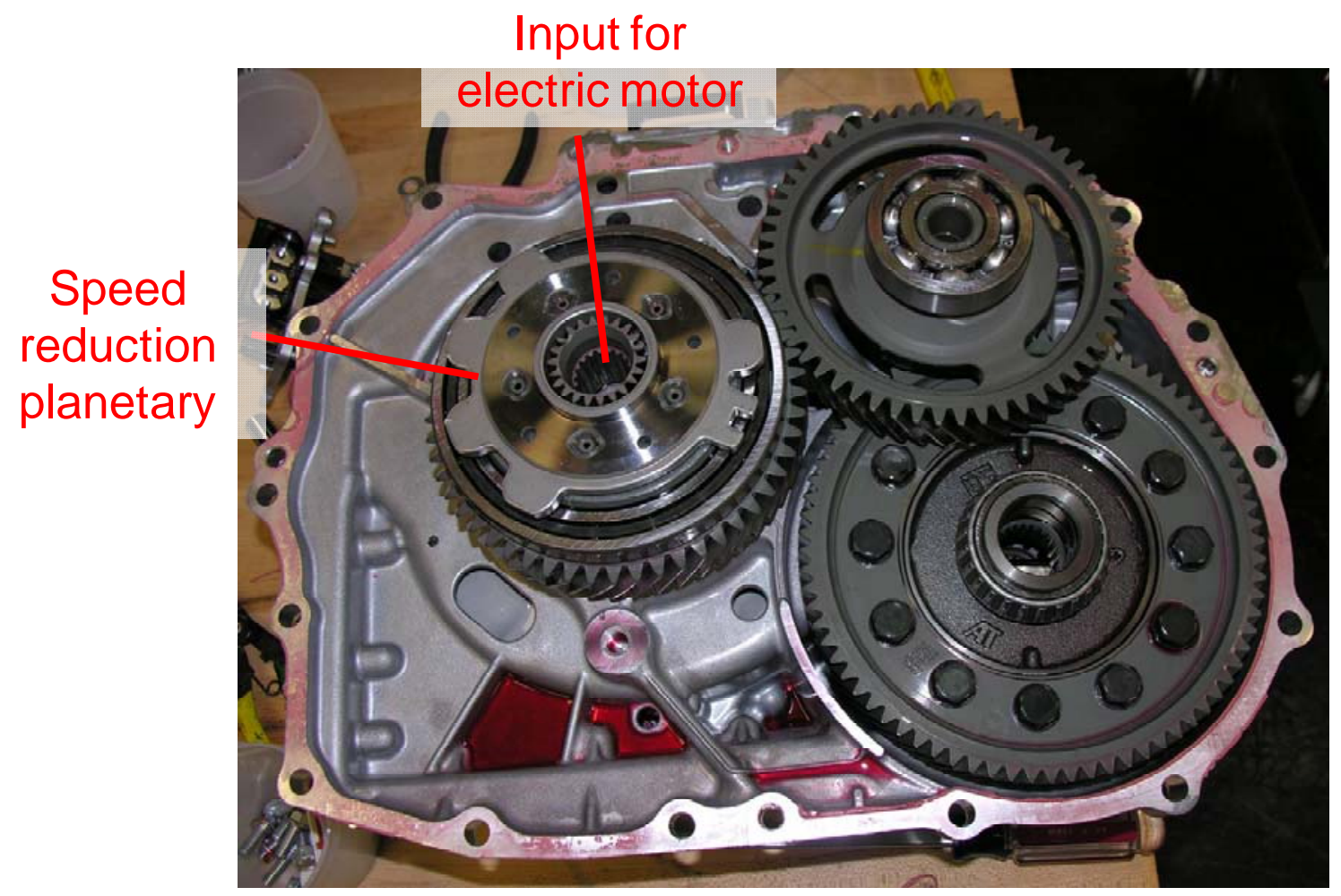

Fig. 2.56. Generator and gear section of ECVT with ring gear and speed reduction planetary shown.

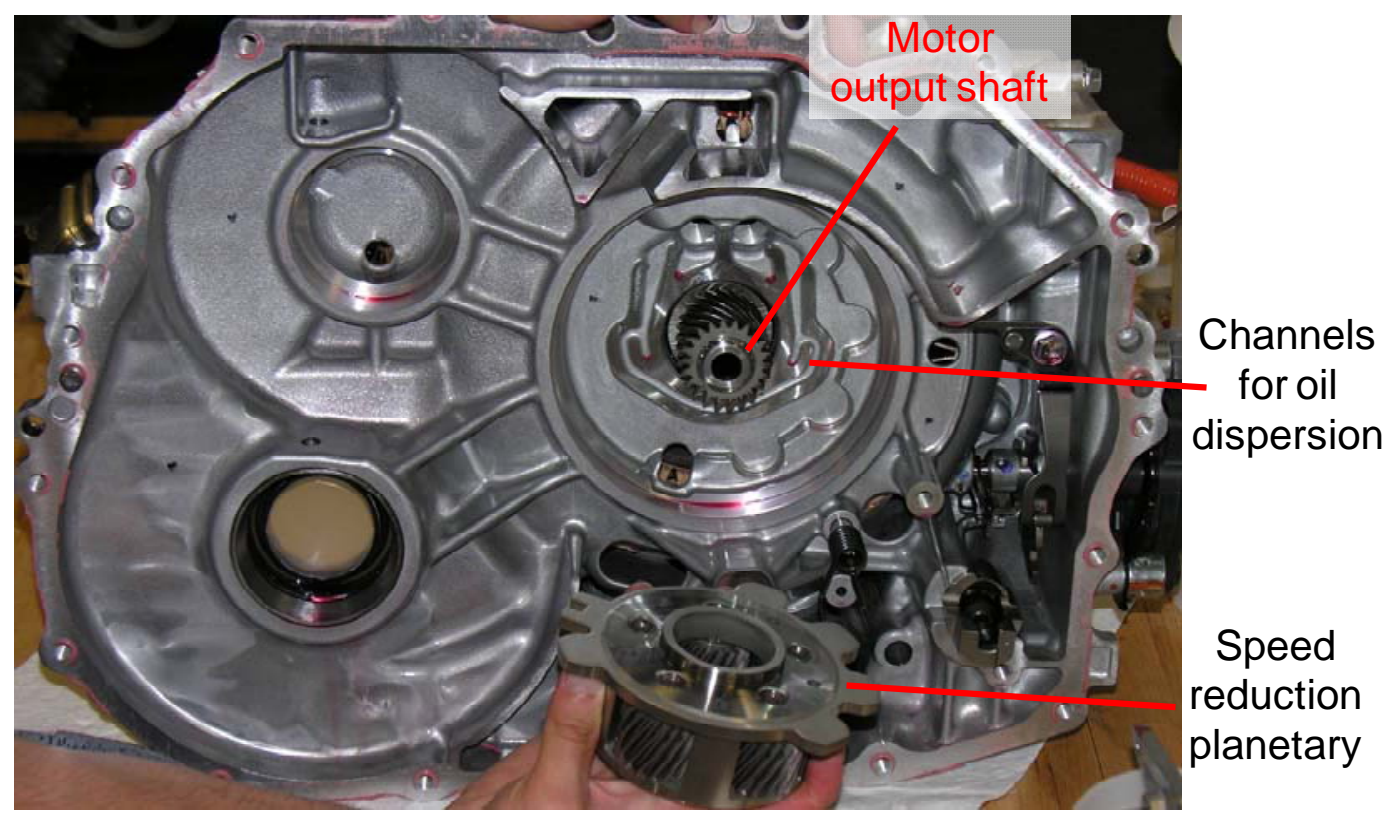

Fig. 2.57. Motor and gear section with speed reduction planetary sun and carrier shown.

A comparison of the 2010 Prius, 2007 Camry, and 2004 Prius ECVT gear arrangements is given in Fig. 2.58. The number of teeth on each gear is noted in black text on a white background. The 2004 Prius design has a chain coupling between the power split planetary ring and the counter drive gear, whereas the planetary ring and counter drive gears mesh directly within the 2010 Prius and 2007 Camry 
transaxle. Additionally, the 2010 Prius and 2007 Camry transaxle has only three separate axes about which gear systems rotate, compared to four axes in the 2004 Prius transaxle. The number of teeth on the planetary gear components does not differ between the three designs, yet the number of teeth on the outside perimeter of the ring gear does vary between designs. The total gear ratio from the 2010 Prius power split planetary ring to the differential output is $(77 / 24) \times(55 / 54)=3.27$. The equivalent gear ratio for the Camry is $(80 / 23) \times(55 / 54)=3.542$ and the 2004 Prius equivalent is $(75 / 26) \times(44 / 30) \times(35 / 36)=$ 4.113. A view of the 2010 Prius and 2007 Camry power-split planetary and speed reduction planetary is given in Fig. 2.59. The number of teeth on the 2010 Prius speed-reduction planetary sun gear is 22 versus 23 for the Camry and the number of teeth on the speed reduction planetary ring gear is 58 and 57 for the 2010 Prius and Camry, respectively. Both the 2010 Prius and Camry have 18 teeth on the speedreduction planetary planet gears, giving a total speed reduction ratio of 2.636 and 2.478 , respectively. The power split planetary system in all of the systems includes four planet gears, and the speed reduction planetary gear systems include five planet gears in the 2010 Prius and Camry. These findings are summarized in Table 2.6.
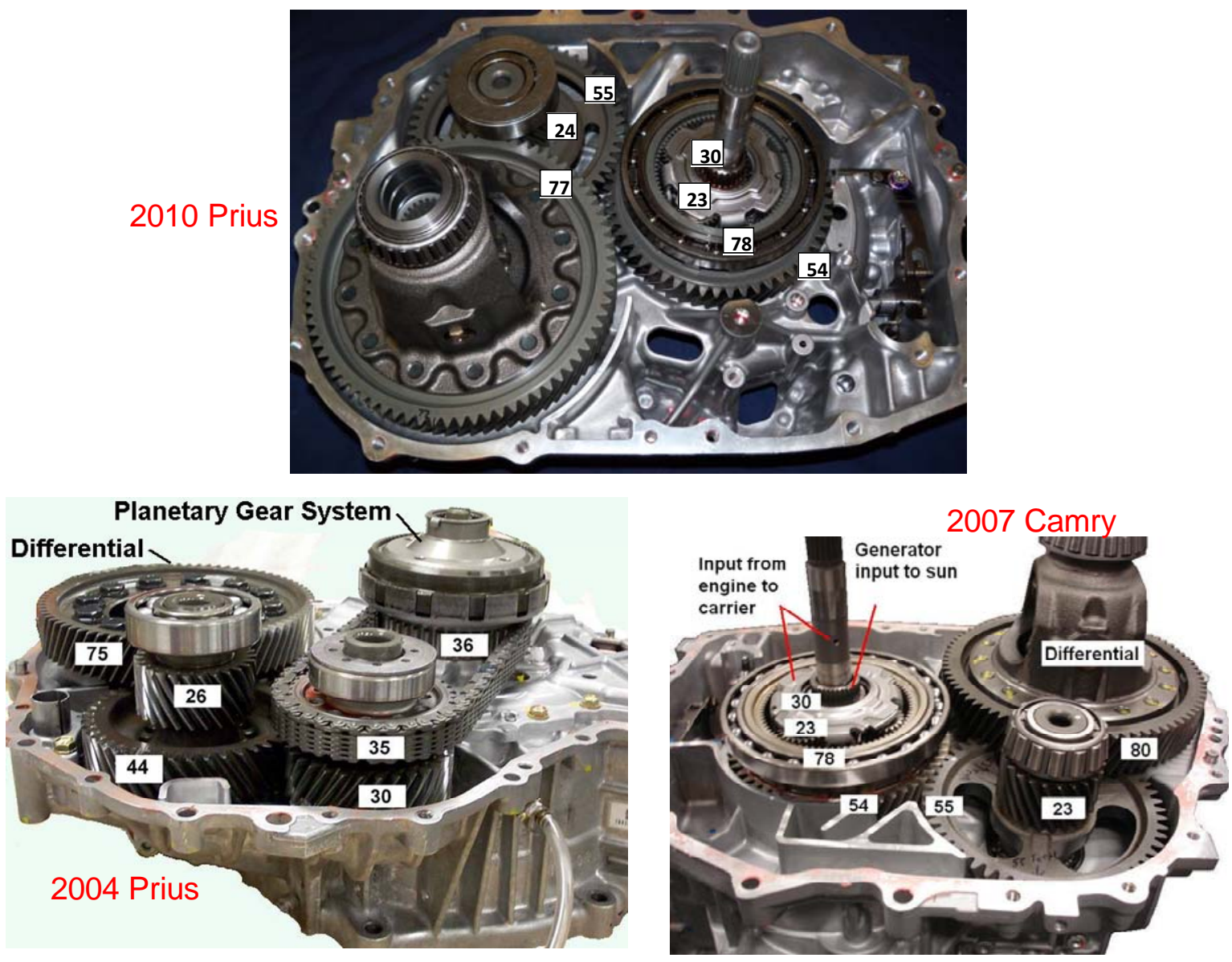

Fig. 2.58. 2010 Prius, 2004 Prius, and 2007 Camry gear teeth. 

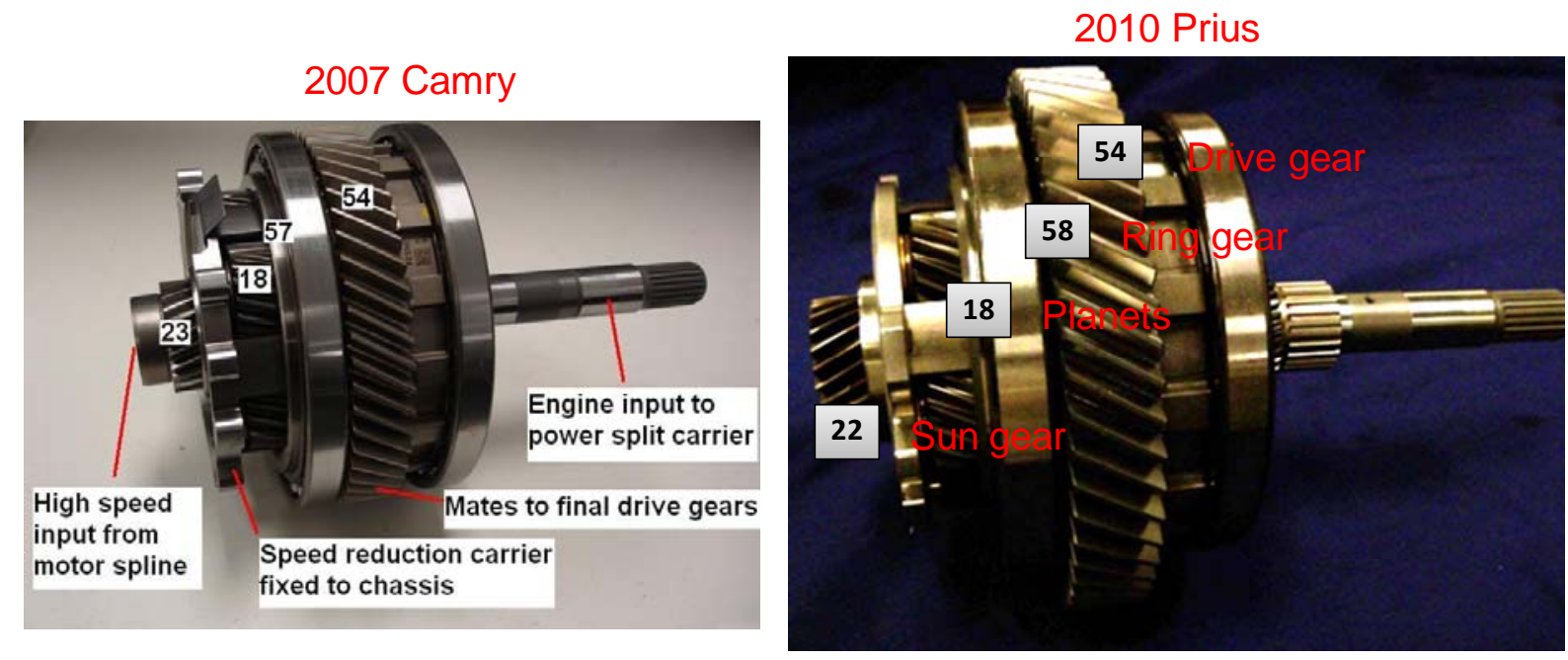

Fig. 2.59. 2007 Camry and 2010 Prius power-split planetary and speed reduction planetary.

Table 2.6. Comparison of gear teeth on 2007 Camry vs. 2010 Prius gears

\begin{tabular}{|c|c|c|}
\hline \multirow{3}{*}{$\begin{array}{l}\text { Power Split } \\
\text { Planetary } \\
\text { Gear Unit }\end{array}$} & The No. of Ring Gear Teeth & 78 vs. 78 \\
\hline & The No. of Pinion Gear Teeth & 23 vs. 23 \\
\hline & The No. of Sun Gear Teeth & 30 vs. 30 \\
\hline \multirow{3}{*}{$\begin{array}{l}\text { Motor Speed } \\
\text { Reduction } \\
\text { Planetary Gear Unit }\end{array}$} & The No. of Ring Gear Teeth & 57 vs. 58 \\
\hline & The No. of Pinion Gear Teeth & 18 vs.18 \\
\hline & The No. of Sun Gear Teeth & 23 vs. 22 \\
\hline \multirow{2}{*}{$\begin{array}{l}\text { Counter } \\
\text { Gears }\end{array}$} & The No. of Drive Gear Teeth & 54 vs. 54 \\
\hline & The No. of Driven Gear Teeth & 55 vs. 55 \\
\hline \multirow{2}{*}{$\begin{array}{l}\text { Final } \\
\text { Gears }\end{array}$} & The No. of Drive Gear Teeth & 23 vs. 24 \\
\hline & The No. of Driven Gear Teeth & 80 vs. 77 \\
\hline Total Deceleration Ratio & & 3.542 vs. 3.268 \\
\hline & & \\
\hline
\end{tabular}

\subsubsection{Motor and Generator Design Assessments}

The primary drive motor of the 2010 Prius is shown in Fig. 2.60. A comparison of the motor conductors used to carry energy between the PCU and the ECVT is provided in Fig. 2.61. Both the motor and generator have three conductors with lengths of about 36 inches 27 inches, respectively. A penny is situated next to the conductors to portray the minute size of the conductors. The conductor size has decreased significantly from the 2004 to the 2010 Prius (motor and generator are the same), the result of increased voltage and speed with only a slightly higher power rating. The 2010 Prius conductors contain 50 unbundled, $0.45 \mathrm{~mm}$ diameter wires, and in all, is approximately equivalent to an 8 American wire gauge (AWG) wire. The 2004 Prius and Camry conductors contain 19 bundles of 9-0.32 mm diameter wires (171 total), whereas the LS 600h contains 124 unbundled, $0.45 \mathrm{~mm}$ diameter wires. 


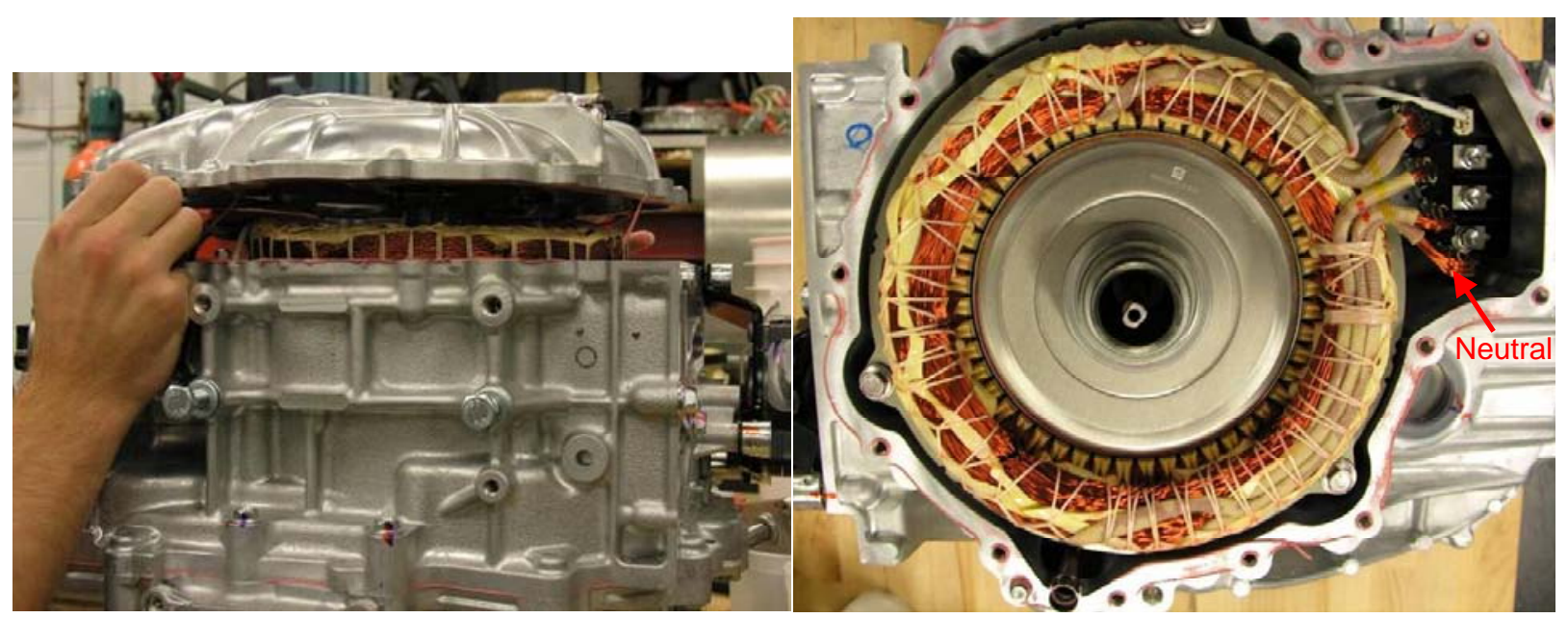

Fig. 2.60. 2010 Prius Motor stator.

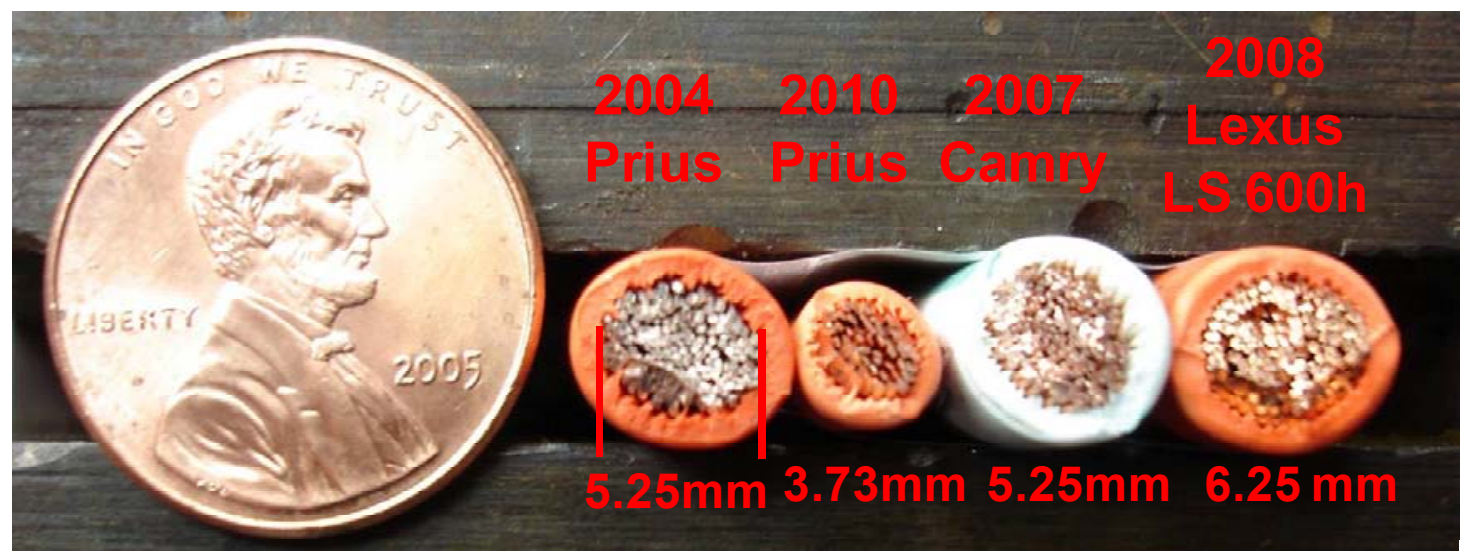

Fig. 2.61. Comparison of motor conductors between PCU and ECVT.

After the external motor conductors reach the ECVT, a feed-through terminal (visible in Fig. 2.60) is used to secure the cable-harness (visible in Fig. 2.54). The three-phase motor leads connect to the other side (not visible) of the feed-through terminal. Each phase of the 2010 Prius motor stator windings consist of twelve - 20 AWG wires with 8 coils (poles) in series, with each coil having 11 turns. Each phase accounts for about $1.644 \mathrm{~kg}$ of copper, with a total of $4.93 \mathrm{~kg}$ of copper.

One of the most noticeable discrepancies between the 2010 Prius electric motor and previous Toyota designs is the design of the rotor shown in Figs. 2.62 and 2.63. Figure 2.62 shows the stator assembly without the rotor after it was removed from the ECVT. Three bolts secure the stator as they protrude through the outer circumference of the stator in a direction parallel to the rotor shaft.

While the 2010 Prius motor permanent magnets (PMs) are in a ' $\mathrm{V}$ ' shaped orientation, the image on the right in Fig. 2.63 indicates a presence of large openings in the rotor laminations. These openings certainly reduce the overall mass of the rotor and they also likely influence the torque profile. Additionally, the design may have reduced eddy current losses at the shaft, as the large voids deter flux transients from occurring in this area. Small notches (also observed in previous designs) are located on the outer radial surface of the rotor close to the magnets, near the small support bridges. This notch certainly influences the air-gap flux (and reluctance) and overall torque signature of the machine. An additional design 
feature of interest is the small inner diameter (ID) of the rotor lamination, and thus the outer diameter (OD) of the rotor shaft. Previous designs consist of a rotor shaft with a much larger $\mathrm{O}$, as is visible in the left image of Fig. 2.63. Stator laminations of the LS600h motor, 2010 Prius motor, and Camry motor have ODs of 7.88", 10.395", and 10.395", respectively. As the diameters of the 2010 Prius and Camry motor stators and rotors are identical, the stator core mass per unit stack length (without copper) of the 2010 Prius stator is slightly higher than that of the Camry; $11.06 / \mathrm{kg} / 2.0 "=5.53 \mathrm{~kg} /$ in versus $12.38 \mathrm{~kg} / 2.4 "=5.16 \mathrm{~kg} / \mathrm{in}$, respectively. However, the rotor mass per unit length of the 2010 Prius is slightly lower than that of the Camry; $6.7 \mathrm{~kg} / 2 "=3.35 \mathrm{~kg} / \mathrm{in}$ versus $9.03 \mathrm{~kg} / 2.4 "=3.76 \mathrm{~kg} / \mathrm{in}$.
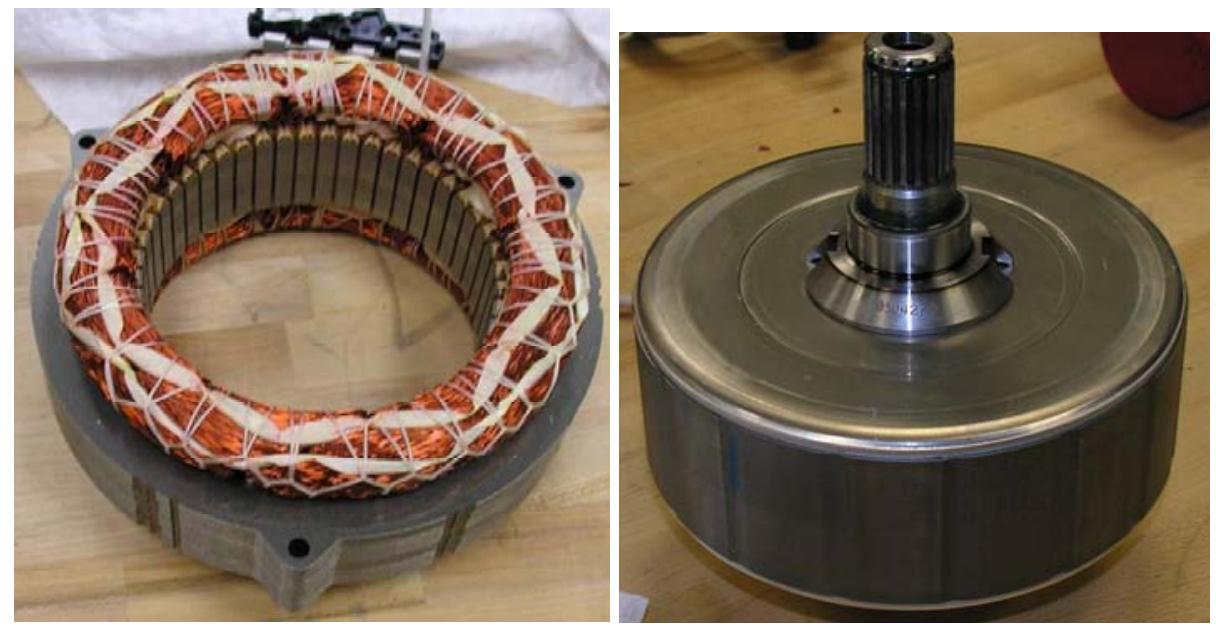

Fig. 2.62. 2010 Prius Motor stator (left) and rotor (right).
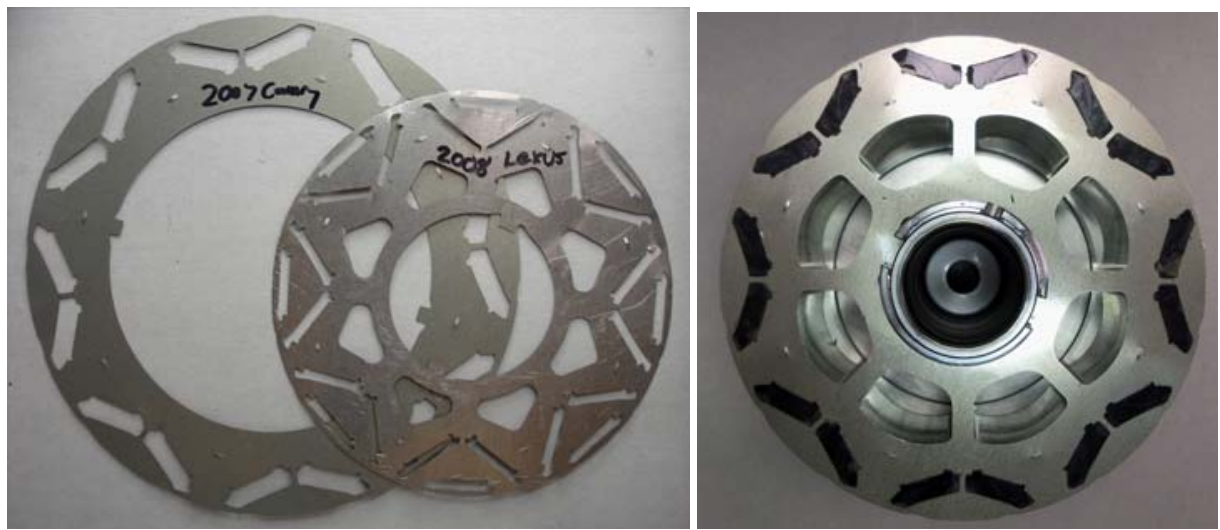

Fig. 2.63. Comparison of motor rotor laminations, Camry (left), LS 600h (middle), and 2010 Prius (right).

The entire motor mass is $22.69 \mathrm{~kg}$, with the stator and rotor weighing $16.0 \mathrm{~kg}$ and $6.7 \mathrm{~kg}$, respectively. This tally does not include the housing, heat exchanger, bearings, gears, etc. After the copper windings are removed, the remaining stator assembly weighs about $11 \mathrm{~kg}$. The 2010 Prius stator mass of $16 \mathrm{~kg}$ compares with the LS 600h, Camry, and 2004 Prius stator masses of 18.75, 18.0, and $25.9 \mathrm{~kg}$, respectively. A reduction in the usage of copper is noticed as the 2010 Prius motor contains only $4.93 \mathrm{~kg}$ (10.9 lbs) of copper, whereas the Camry and 2004 Prius motors contain $5.7 \mathrm{~kg}(12.6 \mathrm{lbs})$ and $6.8 \mathrm{~kg}$ (15.0 lbs) of copper, respectively. Note that the LS $600 \mathrm{~h}$ contains only $3.6 \mathrm{~kg}(8.0 \mathrm{lbs})$ of copper, but its elongated package shape differs greatly from the Camry and Prius packages. 
The 2010 Prius motor magnets weigh 48 grams and measure $49.3 \mathrm{~mm} \times 17.88 \mathrm{~mm} \times 7.16 \mathrm{~mm}$ in comparison with 77 grams and dimensions of $83.1 \mathrm{~mm} \times 18.9 \mathrm{~mm} \times 6.5 \mathrm{~mm}$ for the 2004 Prius. With only one magnet along the axial length of the motor rotor, 16 magnets contribute to a total of $0.768 \mathrm{~kg}$ (1.7 lbs). The LS 600h, Camry, and 2004 Prius have total magnet masses of $1.349 \mathrm{~kg}(3.0 \mathrm{lbs}), 0.928 \mathrm{~kg}$ (2.0 lbs), and $1.232 \mathrm{~kg}(2.7 \mathrm{lbs})$.

Various design characteristics of the 2010 Prius, LS 600h, Camry, and 2004 Prius motors are provided in Table 2.7. Results from the packaging assessments were used in combination with findings from the experimental evaluation to determine the SP and PD of the 2010 Prius and a comparison is provided in Table 2.8. Details regarding the power rating are provided in Section 3.4. There are substantial improvements of PD and SP over the 2004 Prius, and the values are similar to the 2007 Camry.

The 2010 Prius generator stator and rotor is shown in Fig. 2.64. It is apparent that the generator stator is significantly different from the Camry and 2004 Prius designs. The generator has concentrated and potted windings with only with 12 stator teeth, as shown in Fig. 2.65, compared with 48 teeth for the designs mentioned above. Also shown in Fig. 2.65 are cross-sections of the generator stator and rotor. The generator has 4 small magnets with dimensions of $0.691 \mathrm{~mm} \times 21.06 \mathrm{~mm} \times 6.35 \mathrm{~mm}$ stacked and glued to form a $27.64 \mathrm{~mm}$ (1.08") long magnet. With each magnet weighing 28 grams (four 7 gram magnets), the total magnet mass for the 2010 Prius generator is 448 grams. The mass of the 2010 Prius generator rotor and stator is $3.93 \mathrm{~kg}$ and $8.58 \mathrm{~kg}$, respectively, with a total mass of $12.5 \mathrm{~kg}$. These masses compare closely with that of the 2004 Prius generator. This does not include the housing, heat exchanger, bearings, gears, etc.

The generator is enclosed with a gray potting compound. A sample of the compound was removed for quantitative analysis, and an SEM image of the sample is shown in Fig. 2.66. The figure indicates that an Al-O matrix is loaded with particulates, and the composition (by mass) of each component is labeled beside the SEM image. A summary of generator design characteristics is provided in Table 2.9.
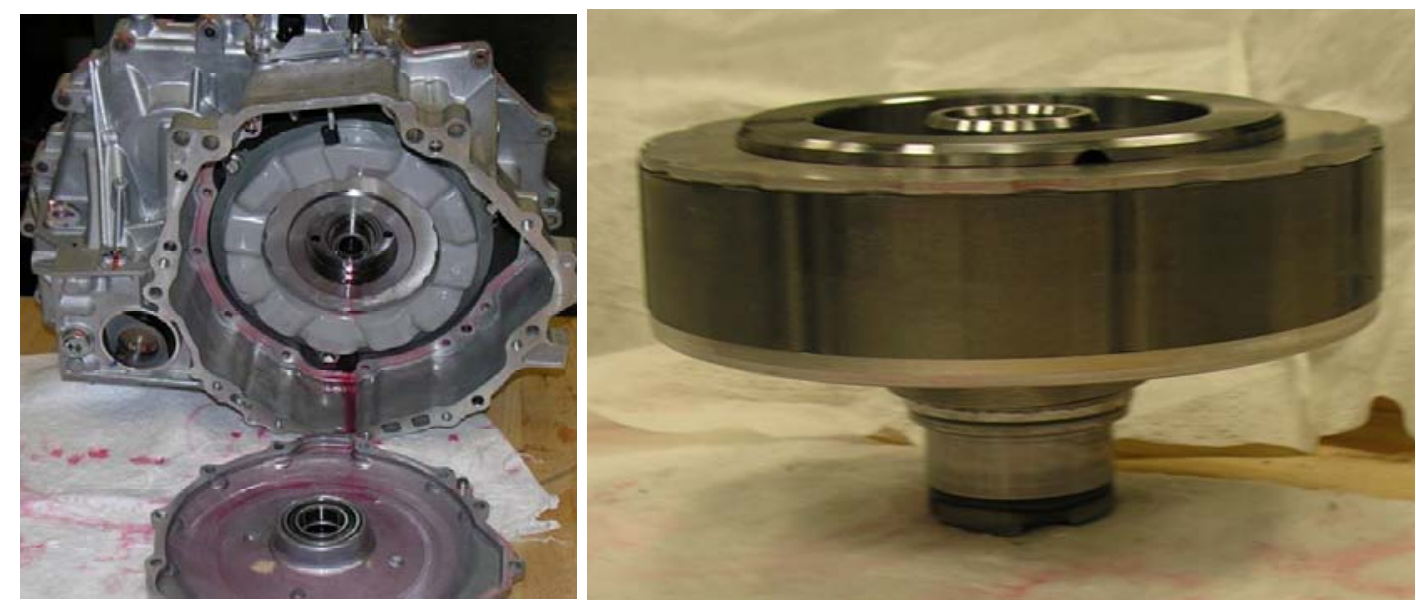

Fig. 2.64. 2010 Prius generator stator and rotor. 
Table 2.7. 2010 Prius, LS600h, Camry, and 2004 Prius motor design characteristics

\begin{tabular}{|c|c|c|c|c|c|}
\hline Parameter & 2010 Prius & LS 600h & Camry & 2004 Prius & Comments \\
\hline \multicolumn{6}{|l|}{ Lamination Dimensions } \\
\hline Stator OD, cm & 26.4 & 20.0 & 26.4 & 26.9 & \\
\hline Stator ID, cm & 16.19 & 13.086 & 16.19 & 16.19 & \\
\hline Stator stack length, cm & 5.08 & 13.54 & 6.07 & 8.4 & \\
\hline Rotor OD, cm & 16.04 & 12.91 & 16.05 & 16.05 & \\
\hline $\begin{array}{l}\text { Rotor lamination ID, } \\
\mathrm{cm}\end{array}$ & 5.1 & 5.3 & 10.5 & 11.1 & \\
\hline Rotor stack length, cm & 5.0165 & 13.59 & 6.2 & 8.36 & \\
\hline Air gap, mm & 0.73 & 0.89 & 0.73025 & 0.73025 & \\
\hline $\begin{array}{l}\text { Lamination thickness, } \\
\mathrm{mm}\end{array}$ & 0.305 & 0.28 & 0.31 & 0.33 & \\
\hline \multicolumn{6}{|l|}{ Mass of Assemblies } \\
\hline Rotor mass, kg & 6.7 & 11.93 & 9.03 & 10.2 & Includes rotor shaft. \\
\hline Stator mass, $\mathrm{kg}$ & 15.99 & 18.75 & 18.0 & 25.9 & \\
\hline Stator core mass, kg & 10.36 & 15.15 & 12.38 & 19.05 & Laminations only. \\
\hline \multicolumn{6}{|l|}{ Stator Wiring } \\
\hline Number of stator slots & 48 & 48 & 48 & 48 & \\
\hline Stator turns per coil & 11 & 7 & 14 & 9 & \\
\hline $\begin{array}{l}\text { Parallel circuits per } \\
\text { phase }\end{array}$ & 0 & 2 legs & 2 legs & 0 & \\
\hline $\begin{array}{l}\text { Coils in series per } \\
\text { phase }\end{array}$ & 8 & 4 per leg & 4 per leg & 8 & \\
\hline $\begin{array}{l}\text { Number of wires in } \\
\text { parallel }\end{array}$ & 12 & 9 per leg & 9 per leg & 13 & 18 total per phase \\
\hline Wire size, AWG & 20 & $\begin{array}{c}\sim 0.032 " \equiv \\
20\end{array}$ & 20 & 19 & \\
\hline $\begin{array}{l}\text { Phase resistance at } \\
21^{\circ} \mathrm{C} \text {, ohms }\end{array}$ & 0.077 & 0.0225 & 0.023 & 0.069 & $\begin{array}{l}\text { Average of phase-to- } \\
\text { phase divided by two. }\end{array}$ \\
\hline $\begin{array}{l}\text { Total mass of stator } \\
\text { copper, kg }\end{array}$ & 4.93 & 3.59 & 5.6 & 6.8 & \\
\hline Slot depth, mm & 30.9 & 19.25 & 30.9 & 33.5 & \\
\hline Slot opening, $\mathrm{mm}$ & 1.88 & 1.88 & 1.88 & 1.93 & At air-gap \\
\hline \multicolumn{6}{|l|}{ Casing } \\
\hline Motor casing mass, $\mathrm{kg}$ & 14.1 & 14 & 14.67 & 8.9 & Resolver, pump, etc \\
\hline $\begin{array}{l}\text { Motor casing diameter, } \\
\mathrm{cm}\end{array}$ & 30.2 & 27.5 & 30.2 & 29.9 & \\
\hline $\begin{array}{l}\text { Motor casing axial } \\
\text { length, } \mathrm{cm}\end{array}$ & 16.1 & 27.9 & 17.0 & 20.5 & \\
\hline \multicolumn{6}{|c|}{ Magnets (neodymium iron boron [NdFeB]) } \\
\hline $\begin{array}{l}\text { Magnet dimensions, } \\
\mathrm{mm}\end{array}$ & $\begin{array}{c}49.3 \times 17.88 \times \\
7.16\end{array}$ & $\begin{array}{c}66.4 \times 18.7 \times 3 \\
.05\end{array}$ & $\begin{array}{c}60.6 \times 19.1 \times 6 \\
.6\end{array}$ & $\begin{array}{l}83.1 \times 18.9 \times 6 \\
5\end{array}$ & One magnet. \\
\hline Magnet volume, $\mathrm{cm}^{3}$ & 6.31 & 3.78 & 7.63 & 10.2 & One magnet. \\
\hline Magnet mass, grams & 48 & 28.1 & 58 & 77 & One magnet. \\
\hline $\begin{array}{l}\text { Total mass of magnets, } \\
\mathrm{kg}\end{array}$ & 0.768 & 1.349 & 0.928 & 1.232 & $\begin{array}{l}\text { Entire magnet mass in } \\
\text { rotor. }\end{array}$ \\
\hline
\end{tabular}


Table 2.8. SP and PD estimates for HEV motors

\begin{tabular}{|l|ccc|c|}
\hline \multicolumn{1}{|c|}{ Parameter } & 2010 Prius & LS 600h & Camry & 2004 Prius \\
\hline $\begin{array}{l}\text { Motor peak SP (without } \\
\text { converter), } \mathrm{kW} / \mathrm{kg}\end{array}$ & $60 / 36.7=\mathbf{1 . 6}$ & $110 / 44.7=\mathbf{2 . 4 6}$ & $70 / 41.7=\mathbf{1 . 6 8}$ & $50 / 45.0=\mathbf{1 . 1 1}$ \\
\hline Motor peak PD, $\mathrm{kW} / \mathrm{L}$ & $60 / 12.5=\mathbf{4 . 8}$ & $110 / 16.7=\mathbf{6 . 5 9}$ & $70 / 14.8=\mathbf{4 . 7 3}$ & $50 / 15.4=\mathbf{3 . 2 5}$ \\
\hline
\end{tabular}

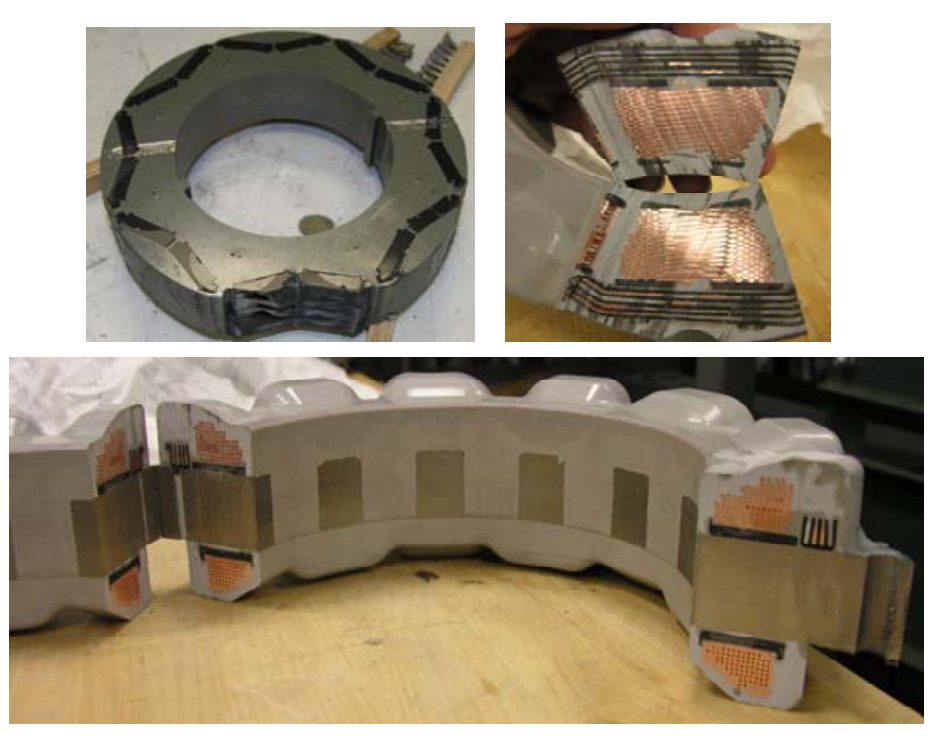

Fig. 2.65. Cross-sections of 2010 Prius generator.

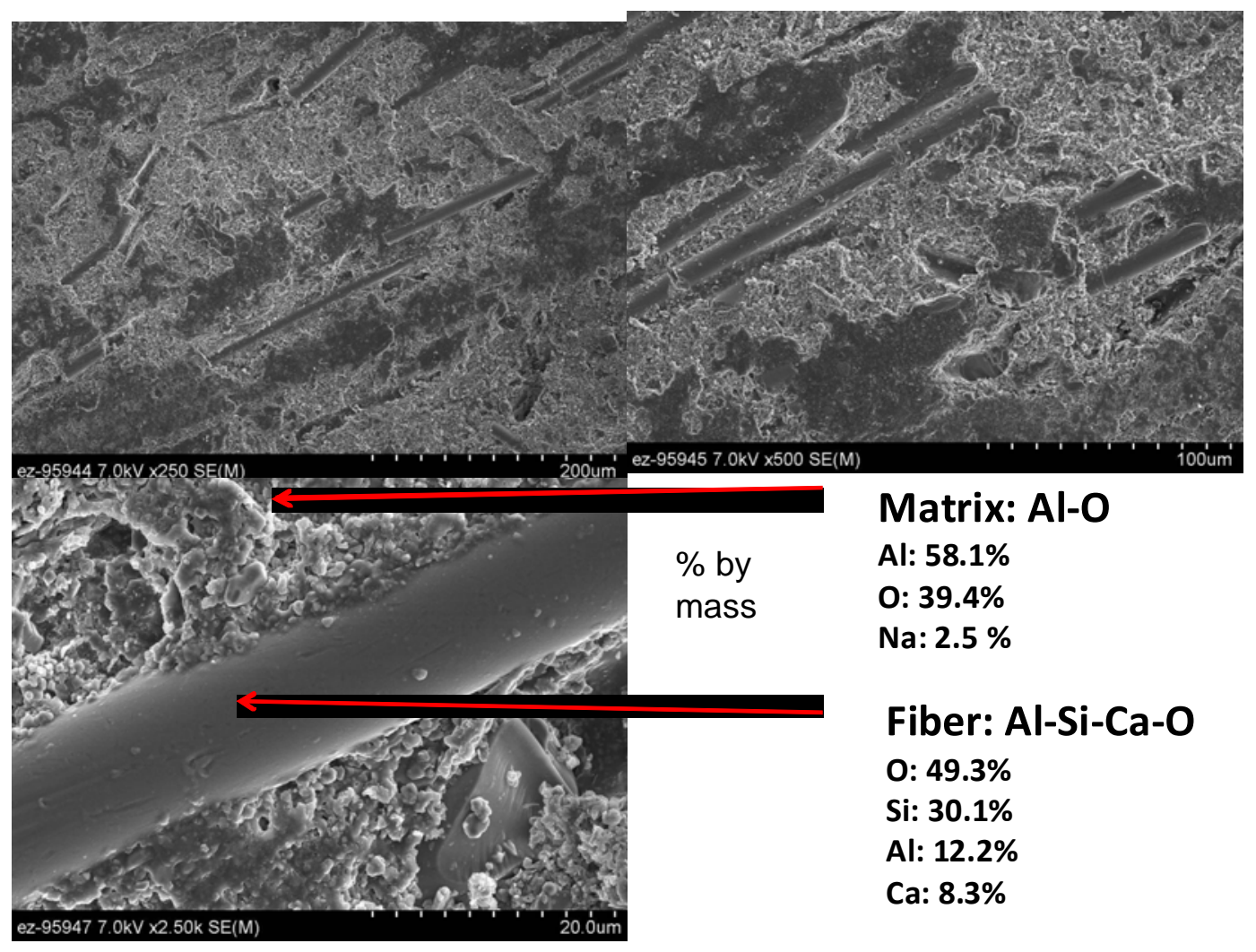

Fig. 2.66. SEM of 2010 Prius generator potting compound. 
Table 2.9. 2010 Prius, LS600h, Camry, and 2004 Prius generator design characteristics

\begin{tabular}{|c|c|c|c|c|c|}
\hline Parameter & 2010 Prius & LS 600h & Camry & 2004 Prius & Comments \\
\hline \multicolumn{6}{|l|}{ Lamination Dimensions } \\
\hline Stator OD, mm & 246.0 & 263.9 & Same as LS & 236.2 & \\
\hline Stator ID, mm & 152.7 & 162.1 & Same as LS & 142.6 & \\
\hline Stator stack length, cm & 2.7 & 7.07 & 3.58 & 3.05 & \\
\hline Rotor OD, mm & 151.3 & 160.5 & Same as LS & 140.72 & \\
\hline Rotor lamination ID, mm & 90.0 & $\sim 87.0$ & 95.63 & 85.09 & \\
\hline Lamination thickness, $\mathrm{mm}$ & 0.305 & $\sim 0.30$ & 0.31 & 0.33 & \\
\hline \multicolumn{6}{|l|}{ Mass of Assemblies } \\
\hline Rotor mass, kg & 3.93 & 9.70 & 5.19 & 4.01 & $\begin{array}{l}\text { Includes } \\
\text { rotor shaft }\end{array}$ \\
\hline Stator mass, $\mathrm{kg}$ & 8.58 & 20.50 & 12.09 & 9.16 & \\
\hline \multicolumn{6}{|l|}{ Stator Wiring } \\
\hline Number of stator slots & 12 & 48 & 48 & 48 & \\
\hline $\begin{array}{l}\text { Number of wires per } \\
\text { phase (number in parallel) }\end{array}$ & & $28(14)$ & $18(9)$ & 12 & \\
\hline Wire size, $A W G$ & $\sim 15$ & 20 & 20 & 20 & \\
\hline
\end{tabular}

\subsubsection{PM Characteristic Assessments}

Hysteresis tests were conducted on the 2010 Prius motor PMs using the Walker Scientific AMH-40 hysteresisgraph (shown in Fig. 2.67), which is capable of producing 30,000 Oersteds of magnetic field strength. A hysteresis test provides information regarding the remanent flux density and coercivity of a magnet and these tests are often conducted over a wide range of temperatures. The remanent flux density, $\mathrm{B}_{\mathrm{r}}$, is the remaining flux density created by the magnet with no external field applied. Or simply stated the remanent flux density represents the strength of the magnet. The remanent flux density decreases to some extent with increasing temperature. The coercivity of a magnet is defined to be the intensity of the magnetic field required to reduce the magnetization of the magnet to zero (i.e. demagnetize the magnet), and the coercivity of a magnet also decreases with increasing temperature. Coercivity is an especially important characteristic of PMs that are used in HEV applications, which often involve high temperature and high field weakening operation conditions. 


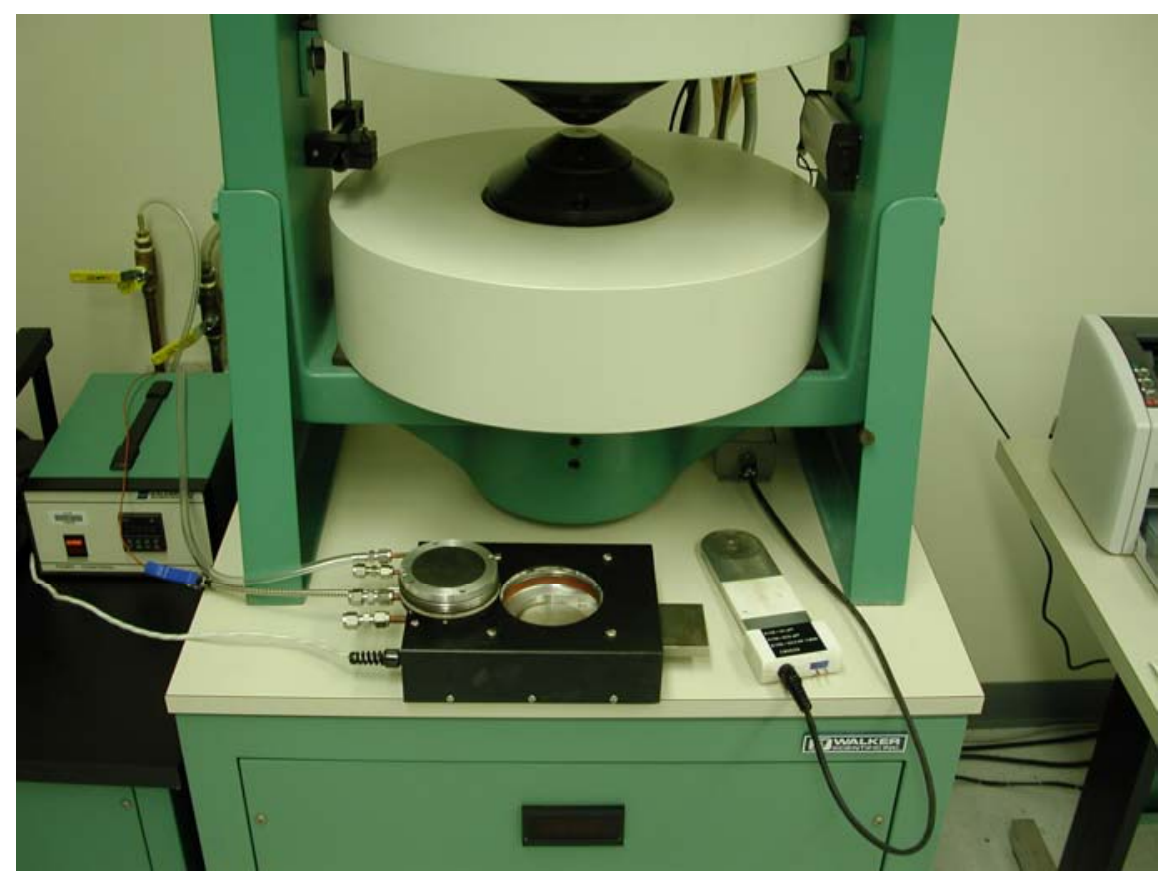

Fig. 2.67. Walker Scientific hysteresis graph.

During hysteresis tests, the magnet is subjected to positive and negative magnetic fields while the impact of the externally applied magnetic field on the magnet is observed. A graph from hysteresis tests conducted on a magnet from the 2010 Prius motor rotor at $114^{\circ} \mathrm{C}$ is shown in Fig. 2.68. Two curves are shown on the graph with the burgundy trace being the normal, or total magnetic flux density, and the turquoise trace representing the intrinsic magnetic flux density. The intrinsic flux density is the flux density solely created by the magnet, which is obtained by subtracting the applied flux density from the total flux density. The remanent flux density is the value at which both curves intersect with the y-axis, which is at $\mathrm{y}=12.20 \mathrm{kG}$ in this case. The value of coercivity is found at the point where the intrinsic curve crosses the $\mathrm{x}$-axis, which is $\mathrm{x}=14.36 \mathrm{kOe}$ in this case. A similar graph is provided in Fig. 2.69, with the hysteresis evaluation conducted at an ambient temperature of $215^{\circ} \mathrm{C}$. Notice that the curves are much closer to the origin when compared to Fig. 2.68. As the temperature increased from $114-215^{\circ} \mathrm{C}$, the remanent flux density and coercivity decreased from 12.20 to $10.51 \mathrm{kG}$ and 14.36 to $5.45 \mathrm{kOe}$, respectively. The drastic decrease of the coercivity indicates that the magnet is much more susceptible to demagnetization at high temperatures. 


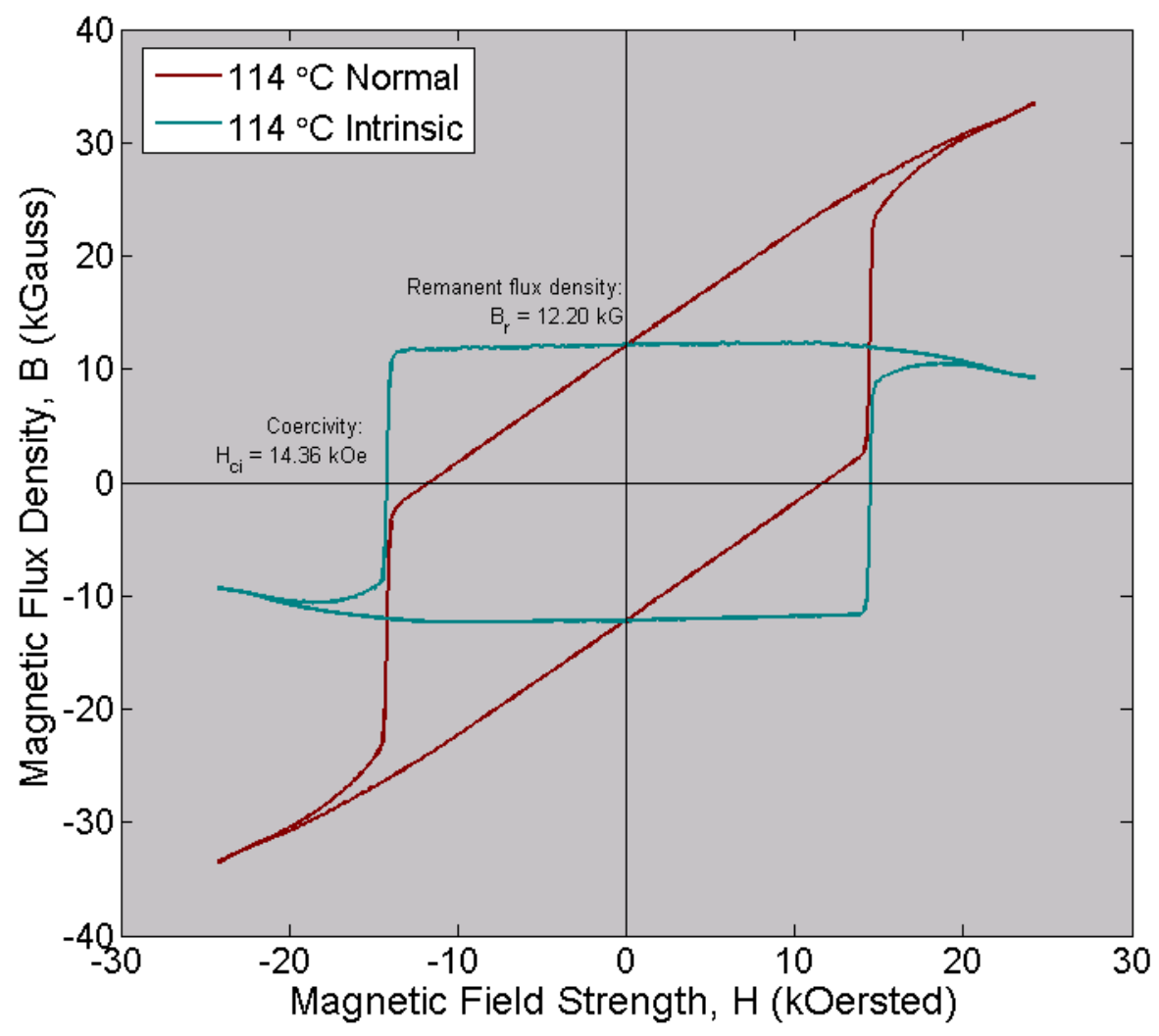

Fig. 2.68. Hysteresis graph for 2010 Prius motor magnet at $114^{\circ} \mathrm{C}$.

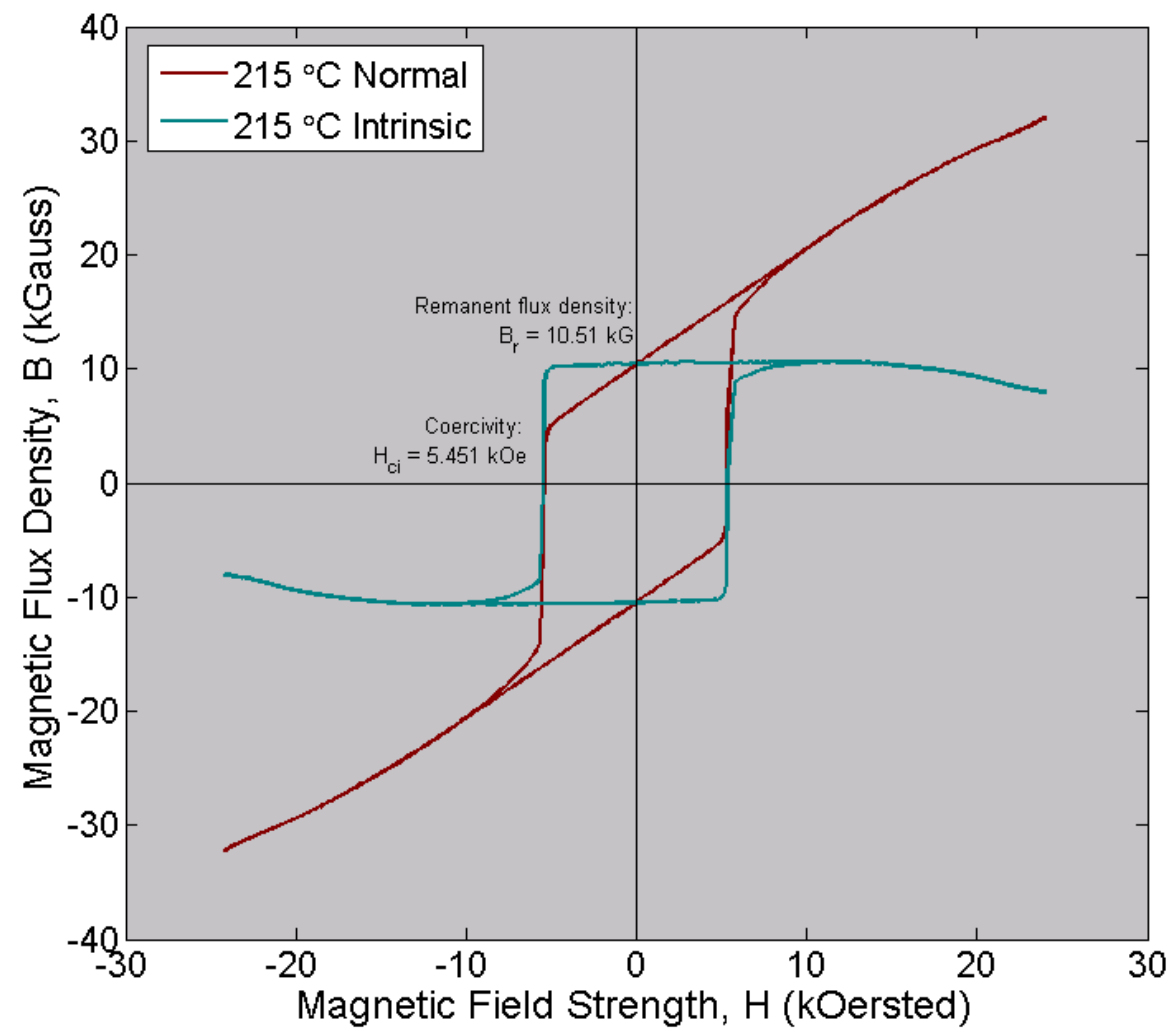

Fig. 2.69. Hysteresis graph for 2010 Prius motor magnet at $215^{\circ} \mathrm{C}$. 
Intrinsic curves from hysteresis tests conducted with a 2010 Prius motor magnet at various temperatures have been combined onto one plot in Fig. 2.70. These curves further exemplify the diminishing nature of the remanent flux density and coercivity with increasing temperature. A similar graph containing the intrinsic curves obtained from the 2004 Prius motor magnet hysteresis tests is provided in Fig. 2.71. Although it is difficult to make a detailed comparison using these figures, a general comparison indicates that the coercivity of the 2004 Prius magnet is higher than that of the 2010 Prius. Note that the unnatural flux density characteristics for high field strength magnitudes is a common phenomenon observed during hysteresisgraph measurements. The effect of the phenomenon does not impose significant impact upon the measurement of coercivity since the knee of the curve is well defined for normal and intrinsic traces.

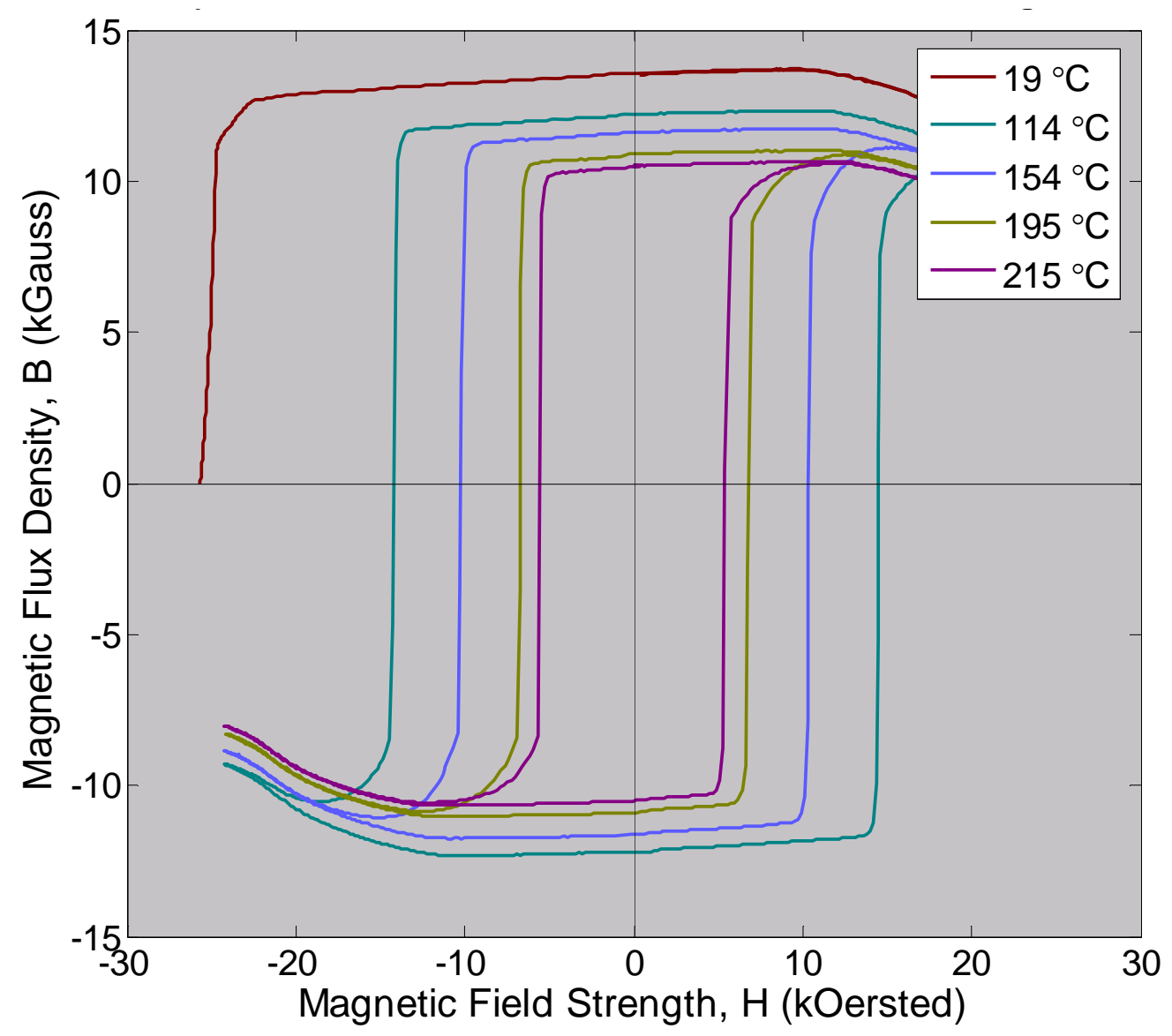

Fig. 2.70. Intrinsic hysteresis graphs for 2010 Prius motor magnet at various temperatures. 


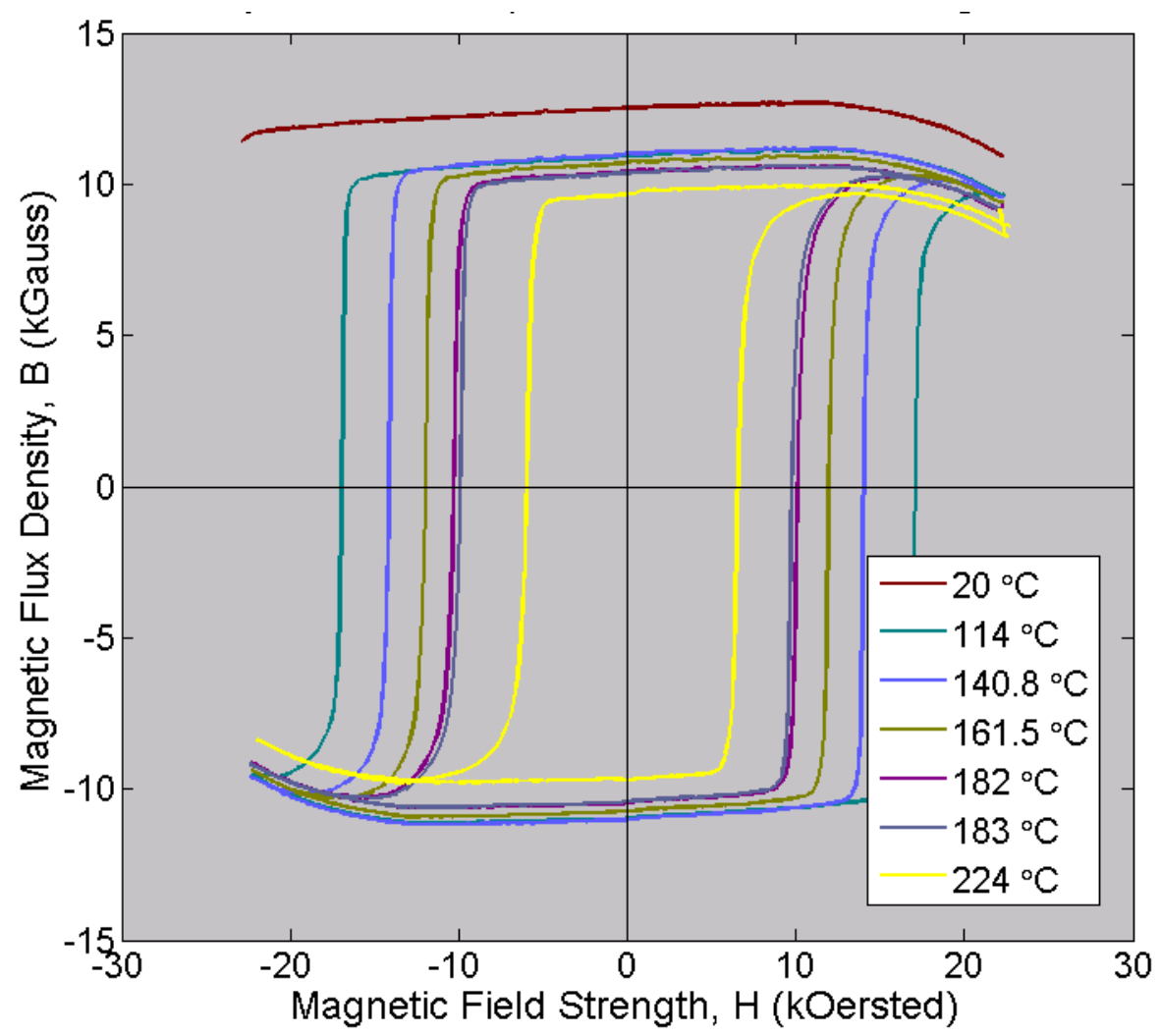

Fig. 2.71. Intrinsic hysteresis graphs for 2004 Prius motor magnet at various temperatures.

To provide a more straight forward comparison of the remanent flux density characteristics of the 2010 Prius motor and generator magnets, the LS 600h, Camry, and 2004 Prius motor magnets, the values were plotted versus temperature in Fig. 2.72. The strength of the 2010 Prius motor magnet is much higher than the others, and the LS 600h and Camry motor magnets are marginally higher than the strength of the 2004 Prius motor magnets, except for temperatures beyond about $200^{\circ} \mathrm{C}$. A similar plot is shown in Fig. 2.73 for the coercivity versus temperature relationship of the 2010 Prius motor and generator, the LS 600h, Camry, and 2004 Prius motor magnets. The coercivity of the 2010 Prius generator magnet is greater than all of the other Toyota and Lexus magnets analyzed thus far, yet the 2010 Prius motor magnet is quite low. Although the LS 600h and Camry motor magnets are slightly stronger than the 2010 Prius generator and 2004 Prius magnets, their coercivity is lower and are therefore more susceptible to demagnetization when subjected to high temperatures and/or high strength magnetic fields which oppose the direction of the magnetic field of the magnet. It is common to apply opposing magnetic fields to the magnets when operating at high speeds, wherein high back-electromotive force (back-emf) voltages are subdued to enable high speed operation within the voltage constraints. The 2010 Prius magnets are likely produced by Hitachi Metals under the brand, Neomax. 


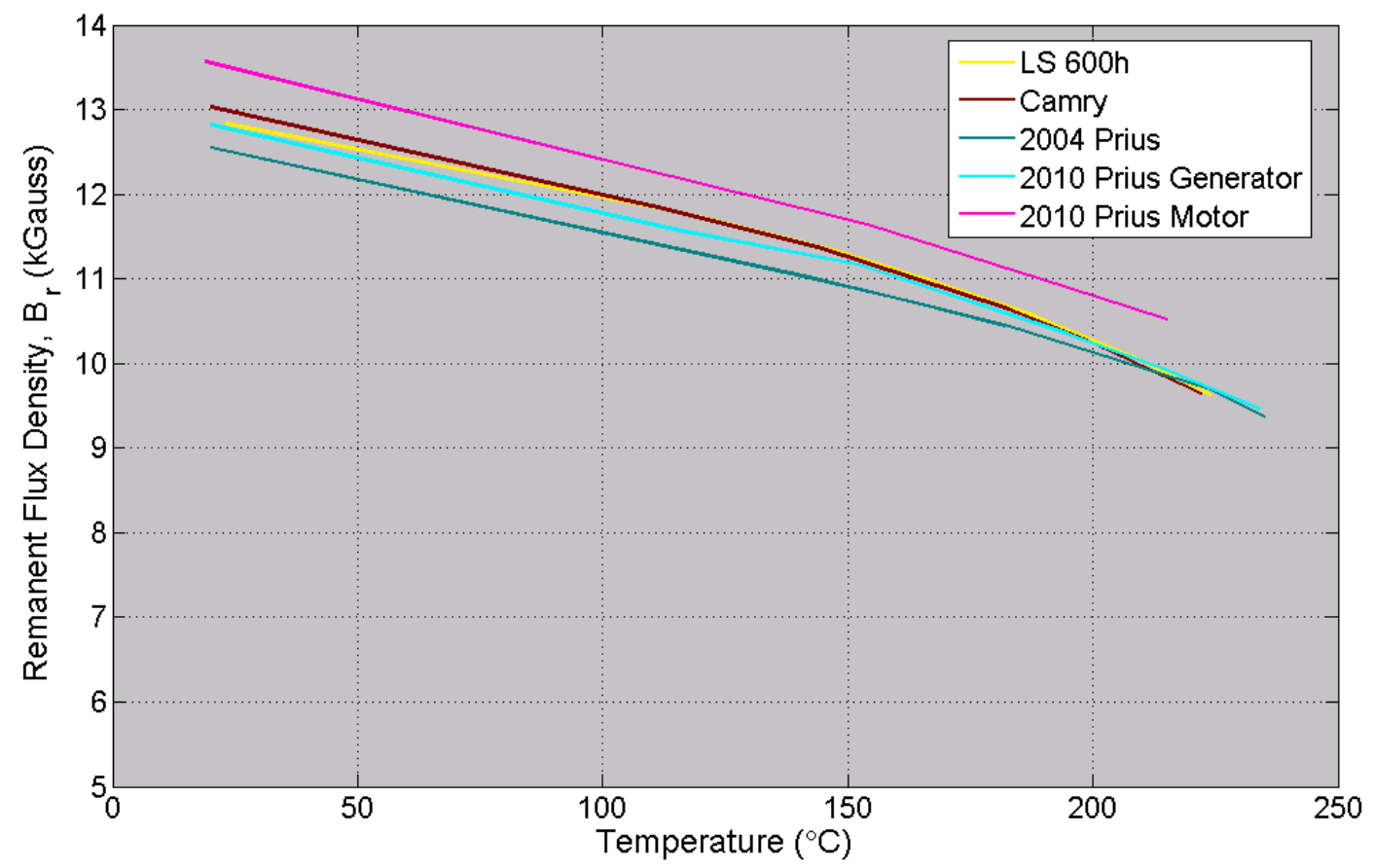

Fig. 2.72. Remanent flux density for LS 600h, Camry, 2004 Prius, and 2010 Prius motor magnet.

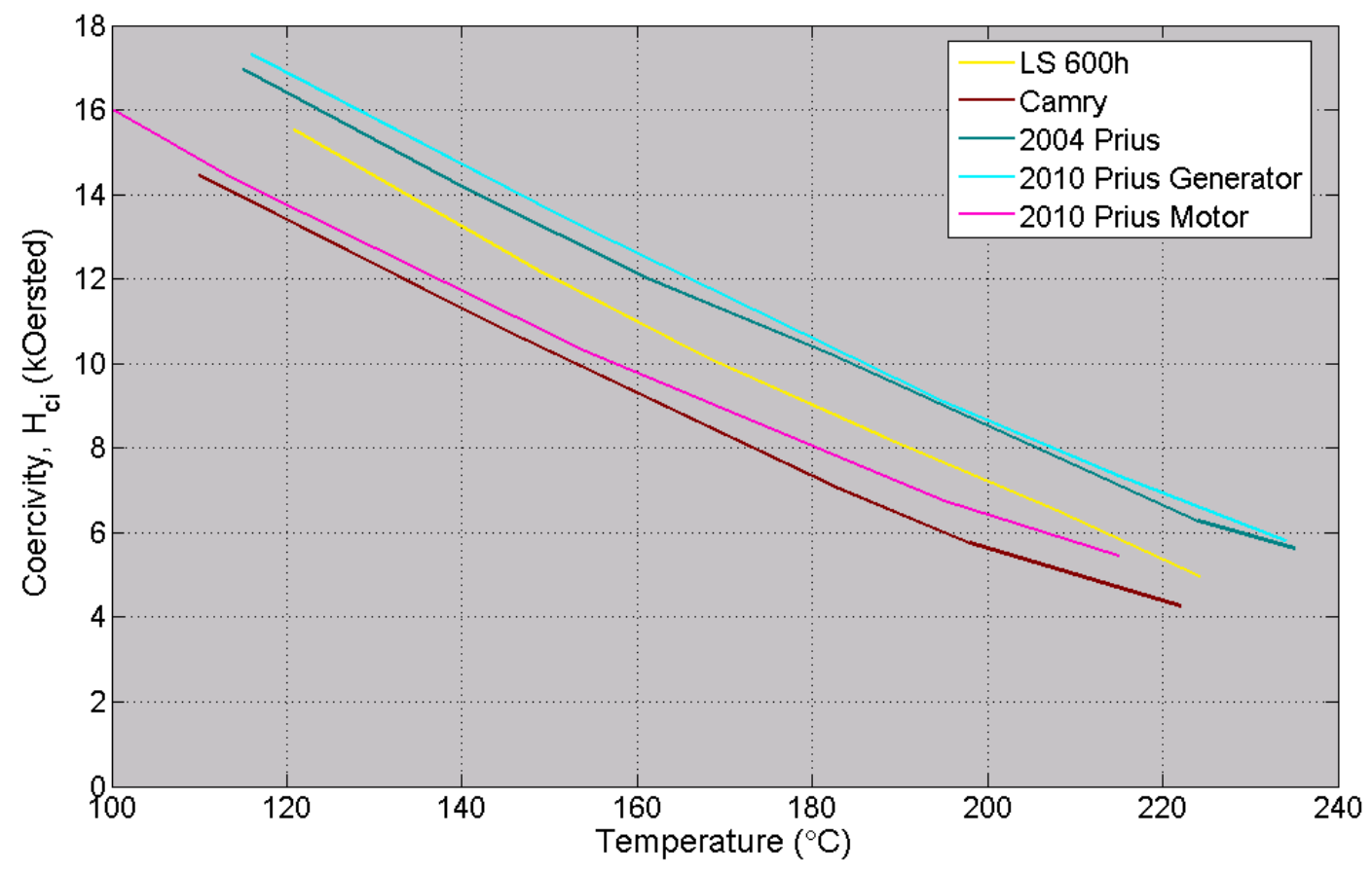

Fig. 2.73. Coercivity of LS 600h, Camry, 2004 Prius, and 2010 Prius motor magnet. 


\section{BENCHMARKING TESTS OF 2010 PRIUS PMSM AND PCU}

This section describes the 2010 Prius subassembly preparation and the back-emf, locked-rotor, performance/efficiency, and continuous load duration tests. With the exception of the back-emf and locked-rotor tests, which do not require inverter operation, each was performed using both the PMSM and inverter subsystems of the 2010 Prius.

\subsection{SUBSYSTEM PREPARATION FOR TESTING}

As design and packaging assessments of the ECVT and PCU were being conducted, preparation for testing of the subsystems commenced. These preparations include hardware design and fabrication, controller/interface development, and instrumentation for the DAQ. Although basic framework was available from previous benchmarking efforts, a significant portion of the efforts devoted to controller/interface and DAQ development required innovation.

\subsubsection{Hardware Preparation}

Since the 2010 Prius motor rotor shaft is not directly accessible, the customized shaft and face plate, shown in Fig. 3.1, was designed and fabricated to provide direct external access to the motor rotor. The shaft was designed such that the speed reduction gear system is removed, with the female splined end of the shaft (on the lower left) mating with the motor rotor. The other splined end (on the upper left) interfaces with the face-mount torque transducer. A sealed bearing provides support for the output to the torque transducer, where the gear section was originally attached, but is no longer used. Although this task is conceptually simple, many important design considerations must be made prior to the fabrication of this part. For example, the shaft must mate with bearing surfaces appropriately in order for stable support to be obtained. Additionally, various shoulders were strategically positioned in order to provide stability in response to forces in the axial direction. These aspects become of particular concern for high speed operations. Another important consideration is the impact of the removing the speed reduction gear components, in particular the shafts which are used to channel oil to bearings for lubrication. Therefore, oil flow tests were conducted before and after the modifications in order to ensure tests were conducted with these systems operating normally.
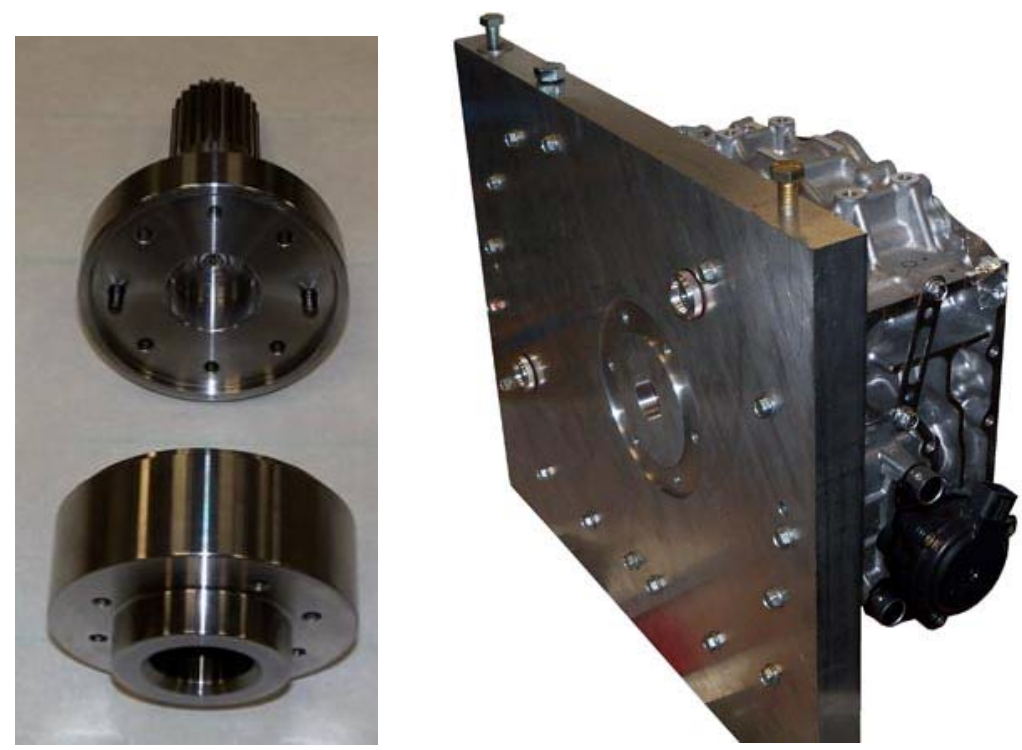

Fig. 3.1. Customized shaft (left) and plate (right). 
After the modifications and preparatory tests were executed, the ECVT assembly was installed in an ORNL test cell, shown in Fig. 3.2. A coolant regulator was used to regulate the coolant temperature, which first feeds the PCU and then the ECVT heat exchanger. A $400 \mathrm{hp}$ dynamometer was used to apply a mechanical load as torque and speed were measured with a torque transducer.

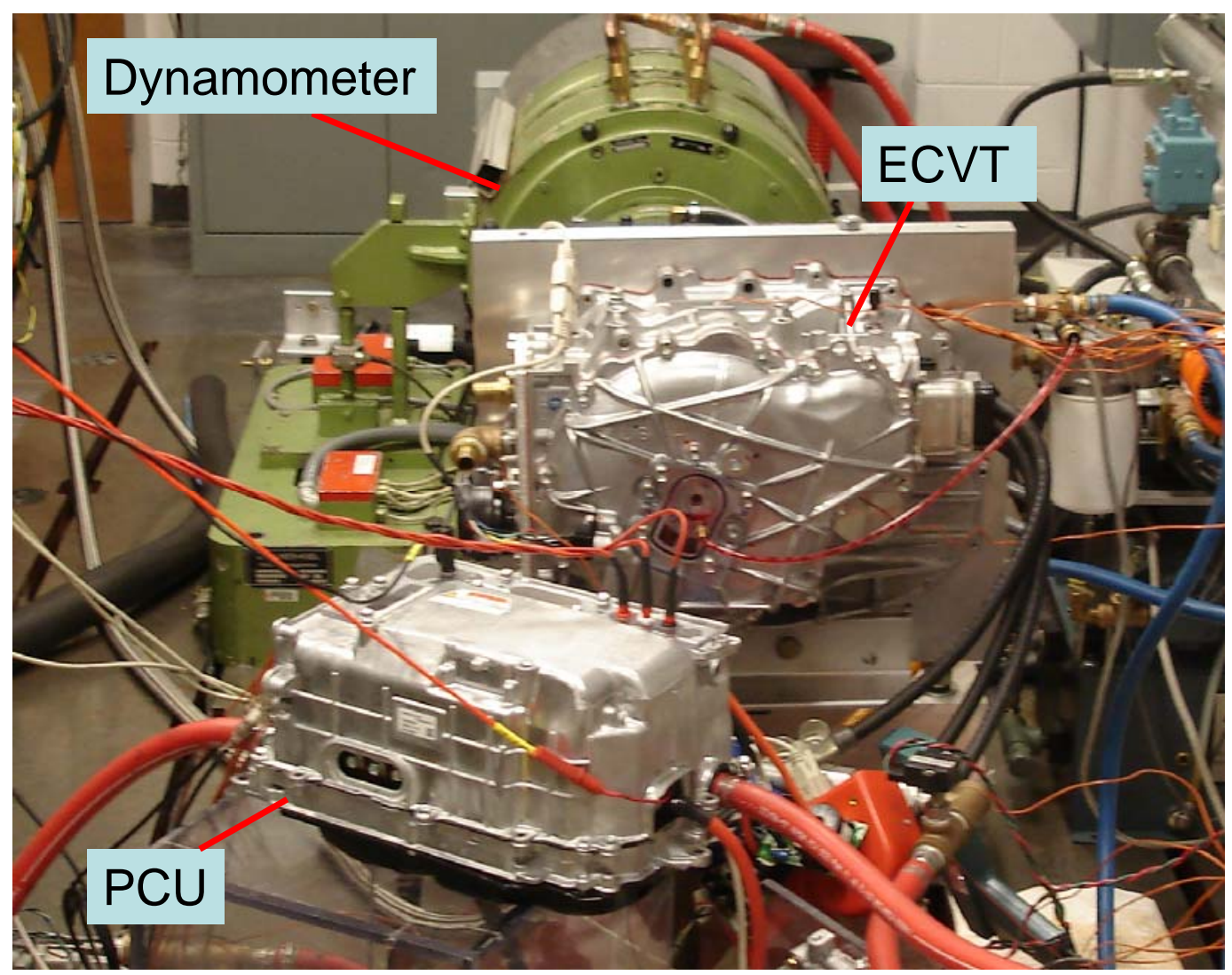

Fig. 3.2. 2010 Prius installation in ORNL test cell.

\subsubsection{Instrumentation and DAQ Development}

The PCU, PMSM, and ECVT were instrumented with TCs in order to monitor and record thermal conditions and characteristics of the subsystem during various operation conditions. In preparation for performance, efficiency, and continuous duration tests in the ORNL laboratory, the subsystems were instrumented with various measurement devices to monitor the conditions listed in Table 3.1. Details of the TC installations within the ECVT assembly are provided in Fig. 3.3. Red letters indicate the characters assigned to each location for easy identification during data analysis. For example, TCs ' $\mathrm{B}$ ', 'C', 'D' and ' $E$ ' are installed in the front section of stator windings in the 3,10, 7, and 1 o'clock positions, respectively. TCs 'I', 'J', 'K', and ' $\mathrm{L}$ ' have similar locations in the rear section of the stator windings. TCs ' $F$ '- 'H' monitor case temperatures, and ' $M$ ' monitors oil temperatures. 
Table 3.1. Conditions monitored during 2010 Prius evaluations

\begin{tabular}{|l|c|}
\hline \multicolumn{1}{|c|}{ Conditions Measured } & Comments \\
\hline Inverter/dc-dc converter temperatures & 7 device measurements \\
\hline Inverter coolant in/out temperature & $2 \mathrm{TCs}$ \\
\hline ECVT coolant in/out temperature & $2 \mathrm{TCs}$ \\
\hline PMSM stator core/winding temperatures & $8 \mathrm{TCs}$ \\
\hline PMSM cooling oil temperatures & $1 \mathrm{TCs}$ \\
\hline ECVT casing temperatures & $3 \mathrm{TCs}$ \\
\hline Coolant flow rate & 1 flowmeter \\
\hline Pressure of coolant & 3 pressure transducers \\
\hline DC voltage to inverter & voltage taps \\
\hline DC to inverter & $1 \mathrm{CT}$ \\
\hline PMSM input current & $3 \mathrm{CTs}$ \\
\hline PMSM input voltage & 3 voltage taps \\
\hline Shaft speed & Existing Toyota sensor \\
\hline Position & Existing Toyota absolute position sensor \\
\hline Torque & Himmelstein dynamometer torque cell \\
\hline
\end{tabular}
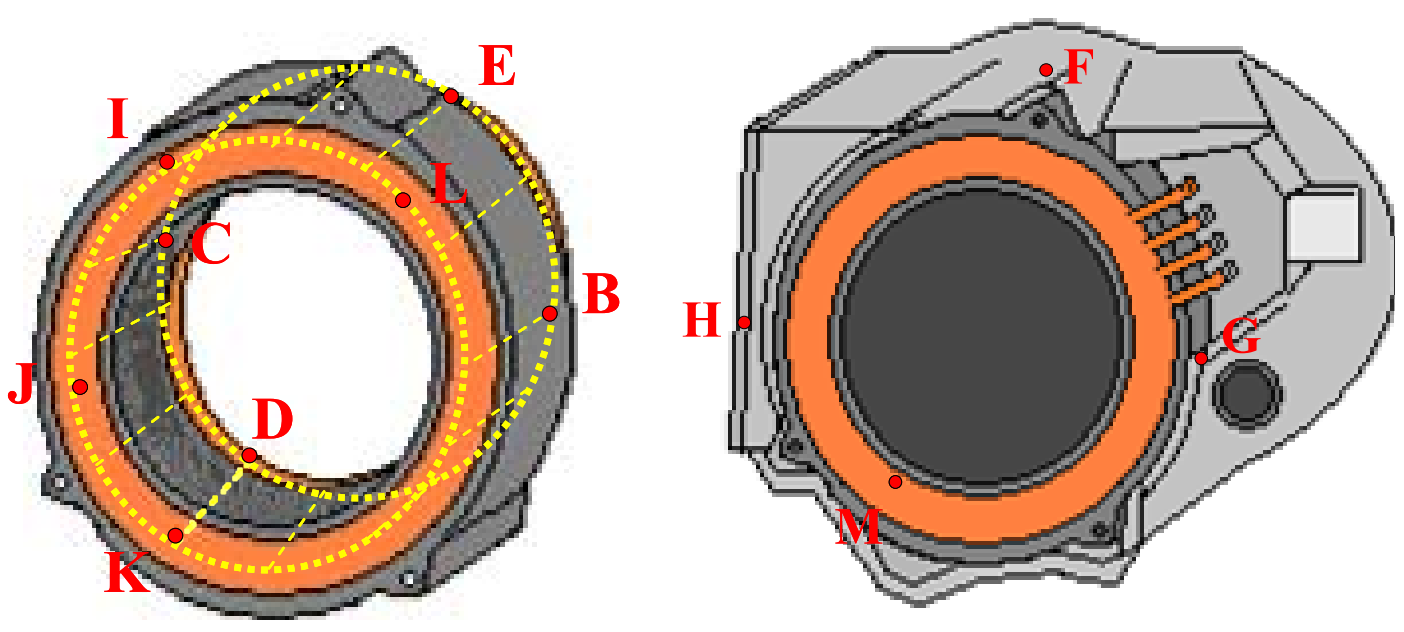

Fig. 3.3. Locations of TCs within ECVT assembly.

Device temperatures within the PCU were monitored by utilizing on-chip device sensing techniques. Measurement locations ' $\mathrm{V}$ ' through ' $\mathrm{AB}$ ' are indicated in Fig. 3.4 for each leg of the motor inverter, generator inverter, and boost converter. However, due to the intensive electromagnetic interference (EMI) environment using this method, measurements proved to be more accurate if only a few signals were chosen to be monitored and remaining leads were eliminated. This reduces the amount of "crosstalk" and ground loops amongst sensor leads and sensing circuitry. Therefore, signals from the locations of 'W' and 'AB' were selected. Future efforts will be devoted to the improvement of this measurement technique. 


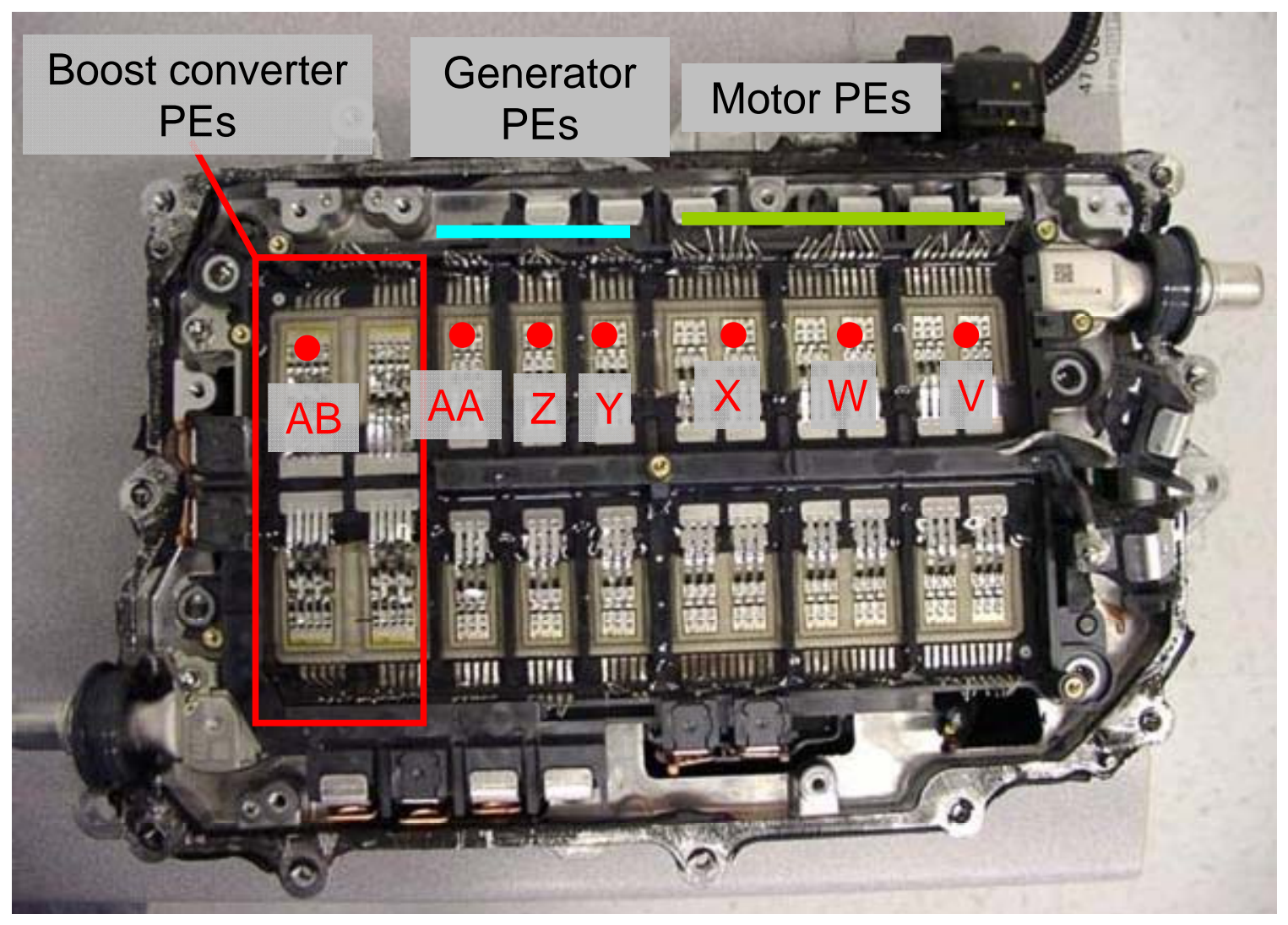

Fig. 3.4. Device temperature monitoring locations within 2010 Prius PCU.

A program written in the Visual Basic programming language was developed to collect data from various measurement instruments and merge the data into a convenient spreadsheet format. Torque, speed, and mechanical power were obtained using a Himmelstein torque and speed transducer. Temperature measurement signals from thermistors and TCs were collected with a Keithly 2700 acquisition unit. A Yokogawa PZ4000 power analyzer was used to carry out electrical measurements such as ac and dc rms voltage, rms current, real power, and many other properties of the waveforms.

The DAQ system was important not only for data logging, but it also served as a real time feedback system in which system conditions were monitored to ensure that operational limitations were not violated and to ensure that the system was being operated in an optimal manner. Temperature and current constraints were the primary limitations of the entire drive system. Efficiencies were calculated using the mechanical and electrical data and were used to verify that the controller operation was optimized.

\subsubsection{Controller and Interface Development}

The hybrid subsystems of the 2010 Prius were evaluated for performance and efficiency characteristics such as peak and continuous power ratings and motor/inverter efficiency. Continuous operational capabilities are greatly affected by the heat transfer characteristics of the motor, which is cooled through oil circulation and an ethylene-glycol coolant loop. The hybrid subsystems were operated over a broad torque-speed range in order to collect and analyze thermal and electrical data at a multitude of operation points. For each operation point during efficiency evaluations, the system was held in steady state for at least 20 seconds as a minimum of 5 data samples were taken. 
ORNL's dynamometer test cell and Opal-RT-based speed and current feedback controller were adapted to provide the torque needed at each reference speed. Thus, as the applied torque from the dynamometer was varied manually, the controller regulated the torque producing current appropriately. The current controller consists of two standard proportional-integral (PI) controllers for the direct and quadrature currents, $i_{d}$ and $i_{q}$, respectively. These $d-q$ components are obtained by applying the $d-q$ transformation to the three-phase currents which have a fixed reference for steady state operation. The transformation converts the three-phase currents into two-phase vectors, which have a reference that rotates with the rotor. Therefore, precise rotor position feedback is used during this transformation.

The steady state torque equation for the salient PM machine is expressed by:

$$
\tau_{L}=n_{p}\left(L_{d}-L_{q}\right) i_{d} i_{q}+n_{p} K i_{q}
$$

where

$n_{p}$ is the number of pole pairs,

$L_{d}$ is the $d$-axis inductance,

$L_{q}$ is the $q$-axis inductance, and

$K$ is the back-emf and torque-current factor.

The total torque given by Eq. (1) consists of two torque terms which are reluctance torque and PM torque, respectively. PM torque is produced only by the current component along the q-axis. If current is applied which results with a negative component along the $d$-axis, positive reluctance torque is developed since the difference, $L_{d}-L_{q}$, in the first term is negative and all remaining variables and constants are positive in the motoring region. In theory, there is an infinite amount of $d-q$ current combinations that will satisfy a particular operation condition. There is an optimal $d$ - $q$ current combination in which the motor efficiency is maximized for each particular torque. It is difficult to determine the optimal current trajectories for the entire torque-speed range, as complex factors such as effects of saturation and harmonics must be considered. Therefore, the DAQ was used to monitor the system efficiency to ensure that the controller is operating optimally.

A high level diagram of the Opal-RT controller and interface system is shown in Fig. 3.5. A console personal computer (PC) is used to develop and modify control schemes in a block diagram format, which is converted and compiled to traditional programming languages (mostly $\mathrm{C}$ ) and sent to the target nodes through an ethernet network. The target nodes execute the controller code in real time and the console PC is used to control the mode of the controller operation as well as to update various parameters if desired. While the development process is more straightforward than microprocessor programming, the PC based architecture of the target nodes introduces a significant degradation in terms of control sampling frequency. Therefore, the system resources must be utilized in an efficient manner. 


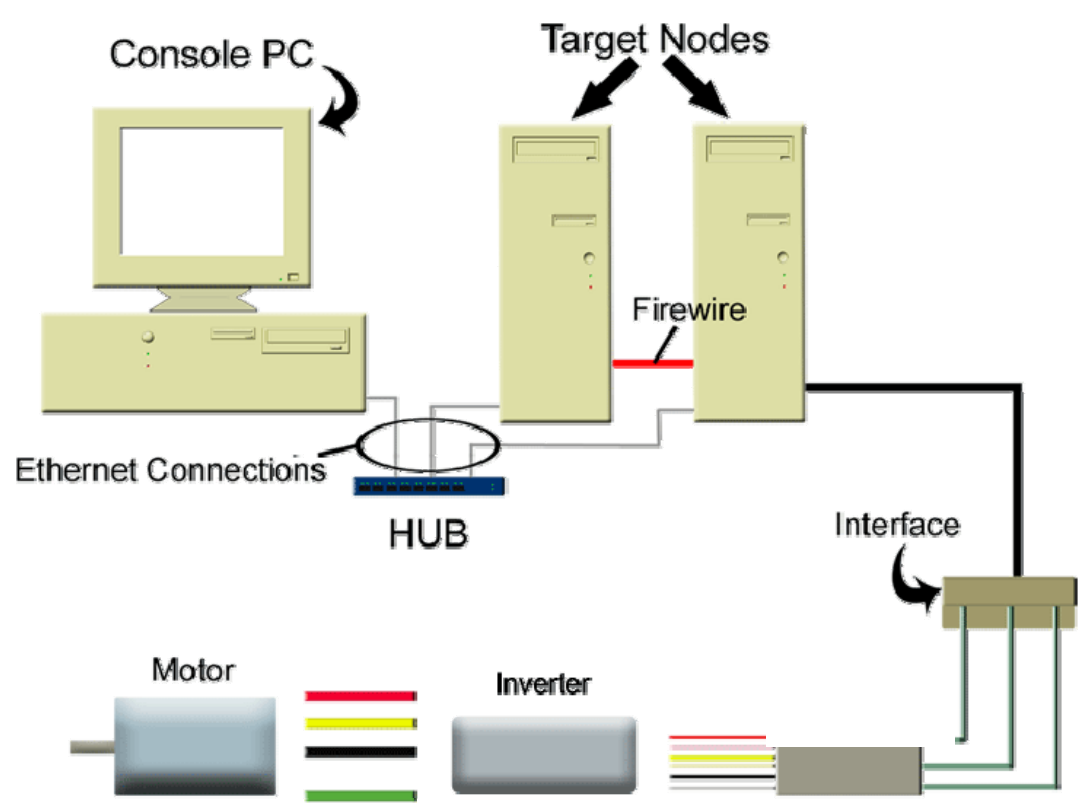

Fig. 3.5. Opal-RT controller and interface system.

\subsection{BACK-EMF TEST RESULTS}

The non-energized 2010 Prius PMSM was spun at various speeds over its full design range to obtain back-emf data. The shaft speed and back-emf data (line-to-neutral rms averaged for the three phases) is plotted in Fig. 3.6. Generally, the induced back-emf voltage of the Camry is about $80 \%$ of that of the 2010 Prius and the LS $600 \mathrm{~h}$ is about $84 \%$ of that of the Camry. Back-emf tests were repeated throughout the performance/efficiency mapping test to verify that no magnetic strength was lost in the rotor during performance tests or extended periods of high-temperature testing. As expected, there were no significant differences in the data obtained during consecutive back-emf tests.

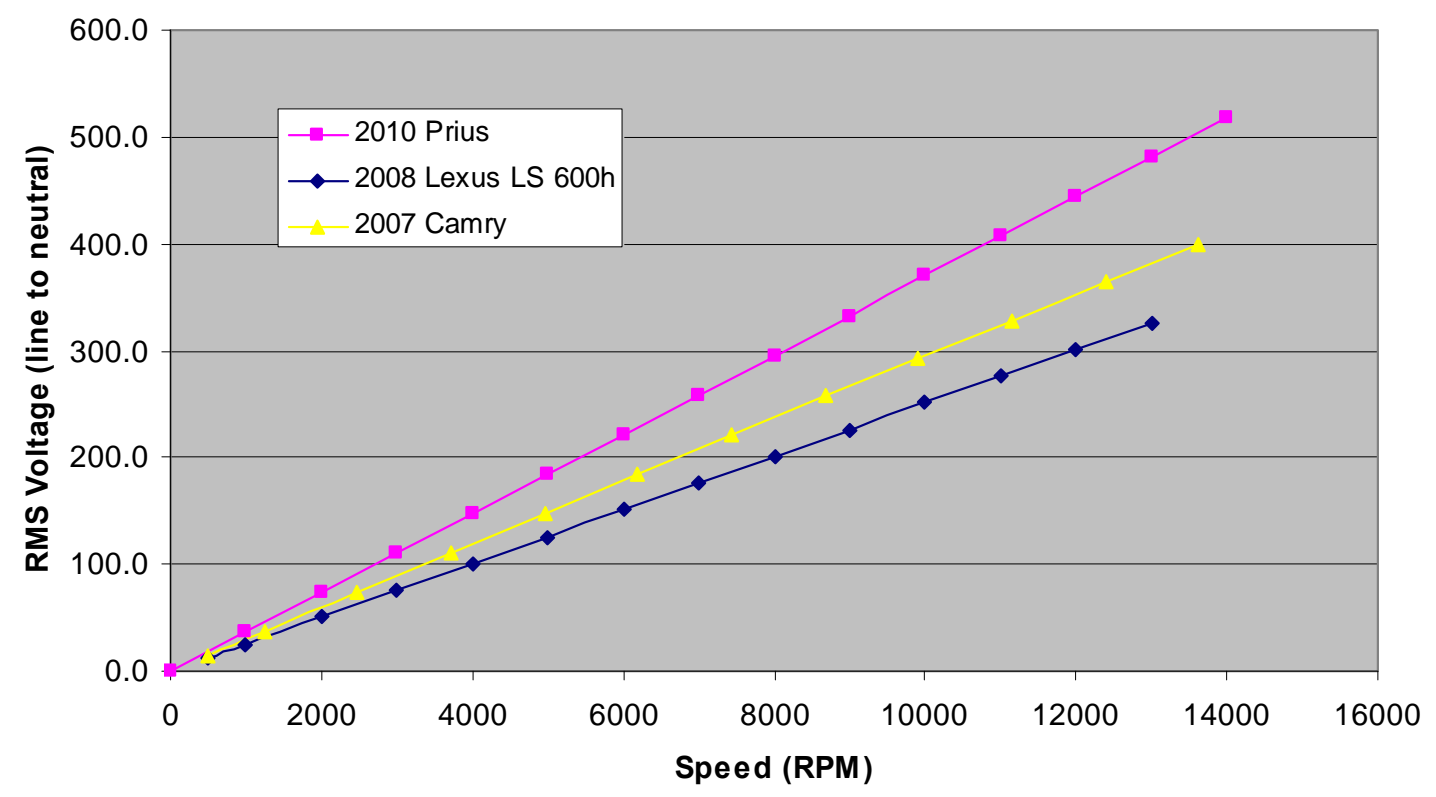

Fig. 3.6. 2010 Prius, LS 600h, and Camry motor back-emf test results. 


\subsection{LOCKED ROTOR TEST}

A series of locked rotor tests were performed to determine the torque-producing behavior of the PMSM motor. During locked rotor tests, the rotor is rotated throughout an electrical cycle and the shaft is rigidly locked at each position as dc current is applied. Torque values were obtained from an in-line shaft torque sensor when the motor windings were energized. The resulting data was used to produce torque versus electrical position plots, which are shown in Fig. 3.7 for various current levels. The shape of the waveform is similar to that of the Camry waveforms, shown in Fig. 3.8. The peak torque for both systems at each current level was chosen and plotted versus current, as shown in Fig. 3.9. For all measured current levels, the 2010 Prius produces greater torque than the other designs for a given current. For low current levels, the Camry produces a greater amount of torque than the LS 600h. However, the LS $600 \mathrm{~h}$ trace does not reveal extreme impacts of saturation, and the curves cross at a current level just above $300 \mathrm{~A}$. A similar phenomenon would occur if the 2010 Prius were operated at higher current levels. Notice that the published peak torque of $300 \mathrm{Nm}$ for the LS $600 \mathrm{~h}$ requires a current level of about $430 \mathrm{~A}$. A second look at the minute motor conductor sizes in Fig. 2.61 roughly infers that high current levels are only possible for very short amounts of time. Furthermore, conditions within the stator windings are much more extreme, where high-current carrying conductors are bunched together and are surrounded by materials which have limited heat transfer capabilities.

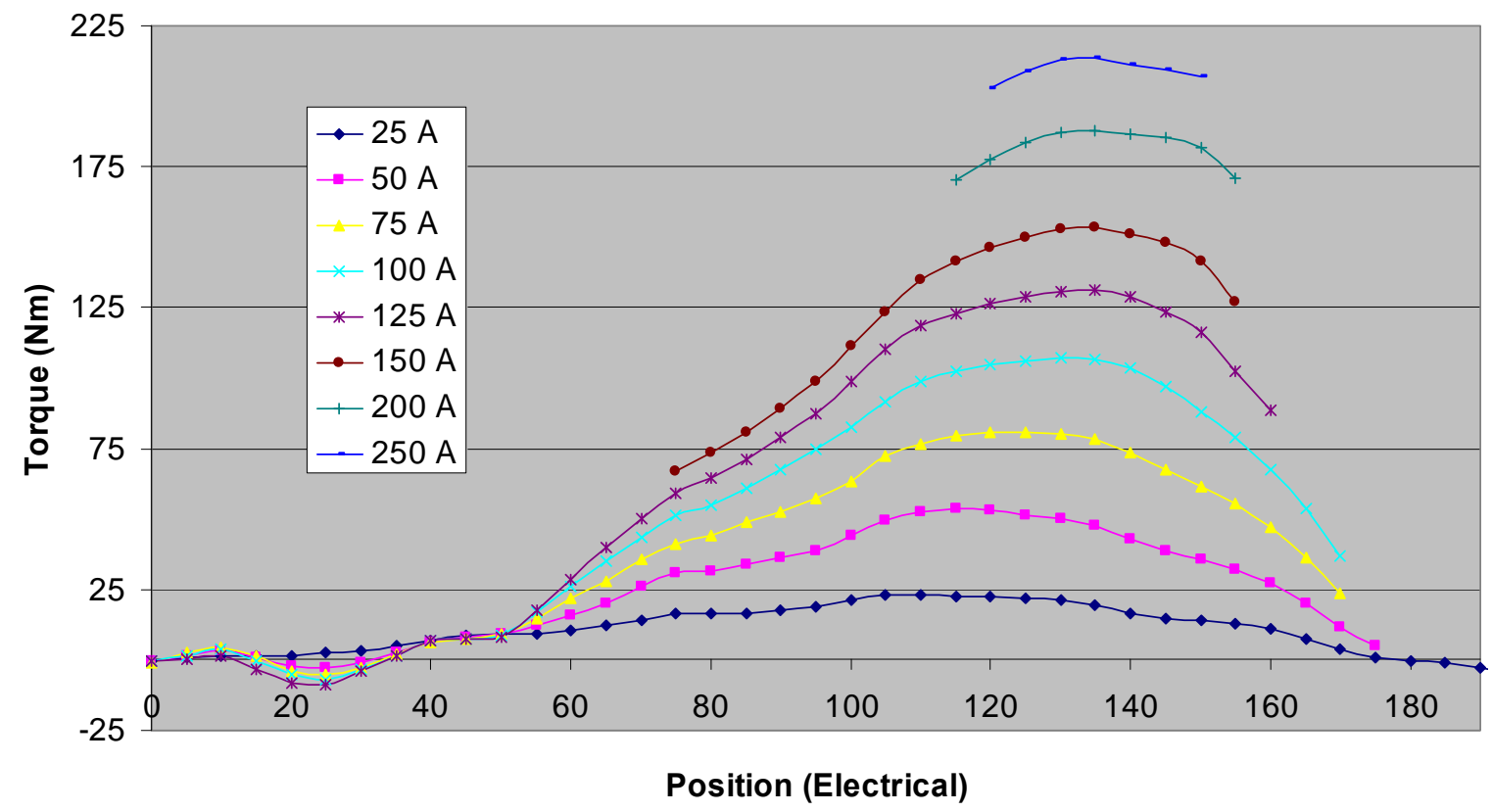

Fig. 3.7. 2010 Prius locked rotor torque vs. position for various current levels. 


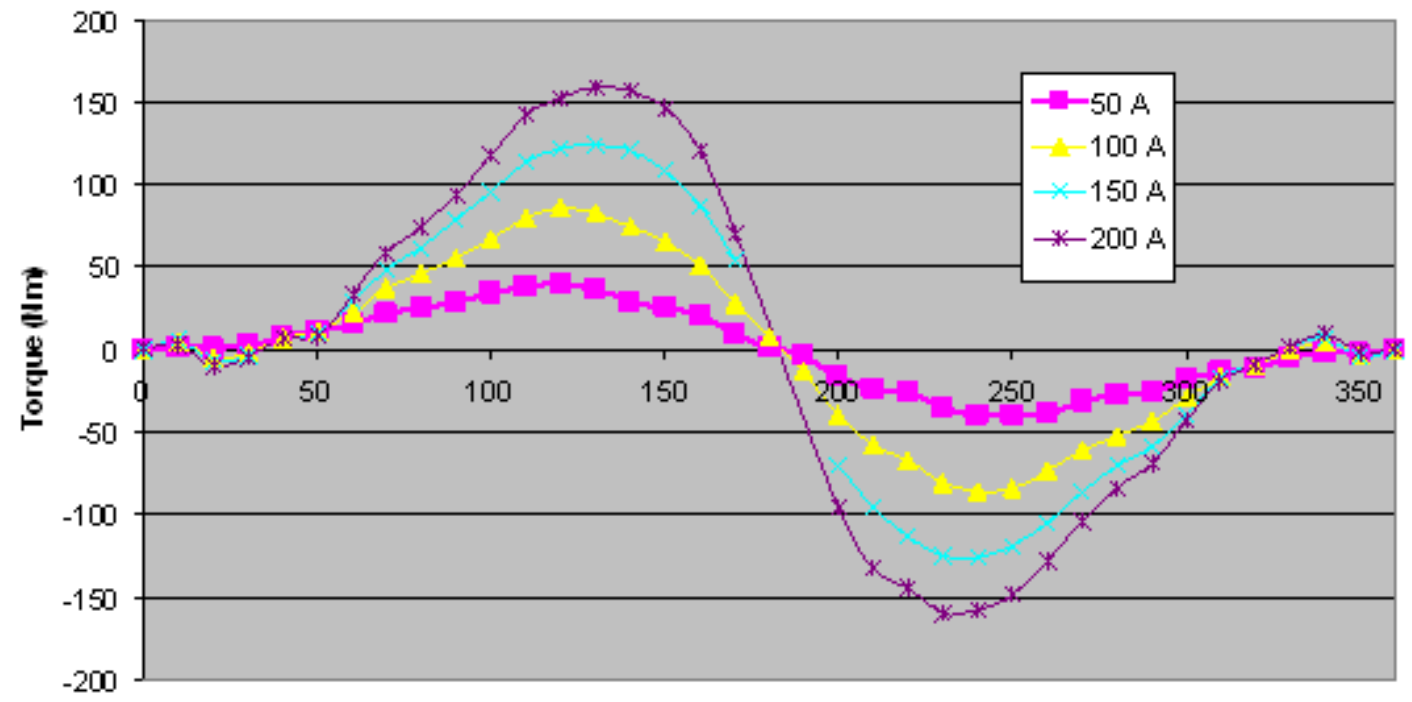

Electrical Position (D egrees)

Fig. 3.8. 2007 Camry locked rotor torque vs. position for various de currents.

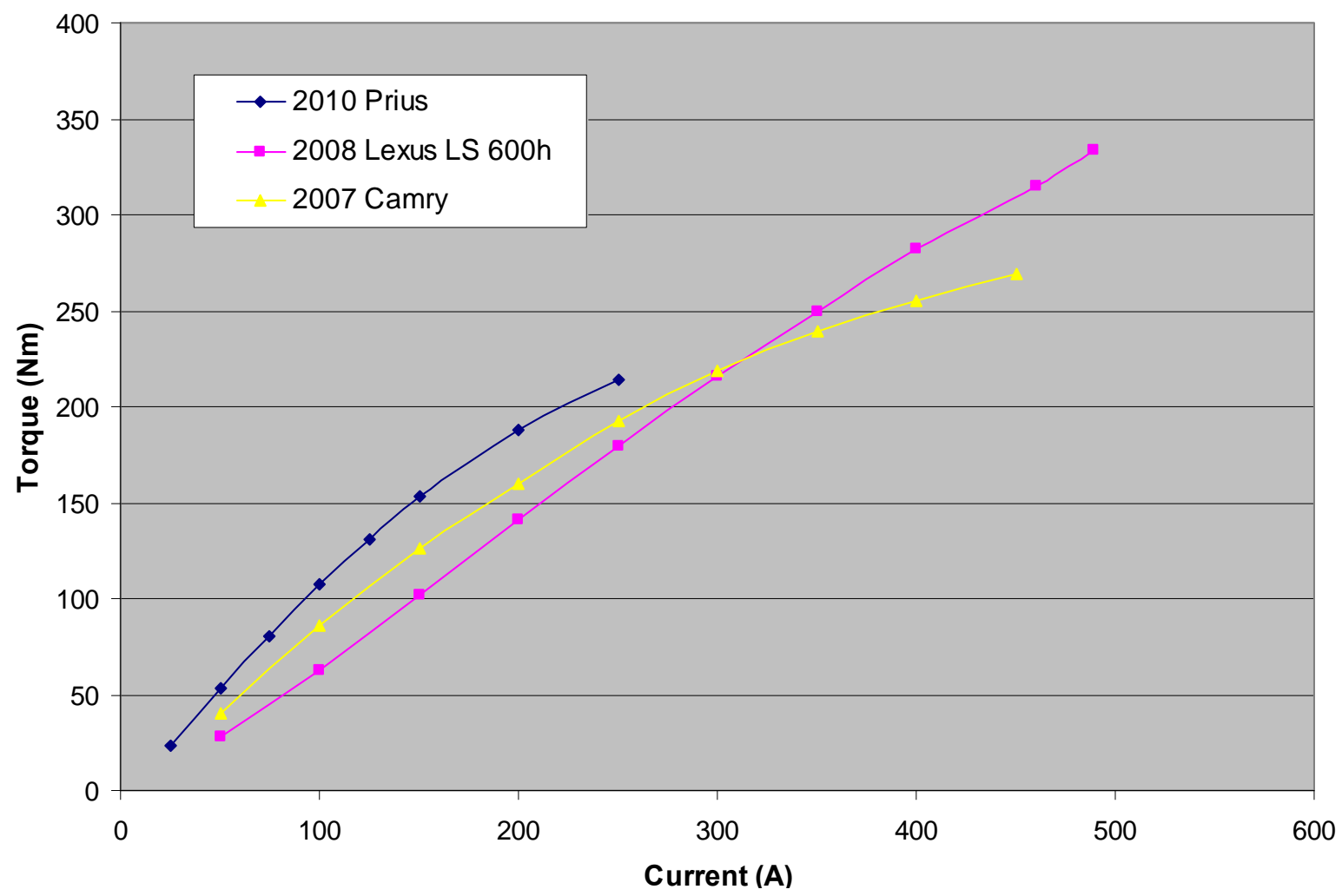

Fig. 3.9. 2010 Prius, 2008 LS 600h, and 2007 Camry peak locked rotor torque vs. de current.

Interior PM motors have two torque components and there is an optimal current angle at which the two torque components produce the maximum torque per current. Fig. 3.10 shows the PM torque, reluctance torque, and the total sum of the two torque components for a constant exemplar current magnitude. 
Although the maximum PM torque is produced at a current angle of zero electrical degrees and the maximum reluctance torque is produced at 45 electrical degrees, the maximum total torque is produced at about 35 electrical degrees. This optimal current angle varies with many conditions such as current magnitude and speed.

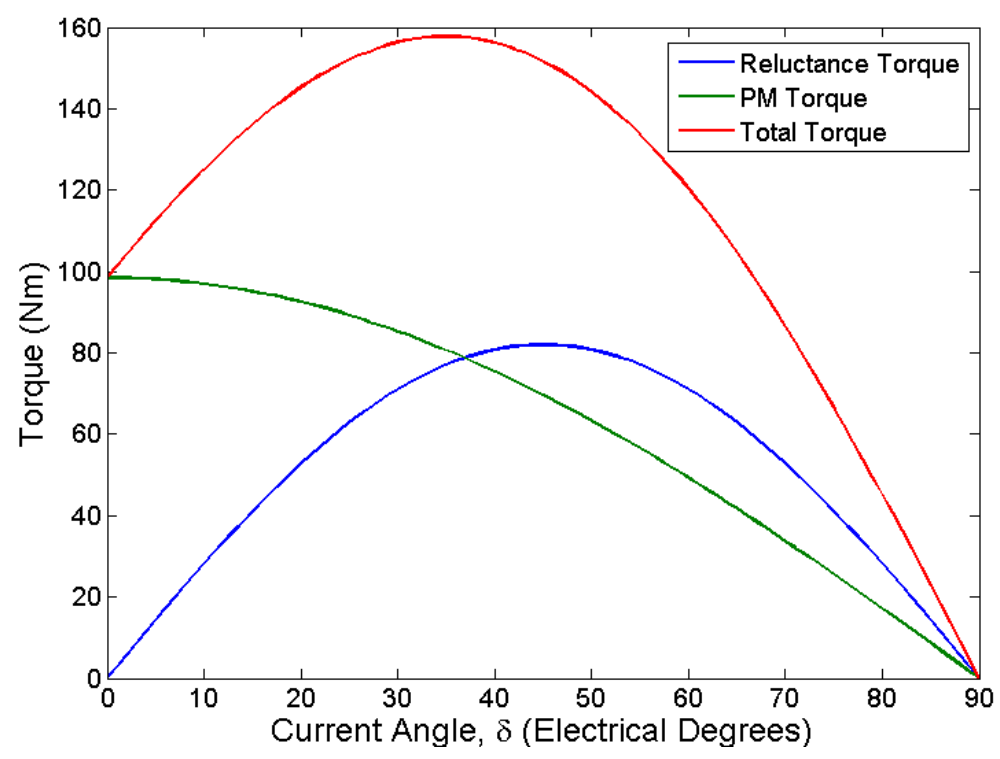

Fig. 3.10. Reluctance and PM components of torque for general PMSM.

\subsection{PERFORMANCE AND EFFICIENCY EVALUATIONS}

This section provides information about the performance and efficiency evaluations of the 2010 Prius hybrid subsystem components. The motor and inverter characteristics were evaluated simultaneously with power provided directly to the dc link, as opposed to the power being supplied through the boost converter. Otherwise, the $27 \mathrm{~kW}$ power rating of the dc-dc converter would have limited the capabilities of the motor and inverter during the performance and efficiency assessment process. The dc-link voltage was maintained at 230,500, and $650 \mathrm{Vdc}$ and a switching frequency of $5 \mathrm{kHz}$ was used. Both space vector pulse width modulation (SVPWM) and sine-triangle pulse width modulation were utilized during the tests, and as expected, SVPWM typically produced the best performance. Motor efficiency was measured throughout the entire torque-speed range in which the motor is capable of operating. For each operation point, the motor was controlled in steady state for at least 20 seconds and at least 5 data points were averaged to generate the efficiency maps. The efficiency contour map in Fig. 3.11 represents the steady state efficiency characteristics of the motor for efficiencies above $60 \%$ with a dc-link voltage of $650 \mathrm{~V}$. The peak efficiency is $96 \%$ between about 4500 and $6500 \mathrm{rpm}$ and efficiencies above $88 \%$ are spread over a large area of the operation region. Note that for much of the high torque regions, a coolant temperature of $\sim 10^{\circ} \mathrm{C}$ was used to permit extensive testing in this region. Otherwise, the torque levels nearing $200 \mathrm{Nm}$ could only be maintained for extremely short periods of time before reaching stator temperature limits. Even with such a low coolant temperature, the duration of operation at extreme points was severely limited. It was ensured that reasonable stator winding temperatures were maintained, thereby ensuring that the winding resistance was not affected by abnormally low coolant temperatures, thereby potentially tainting the efficiency measurement. 


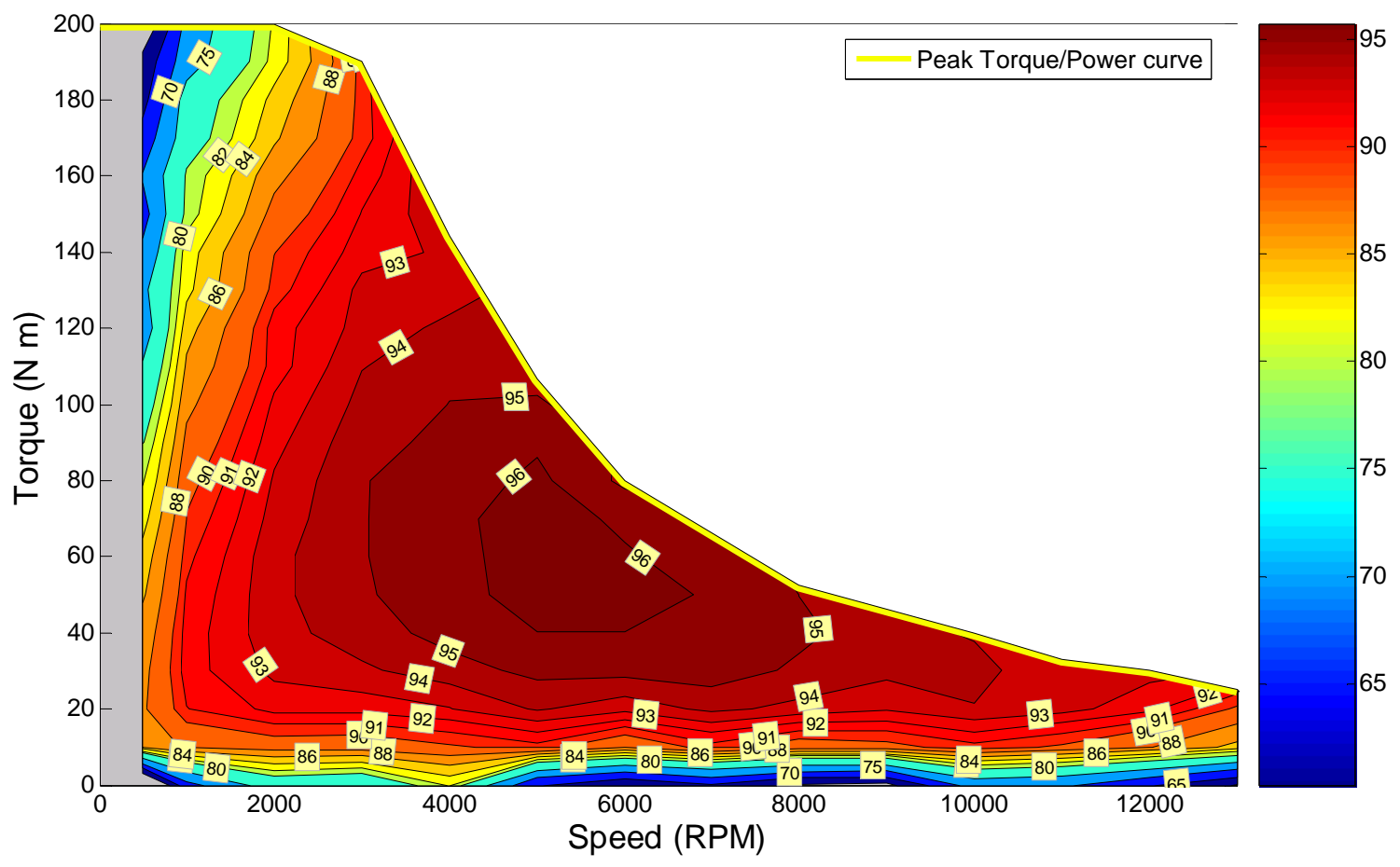

Fig. 3.11. 2010 Prius motor efficiency contours for 650 Vdc.

The yellow line in Fig. 3.11 indicates the peak torque and power capability of the motor. An 18 second duration requirement for FreedomCAR and Vehicle Technologies (FCVT) targets has be implemented in order to establish a generalized peak capability guideline for benchmarked systems as well as developmental systems within R\&D programs. Otherwise, motor designers could tout extremely high power ratings, even though the duration capability at this power level may only be less than a second, for example. It was verified that the 2010 Prius motor is capable of producing $60 \mathrm{~kW}$ for 18 seconds prior to reaching a stator temperature of $150^{\circ} \mathrm{C}$.

Shown in Fig. 3.12 is the efficiency map for the 2010 Prius motor inverter at $650 \mathrm{Vdc}$. These results are quite similar to inverter efficiency measurements observed in previous subsystem studies. The peak efficiency is above $99 \%$ for speeds and torques above $4500 \mathrm{rpm}$ and about $30 \mathrm{Nm}$. Additional inverter efficiency measurements were conducted with dc-link voltages of $500 \mathrm{~V}$ and $225 \mathrm{~V}$ and the corresponding inverter efficiency maps are shown in Figs. 3.13 and 3.14, respectively. Although the discrepancies between the maps are not straightforward, higher switching losses are associated with higher dc-link voltages. Therefore, the $225 \mathrm{~V}$ inverter efficiency maps reveal higher efficiencies for low speed and torque conditions. To further exemplify the phenomenon, observe in Fig. 3.12 that the 98\% efficiency contour at $650 \mathrm{~V}$ is nearly vertical at about 4,000 rpm and inverter efficiencies drop quickly as the applied torque approaches zero. For the $500 \mathrm{~V}$ inverter efficiency map in Fig. 3.13, the 98\% efficiency contour is nearly vertical at about 3,000 rpm. Likewise, the $225 \mathrm{~V}$ inverter efficiency map in Fig. 3.14 contains a nearly vertical $98 \%$ efficiency contour at $2,000 \mathrm{rpm}$. The total impact can be observed in the combined motor and inverter efficiency maps for voltages of $650 \mathrm{~V}, 500 \mathrm{~V}$, and $250 \mathrm{~V}$ shown in Figs. 3.15, 3.16, and 3.17, respectively. A simple comparison can be made by observing the peak efficiency of $93 \%$ at $2,000 \mathrm{rpm}$ and about $40 \mathrm{Nm}$ for the $225 \mathrm{~V}$ efficiency map versus $88 \%$ for the same operation point on the $650 \mathrm{~V}$ efficiency maps. These benefits are only realized at low and moderate speeds and torque levels, where the motor does not require increased voltage excitation. As motor speed and current demands increase, higher excitation voltages produce the best overall system efficiency despite increased switching losses. 


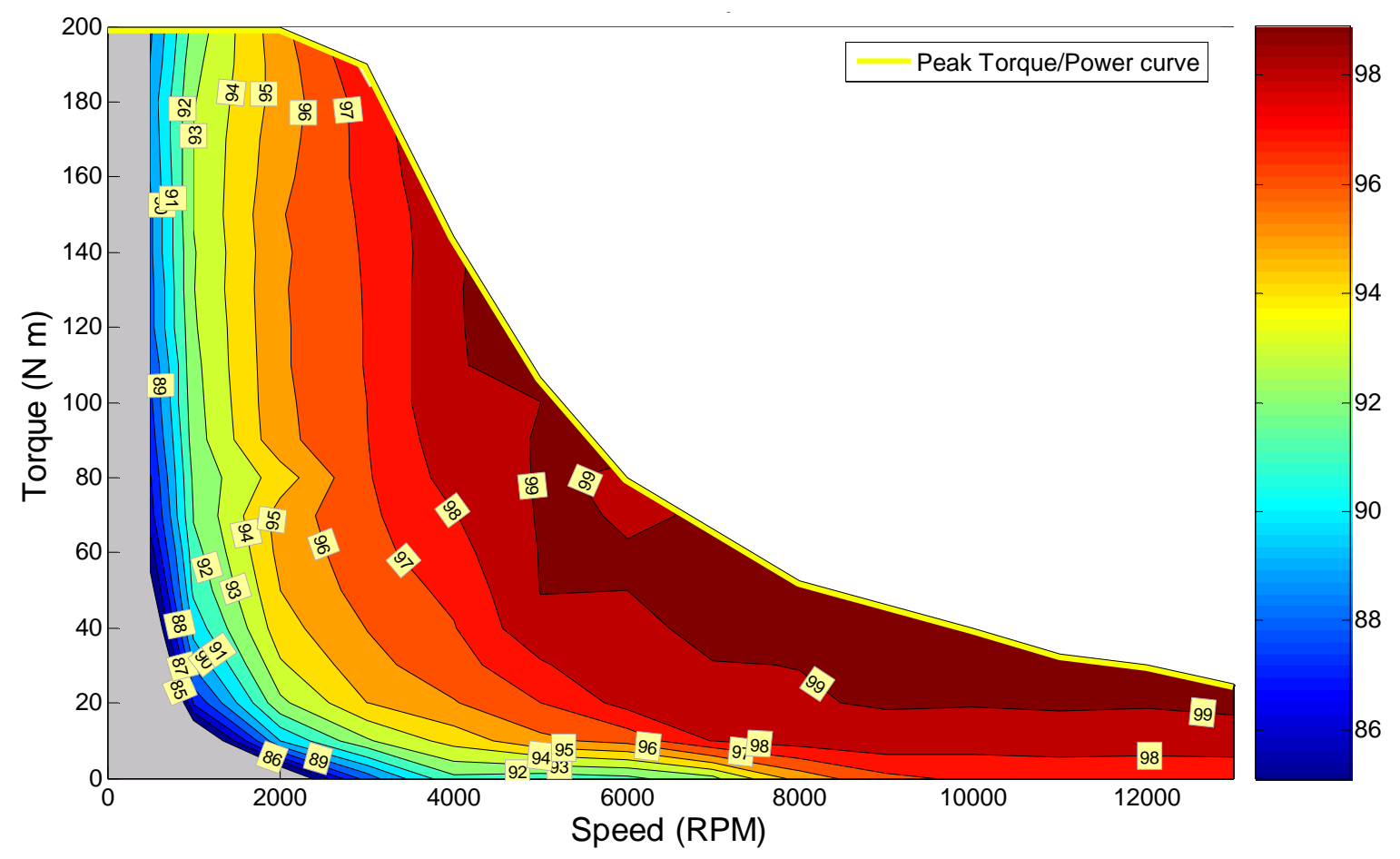

Fig. 3.12. 2010 Prius inverter efficiency contours at $650 \mathrm{Vdc}$.

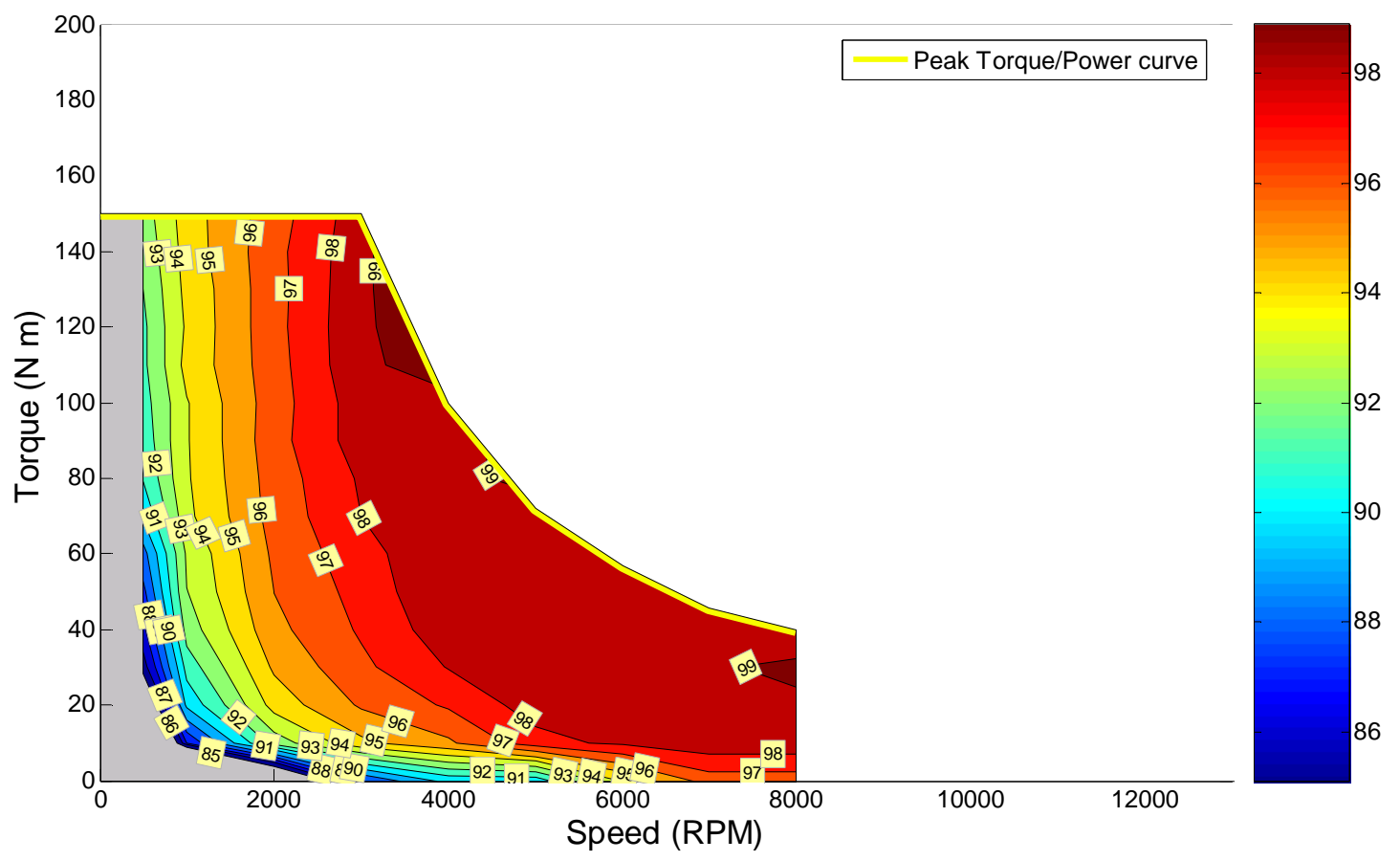

Fig. 3.13. 2010 Prius inverter efficiency contours at $500 \mathrm{Vdc}$. 


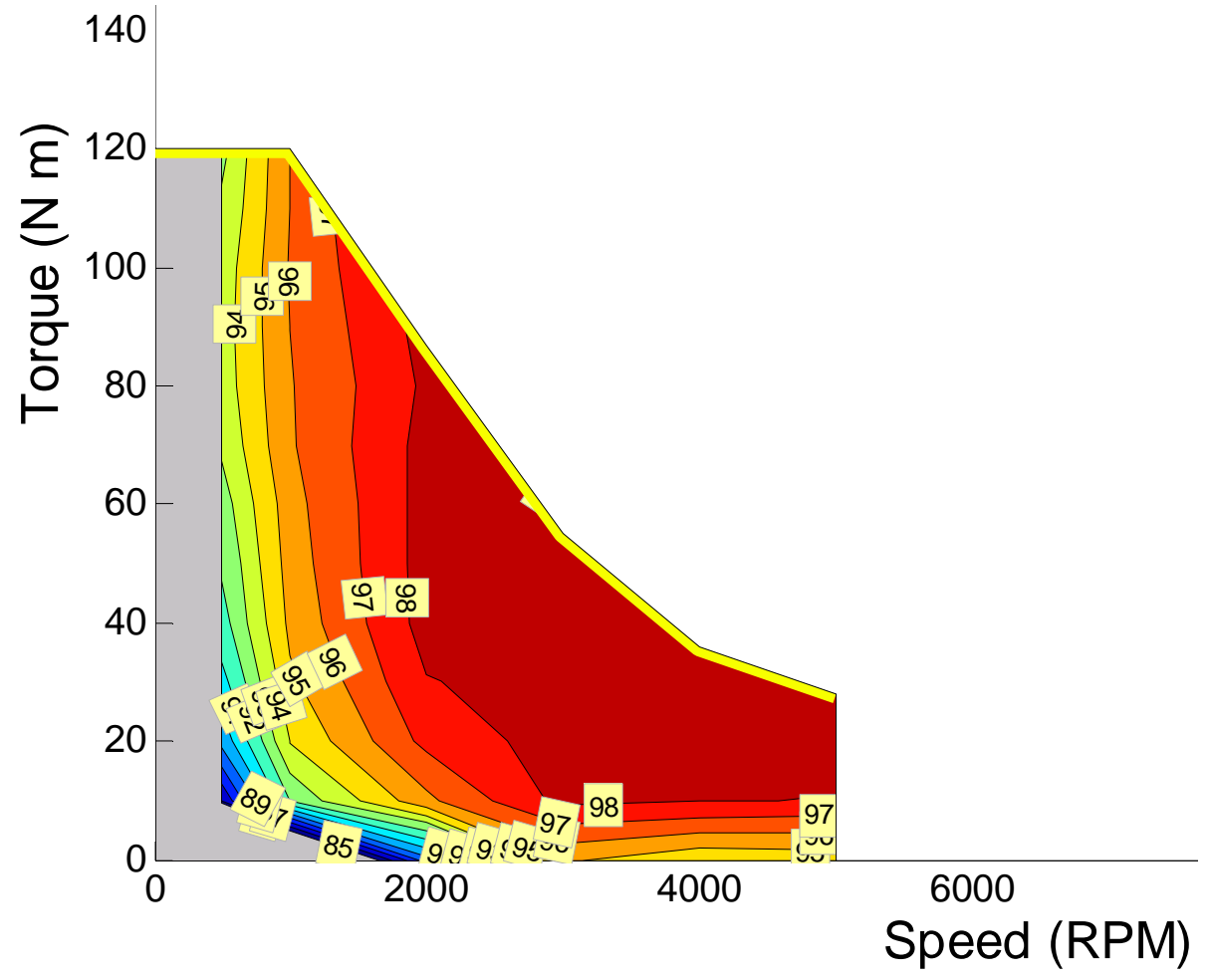

Fig. 3.14. 2010 Prius inverter efficiency contours at 225 Vdc.

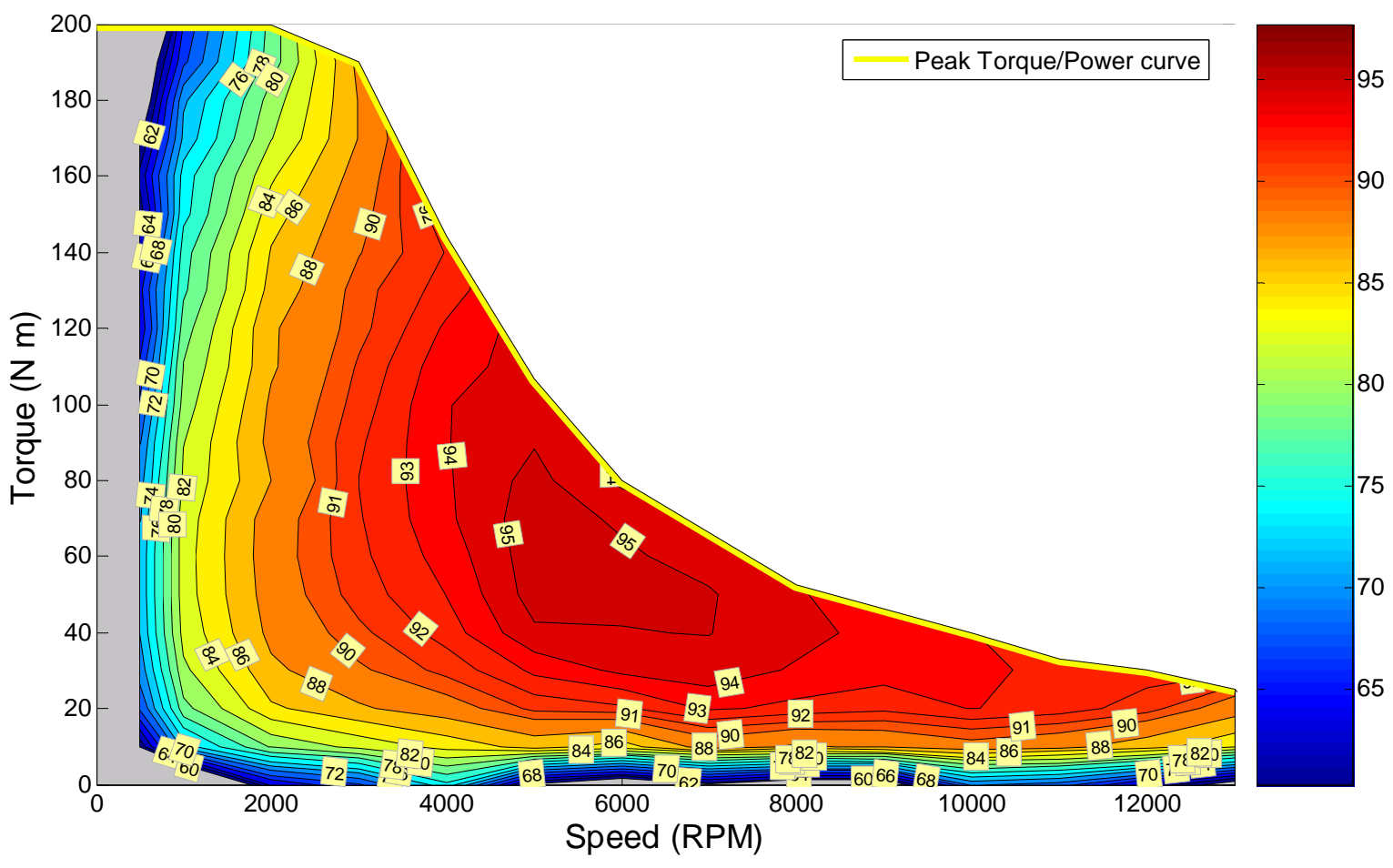

Fig. 3.15. 2010 Prius combined motor-inverter efficiency contours at 650 Vdc. 


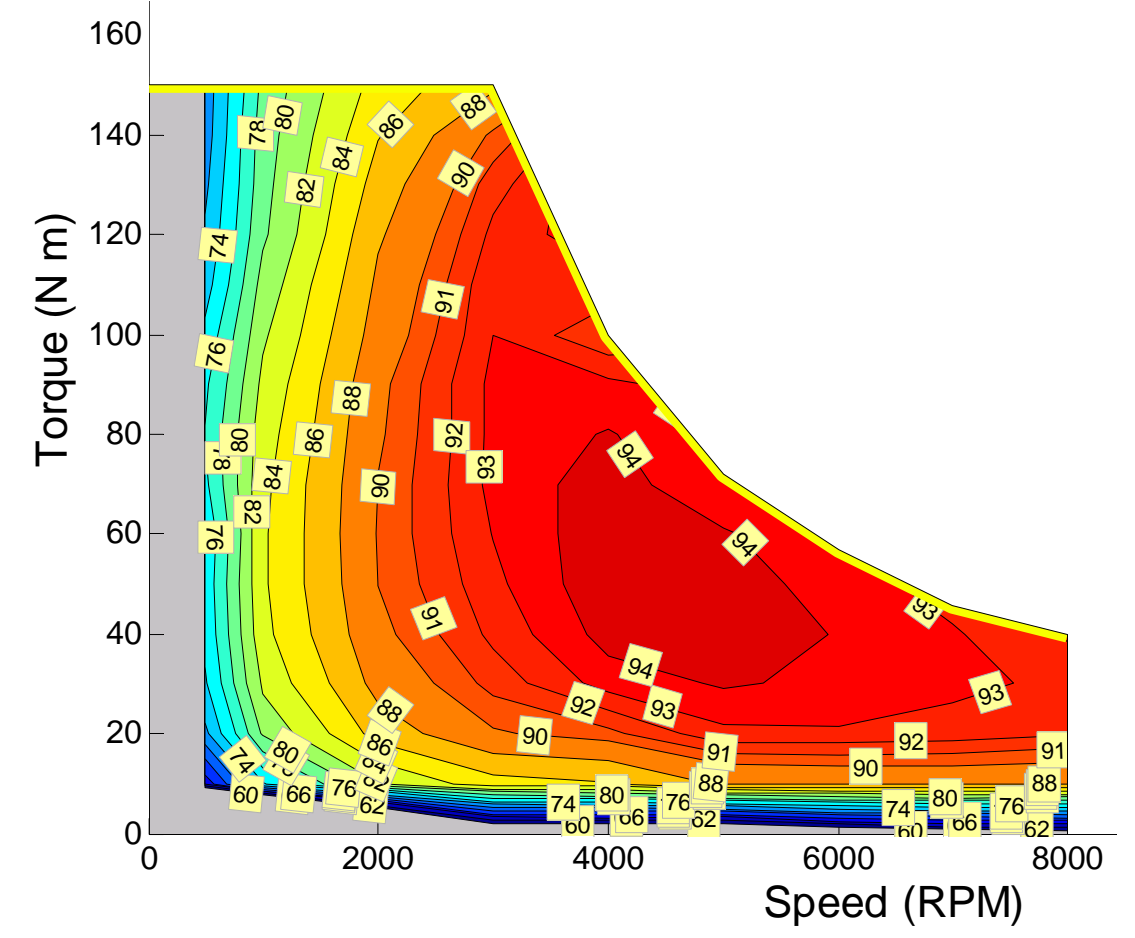

Fig. 3.16. 2010 Prius combined motor-inverter efficiency contours at 500 Vdc.

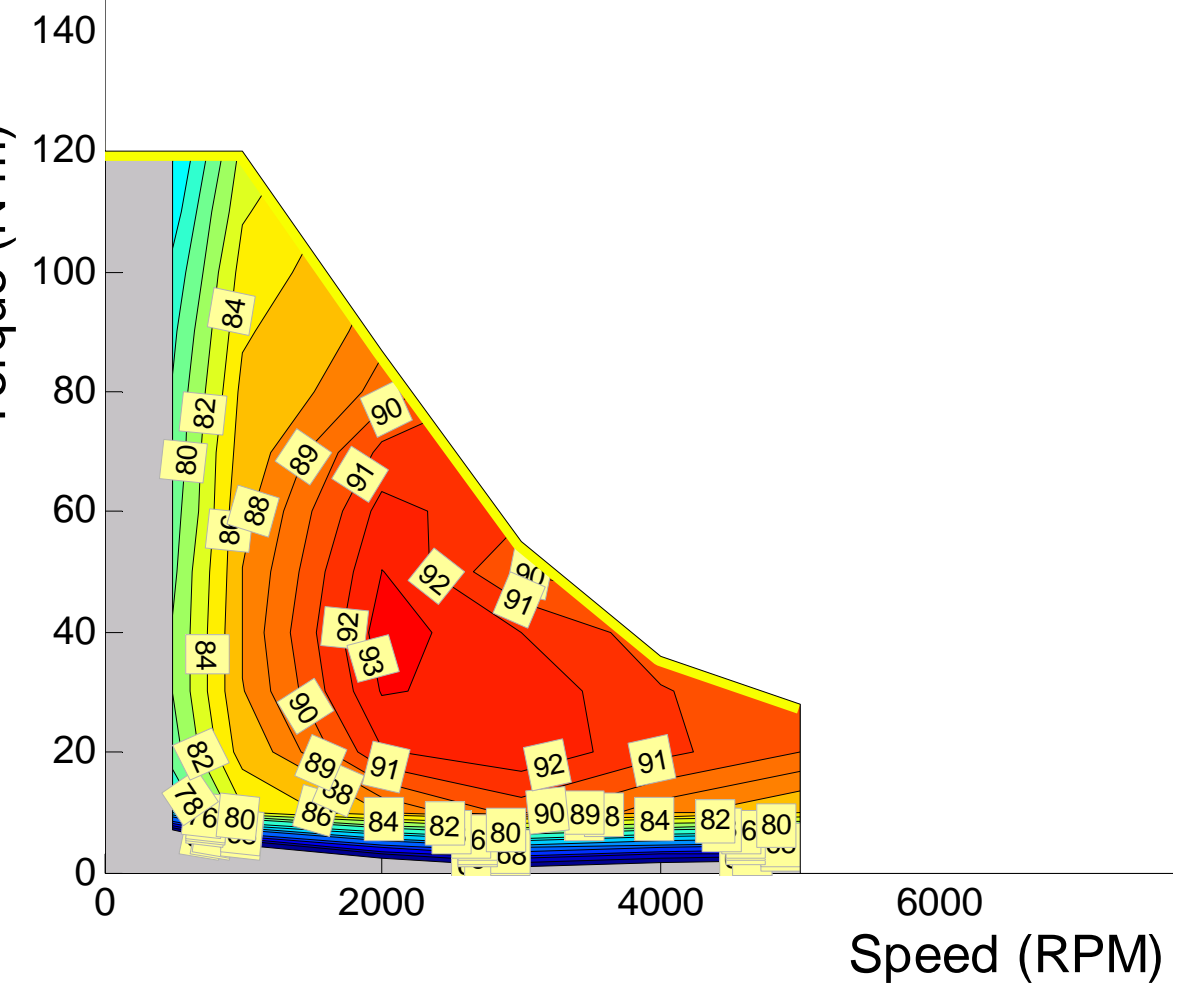

Fig. 3.17 2010 Prius combined motor-inverter efficiency contours at 225 Vdc.

An efficiency map for the 2010 Prius combined motor and inverter is provided in Fig. 3.18. This map is very similar to the combined efficiency map in Fig. 3.15, yet only combined efficiencies greater than $77 \%$ 
are indicated. This approach narrows the numerical range represented by the color spectrum and thereby making the most common efficiency range easier to analyze by color. Similar maps are shown for the Lexus, Camry, and 2004 Prius subsystems in Figs. 3.19, 3.20 and 3.21, respectively. Although the power level of the 2010 Prius is lower than that of the Camry and Lexus, the total efficiency appears to be greater, with a peak combined efficiency of $95 \%$ versus about $92-93 \%$ for the other system. In comparison with the 2004 Prius, the 2010 Prius system has significant improvements, but a direct comparison of efficiency maps is difficult as the speed and torque ranges of the motors are so different.

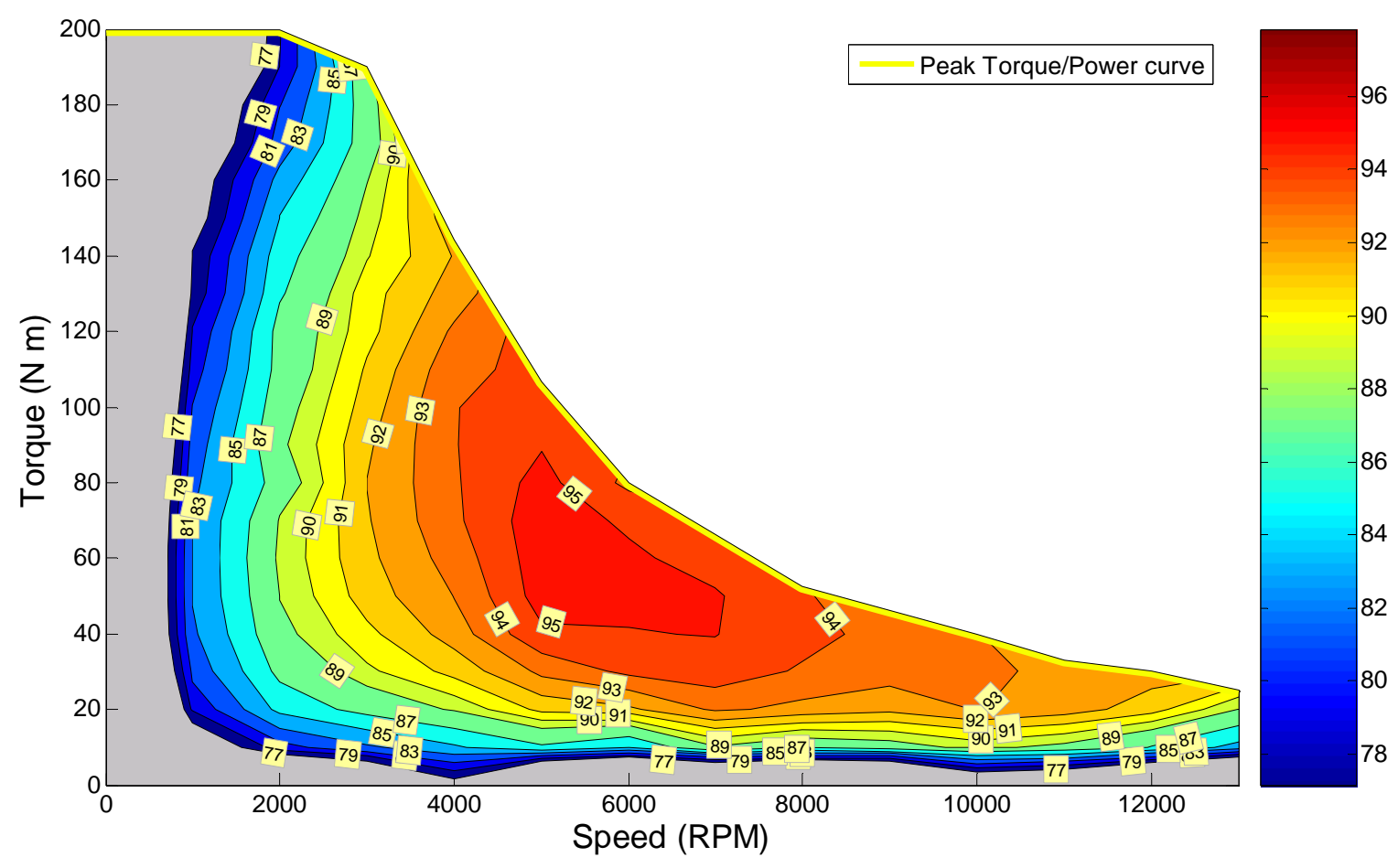

Fig. 3.18. 2010 Prius motor-inverter combined efficiency contours at $650 \mathrm{~V}$ for $77 \%$ and above. 


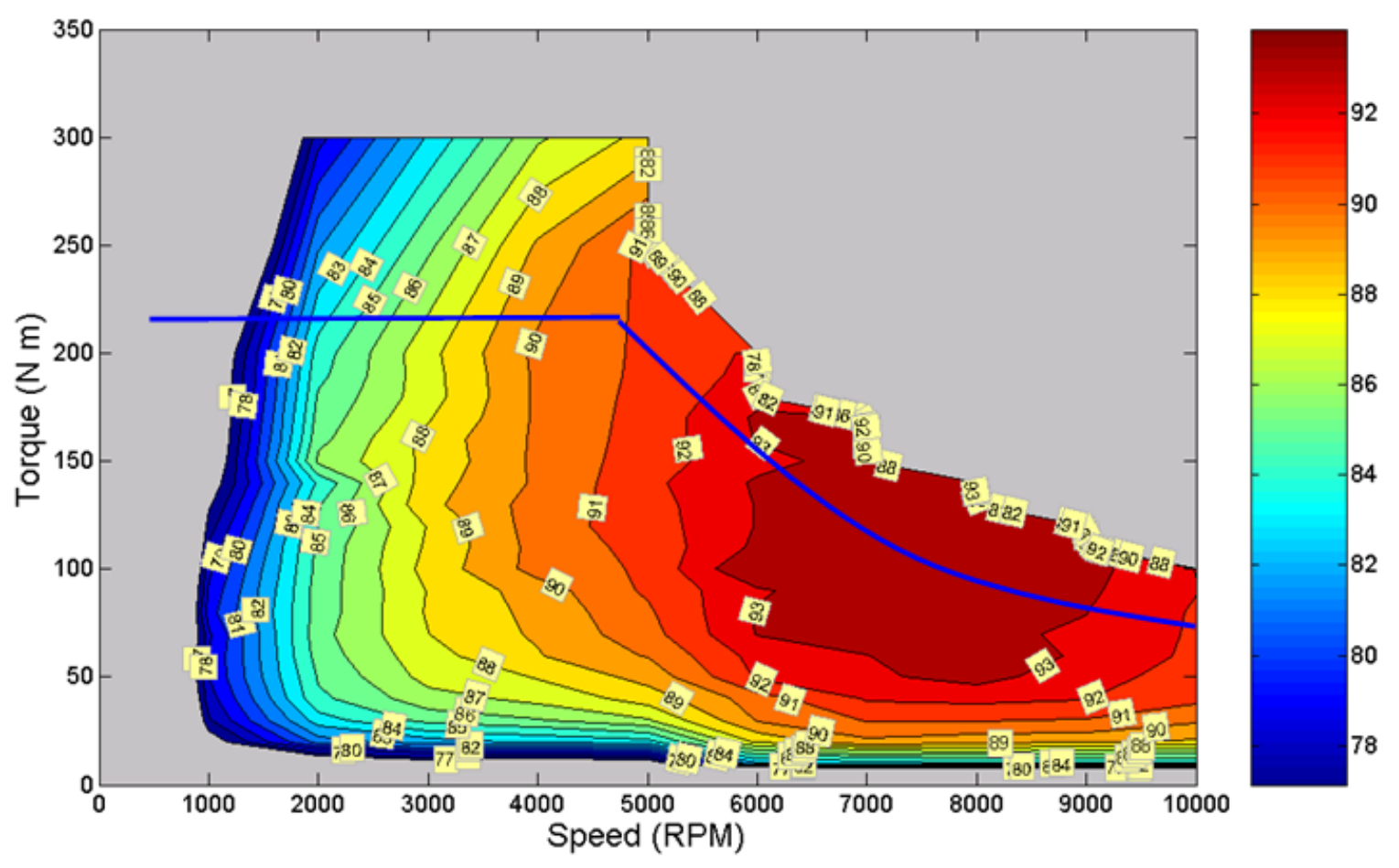

Fig. 3.19. LS 600h motor-inverter combined efficiency contours at $650 \mathrm{~V}$ for $77 \%$ and above.

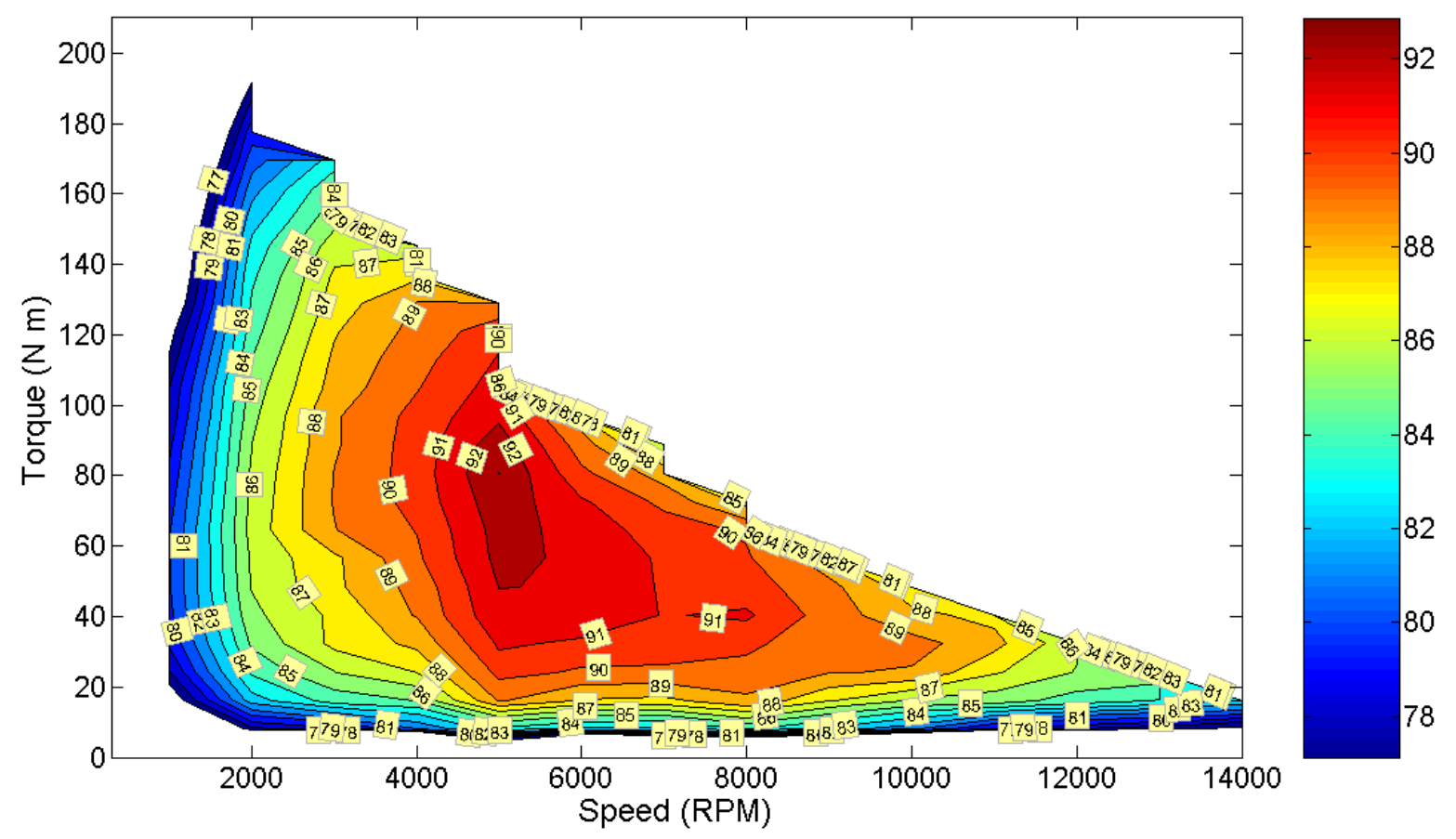

Fig. 3.20. 2007 Camry motor/inverter efficiency contours at $650 \mathrm{~V}$ for $77 \%$ and above. 


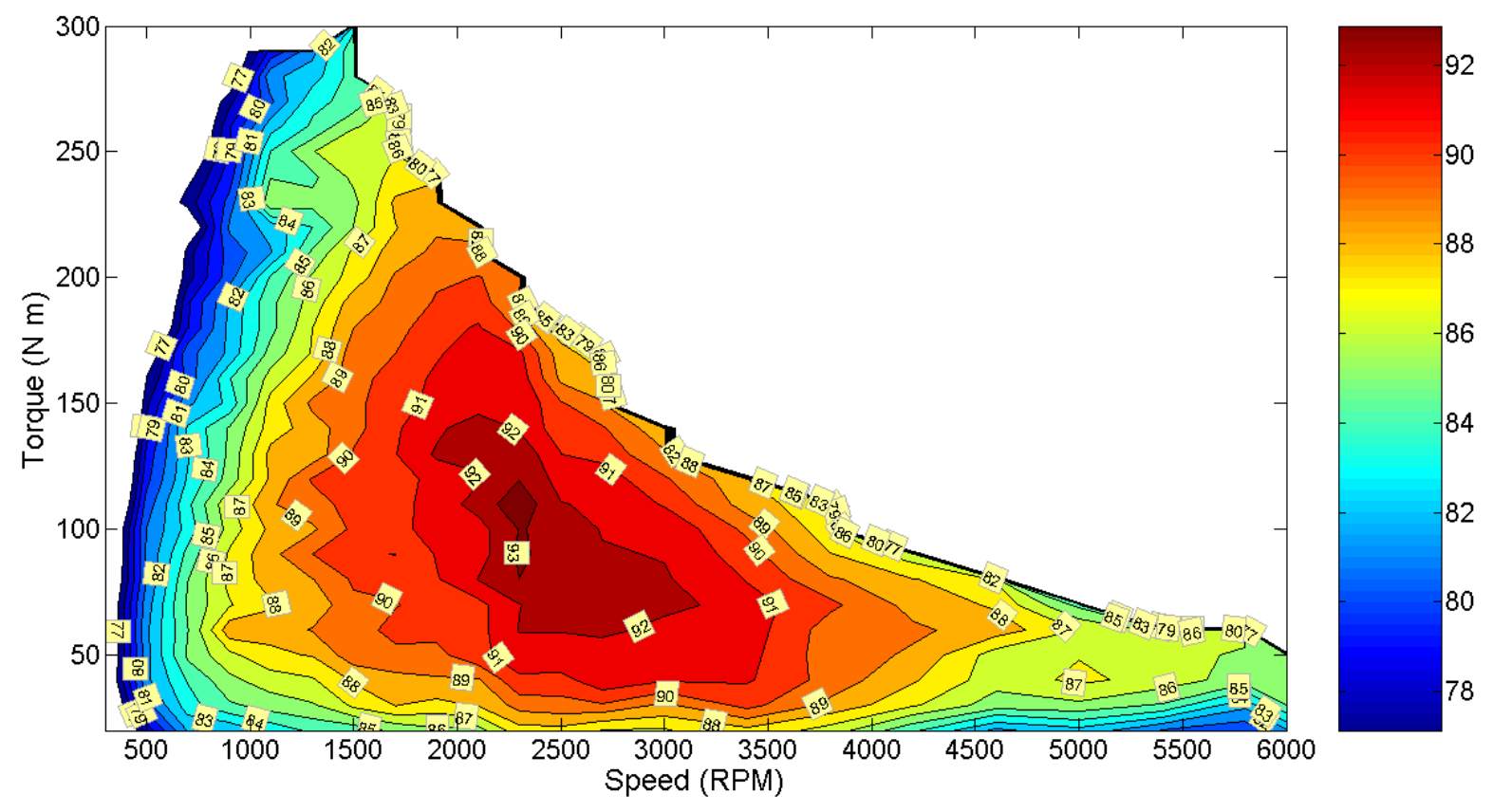

Fig. 3.21. 2004 Prius motor/inverter efficiency contours for $77 \%$ and above.

\subsection{CONTINOUS LOAD DURATION TESTS}

The 2010 Prius motor was operated at continuous power levels for different speeds to observe the continuous capability of the motor under various conditions. Continuous tests were conducted at 25 and $50 \mathrm{~kW}$ at $3,000,5,000$, and 7,000 rpm with a coolant temperatures of 25,50 , and $65^{\circ} \mathrm{C}$. For each case, motor temperatures were allowed to stabilize prior to initiating the continuous tests and the Bay-Voltex coolant temperature regulation unit was used to regulate the coolant at a desired temperature.

TCs and thermistors were installed in various locations throughout the ECVT and PCU with locations described in Section 3.1.2 and indicated in Figs. 3.3 and 3.4. Coolant temperatures are indicated by the traces labeled "N: Bef Inv", "O: Aft Inv", and "P: Aft Mot", to represent the inverter coolant input, motor coolant input (inverter output), and motor coolant output temperatures, respectively.

Figure 3.22 shows the measured temperatures during conducted at a power level of $25 \mathrm{~kW}$ and a motor speed of 3,000 rpm with a coolant temperature of $25^{\circ} \mathrm{C}$. The traces are labeled and identified by color in the key provided on the left. The most extreme motor temperature, "E: 1 clock", is indicated by a brown trace. Mechanical power, "Pmech," is represented by a blue trace. The data point symbols for each trace are not distinguishable in the figure since the time elapsed is so large and the data points are close together. A table indicates the time duration for the associated stator temperature limitation in the upper left corner of the figure. For example, the motor can operate at $25 \mathrm{~kW}\left(3,000 \mathrm{rpm}\right.$ and $25^{\circ} \mathrm{C}$ coolant $)$ for about 10:16 (minutes:seconds) prior to reaching a stator temperature of $100^{\circ} \mathrm{C}$. If the stator temperature limit is raised to $130^{\circ} \mathrm{C}$, the motor can operate for about 28:49 under these conditions. Thus, the extent of continuous operation capabilities depends greatly upon stator temperature limitations. Aside from signal 'E', signals ' $\mathrm{C}$ ', 'I', 'L', and ' $\mathrm{K}$ ' were the most extreme motor temperatures throughout all continuous tests. The most extreme PCU temperature measurement, labeled "AB: G inv", reaches a steady temperature of about $60^{\circ} \mathrm{C}$. However, the accuracy of this on-chip temperature measurement is predicted to only be within $5-10^{\circ} \mathrm{C}$, as the measurement changes significantly and immediately upon inverter activation and deactivation. Future efforts will be made to improve this measurement technique. 


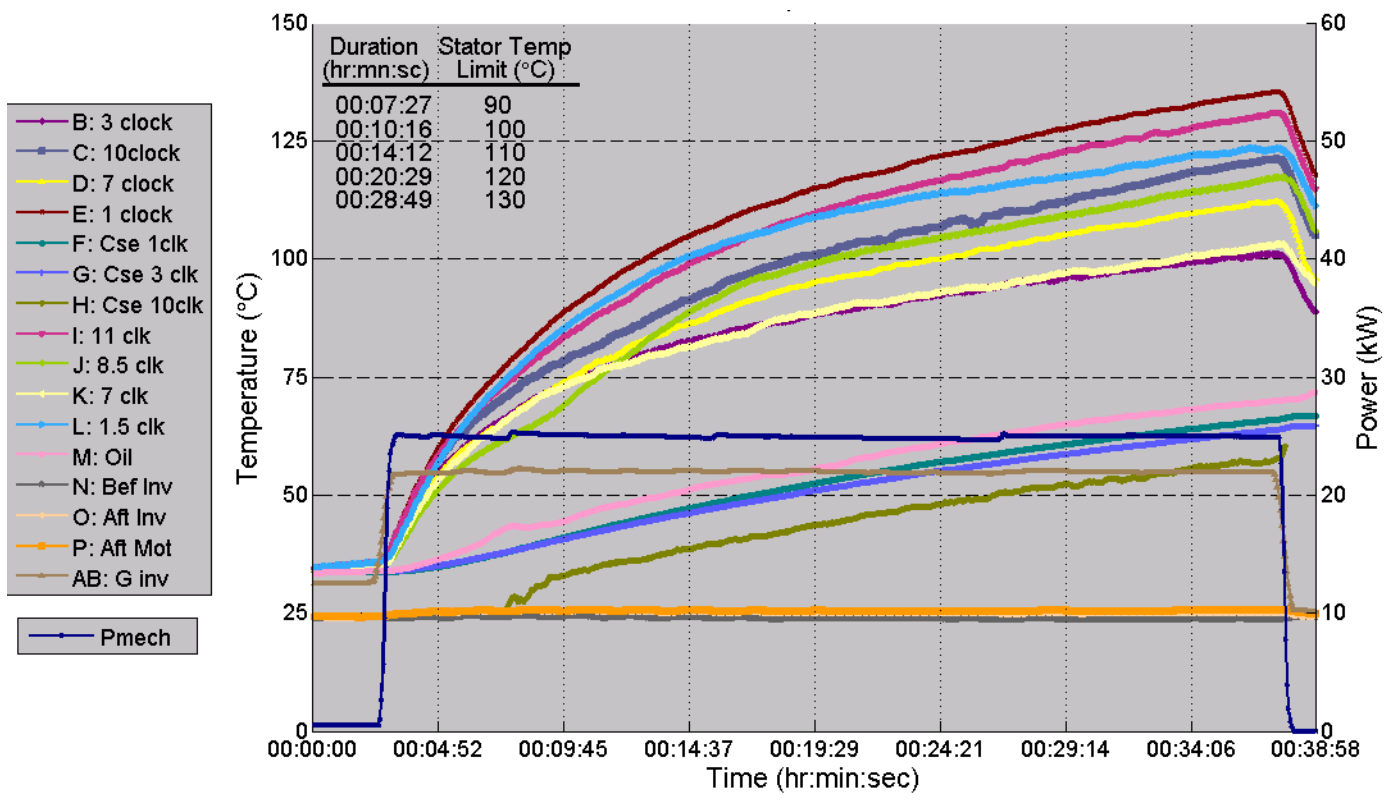

Fig. 3.22. 2010 Prius temperatures during $25 \mathrm{~kW}$ continuous test at $3,000 \mathrm{rpm}$ with $25^{\circ} \mathrm{C}$ coolant.

Stator temperature limitations are set to prevent potential damage within the stator windings and to prevent demagnetization of the PMs. Long term effects which affect the life of the PMSM must also be considered when choosing a stator temperature limitation. According to the 2010 Prius repair manual, the stator temperature is generally kept below $100^{\circ} \mathrm{C}$. Figure 3.23 shows the motor temperatures measured during tests conducted at a power level of $50 \mathrm{~kW}$ and a rotor speed of 5,000 rpm. The motor is capable of operating at $50 \mathrm{~kW}$ for $4: 34$ (minutes:seconds) prior to reaching a stator temperature limit of $150^{\circ} \mathrm{C}$. A portion of some of the traces are missing due to suspect influence of EMI and measurement error. Nonetheless, the most extreme temperature measurement remained unaffected.

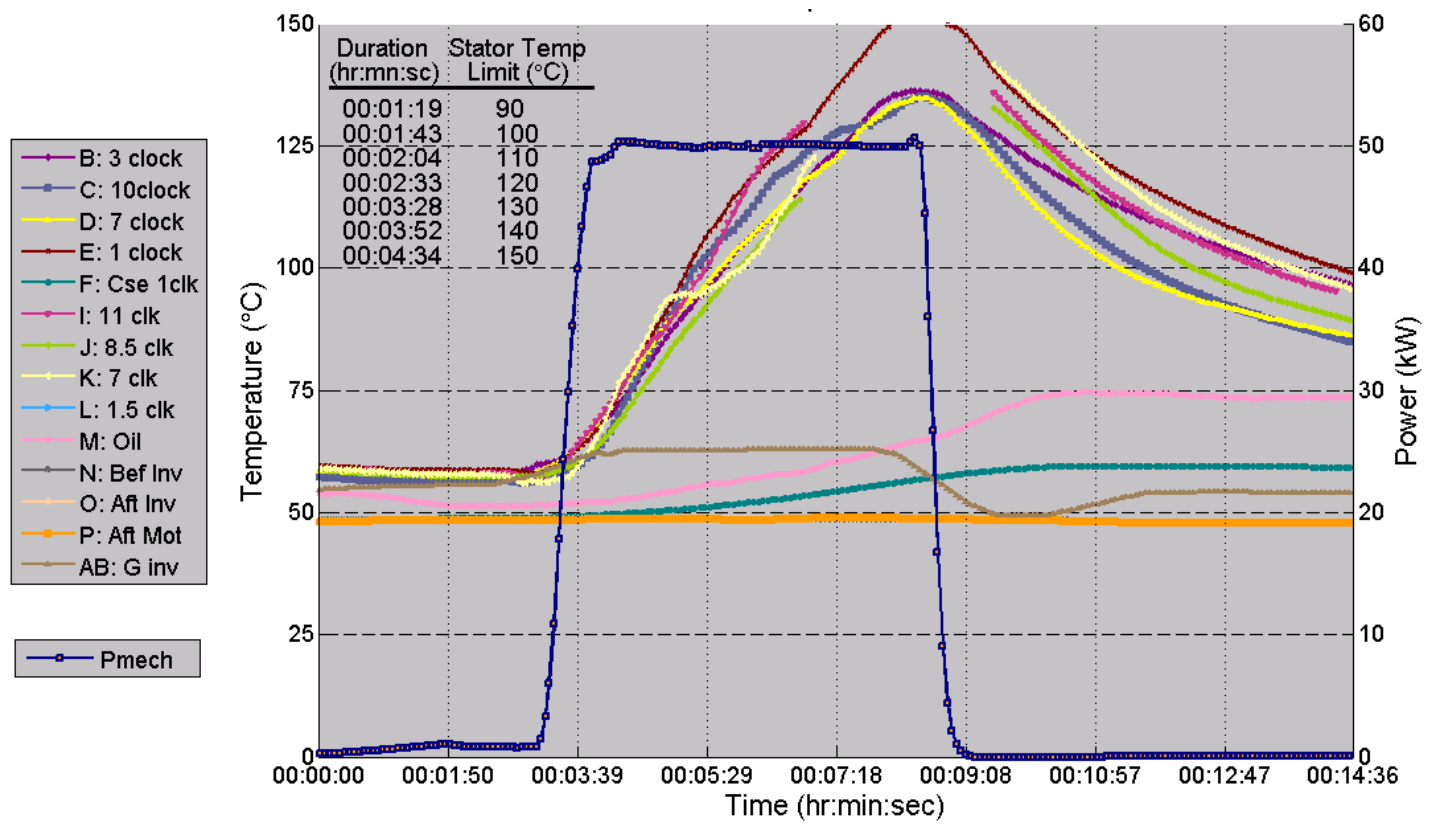

Fig. 3.23. 2010 Prius temperatures during $50 \mathrm{~kW}$ continuous test at $5,000 \mathrm{rpm}$ with $50^{\circ} \mathrm{C}$ coolant. 
A plot similar to those in Figs. 3.22 and 3.23 is shown in Fig. 3.24 for operation at $50 \mathrm{~kW}$ and 7,000 rpm with a coolant temperature of $25^{\circ} \mathrm{C}$. The motor operated at this condition for 5:19 (minutes:seconds) before reaching a stator temperature of $150^{\circ} \mathrm{C}$. For all coolant temperatures and a power level of $50 \mathrm{~kW}$, the motor has a lower duration capability at 7,000 rpm versus 5,000 rpm.

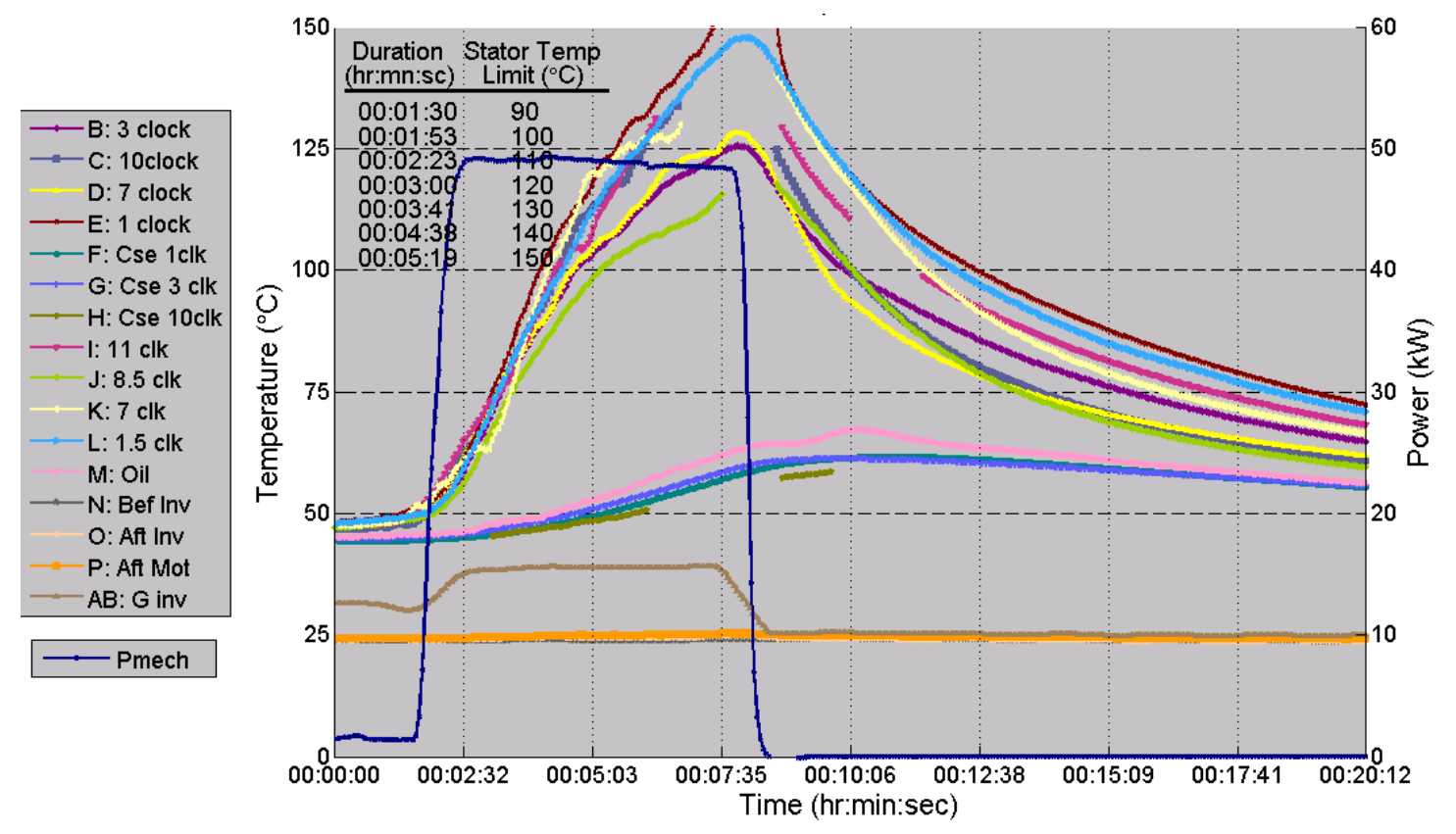

Fig. 3.24. 2010 Prius temperatures during $50 \mathrm{~kW}$ continuous test at $7,000 \mathrm{rpm}$ with $25^{\circ} \mathrm{C}$ coolant.

Graphs similar to Figs. 3.22, 3.23, and 3.24 were generated for each test condition and while they are informative, it is difficult to fully study the impact of various power levels, motor speeds, coolant temperature, and stator temperature limitations upon the extent of time at which the motor can operate under these conditions. Therefore, the duration times shown in the upper left corner of the previous figures were used to produce graphs which provide more meaningful comparisons. In Fig. 3.25, the time durations associated with operation at $25 \mathrm{~kW}$ with $50^{\circ} \mathrm{C}$ coolant is graphed versus speed. Each trace represents time durations which correlate to a particular stator temperature limit. Through inspection of this graph, it is more evident that the duration of operation at $25 \mathrm{~kW}$ is greater at 5,000 rpm than for any other speed at which these continuous tests were conducted. Note that in this case, the stator temperature essentially stabilized near $123^{\circ} \mathrm{C}$ at $5,000 \mathrm{rpm}$, which is represented by the upper most trace. Thus, the trace for a temperature of $160^{\circ} \mathrm{C}$ would theoretically have a data point at 5,000 rpm that approaches infinity. A similar graph is shown in Fig. 3.26 for a power level of $50 \mathrm{~kW}$ with a coolant temperature of $50^{\circ} \mathrm{C}$. At $5,000 \mathrm{rpm}$, the motor operated for over 4.5 minutes before reaching a stator temperature of $150^{\circ} \mathrm{C}$. For low stator temperature limits, the duration capability does not change significantly as the motor speed increases from 5,000-7,000 rpm. 


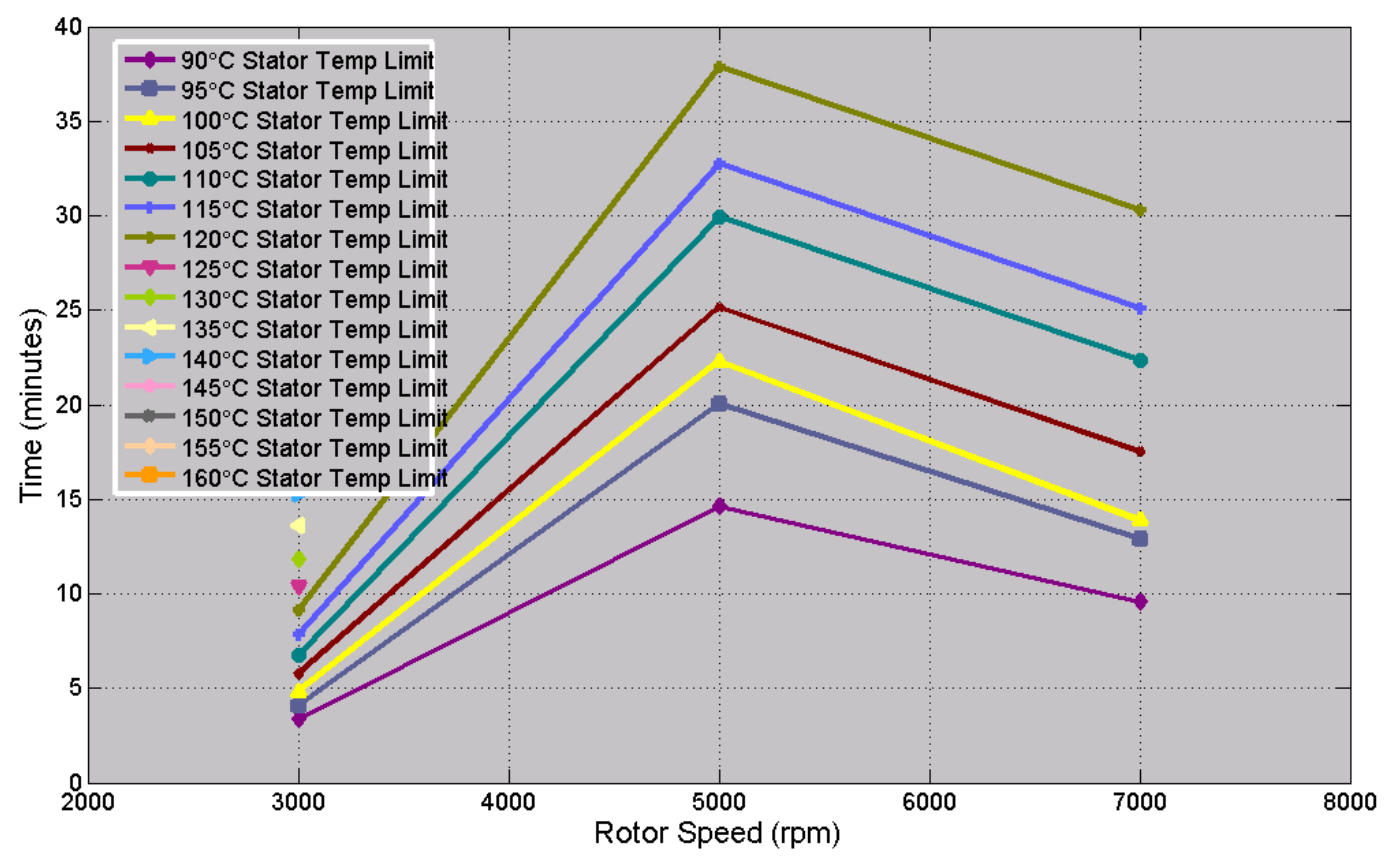

Fig. 3.25. 2010 Prius $25 \mathrm{~kW}$ continuous duration vs. speed with $50^{\circ} \mathrm{C}$ coolant.

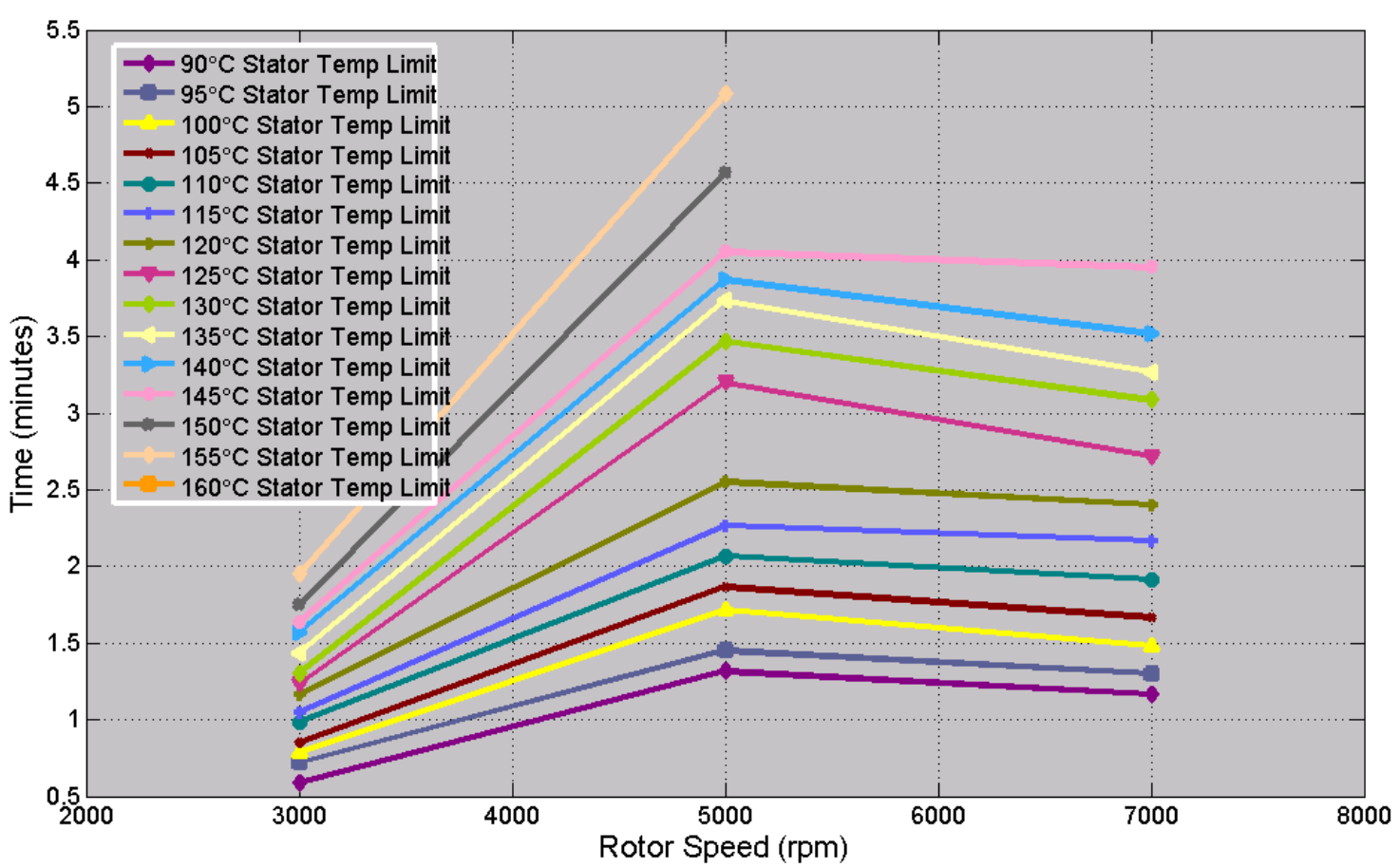

Fig. 3.26. 2010 Prius $50 \mathrm{~kW}$ continuous duration vs. speed with $50^{\circ} \mathrm{C}$ coolant.

The previous graphs provided a clear indication of the influence of speed and power level upon duration capabilities. To provide a more clear assessment of the impact of stator temperature limitations, coolant temperature, and power level upon duration capability, duration time is plotted versus the stator temperature limit in Fig. 3.27 for operations at 3,000 rpm. Each trace represents a particular power level and coolant temperature combination. If the stator temperature limit is designated to be $120^{\circ} \mathrm{C}$, it can be observed that motor is capable of operating at $25 \mathrm{~kW}$ for over 20 minutes with $25^{\circ} \mathrm{C}$ coolant, but about 
9 minutes and 7 minutes with coolant temperatures of $50^{\circ} \mathrm{C}$ and $65^{\circ} \mathrm{C}$, respectively. It is noticeable from the $50 \mathrm{~kW}$ traces that coolant temperature does not greatly affect the continuous capability at high power levels. Characteristics similar to what are observed in Fig. 3.27 are observed in Fig. 3.28, where duration time is plotted versus stator temperature limit at $5,000 \mathrm{rpm}$ for various power levels and coolant temperatures. For a stator temperature limit of $105^{\circ} \mathrm{C}$, the motor is capable of operating at $25 \mathrm{~kW}$ for about 45,25 , and 9 minutes with 25,50 , and $65^{\circ} \mathrm{C}$ coolant, respectively.

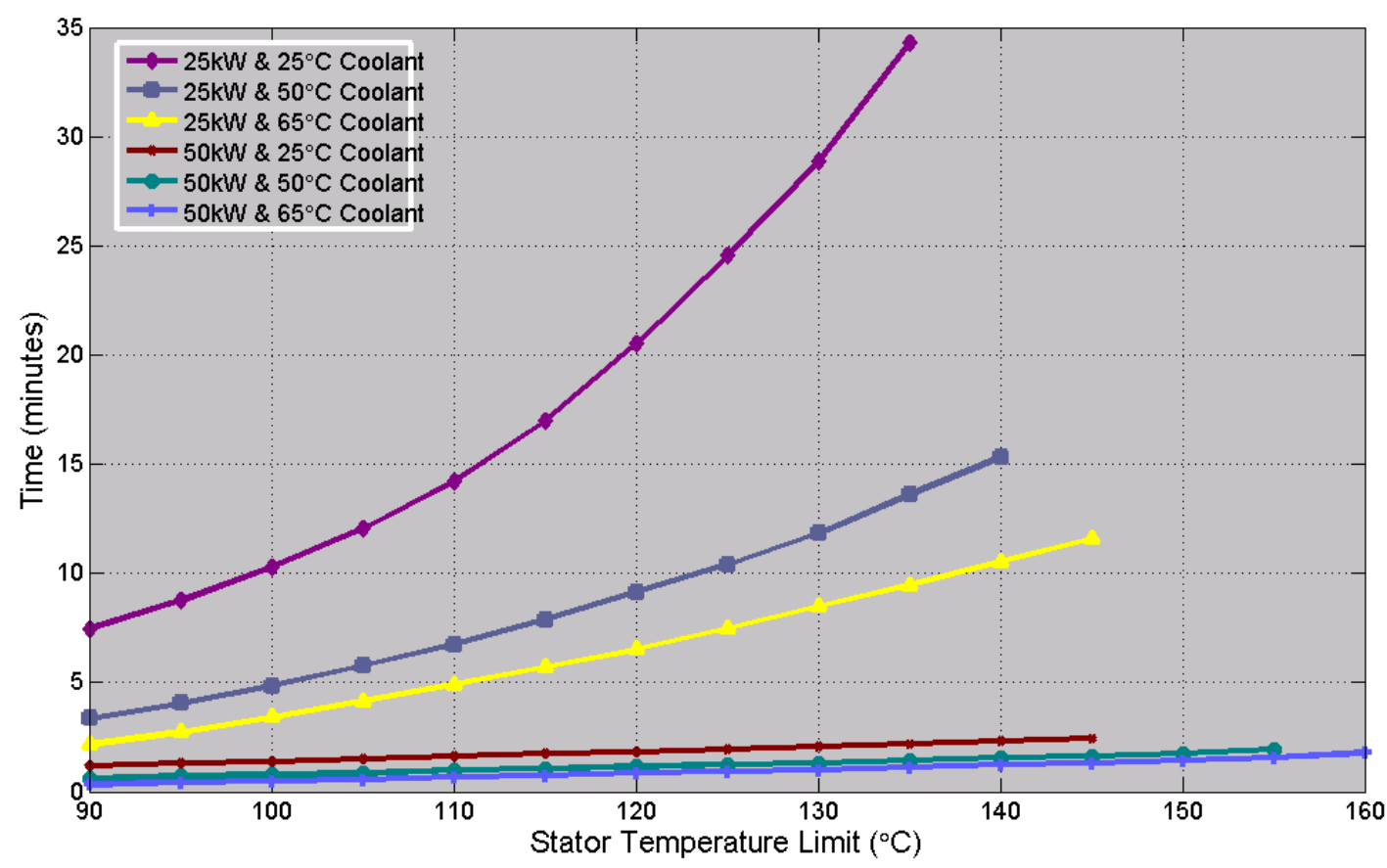

Fig. 3.27. 2010 Prius continuous duration at 3,000 rpm with various power levels and coolant temperatures.

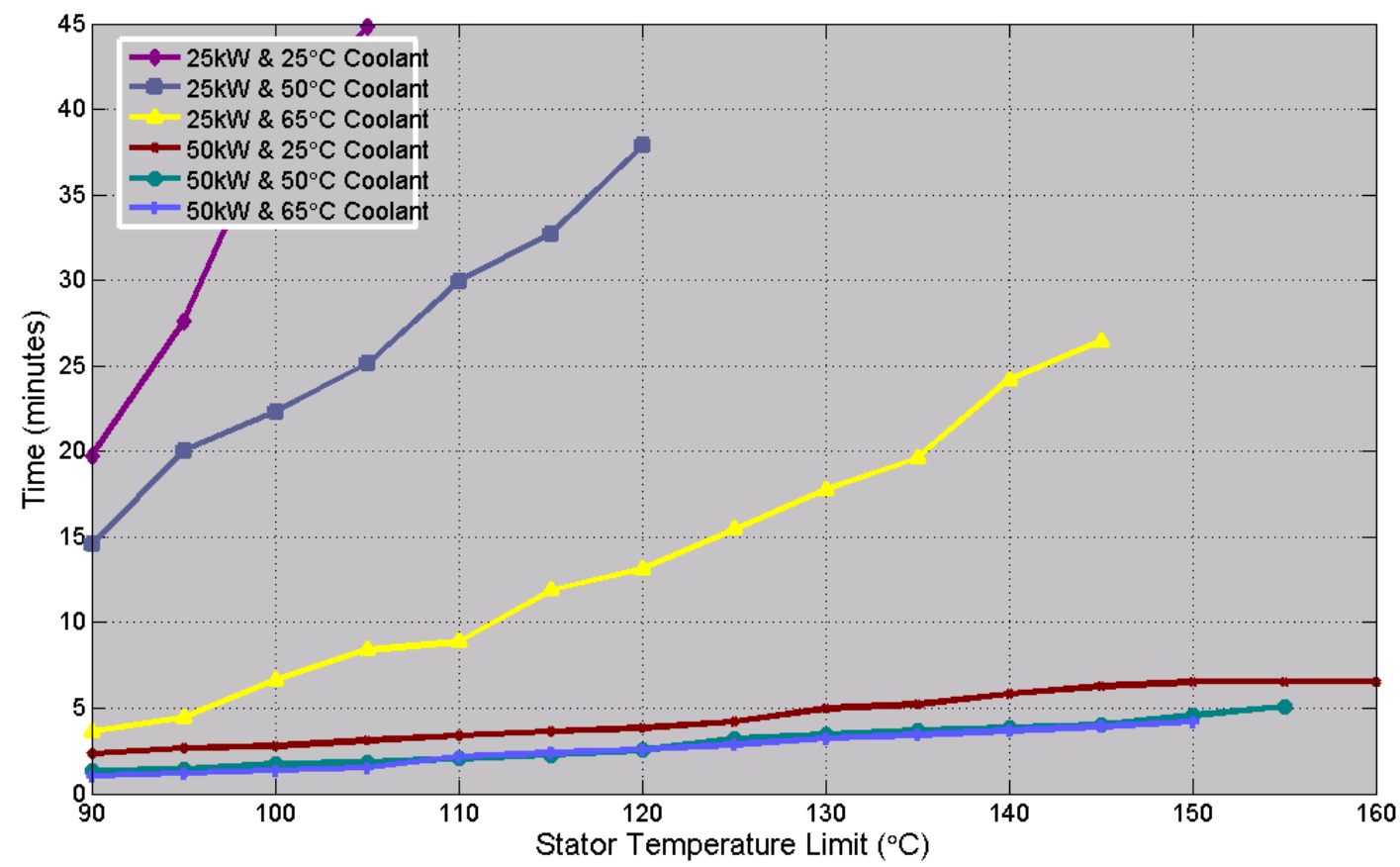

Fig. 3.28. 2010 Prius continuous duration at 5,000 rpm with various power levels and coolant temperatures. 
Duration information from the continuous studies upon the Camry and LS 600h motors at 5,000 rpm is provided in Fig. 3.29. At a power level of $50 \mathrm{~kW}$, the LS $600 \mathrm{~h}$ and Camry are capable if operating for about 10 minutes versus about 4 minutes for the 2010 Prius, before reaching a stator temperature limit of $140^{\circ} \mathrm{C}$. A similar graph is provided in Fig. 3.30 for operation at 7,000 rpm with various power levels and coolant temperatures. The motor is capable of operating for 30 minutes at $25 \mathrm{~kW}$ with $65^{\circ} \mathrm{C}$ before reaching a stator temperature of $145^{\circ} \mathrm{C}$, while the stator temperature stabilized at about $110^{\circ} \mathrm{C}$ with $25^{\circ} \mathrm{C}$ coolant. If the stator temperature limit is designated to be $150^{\circ} \mathrm{C}$ the motor can operate at $50 \mathrm{~kW}$ for about 5 and 3 minutes with coolant temperatures of $25^{\circ} \mathrm{C}$ and $65^{\circ} \mathrm{C}$, respectively.

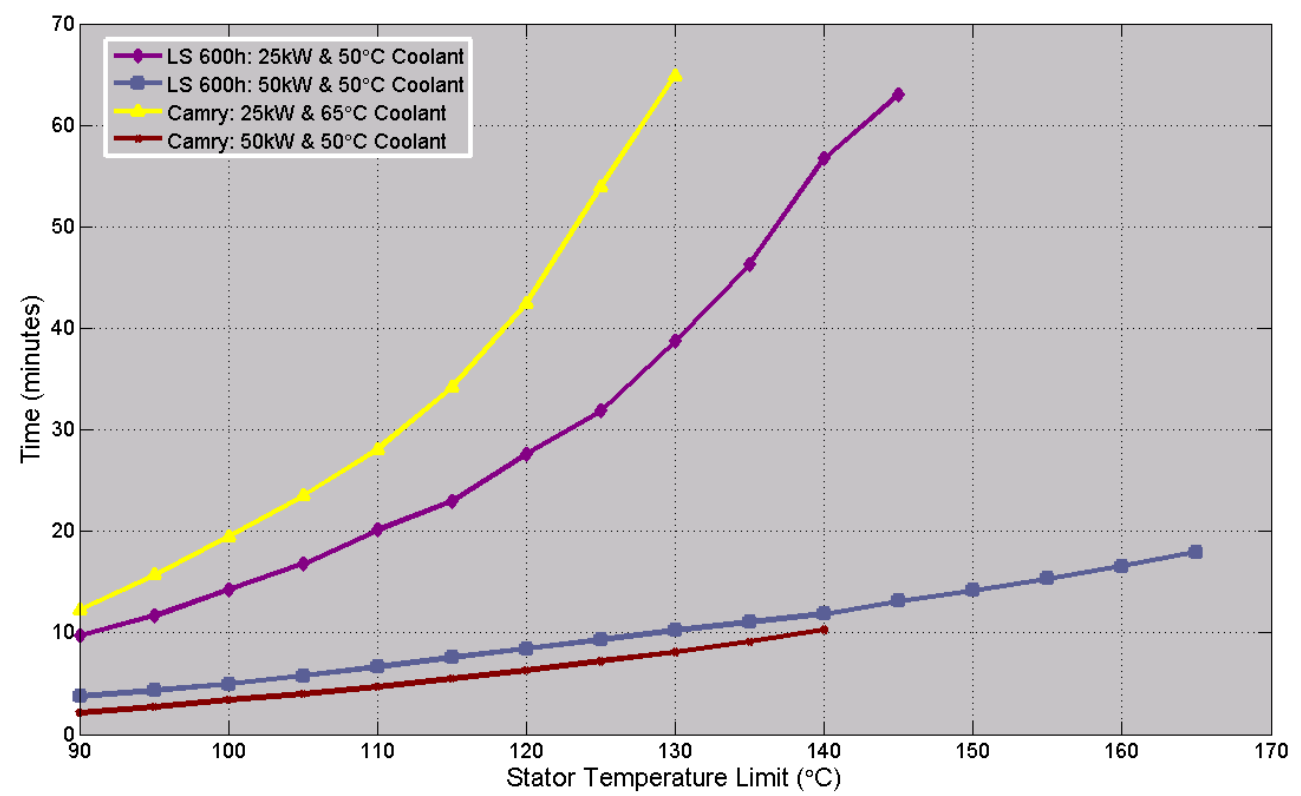

Fig. 3.29. LS 600h and Camry continuous duration at 5,000 rpm with various power levels and coolant temperatures.

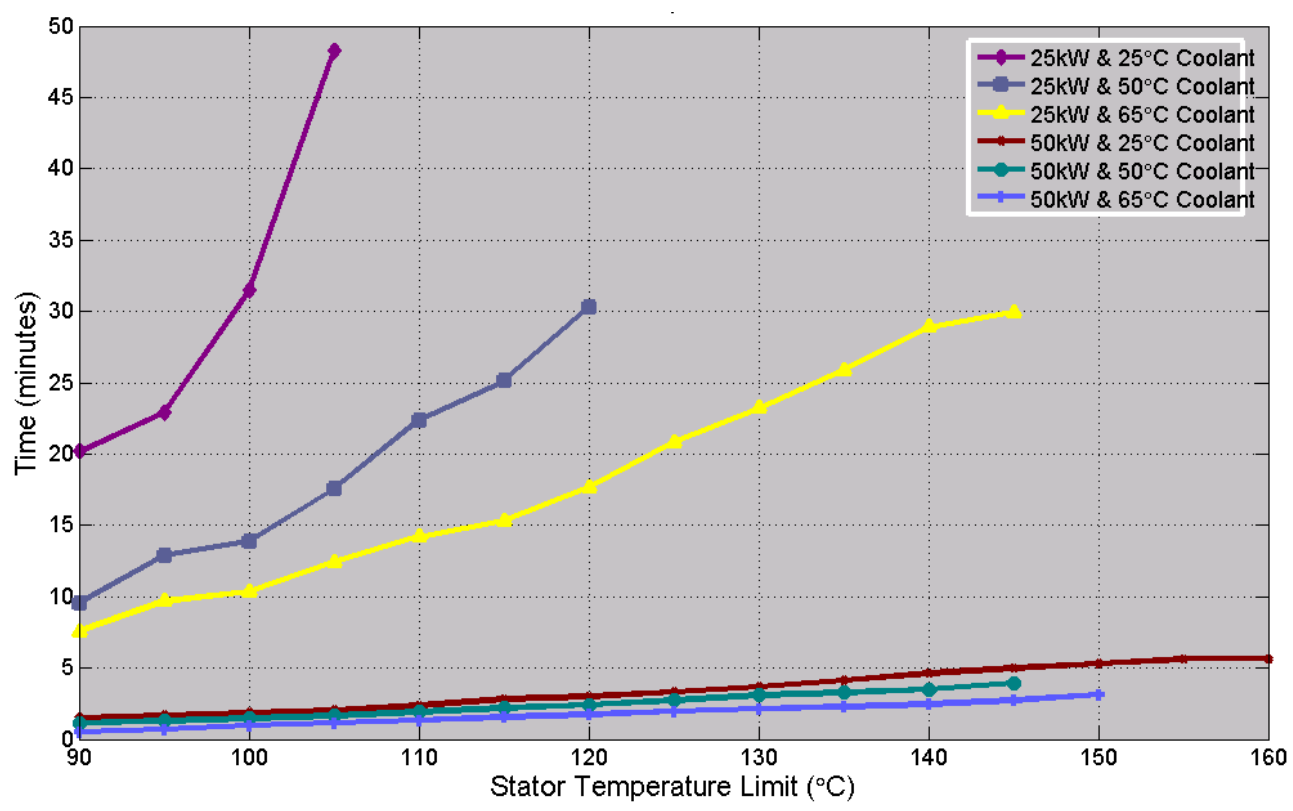

Fig. 3.30. 2010 Prius continuous duration at 7,000 rpm with various power levels and coolant temperatures. 
It is clear that defining the continuous operation capability of a motor depends on many variables, which even includes the definition of continuous operation. For example, continuous operation could be defined to be operation at a particular power level for an infinite amount of time, or a particular time restraint could be included in the definition. For HEV and particularly electric vehicle (EV) applications, it is crucial that the motor is capable of operating continuously at designated power levels. Many aspects must be considered for these conditions, and if properly designed, the volume and mass of the electric drive system can be optimized to match the demands of the system. 


\section{SUMMARY AND CONCLUSIONS}

The 2010 Toyota Prius subsystem assemblies were physically evaluated and comprehensively tested in the laboratory to fully assess their performance, efficiency, design, and packaging characteristics. Laboratory evaluations included back-emf, locked rotor, performance, efficiency mapping, and continuous load tests. Overall, the 2010 Prius ( $3^{\text {rd }}$ generation Prius) greatly surpassed the 2004 Prius $\left(2^{\text {nd }}\right.$ generation Prius) in areas such as SP, PD, and continuous operation capability. The total PCU mass and volume of $13 \mathrm{~kg}$ and $16.2 \mathrm{~L}$ reflect the overall trend realized throughout the PCU, with a motor inverter SP of $16.6 \mathrm{~kW} / \mathrm{kg}$ and PD of $11.1 \mathrm{~kW} / \mathrm{L}$. For comparison, the 2004 Prius, 2007 Camry, and 2008 Lexus LS $600 \mathrm{~h}$, the motor inverter SPs are roughly $5.7,9.3$, and $14.9 \mathrm{~kW} / \mathrm{kg}$, respectively, and the power densities are $5.7,11.7$, and $17.2 \mathrm{~kW} / \mathrm{L}$, respectively.

In comparison with all of the systems, the 2010 Prius motor inverter package displays a significant reduction in mass for a given power, but only surpasses the 2004 Prius in motor in PD. It appears that the integrated cooling technique of the 2010 Prius influenced this decrease in mass, as the dense heat plates of the power module have been removed and the design no longer requires a heavy, cast aluminum heat exchanger. The cooling technique is not as effective as the LS $600 \mathrm{~h}$ double sided cooling technique, but it is likely more cost effective in terms of manufacturing costs. In contrast with the 2004 Prius and 2007 Camry, the boost converter PEs were integrated into one module with the motor and generator inverters.

The 2010 Prius outperformed the 2004 Prius and Camry motor in terms of efficiency, and the SP and PD ratings are very similar the that of the Camry. Motor efficiency measurements reached $96 \%$ are above $90 \%$ for a great portion of the operation range and the 2010 Prius motor can operate at $60 \mathrm{~kW}$ (at $4,000 \mathrm{rpm}$ ) for 18 seconds before reaching a stator winding temperature of $150^{\circ} \mathrm{C}$. The elongated design of the LS $600 \mathrm{~h}$ motor renders many benefits in terms of SP, PD, copper, and magnet material costs. The 2010 Prius motor contains $4.93 \mathrm{~kg}$ of copper versus 6.8, 5.6, and $3.59 \mathrm{~kg}$ for the 2004 Prius, Camry, and LS 600h, respectively. The motor rotor has a similar 'V' shaped PM arrangement, but the overall lamination is significantly different with a much smaller ID and large holes between the shaft and the primary flux path near the magnets. With a lamination stack length of 2 inches, the 2010 Prius motor PD is $4.8 \mathrm{~kW} / \mathrm{L}$ and $1.6 \mathrm{~kW} / \mathrm{kg}$, compared with $5.9 \mathrm{~kW} / \mathrm{L}$ and $1.7 \mathrm{~kW} / \mathrm{kg}$ for the Camry, respectively. Studies showed that higher system (motor and inverter) efficiencies can be obtained by operating at lower dc link voltages, when increased voltage is not required. The increased efficiency is primarily due to a reduction in switching losses and slight reduction of eddy current losses.

Continuous duration varies significantly with motor speed and specified stator temperature limit for each power level. For example, the 2010 Prius PMSM is able to sustain a power level of $25 \mathrm{~kW}$ at 5,000 rpm with $50^{\circ} \mathrm{C}$ coolant for about 25 minutes with a stator temperature limit of $150^{\circ} \mathrm{C}$. However, the duration for the same conditions held at 3,000 rpm is only about 6 minutes. There is no standard for establishing continuous or peak power rating specifications for motors designed for HEV applications such as the LS $600 \mathrm{~h}$, Camry, and Prius motors. The significant impact of these conditions highlights a very important reason for performing benchmarking tests on HEV subsystems - current technologies must be verified and thoroughly examined objectively before the results are used by the FCVT program and researchers. The influence of HEV specifications on technical goals and program planning would be drastically different if unclear published specifications of HEV systems were used as a baseline.

Among the vast amount of information obtained during benchmarking efforts, the significant findings are summarized in Table 4.1. Some of the information obtained from the 2010 Prius, LS 600h, Camry, and 2004 Prius benchmarking studies has been and will be used by researchers to improve/verify analytical models. As a next step in the benchmarking efforts at ORNL, focus will be placed on the Hyundai Sonata hybrid vehicle. Technological advances which facilitate higher power capability, PD, SP, efficiency, reliability, and cost effectiveness of HEV components are essential as HEVs become increasingly 
dependant upon the electrical portion of the drive system and as the EV and HEV market continues to expand in the future.

Table 4.1. 2010 Prius, 2008 LS 600h, 2007 Camry, and 2004 Prius design comparison highlights

\begin{tabular}{|c|c|c|c|c|c|}
\hline Parameter & 2010 Prius & LS 600h & Camry & 2004 Prius & Comments \\
\hline \multicolumn{6}{|l|}{ Transaxle } \\
\hline Motor power rating & $60 \mathrm{~kW}$ & $110 \mathrm{~kW}$ & $70 \mathrm{~kW}$ & $50 \mathrm{~kW}$ & $\begin{array}{l}\text { Tested } 18 \text { second } \\
\text { power rating }\end{array}$ \\
\hline Motor stator OD & $10.39^{\prime \prime}$ & $7.87^{\prime \prime}$ & $10.39^{\prime \prime}$ & $10.59^{\prime \prime}$ & \\
\hline Motor lamination stack & $2.0^{\prime \prime}$ & $5.33^{\prime \prime}$ & $2.39^{\prime \prime}$ & $3.3^{\prime \prime}$ & \\
\hline Motor mass & $36.7 \mathrm{~kg}$ & $44.7 \mathrm{~kg}$ & $41.7 \mathrm{~kg}$ & $45.0 \mathrm{~kg}$ & \multirow{2}{*}{$\begin{array}{l}\text { Includes casing } \\
\text { and cooling } \\
\text { system }\end{array}$} \\
\hline Motor volume & $12.5 \mathrm{~L}$ & $16.7 \mathrm{~L}$ & $14.8 \mathrm{~L}$ & $15.4 \mathrm{~L}$ & \\
\hline Motor SP & $1.6 \mathrm{~kW} / \mathrm{kg}$ & $2.46 \mathrm{~kW} / \mathrm{kg}$ & $1.68 \mathrm{~kW} / \mathrm{kg}$ & $1.11 \mathrm{~kW} / \mathrm{kg}$ & \\
\hline Motor PD & $4.8 \mathrm{~kW} / \mathrm{L}$ & $6.59 \mathrm{~kW} / \mathrm{L}$ & $4.73 \mathrm{~kW} / \mathrm{L}$ & $3.25 \mathrm{~kW} / \mathrm{L}$ & \\
\hline Toque rating & $205 \mathrm{Nm}$ & $300 \mathrm{Nm}$ & $270 \mathrm{Nm}$ & $400 \mathrm{Nm}$ & \\
\hline Motor speed rating & $13,500 \mathrm{rpm}$ & $10,230 \mathrm{rpm}$ & $14,000 \mathrm{rpm}$ & $6,000 \mathrm{rpm}$ & \\
\hline Motor winding & Series & Parallel & Parallel & Series & \\
\hline \multicolumn{6}{|l|}{ PCU } \\
\hline Nominal battery voltage & $201.6 \mathrm{~V}$ & $288 \mathrm{~V}$ & $244.8 \mathrm{~V}$ & $201.6 \mathrm{~V}$ & \\
\hline $\begin{array}{l}\text { Maximum dc-link } \\
\text { voltage }\end{array}$ & $650 \mathrm{Vdc}$ & $650 \mathrm{Vdc}$ & $650 \mathrm{Vdc}$ & $500 \mathrm{Vdc}$ & \\
\hline Boost converter power & $27 \mathrm{~kW}$ & $36.5 \mathrm{~kW}$ & $30 \mathrm{~kW}$ & $20 \mathrm{~kW}$ & \\
\hline $\begin{array}{l}\text { Filter capacitor (battery } \\
\text { level) }\end{array}$ & $\begin{array}{l}470 \mathrm{Vdc} \\
315 \mu \mathrm{F}\end{array}$ & $\begin{array}{l}500 \mathrm{Vdc}, \\
378 \mu \mathrm{F}\end{array}$ & $\begin{array}{l}500 \mathrm{Vdc}, \\
378 \mu \mathrm{F}\end{array}$ & $\begin{array}{l}600 \mathrm{Vdc} \\
282 \mu \mathrm{F}\end{array}$ & \\
\hline $\begin{array}{l}\text { Smoothing capacitor } \\
\text { (boosted level) }\end{array}$ & $\begin{array}{l}750 \mathrm{Vdc}, \\
888 \mu \mathrm{F}\end{array}$ & $\begin{array}{l}750 \mathrm{Vdc}, \\
2,629 \mu \mathrm{F}\end{array}$ & $\begin{array}{l}750 \mathrm{Vdc}, \\
2098 \mu \mathrm{F}\end{array}$ & $\begin{array}{l}600 \mathrm{Vdc}, \\
1,130 \mu \mathrm{F}\end{array}$ & \\
\hline Entire PCU mass & $13.0 \mathrm{~kg}$ & $17.9 \mathrm{~kg}$ & $17.86 \mathrm{~kg}$ & $21.2 \mathrm{~kg}$ & \\
\hline Entire PCU volume & $16.2 \mathrm{~L}$ & $13.7 \mathrm{~L}$ & $11.7 \mathrm{~L}$ & $17.8 \mathrm{~L}$ & \\
\hline Motor inverter mass & $3.6 \mathrm{~kg}$ & $7.4 \mathrm{~kg}$ & $7.5 \mathrm{~kg}$ & $8.8 \mathrm{~kg}$ & \\
\hline Motor inverter volume & $5.4 \mathrm{~L}$ & $6.4 \mathrm{~L}$ & $6 \mathrm{~L}$ & $8.7 \mathrm{~L}$ & \\
\hline Motor inverter SP & $16.6 \mathrm{~kW} / \mathrm{kg}$ & $14.9 \mathrm{~kW} / \mathrm{kg}$ & $9.3 \mathrm{~kW} / \mathrm{kg}$ & $5.7 \mathrm{~kW} / \mathrm{kg}$ & \\
\hline Motor inverter PD & $11.1 \mathrm{~kW} / \mathrm{L}$ & $17.2 \mathrm{~kW} / \mathrm{L}$ & $11.7 \mathrm{~kW} / \mathrm{L}$ & $5.7 \mathrm{~kW} / \mathrm{L}$ & \\
\hline $\begin{array}{l}\text { DC-dc (boost) converter } \\
\text { mass }\end{array}$ & $5.1 \mathrm{~kg}$ & $6.9 \mathrm{~kg}$ & $6.6 \mathrm{~kg}$ & $4.8 \mathrm{~kg}$ & \\
\hline $\begin{array}{l}\text { DC-dc (boost) converter } \\
\text { volume }\end{array}$ & $4.8 \mathrm{~L}$ & $4 \mathrm{~L}$ & $3.5 \mathrm{~L}$ & $5.1 \mathrm{~L}$ & \\
\hline $\begin{array}{l}\text { DC-dc (boost) converter } \\
\text { SP }\end{array}$ & $5.3 \mathrm{~kW} / \mathrm{kg}$ & $5.3 \mathrm{~kW} / \mathrm{kg}$ & $4.5 \mathrm{~kW} / \mathrm{kg}$ & $4.2 \mathrm{~kW} / \mathrm{kg}$ & \\
\hline $\begin{array}{l}\text { DC-dc (boost) converter } \\
\text { PD }\end{array}$ & $5.6 \mathrm{~kW} / \mathrm{L}$ & $9.1 \mathrm{~kW} / \mathrm{L}$ & $8.6 \mathrm{~kW} / \mathrm{L}$ & $3.9 \mathrm{~kW} / \mathrm{L}$ & \\
\hline
\end{tabular}




\section{REFERENCES}

1. Source: http://www1.eere.energy.gov/vehiclesandfuels/, April 2008.

2. J. S. Hsu, S. C. Nelson, P. A. Jallouk, C. W. Ayers, R. H. Wiles, S. L. Campbell, C. L. Coomer, K. T. Lowe, and T. A. Burress, Report on Toyota Prius Motor Thermal Management, ORNL/TM2005/33, UT-Battelle, LLC, Oak Ridge National Laboratory, Oak Ridge, Tennessee, February 2005.

3. R. H. Staunton, C. W. Ayers, J. Chiasson, T. A. Burress, and L. D. Marlino, Evaluation of 2004 Toyota Prius Hybrid Electric Drive System, ORNL/TM-2006-423, UT-Battelle, LLC, Oak Ridge National Laboratory, Oak Ridge, Tennessee, May 16, 2006.

4. R. H. Staunton, T. A. Burress, and L. D. Marlino, Evaluation of 2005 Honda Accord Hybrid Electric Drive System, ORNL/TM-2006-535, UT-Battelle, LLC, Oak Ridge National Laboratory, Oak Ridge, Tennessee, September 2006.

5. T. A. Burress, C. L. Coomer, S. L. Campbell, L. E. Seiber, L. D. Marlino, R. H. Staunton, and J. P. Cunningham, Evaluation of the 2007 Toyota Camry Hybrid Synergy Drive System, ORNL/TM2007/190, UT-Battelle, Oak Ridge National Laboratory, Oak Ridge, Tennessee, Revised April 2008.

6. T. A. Burress, C. L. Coomer, S. L. Campbell, A. A. Wereszczak, J. P. Cunningham, L. D. Marlino, L. E. Seiber, and H. T. Lin, Evaluation of the 2008 Lexus LS 600h Hybrid Synergy Drive System, ORNL/TM-2008/185, UT-Battelle, Oak Ridge National Laboratory, Oak Ridge, Tennessee, January 2009.

7. Source: http://www.edmunds.com/toyota/prius/2010/review.html, September 2010.

8. Source:

http://pressroom.toyota.com/pr/tms/toyota/document/10 Prius_Product Info final.pdf?ncid=12067, September 2010. 


\section{DISTRIBUTION}

Internal

1. D. J. Adams

2. T. A. Burress

3. S. L. Campbell

4. C. L. Coomer

5. J. P. Cunningham

6. K. P. Gambrell

7. J. B. Green, Jr.
8. J. S. Hsu

9. L. D. Marlino

10. M. Olszewski

11. L. E. Seiber

12. R. H. Staunton

13. Laboratory Records

\section{External}

14. S. J. Boyd, U.S. Department of Energy, EE-2G/Forrestal Building, 1000 Independence Avenue, S.W., Washington, D.C. 20585.

15. J. Cox, Chrysler Group LLC, 800 Chrysler Drive, Auburn Hills, Michigan 48326.

16. J. Czubay, General Motors, john.czubay@gm.com

17. H. Dadkhah, Daimler Chrysler, hd2@chrysler.com

18. R. R. Fessler, BIZTEK Consulting, Inc., 820 Roslyn Place, Evanston, Illinois 60201-1724.

19. S. Gopalakrishnan, General Motors Corporation, RMB-356, Mail Code 480-106-390, 30500 Mound Road, Warren, Michigan 48090.

20. G. Hagey, Sentech, Inc., 501 Randolph Street, Williamsburg, Virginia 23185.

21. E. Jih, Ford Motor Company, Scientific Research Laboratory, 2101 Village Road, MD-1170, Rm. 2331, Dearborn, Michigan 48121.

22. F. Leonardi, Ford Motor Company, 15050 Commerce Drive, North, Dearborn, Michigan 481201261.

23. F. Liang, Ford Motor Company, Scientific Research Laboratory, 2101 Village Road, MD1170, Rm. 2331/SRL, Dearborn, Michigan 48121.

24. M. W. Lloyd, Energetics, Inc., 7164 Columbia Gateway Drive, Columbia, Maryland 21046.

25. F. P. McCluskey, National Renewable Energy Laboratory, 1617 Cole Boulevard, Golden, Colorado 80401.

26. M. Mehall, Ford Motor Company, Scientific Research Laboratory, 2101 Village Road, MD-2247, Rm. 3317, Dearborn, Michigan 48124-2053.

27. C. Namuduri, General Motors Company, RMB-356, Mail Code 480-106-390, 30500 Mound Road, Warren, Michigan 48090.

28. W. Newgeon, Chrysler Group LLC, 800 Chrysler Drive, Auburn Hills, Michigan 48326.

29. M. O'Keefe, National Renewable Energy Laboratory, 1617 Cole Boulevard, Golden, Colorado 80401-3305.

30. N. Olds, United States Council for Automotive Research (USCAR), nolds@uscar.org

31. S. A. Rogers, U.S. Department of Energy, EE-2G/Forrestal Building, 1000 Independence Avenue, S.W., Washington, D.C. 20585.

32. G. S. Smith, General Motors Advanced Technology Center, 3050 Lomita Boulevard, Torrance, California 90505.

33. B. Welchko, General Motors Advanced Technology Center, 3050 Lomita Boulevard, Torrance, California 90505. 